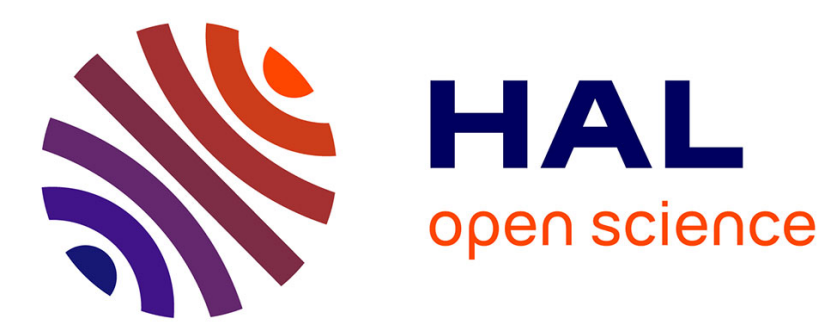

\title{
Évaluation de la robustesse des examens d'immuno-hematologie érythrocytaire en fonction du délai et de la température d'acheminement des échantillons biologiques
}

Boiteux Élise

\section{To cite this version:}

Boiteux Élise. Évaluation de la robustesse des examens d'immuno-hematologie érythrocytaire en fonction du délai et de la température d'acheminement des échantillons biologiques. Sciences pharmaceutiques. 2014. dumas-01074853

\section{HAL Id: dumas-01074853 https://dumas.ccsd.cnrs.fr/dumas-01074853}

Submitted on 15 Oct 2014

HAL is a multi-disciplinary open access archive for the deposit and dissemination of scientific research documents, whether they are published or not. The documents may come from teaching and research institutions in France or abroad, or from public or private research centers.
L'archive ouverte pluridisciplinaire $\mathbf{H A L}$, est destinée au dépôt et à la diffusion de documents scientifiques de niveau recherche, publiés ou non, émanant des établissements d'enseignement et de recherche français ou étrangers, des laboratoires publics ou privés. 


\section{Université PHARMACIE}

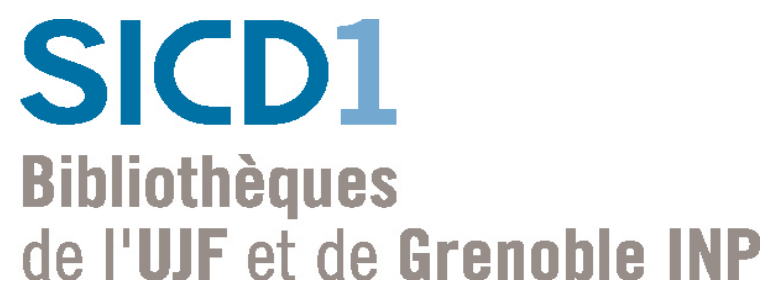

\section{AVERTISSEMENT}

Ce document est le fruit d'un long travail approuvé par le jury de soutenance et mis à disposition de l'ensemble de la communauté universitaire élargie.

Il n'a pas été réévalué depuis la date de soutenance.

Il est soumis à la propriété intellectuelle de l'auteur. Ceci implique une obligation de citation et de référencement lors de l'utilisation de ce document.

D'autre part, toute contrefaçon, plagiat, reproduction illicite encourt une poursuite pénale.

Contact au SICD1 de Grenoble : thesebum@ujf-grenoble.fr

\section{LIENS}

Code de la Propriété Intellectuelle. articles L 122. 4 Code de la Propriété Intellectuelle. articles L 335.2- L 335.10 http://www.cfcopies.com/V2/leg/leg_droi.php http://www.culture.gouv.fr/culture/infos-pratiques/droits/protection.htm 
UNIVERSITE JOSEPH FOURIER

FACULTE DE PHARMACIE DE GRENOBLE

EVALUATION DE LA ROBUSTESSE DES EXAMENS

D'IMMUNO-HEMATOLOGIE ERYTHROCYTAIRE

EN FONCTION DU DELAI ET DE LA TEMPERATURE D'ACHEMINEMENT

DES ECHANTILLONS BIOLOGIQUES

\begin{abstract}
MEMOIRE
DU DIPLOME D’ETUDES SPECIALISEES DE BIOLOGIE MEDICALE

Conformément aux dispositions du décret $\mathrm{N}^{\circ} 90-810$ du 10 septembre 1990, tient lieu de

THESE
\end{abstract}

Présentée à la Faculté de Pharmacie de GRENOBLE

Et soutenue publiquement le 08 octobre 2014

Pour obtenir le grade de DOCTEUR EN PHARMACIE

Par $\mathrm{M}^{\text {elle }}$ Elise BOITEUX

Née le 09 Janvier 1988 à Rambouillet

Devant le jury composé de :

Président :

Monsieur le Professeur Pascal MOSSUZ

Membres :

Monsieur le Professeur Patrice MORAND

Madame le Docteur Claudine GIROUX-LATHUILE

Madame le Docteur Cathy BLIEM

Madame le Docteur Bénédicte BULABOIS 


\section{UFR de Pharmacie de Grenoble}

DOMAINE DE LA MERCI

38706 LA TRONCHE CEDEX - France

TEL : +33(0)475637100

FAX : $+33(0) 475637170$

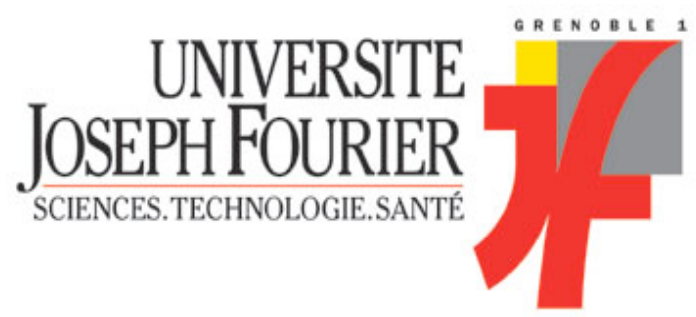

Doyen de la Faculté : M. le Pr. Christophe RIBUOT

Vice-doyen et Directeur des Etudes : Mme Delphine ALDEBERT

Année 2013-2014

ENSEIGNANTS A L'UFR DE PHARMACIE

PROFESSEURS DES UNIVERSITES (n=12)

$\begin{array}{lll}\text { BAKRI } & \text { Aziz } & \begin{array}{l}\text { Pharmacie Galénique et Industrielle, Formulation et } \\ \text { Procédés Pharmaceutiques (TIMC-IMAG) }\end{array} \\ \text { BOUMENDJEL } & \text { Ahcène } & \text { Chimie Organique (D.P.M.) } \\ \text { BURMEISTER } & \text { Wim } & \text { Biophysique (U.V.H.C.I) } \\ \text { DECOUT } & \text { Jean-Luc } & \text { Chimie Inorganique (D.P.M.) } \\ \text { DROUET } & \text { Christian } & \text { Immunologie Médicale (TIMC-IMAG) } \\ \text { DROUET } & \text { Emmanuel } & \text { Microbiologie (U.V.H.C.I) - } \\ \text { GODIN-RIBUOT } & \text { Diane } & \text { Physiologie-Pharmacologie (HP2) } \\ \text { LENORMAND } & \text { Jean Luc } & \text { Ingénierie Cellulaire, Biothérapies (THEREX, } \\ & & \text { IMAG) } \\ \text { MARTIN } & \text { Donald } & \text { Laboratoire TIMC-IMAG (UMR 5525 UJF-CNRS) } \\ \text { PEYRIN } & \text { Eric } & \text { Chimie Analytique (D.P.M.) } \\ \text { RIBUOT } & \text { Christophe } & \text { Physiologie - Pharmacologie (HP2) } \\ \text { WOUESSIDJEWE } & \text { Denis } & \text { Pharmacotechnie (D.P.M.) }\end{array}$

PROFESSEURS DES UNIVERSITES-PRATICIEN HOSPITALIER (n=6)

$\begin{array}{lll}\text { ALLENET } & \text { Benoit } & \text { Pharmacie Clinique (THEMAS TIMC-IMAG/MCU-PH) } \\ \text { CORNET } & \text { Murielle } & \text { Parasitologie-Mycologie Médicale (LAPM, PU-PH) } \\ \text { DANEL } & \text { Vincent } & \text { Toxicologie (SMUR SAMU / PU-PH) } \\ \text { FAURE } & \text { Patrice } & \text { Biochimie (HP2/PU-PH) } \\ \text { MOSSUZ } & \text { Pascal } & \text { Hématologie (PU-PH-THEREX-TIMC) } \\ \text { SEVE } & \text { Michel } & \text { Biochimie }- \text { Biotechnologie (IAB, PU-PH) }\end{array}$

PROFESSEURS EMERITES $(\mathbf{n}=\mathbf{2})$

$\begin{array}{lll}\text { CALOP } & \text { Jean } & \text { Pharmacie Clinique (TIMC-IMAG, PU-PH) } \\ \text { GRILLOT } & \text { Renée } & \text { Parasitologie - Mycologie Médicale (L.A.P.M) }\end{array}$

MAITRES DE CONFERENCES DES UNIVERSITES (n=32)

$\begin{array}{lll}\text { ALDEBERT } & \text { Delphine } & \text { Parasitologie-Mycologie (L.A.P.M) } \\ \text { BATANDIER } & \text { Cécile } & \text { Nutrition et Physiologie (L.B.F.A) }\end{array}$




\begin{tabular}{|c|c|c|}
\hline BELAIDI-CORSAT & Elise & Pharmacologie Physiologie -(HP2) \\
\hline BOURGOIN & Sandrine & Biochimie - Biotechnologie (IAB) \\
\hline BRETON & Jean & Biologie Moléculaire / Biochimie (L.C.I.B - LAN) \\
\hline BRIANCON-MARJOLLET & Anne & Physiologie Pharmacologie (HP2) \\
\hline BUDAYOVA SPANO & Monika & Biophysique (I.B.S) \\
\hline CAVAILLES & Pierre & Biologie Cellulaire et génétique (L.A.P.M) \\
\hline CHOISNARD & Luc & Pharmacotechnie (D.P.M) \\
\hline DELETRAZ-DELPORTE & Martine & $\begin{array}{l}\text { Droit Pharmaceutique } \\
\text { (Equipe SIS « Santé, Individu, Société »-EAM 4128) }\end{array}$ \\
\hline DEMEILLIERS & Christine & Biochimie (L.B.F.A) \\
\hline DURMORT-MEUNIER & Claire & Biotechnologies (I.B.S) \\
\hline GEZE & Annabelle & Pharmacotechnie (D.P.M) \\
\hline GILLY & Catherine & Chimie Thérapeutique (D.P.M) \\
\hline GROSSET & Catherine & Chimie Analytique (D.P.M) \\
\hline GUIEU & Valérie & Chimie Analytique (D.P.M) \\
\hline HININGER-FAVIER & Isabelle & Biochimie (L.B.F.A) \\
\hline JOYEUX-FAURE & Marie & Physiologie - Pharmacologie (HP2) \\
\hline KHALEF & Nawel & Pharmacie Galénique (TIMC-IMAG) \\
\hline KRIVOBOK & Serge & Biologie Végétale et Botanique (L.C.B.M) \\
\hline MELO DE LIMA & Christelle & Biostatistiques (L.E.C.A) \\
\hline MOUHAMADOU & Bello & Cryptogamie, Mycologie Générale (L.E.C.A) \\
\hline NICOLLE & Edwige & Chimie Thérapeutique (D.P.M) \\
\hline OUKACINE & Farid & Chimie Thérapeutique (D.P.M) \\
\hline PERES & Basile & Pharmacognosie (D.P.M) \\
\hline PEUCHMAUR & Marine & Chimie Organique (D.P.M.) \\
\hline RACHIDI & Walid & Biochimie (L.C.I.B) \\
\hline RAVEL & Anne & Chimie Analytique (D.P.M) \\
\hline RAVELET & Corinne & Chimie Analytique (D.P.M) \\
\hline SOUARD & Florence & Pharmacognosie (D.P.M) \\
\hline TARBOURIECH & Nicolas & Biophysique (U.V.H.C.I.) \\
\hline VANHAVERBEKE & Cécile & Chimie (D.P.M) \\
\hline
\end{tabular}

MAITRE DE CONFERENCE DES UNIVERSITES-PRATICIEN HOSPITALIER $(\mathbf{n}=\mathbf{3})$

$\begin{array}{lll}\text { BEDOUCH } & \text { Pierrick } & \text { Pharmacie Clinique (THEMAS TIMC-IMAG/MCU-PH) } \\ \text { BUSSER } & \text { Benoit } & \text { Pharmacie (MCU-PH-IAB-INSERM) } \\ \text { GERMI } & \text { Raphaëlle } & \text { Microbiologie (U.V.H.C.I/MCU-PH) }\end{array}$

\section{PROFESSEUR CERTIFIE (PRCE) (n=2)}

$\begin{array}{lll}\text { FITE } & \text { Andrée } & \text { P.R.C.E } \\ \text { GOUBIER } & \text { Laurence } & \text { P.R.C.E }\end{array}$

PROFESSEURS ASSOCIES (PAST) $(\mathrm{n}=4)$

$\begin{array}{lll}\text { BELLET } & \text { Béatrice } & \text { Pharmacie Clinique } \\ \text { RIEU } & \text { Isabelle } & \text { Qualitologie (Praticien Attaché - CHU) } \\ \text { TROUILLER } & \text { Patrice } & \text { Santé Publique (Praticien Hospitalier }- \text { CHU) }\end{array}$


PROFESSEUR AGREGE (PRAG) $(n=1)$
GAUCHARD
Pierre-Alexis
(D.P.M)

\begin{tabular}{lll} 
ASSISTANTS HOSPITALO-UNIVERSITAIRES $(\mathbf{A H U})(\mathbf{n}=\mathbf{3})$ \\
\hline CHANOINE & Sébastien & Pharmacie Clinique (UF-CHU) \\
GARNAUD & Cécile & Parasitologie-Mycologie \\
VAN NOLLEN & Laetitia & Biochimie Toxicologie (HP2-DNTP-BGM)
\end{tabular}

MEDAILLE D'OR D'ANNE D'INTERNAT SUPPLEMENTAIRE (n=2)

$\begin{array}{lll}\text { BERNARD } & \text { Delphine } & \text { période de } 6 \text { mois - novembre } 2013 \text { à avril } 2014 \\ \text { GAUTIER } & \text { Elodie } & \text { période de } 6 \text { mois - mai } 2014 \text { à novembre } 2014\end{array}$

\begin{tabular}{|c|c|c|}
\hline \multicolumn{3}{|l|}{$\operatorname{ATER}(n=3)$} \\
\hline BRAULT Julie & ATER & Pharmacologie - Laboratoire HP2 (JR) \\
\hline GRAS Emmanuelle & ATER & Physiologie-Pharmacologie - Laboratoire HP2 (JR) \\
\hline LEHMANN Sylvia & ATER & Biochimie Biotechnologie (JR) \\
\hline
\end{tabular}

\section{MONITEUR ET DOCTORANTS CONTRACTUELS}

BEL Coraline
BERTHOIN Lionel
BOSSON Anthony
CAVAREC Fanny
CHRISTEN Aude
CRESPO Xenia
LECERF-SHMIDT Florine
LESART Anne-Cécile
MELAINE Feriel
MORAND Jessica
NASRALLAH Chady
OUIDIR Marion
THOMAS Amandine

Professeur Invité

NURISSO Alessandra
(01-10-2012 au 30-09-2014)

(01-10-2012 au 30-09-2014)

Laboratoire (TIMC-IMAG-THEREX)

(01-10-2013 au 30-09-2015)

Laboratoire GIN

(01-10-2011 au 30-09-2014)

Laboratoire HP2 (JR)

(01-10-2013 au 30-09-2015)

DCM

(01-10-2013 au 30-09-2015)

LBGE

(01-10-2012 au 30-09-2014)

Pharmacochimie (DPM)

(01-10-2009 au 30-09-2013)

Laboratoire (TIMC-IMAG)

(01-11-2011 au 31/10.2014)

Laboratoire HP2(JR)

(01-10-2012 au 30-09-2014)

Laboratoire HP2 (JR)

(01-10-2011 au 30-09.2013)

Laboratoire HP2(JR)

(01-10-2011 au 30-09-2014)

(01-10-2011 au 30-09-2014) Laboratoire HP2 (JR)

CHU : Centre Hospitalier Universitaire

CIB : Centre d'Innovation en Biologie

DPM : Département de Pharmacochimie Moléculaire

HP2 : Hypoxie Physiopathologie Respiratoire et Cardiovasculaire

IAB : Institut Albert Bonniot, Centre de Recherche « Oncogenèse et Ontogenèse »

IBS : Institut de Biologie Structurale

LAPM : Laboratoire Adaptation et Pathogenèse des Microorganismes

LBFA : Laboratoire Bioénergétique Fondamentale et Appliquée

LCBM : Laboratoire Chimie et Biologie des Métaux

LCIB : Laboratoire de Chimie Inorganique et Biologie

LECA : Laboratoire d'Ecologie Alpine

LR : Laboratoire des Radio pharmaceutiques

TIMC-IMAG : Laboratoire Technique de l'Imagerie, de la Modélisation et de Cognition

UVHCI : Unit of Virus Host Cell Interactions 


\section{Remerciements}

J'aimerais exprimer mes profonds remerciements...

A Monsieur le Professeur Pascal MOSSUZ, Président du jury, Je suis très sensible à l'honneur que vous me faites en acceptant de juger mon travail en tant que président du jury. Veuillez trouver ici l'expression de mon respect et de ma sincère reconnaissance.

\section{A Madame le Docteur Claudine GIROUX-LATHUILE}

Directrice de thèse,

Je te remercie de m'avoir accueillie au sein du laboratoire il y a un an et de m'avoir fait confiance pour ce travail. Merci pour ta disponibilité, ton dynamisme, et ta gentillesse. Tes conseils et tes encouragements me poussent à vouloir continuer à évoluer dans ce domaine.

\section{A Monsieur le Professeur Patrice MORAND}

Merci d'avoir accepté de juger mon travail et pris le temps de participer à mon jury. Merci pour votre implication en tant que coordinateur du DES auprès des internes.

\section{A Madame le Docteur Cathy BLIEM}

Je vous remercie de l'honneur que vous me faites de participer à mon jury de thèse, merci pour votre lecture attentive et votre avis de spécialiste.

\section{A Madame le Docteur Bénédicte BULABOIS}

Merci d'avoir pris le temps de juger mon travail, merci pour votre disponibilité tout au long de mon internat et votre gentillesse. 
A Sophie ANSELME-MARTIN et Marion BRONNERT, pour votre encadrement, vos conseils et votre gentillesse tout au long de cette année passée à l'EFS de Grenoble. Travailler avec vous a été un réel plaisir, $j$ 'espère en avoir à nouveau l'occasion par la suite.

A toutes les secrétaires, techniciennes et techniciens du laboratoire IHE et de la Distribution de l'EFS Grenoble. Merci pour votre accueil, vos conseils avisés et votre bonne humeur de tous les jours.

A Christelle MORAND et le service de Prélèvement de l'EFS de Grenoble. Un grand merci au Docteur Marie-Pierre BERARD qui a accepté de réaliser tous les entretiens pré-don des donneurs convoqués.

A Cécile ARDILOUZE et son équipe du service de Promotion du don de l'EFS de Grenoble,

A Jacqueline DANTE et le service des Produits à usage de Laboratoire, Enseignement et Recherche (PLER) de I'EFS, merci à Bruno LAFEUILLADE et Yannick BOUVIER sur le site de Grenoble,

Au service Technique de l'EFS, merci à Luc ANDRE qui m'a aidée à dompter le réfrigérateur et m'a m'aiguillée sur toutes les données techniques,

Au service Informatique de l'EFS de Grenoble, merci à Sabine NOVIANT qui m'a sauvée d'un crash d'ordinateur!

Merci à Laurence CHAPEROT et à Stéphane RUCKLY, pour le temps que vous avez consacré à m'aider pour la réalisation des statistiques de cette étude.

Merci également à l'ensemble des biologistes, techniciens et secrétaires qui m'ont accueillie dans leurs laboratoires au cours de mon internat, à Grenoble et à Chambéry. Chaque stage a été riche en enseignements et en rencontres. 
Quelques remerciements plus personnels...

A mes supers parents, un immense merci pour votre soutien pendant mes études et depuis toujours. Merci maman pour le temps passé à relire ma thèse !

A mon petit frère, pas si petit que ça, mais toujours là pour moi.

Merci à tous mes co-internes, ceux avec qui j'ai travaillé, les autres avec qui j'ai passé 4 supers années d'internat, ceux qui m'ont aidé pour ce travail.

Mention spéciale pour ma promo, Alice, Céline, David, Elise, Elodie, Julien, et Pauline, Marion et Mathilde (maintenant presque internes!), j'espère que nos vies futures nous permettront de rester aussi soudés.

A mes amies de fac, Alice, Floriane et Ophélie qui ont transformé ces années d'études en souvenirs inoubliables, entre galères de concours et soirées, stress et fous rires... A Julie ma super coloc...

A mes amis de toujours, Adi, Fafa, Mook, Mymy, Paulo, Pierre, Toto,... Merci d'être toujours là, après toutes ces années. C'est une chance précieuse d'avoir des amis comme vous, vous retrouver est toujours un immense plaisir.

A mon lapin des mers qui se reconnaitra.

A Alex, avec tout mon amour...

Tu as su me supporter pendant cette rédaction, me remonter le moral lors de mes coups de mou et me donner confiance en moi. Merci pour ta présence à mes côtés chaque jour, ta bonne humeur de tous les instants et ton amour. 
INTRODUCTION

PARTIE I : DONNEES BIBLIOGRAPHIQUES ….............................................. 11

A. IMMUNOLOGIE FONDAMENTALE ET IMMUNO-HEMATOLOGIE ...............................11

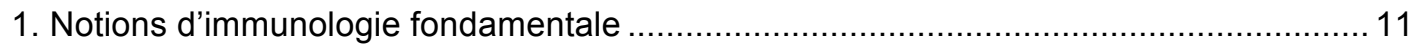

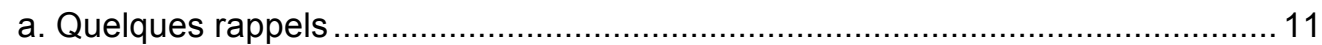

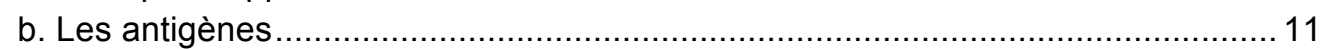

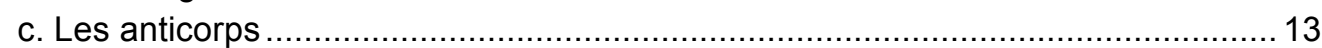

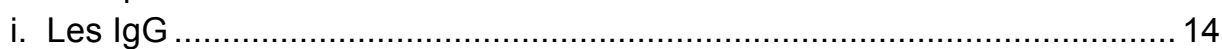

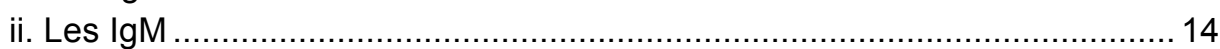

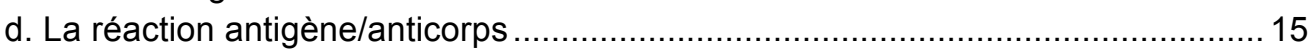

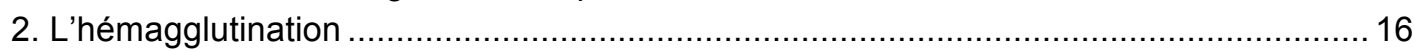

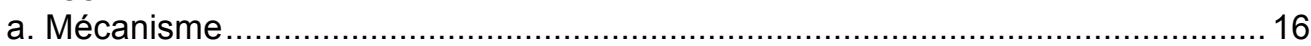

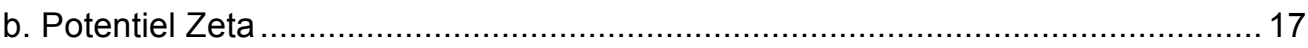

c. Facteurs influençant l'hémagglutination ...................................................... 18

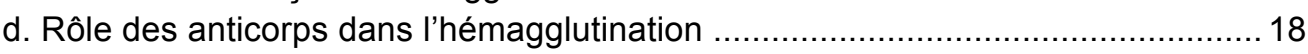

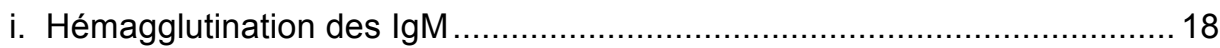

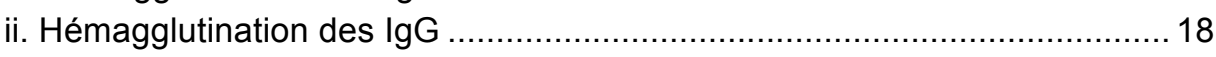

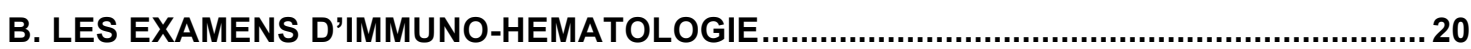

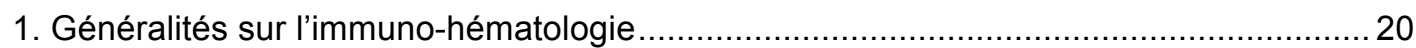

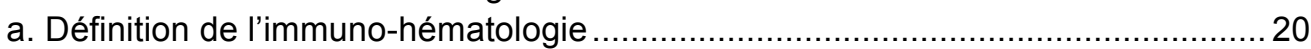

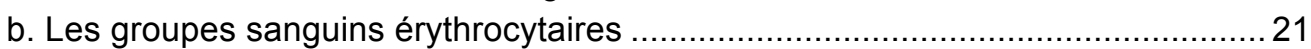

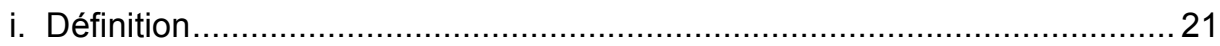

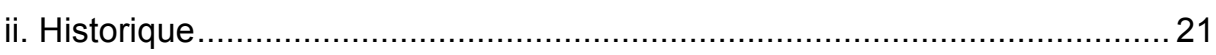

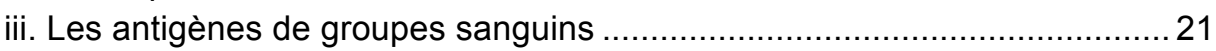

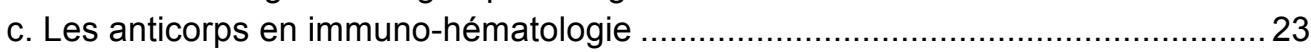

i. Synthèse des anticorps : réponses primaire et secondaire ........................ 23

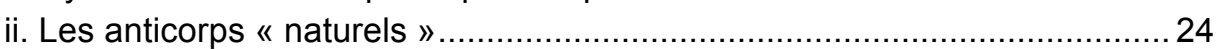

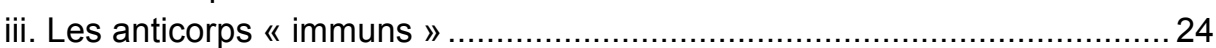

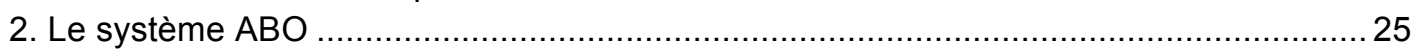

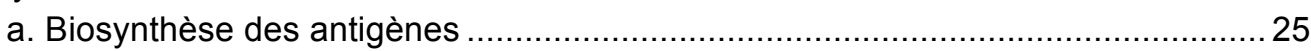

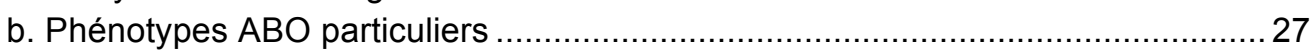

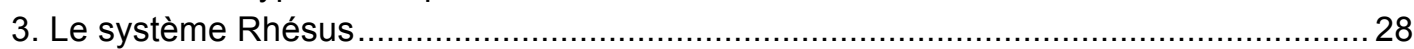

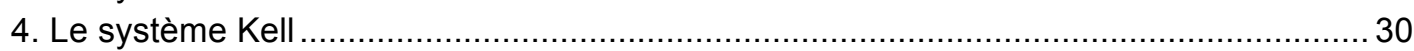

5. Prévention de l'incompatibilité $A B O$ et de l'allo-immunisation RHK ...............................30

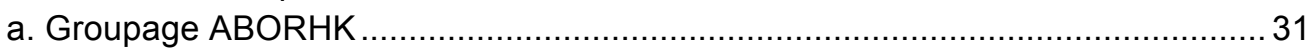

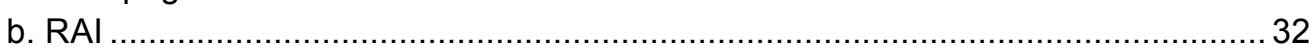

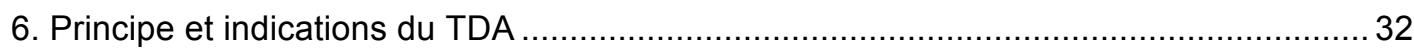

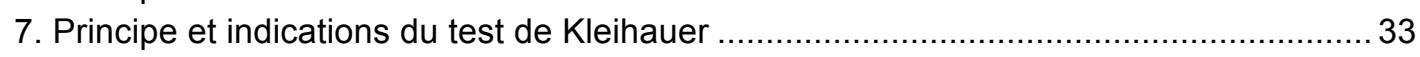

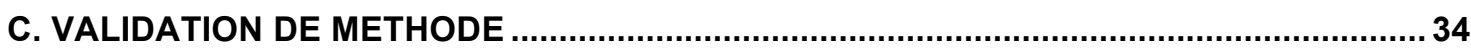

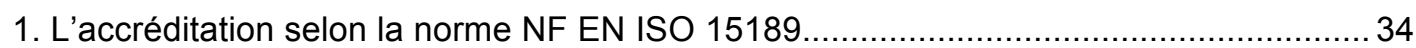

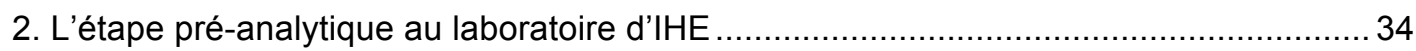

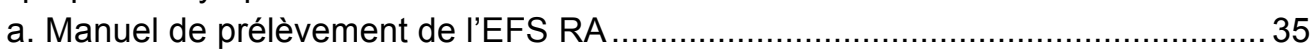

b. Transport et conservation des échantillons dans les autres disciplines de la

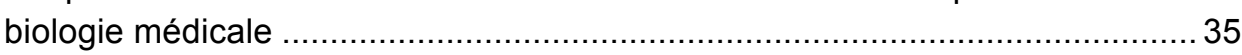

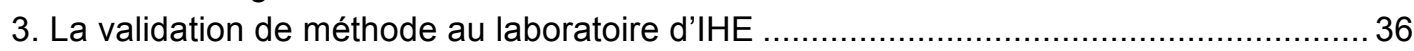

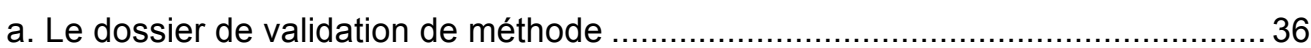

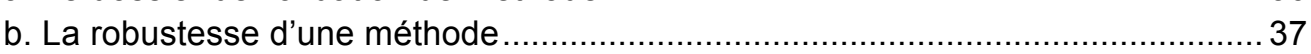

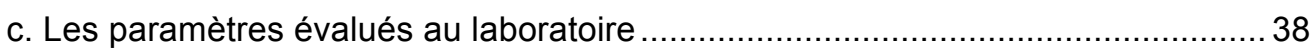




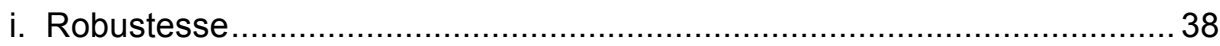

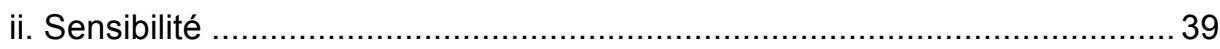

PARTIE II : ETUDE DE LA ROBUSTESSE DES ANALYSES D'IHE .................... 40

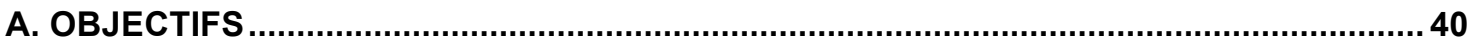

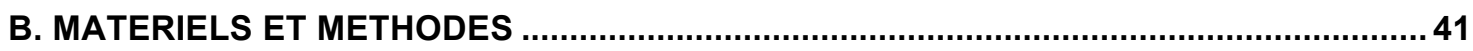

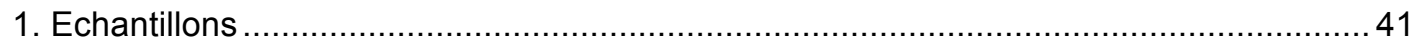

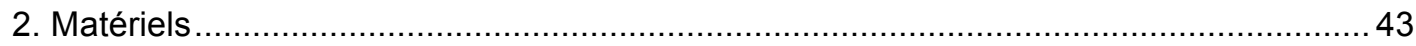

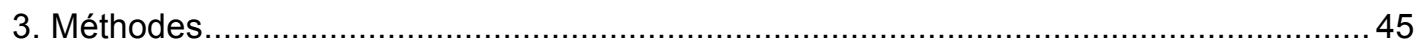

a. Protocole de l'étude pour le groupage ABORHK, la RAI et le TDA ....................45

b. Protocole de l'étude pour le test de Kleihauer .......................................... 47

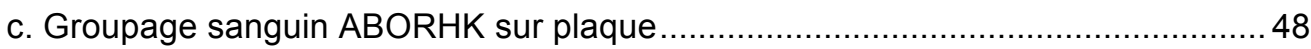

d. Groupage sanguin ABORHK sur gel microfiltration .................................. 50

e. Groupage sanguin ABORHK sur automate Galileo ${ }^{\circledR}$ Immuncor ...................... 51

f. Recherche d'anticorps irréguliers sur gel microfiltration ............................... 52

g. Recherche d'anticorps irréguliers sur automate Qwalys ${ }^{\circledR}$ Diagast....................54

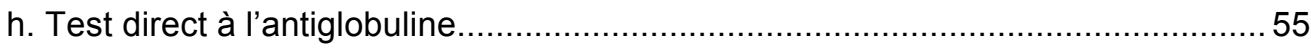

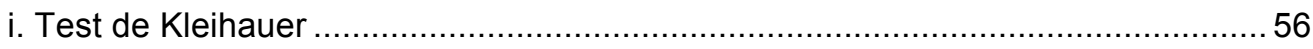

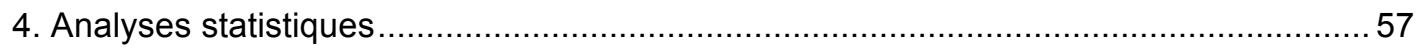

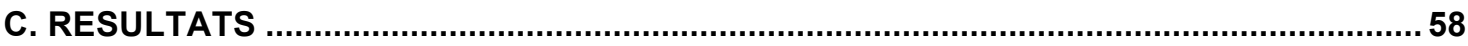

1. Groupages sanguins $A B O$ aux différentes conditions de conservation ........................58

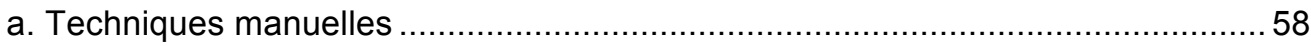

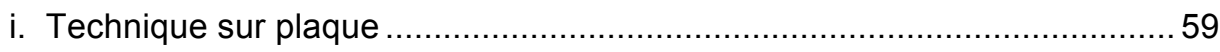

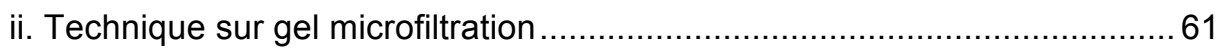

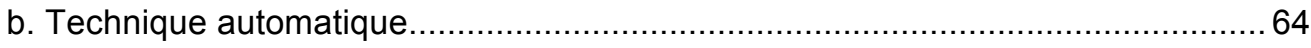

2. Phénotypages sanguins RHK aux différentes conditions de conservation ...................66

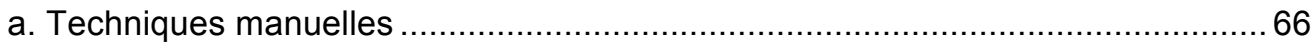

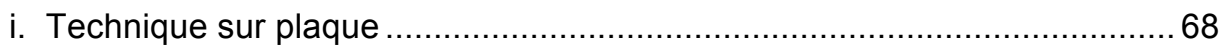

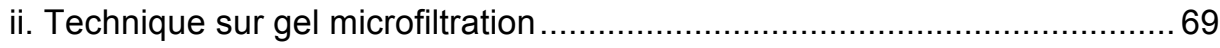

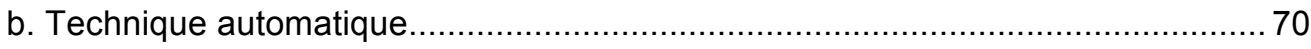

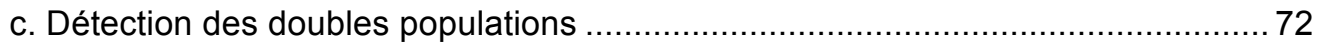

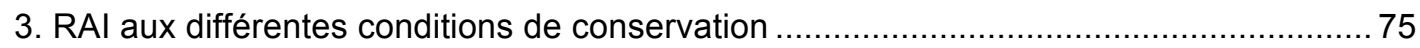

a. Dépistage et identification en technique manuelle .................................. 75

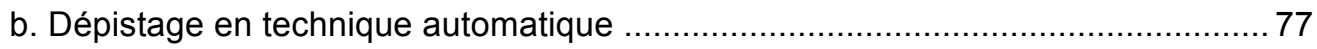

4. TDA aux différentes conditions de conservation ............................................. 80

5. Test de Kleihauer aux différentes conditions de conservation ............................... 82

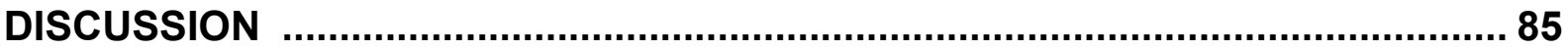

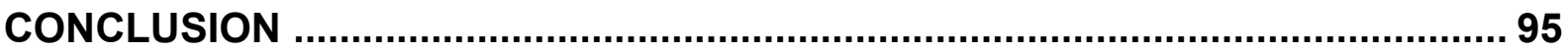

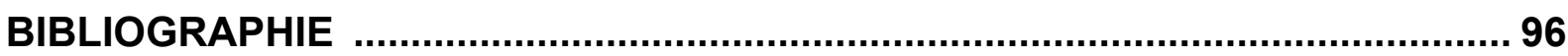

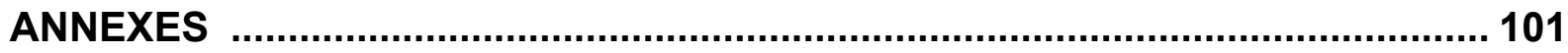

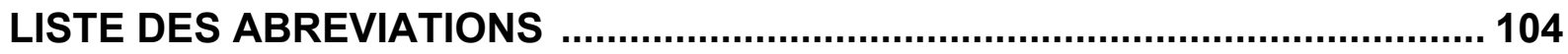

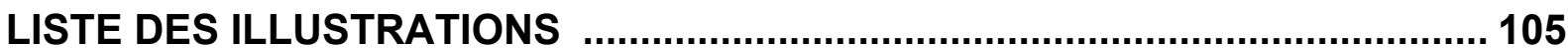




\section{INTRODUCTION}

L'accréditation selon la norme NF EN ISO 15189 (1) est actuellement une préoccupation des biologistes médicaux, que ce soit en ville, à l'hôpital, ou au sein des laboratoires de l'Etablissement Français du Sang (EFS). L'article L.6221-1 du Code de la Santé Publique (2) rend l'accréditation des laboratoires de biologie médicale (LBM) obligatoire.

Selon la législation relative à la biologie médicale (3), tous les LBM doivent avoir précisé leur entrée dans l'accréditation, afin d'être accrédités sur la totalité de leur activité au plus tard le 31 octobre 2020. La norme NF EN ISO 15189 spécifie les exigences de qualité et de compétence applicables aux LBM. L'un des apports essentiels de cette démarche est la maîtrise des phases pré-analytique, analytique et post-analytique d'un examen de biologie médicale, avec notamment la connaissance des méthodes et de leurs limites. L'accréditation est délivrée par le Comité Français d'accréditation (COFRAC), d'abord pour une durée de 4 ans, puis renouvelable par périodes de 5 ans.

Le laboratoire d'Immuno-Hématologie Erytrocytaire (IHE) de l'EFS RhôneAlpes (EFS RA) site de Grenoble a débuté cette démarche d'accréditation en 2005 (date à laquelle celle-ci était volontaire) pour aboutir à une accréditation en 2010. En 2012, le LBM IHE de l'EFS RA site de Grenoble est accrédité pour plus de 96\% de son activité. En 2013, un laboratoire unique de l'EFS RA regroupant dix laboratoires IHE, deux laboratoires HLA (Histocompatibilité), un laboratoire IP (ImmunoPlaquettaire) et un laboratoire IC (Immuno-Cellulaire) est créé et a obtenu l'accréditation pour plus de $80 \%$ de son activité.

Suite aux évaluations effectués par le COFRAC en juin 2013, un point d'amélioration a été évoqué : les exigences en matière de condition de transport des échantillons primaires. Dans son manuel de prélèvement, l'EFS Rhône Alpes préconise un transport des échantillons primaires à température ambiante, pour les examens IHE, dans un délai inférieur à $72 \mathrm{~h}$. Cette exigence est aisée à respecter lorsqu'il s'agit de prélèvements envoyés par le CHU de Grenoble, transmis le plus souvent par un système de pneumatique ou rapidement par des coursiers. En revanche, lorsque le prélèvement est transmis par des établissements de santé ou des laboratoires extérieurs, le transport est assuré à température non dirigée par des 
transporteurs. Outre son caractère non quantifiable et difficile à contrôler, la «température ambiante » est éminemment variable d'une saison à l'autre, particulièrement dans une ville comme Grenoble où la température extérieure peut être négative en hiver et monter jusqu'à $35^{\circ} \mathrm{C}$ en été (4) (Annexe 1).

Dans ce contexte, il apparaît donc nécessaire de préciser nos exigences en vérifiant que les principales analyses immuno-hématologiques de routine ne sont pas affectées par des températures « extrêmes ".

Dans ce travail nous avons évalué la robustesse des techniques de routine au laboratoire IHE de l'EFS RA sur le site de Grenoble, en simulant différentes conditions de températures de transport $\left(+4^{\circ} \mathrm{C},+22^{\circ} \mathrm{C}\right.$ et $\left.38^{\circ}\right)$ et de traitements du prélèvement avant transmission (sang total ou déjà centrifugé). Nous avons choisi d'étudier les examens les plus souvent demandées par les laboratoires extérieurs, à savoir : le groupage sanguin ABORHK, la recherche d'agglutinines irrégulières (RAI), le test direct à l'antiglobuline (TDA) et le test de Kleihauer.

Ce travail de mémoire de DES permettra, dans une première partie, de faire un point bibliographique sur les différents facteurs pouvant influencer la liaison antigène-anticorps puis un rappel concernant les examens étudiés. Nous aborderons également l'état actuel des connaissances et les recommandations concernant la validation d'une méthode d'analyse et la qualification de l'étape pré-analytique incluant le transport des échantillons primaires.

Dans un deuxième temps, nous présenterons les résultats obtenus pour les différentes techniques, dans les différentes conditions de transport simulées.

Enfin, après une analyse de ces résultats, nous conclurons sur la conduite à tenir proposée pour le transport des échantillons primaires en vue de la réalisation des analyses immuno-hématologiques érythrocytaires. 


\section{Partie I : DONNEES BIBLIOGRAPHIQUES}

\section{A. IMMUNOLOGIE FONDAMENTALE ET IMMUNO-HEMATOLOGIE}

\section{1) Notions d'immunologie fondamentale}

\section{a. Quelques rappels}

Le système immunitaire désigne l'ensemble des mécanismes de défense visant à éliminer les substances étrangères d'un organisme. Les deux composantes de ce système sont l'immunité innée et l'immunité adaptative.

L'immunité innée est la première ligne de défense, elle est rapidement mise en place. Cependant, cette composante du système immunitaire n'a pas la capacité d'instaurer une réponse immunitaire spécifique et durable.

L'immunité adaptative est quant à elle hautement spécifique, capable de reconnaître et d'éliminer sélectivement les molécules étrangères, en revanche sa mise en place est plus lente. Elle est capable de reconnaître le Soi du Non Soi. Une autre caractéristique essentielle est sa mémoire immunitaire. En cas d'exposition ultérieure à la même molécule étrangère, une « réponse mémoire » plus rapide et intense que la première sera mise en œuvre (5).

\section{b. Les antigènes}

On appelle antigène toute substance qui, introduite dans un organisme, provoque une réaction immunitaire spécifique. Ils sont caractérisés par leur pouvoir immunogène, faculté à engendrer la formation d'anticorps de manière plus ou moins puissante ; mais également par leur spécificité, c'est-à-dire leur capacité à ne réagir qu'avec l'anticorps correspondant (6). Les antigènes sont des macro-molécules, essentiellement de nature protéique, parfois associées à un sucre, lipide ou même acide nucléique. La partie qui entre en combinaison avec l'anticorps est appelée site antigénique ou déterminant antigénique, il s'agit d'une région en surface de l'antigène qui est complémentaire de la molécule d'anticorps (7). Un antigène possède habituellement un nombre variable de sites antigéniques distincts (Figure 
1). Ainsi, l'immunisation vis-à-vis d'un antigène donné va aboutir à la formation d'anticorps multiples, ceux-ci correspondent chacun à un déterminant antigénique.

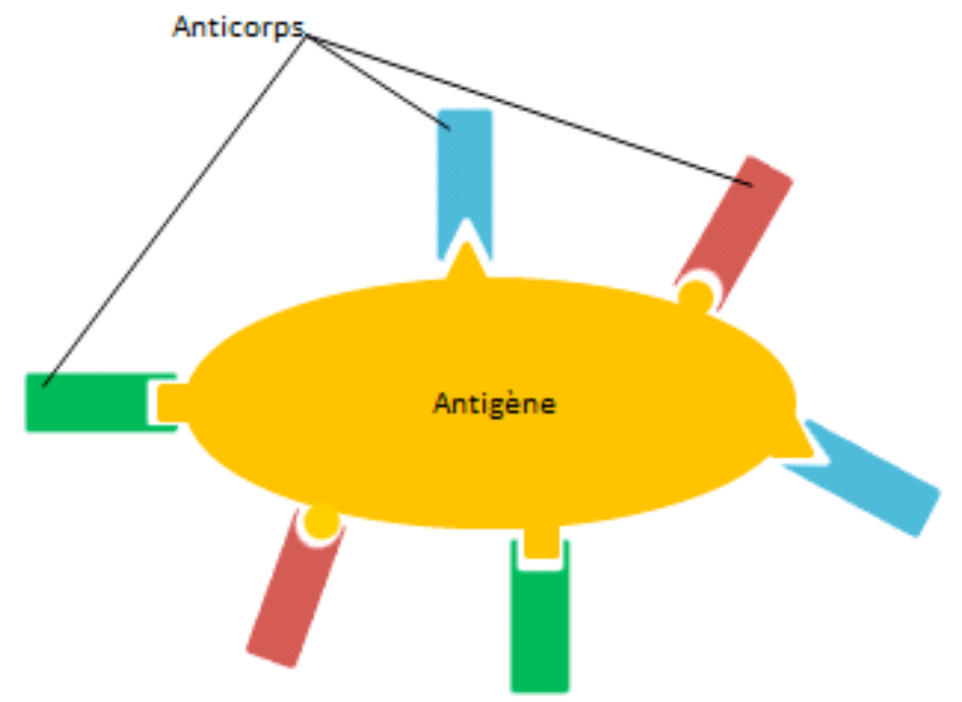

Figure 1 : Représentation d'un antigène et de ses anticorps correspondants. La molécule d'antigène comprend de nombreux sites antigéniques. A chacun correspond un anticorps dont le site de liaison à l'antigène se situe sur son fragment Fab. Les deux sites sont complémentaires.

\section{c. Les anticorps}

Les anticorps, ou immunoglobulines, sont des molécules produites en réponse à une stimulation antigénique et ayant la propriété de se lier spécifiquement à l'antigène qui induit leur production. Le contact entre les lymphocytes B et l'antigène est nécessaire pour induire leur différenciation en plasmocytes sécréteurs d'anticorps. Ces anticorps sont des glycoprotéines qui correspondent à la forme soluble des récepteurs d'antigène des lymphocytes $B$ circulants. II existe cinq classes d'immunoglobulines chez l'homme: $\lg G$, $\lg M, \lg A, \lg D$ et $\lg E$. Elles diffèrent par leur poids moléculaire, leur charge et leur composition en acides aminés et sucres. Chaque immunoglobuline possède une dualité fonctionnelle :

- Le fragment Fab intervient dans la liaison à l'antigène (Figure 1),

- Le fragment Fc est impliqué dans la liaison avec les tissus de l'hôte ou avec le système complément.

La structure de base des immunoglobulines (Figure 2) est une unité de deux chaînes polypeptidiques légères identiques et de deux chaînes polypeptidiques lourdes identiques, reliées par des ponts disulfures (5). 


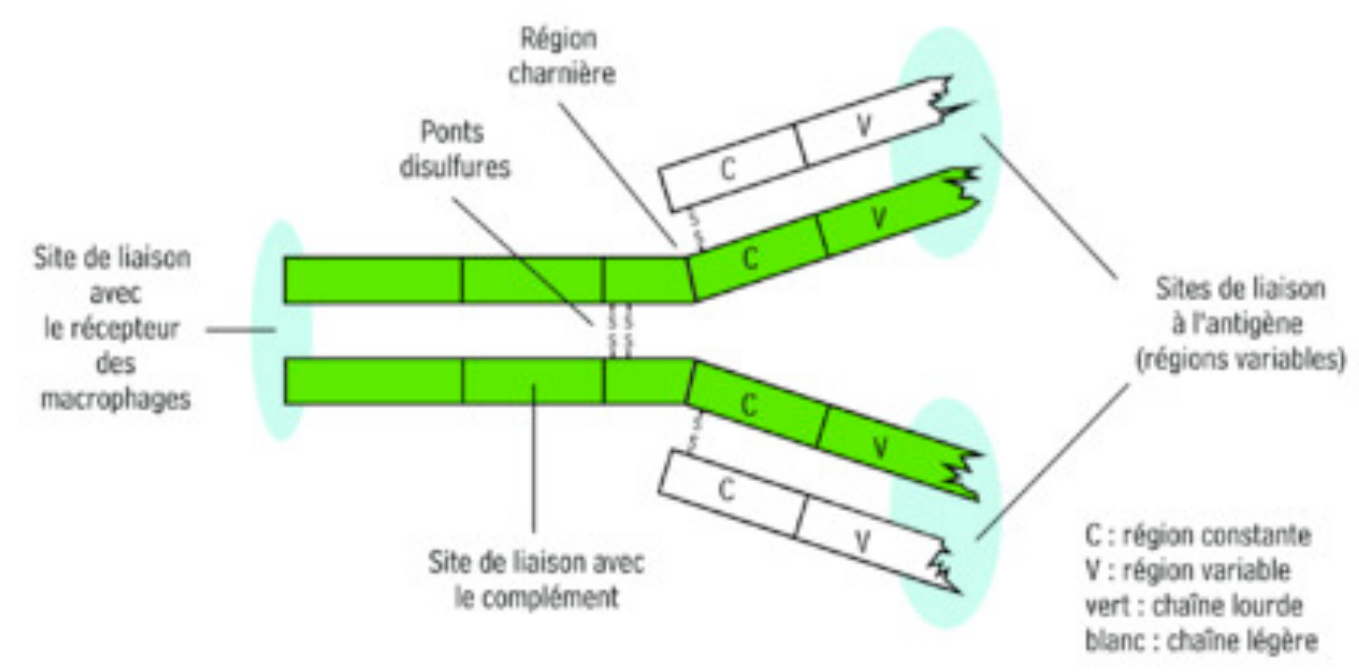

Figure 2 : Structure de base d'une molécule d'immunoglobuline (6).

Seules les immunoglobulines $\lg G$ et $\lg M$ seront développées ici, les $\lg \mathrm{A}$, IgD et IgE ne présentant que très peu d'intérêt en immuno-hématologie et dans notre présent travail.

\section{i. Les $\lg G$}

Les IgG sont les immunoglobulines majoritaires du sérum humain, elles représentent 70 à $75 \%$ des immunoglobulines totales. Ce sont des monomères de $146 \mathrm{kDa}$, relativement pauvres en glucides, constitués de deux chaines lourdes ( $\mathrm{\gamma}$ ) et de deux chaines légères ( $\mathrm{k}$ ou $\lambda$ ), reliées entre elles par deux ponts disulfures (Figure 3a). II existe quatre sous-classes d'lgG, les $\lg G 1 \lg G 2 \lg G 3$ et lgG4. Les IgG sont capables de passer la barrière fœto-placentaire et leur demi-vie est de 23 jours environ. Les IgG sont réparties uniformément dans les compartiments intravasculaire et extravasculaire et sont les principaux anticorps impliqués dans la réponse secondaire (8).

\section{ii. Les $\lg M$}

Les IgM représentent environ $10 \%$ des immunoglobulines totales, elles ont également une constitution glycoprotéique avec un taux de glucides plus élevé que les IgG. La molécule a une structure pentamérique de $970 \mathrm{kDa}$, chaque monomère est constitué de deux chaines lourdes et de deux chaines légères. Ils sont unis l'un à l'autre par une chaine $\mathrm{J}$ et des ponts disulfures au niveau de leur partie $\mathrm{Fc}$, formant ainsi une structure étoilée à cinq branches (Figure 3b). II existe deux sous-classes 
d'IgM, leur demi-vie est seulement de 5 jours. Les molécules d'lgM sont principalement confinées au compartiment intravasculaire et sont synthétisées principalement au cours de la réponse primaire (8).

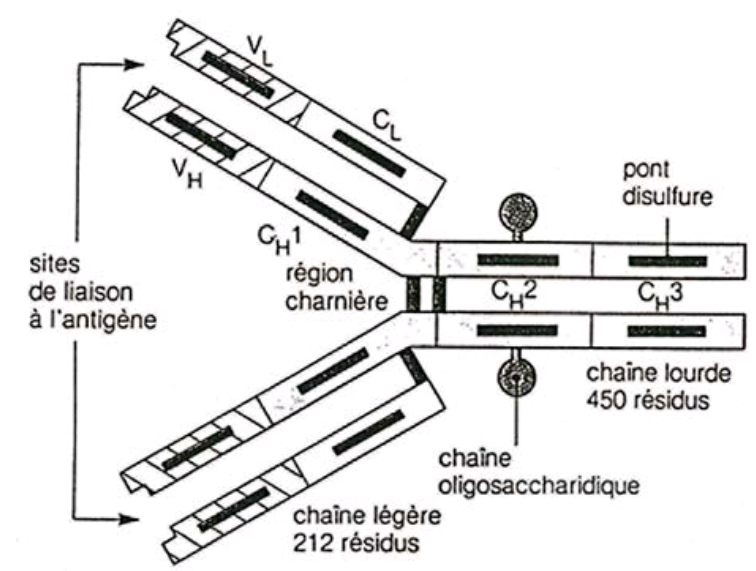

Figure 3 : a. Structure de base d'une $\lg G$;

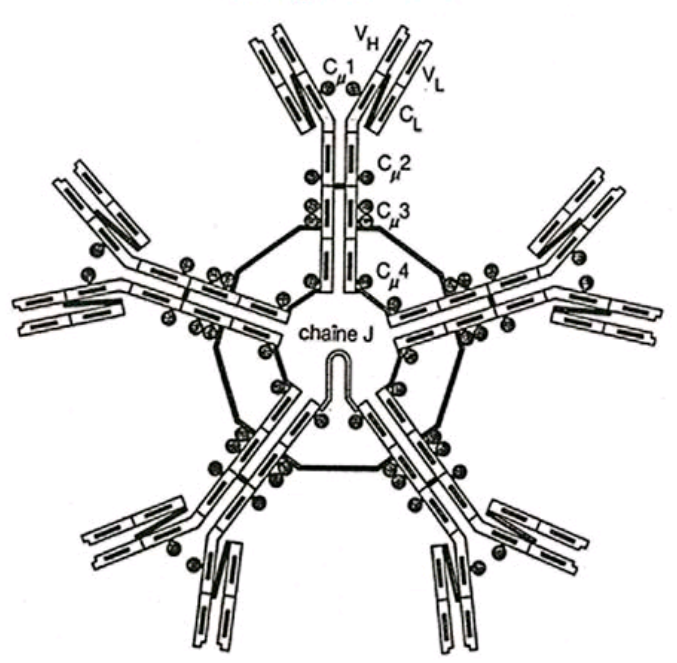

b. Structure de base d'une IgM.

$\mathrm{CH}$ : partie constante des chaines lourdes ; $\mathrm{CL}$ : partie constante des chaines légères ; $\mathrm{VH}$ : région variable des chaines lourdes; VL : région variable des chaines légères. (9)

\section{d. La réaction antigène/anticorps}

Cette réaction est spécifique: à chaque site antigénique correspond un anticorps (fragment Fab). La liaison entre l'antigène et l'anticorps n'est pas covalente mais implique différentes forces (Figure 4) (10) :

- les forces de Van der Waals, liées aux mouvements des électrons entre les deux molécules,

- les forces électrostatiques, entrainant l'attraction entre deux groupements ioniques de force opposée,

- les liaisons hydrogènes, qui correspondent à des ponts hydrogène entre les atomes $\mathrm{H}, \mathrm{N}$ et $\mathrm{O}$,

- les liaisons hydrophobes, actives entre acides aminés aromatiques.

Cette réaction est réversible, la liaison entre l'antigène et l'anticorps peut être dissociée (par la chaleur, le pH acide du milieu, l'augmentation de la concentration ionique, l'action d'un détergent,...), la stabilité du complexe antigène-anticorps peut être mesurée à l'aide d'une constante d'affinité K. 


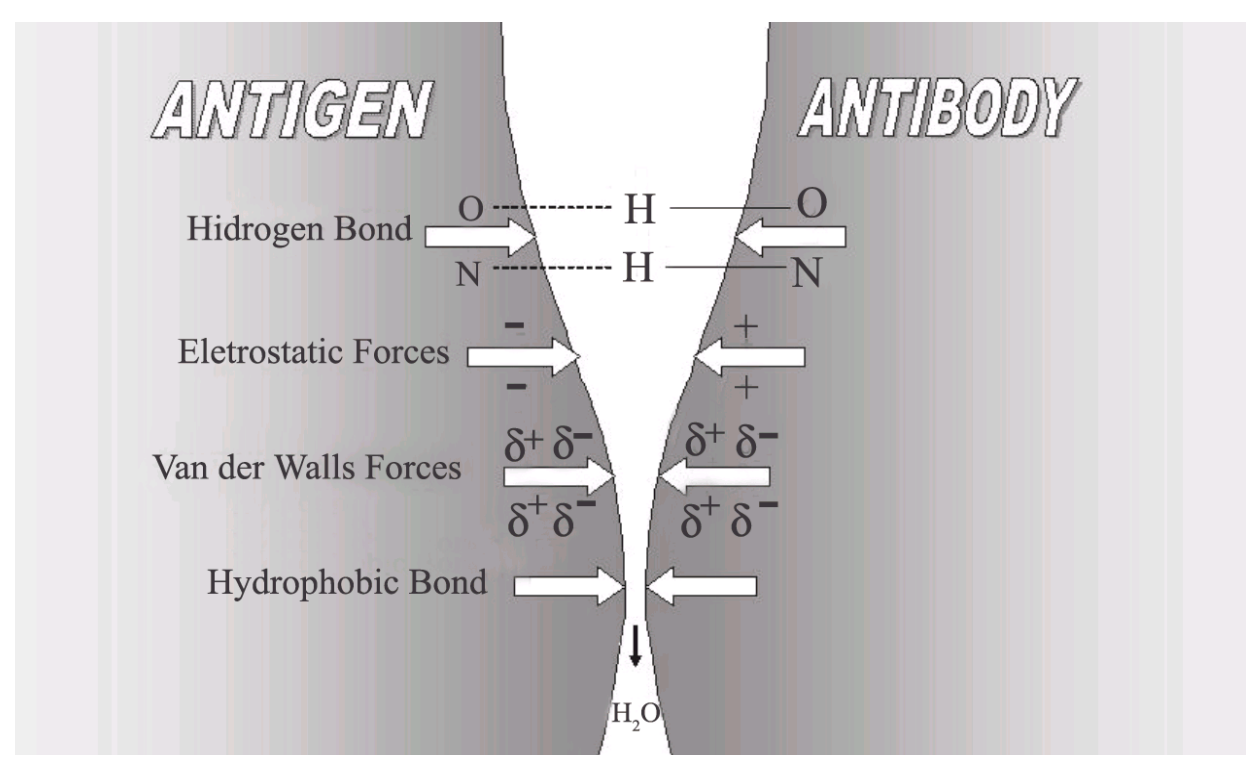

Figure 4: Forces impliquées dans la liaison antigène-anticorps. Les forces de Van der Waals et hydrophobes requièrent un contact rapproché entre l'antigène et l'anticorps, à l'inverse des liaisons hydrogènes et électrostatiques (10).

La liaison entre l'anticorps et son antigène peut être mesurée sur le plan thermodynamique. Quand la réaction est exothermique, c'est-à-dire dégage de l'énergie, la fixation de l'anticorps sur l'antigène est maximale à basse température, $+4^{\circ} \mathrm{C}$, mais faible à $+25^{\circ} \mathrm{C}$, on parle alors d'anticorps «froids ». A l'inverse, quand la réaction est peu exothermique, la fixation de l'anticorps sur l'antigène est optimale à $+37^{\circ} \mathrm{C}$ mais faible à $+4^{\circ} \mathrm{C}$ : on parle d'anticorps « chauds » (11).

\section{2) L'hémagglutination}

\section{a. Mécanisme}

L'hémagglutination désigne l'agglutination des hématies, elle survient lorsque les antigènes de groupes sanguins portés par les hématies sont au contact de leurs anticorps correspondants. Ce phénomène est très largement exploité en immunohématologie pour mettre en évidence la réaction antigène-anticorps. L'agglutination résulte de la formation d'un réseau, entre les antigènes et les anticorps, induisant le rapprochement d'un nombre d'hématies suffisant pour constituer un agglutinat visible à l'œil nu (11). 


\section{b. Potentiel Zeta}

Deux hématies ne peuvent pas s'approcher l'une de l'autre à moins de $180 \AA$ (Figure 5), laissant une distance entre leurs protéines de surface de $79 \AA$ minimum (12). Cette contrainte est capitale en immuno-hématologie.

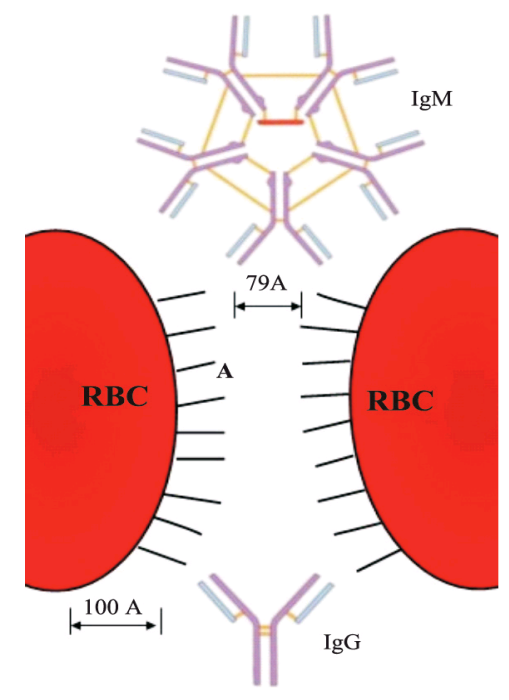

Figure 5 : Représentation de la distance minimum entre deux hématies (10).

Toutes les particules en suspension sont soumises au potentiel Zeta. Cette répulsion mutuelle des hématies est causée par leur surface chargée négativement. Les charges électriques négatives à la surface des hématies maintiennent la présence d'un nuage d'ions positifs (cations) solidaires du globule. Le potentiel Zeta représente la différence de potentiel électrique entre le nuage cationique entourant I'hématie et le milieu ambiant (Figure 6). La force de répulsion des hématies est donc fonction de ce potentiel Zeta, sa valeur en milieu isotonique est de $-16 \mathrm{mV}$ (13).

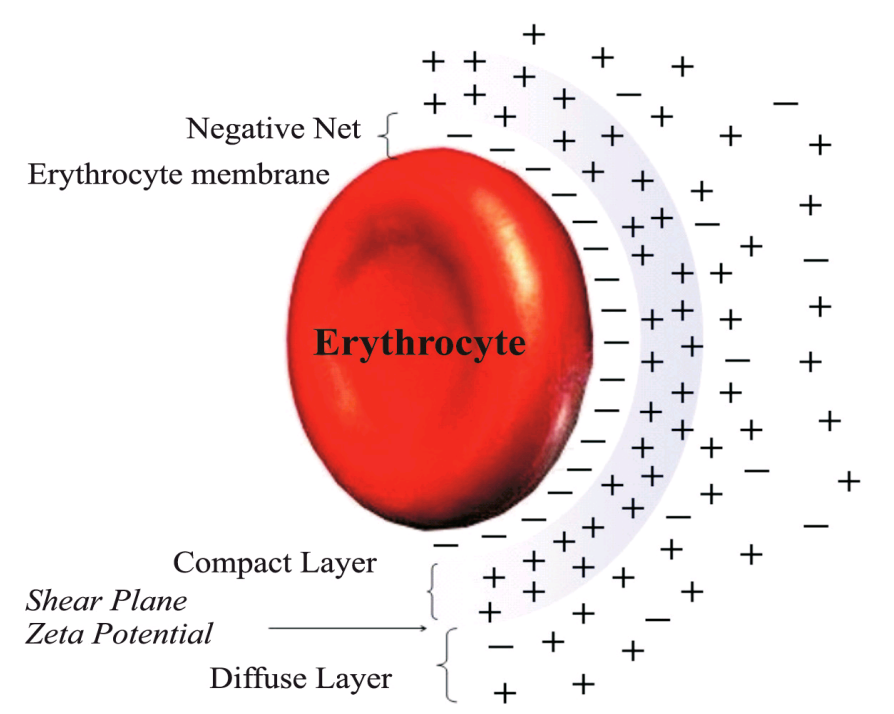

Figure 6 : Représentation schématique du potentiel Zeta. Les hématies en suspension entrainent un réarrangement des charges créant ainsi une double couche ionique qui génère une différence de potentiel électrique appelée le potentiel Zeta (10). 


\section{c. Facteurs influençant l'hémagglutination}

La température est un facteur important de l'agglutination des hématies, on distingue les anticorps « chauds » dont le pouvoir agglutinant est optimal à $37^{\circ} \mathrm{C}$, des anticorps "froids » qui réagissent peu à cette température. La densité antigénique des hématies joue également un rôle essentiel: plus les globules rouges sont recouverts d'antigènes, plus l'agglutination sera conséquente pour un même anticorps (11). Enfin, d'après van Oss, d'autres facteurs influencent l'hémagglutination : la forme de l'hématie, la distance inter-érythrocytaire, la pression osmotique du milieu et l'hydratation de la membrane érythrocytaire (14).

\section{d. Rôle des anticorps dans l'hémagglutination}

On dit qu'un anticorps est « agglutinant » ou « complet » lorsqu'il est capable de provoquer spontanément une agglutination des globules rouges en milieu salin physiologique ( $\mathrm{NaCl}$ 0,15M). En revanche, un anticorps est dit « non agglutinant » ou « incomplet» lorsque sa seule fixation n'est pas suffisante pour provoquer l'agglutination des globules rouges en milieu salin.

\section{i. L'hémagglutination des IgM}

L'efficacité du pouvoir agglutinant d'une immunoglobuline est liée à sa taille et à sa valence (nombre de sites anticorps). Une molécule d'lgM, avec $300 \AA$ d'envergure et une structure pentamérique lui conférant une valence de dix sites anticorps, est efficace pour provoquer l'agglutination (12) (Figure 7). De plus, les IgM agglutinent les hématies si le potentiel Zeta est compris entre $-20 \mathrm{mV}$ et $-16 \mathrm{mV}$, la valeur du potentiel Zeta en milieu isotonique étant de $-16 \mathrm{mV}$, ainsi elles sont spontanément agglutinantes (13).

\section{ii. L'hémagglutination des IgG}

Avec leur envergure de $120 \AA$ et leur valence de deux sites anticorps, les immunoglobulines de type IgG sont peu agglutinantes (Figure 7). Le potentiel Zeta en milieu isotonique n'est également pas favorable car les lgG n'entrainent l'agglutination des hématies que lorsque sa valeur est supérieure à $-10 \mathrm{mV}$. L'artifice permettant l'agglutination des globules rouges par des anticorps IgG est l'adjonction 
d'une antiglobuline anti-lgG. En effet, une fois recouverte par les anticorps IgG, les extrémités $F c$ de ces $\lg G$ ne sont plus séparées que par $60 \AA$, ce qui permet alors à l'antiglobuline anti-lgG de les agglutiner (12).

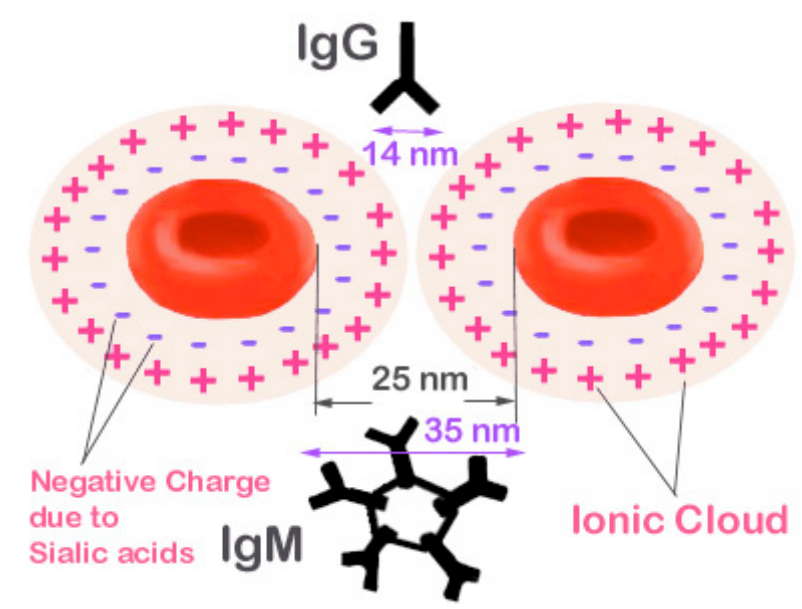

Figure 7 : Représentation schématique de la capacité d'agglutination des hématies par les lgG et les IgM. (Image Diamed®) 


\section{B. LES EXAMENS D'IMMUNO-HEMATOLOGIE}

\section{1) Généralités sur l'immuno-hématologie}

\section{a. Définition de l'immuno-hématologie}

L'immunohématologie correspond à l'étude des antigènes portés par les éléments figurés du sang (hématies, leucocytes, plaquettes), de l'immunisation qu'ils peuvent induire, et des conflits qui en résultent. La mission principale des laboratoires d'IHE de l'EFS est de réaliser les analyses nécessaires pour assurer la sécurité transfusionnelle (15) et prévenir certaines complications obstétricales dans le cadre de l'immunisation fœto-maternelle $(16,17)$.

$\mathrm{Au}$ delà de leurs fonctions biochimiques (18) et compte tenu de leur polymorphisme et de leur caractère immunogène, certains antigènes de groupes sanguins érythrocytaires jouent un rôle essentiel en transfusion, en transplantation et pendant la grossesse. Ils peuvent aussi être la cible d'auto-anticorps, parfois responsables d'anémies hémolytiques auto-immunes. C'est donc sur la détection de ces antigènes et de leurs anticorps correspondants que reposent les règles de compatibilité transfusionnelle et de suivi immuno-hématologique de la femme enceinte. Dans ces contextes, le laboratoire d'immuno-hématologie réalise les examens suivants :

- Groupage sanguin ABORHK

- Recherche d'agglutinines irrégulières (RAI)

- Test direct à l'antiglobuline (TDA)

- Test de Kleihauer (uniquement pour le suivi de la femme enceinte ou en postpartum immédiat)

Les conditions de réalisation des analyses d'immuno-hématologie sont définies par l'arrêté du 26 avril 2002 modifiant l'arrêté du 26 novembre 1999 relatif à la bonne exécution des analyses de biologie médicale (19). Pour chacune des analyses, l'arrêté fixe les champs d'application, les règles de réalisation, le contrôle de qualité interne, les conditions d'automatisation et d'informatisation, ainsi que les mentions devant apparaître sur la carte de groupe sanguin (20). 


\section{b. Les groupes sanguins érythrocytaires}

\section{i. Définition}

Les groupes sanguins se définissent comme un ensemble de caractères exprimés par une cellule sanguine ou par les protéines du plasma. Ces caractères sont les produits d'une unité génétique monofactorielle et sont indépendants les uns des autres, induisant un polymorphisme génétique à l'intérieur de l'espèce humaine. Ce polymorphisme génétique se traduit à ce jour par l'identification par l'International Society of Blood Transfusion (ISBT) de plus de 300 antigènes érythrocytaires, en majorité répertoriés en systèmes de groupes sanguins (21)(Annexe 2). Les groupes sanguins érythrocytaires se répartissent actuellement en 35 systèmes (22), constituant chacun un ensemble d'antigènes allotypiques de la membrane du globule rouge.

\section{ii. Historique}

Le système $A B O$ est le premier système de groupe sanguin identifié chez l'homme. II est découvert en 1900 par Karl Landsteiner qui a annoncé dans le "CentralBlatt für Bakteriologie » que « le sérum d'individus humains sains provoque l'agglutination non seulement des hématies animales mais aussi, souvent, des hématies d'autres individus» (23). C'est en 1901 qu'il met en évidence les trois groupes sanguins $A, B$ et $O$ : une agglutination apparaît avec les sérums de personnes ne possédant pas l'antigène correspondant. Le groupe $A B$ sera décrit en 1902 par ses collaborateurs Decastello et Sturli. Vont être découverts par la suite, par ordre chronologique, les systèmes MNSs (1925), P (1926), Rhésus (1940), puis Lutheran, Kell, Lewis, Duffy, Kidd,... Ces observations ont amélioré la sécurité des transfusions sanguines et cette nouvelle thérapeutique a permis les grands progrès de la médecine, de l'obstétrique et de la chirurgie, qui n'auraient pu être réalisés sans cet apport de sang humain. Pour l'ensemble de ses découvertes, Karl Landsteiner a reçu le prix Nobel de médecine en 1930 (24).

\section{iii. Les antigènes de groupes sanguins}

La plupart des antigènes de groupes sanguins sont synthétisés par la cellule érythroïde mais certains (systèmes Lewis et Chido/Rodgers) sont adsorbés à la surface des hématies à partir du plasma. On distingue deux types de systèmes de 
groupes sanguins selon la nature biochimique de leurs épitopes: les systèmes à épitopes de nature glucidique, portés par des glycoprotéines ou des glycolipides (ABO par exemple) et les systèmes à épitopes peptidiques, portés par des protéines ancrées dans la membrane du globule rouge (Duffy, Rhésus,...). Leur fonction au sein de l'hématie est encore mal connue, cependant on peut classer ces systèmes selon leur catégorie fonctionnelle (25). On distingue des transporteurs membranaires (Rhésus, Kidd,...), des récepteurs (Duffy, MNS,...), des glycoprotéines responsables de phénomènes d'adhérence cellulaire (Indian, Landsteiner-Wiener,...), des glycoprotéines avec fonctions enzymatiques (Kell, Cartwright,...) et des molécules du maintien de la structure membranaire (Gerbich) (Figure 8). Certains groupes sanguins comme $\mathrm{ABO}, \mathrm{Hh}$, Lewis, Kidd sont également des groupes tissulaires (présents sur le surface des hématies mais aussi de nombreuses cellules, tissus ou liquides biologiques), d'autres, comme les systèmes Rhésus, Kell, et Duffy sont en revanche présents sur les globules rouges uniquement (26).

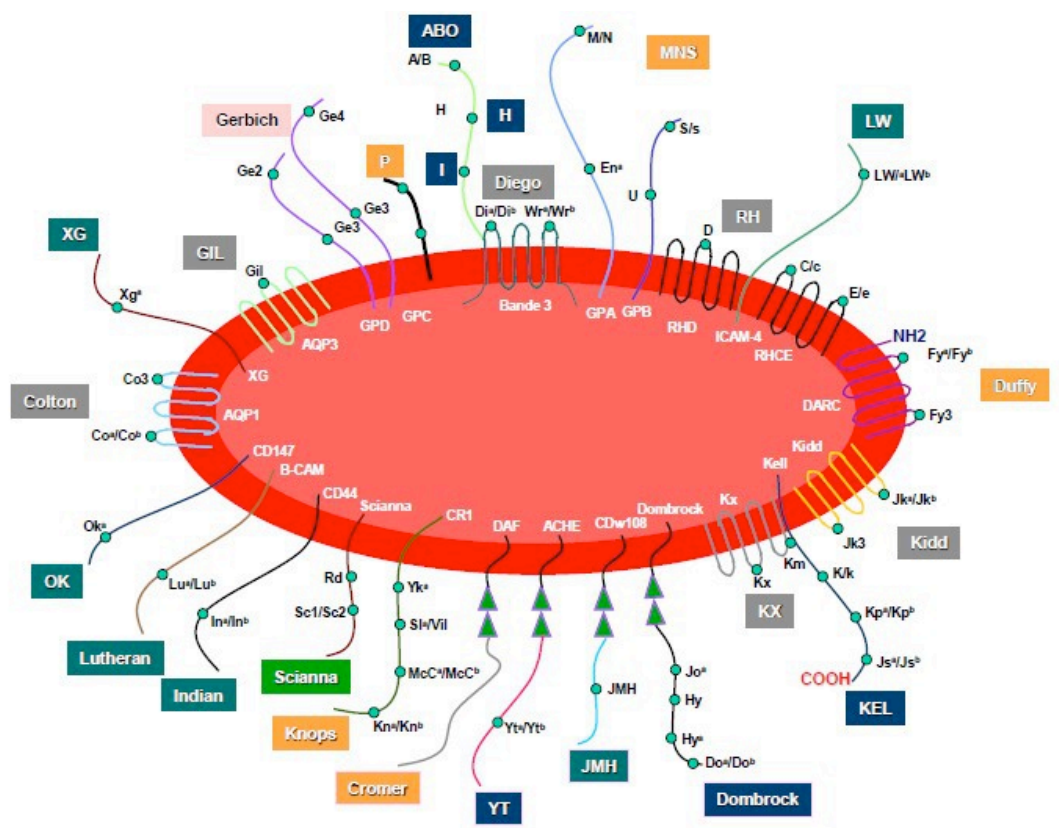

Figure 8: Représentation schématique des systèmes de groupe sanguin sur la membrane érythrocytaire (11).

Les systèmes de groupes sanguins ayant un intérêt majeur en transfusion sanguine et en obstétrique, de part leurs caractéristiques, sont les suivants :

- Le système ABO

- Le système Rhésus

- Le système Kell

- Le système Duffy

- Le système Kidd

- Le système MNS 
Dans ce travail nous ne développerons que les systèmes $A B O$, Rhésus et Kell, qui doivent obligatoirement figurer sur la carte de groupe sanguin.

\section{c. Les anticorps en immuno-hématologie}

i. Synthèse des anticorps : les réponses primaire et secondaire

Suite à une stimulation antigénique, l'immunité innée intervient et la réponse primaire se met en place. Celle-ci instaure la sécrétion d'immunoglobulines de type IgM par les plasmocytes, dans un premier temps, puis d'un mélange d'IgM et d'IgG, après une dizaine de jour. Cette réponse est rapide mais peu spécifique. En revanche lors d'un deuxième contact avec le même antigène, l'immunité adaptative prend le relai : c'est la réponse dite secondaire. Cette réponse fait appel à la mémoire immunitaire et va entrainer la sécrétion d'immunoglobulines de type lgG possédant une forte affinité pour l'antigène, de manière rapide, durable et à des taux plus élevés.

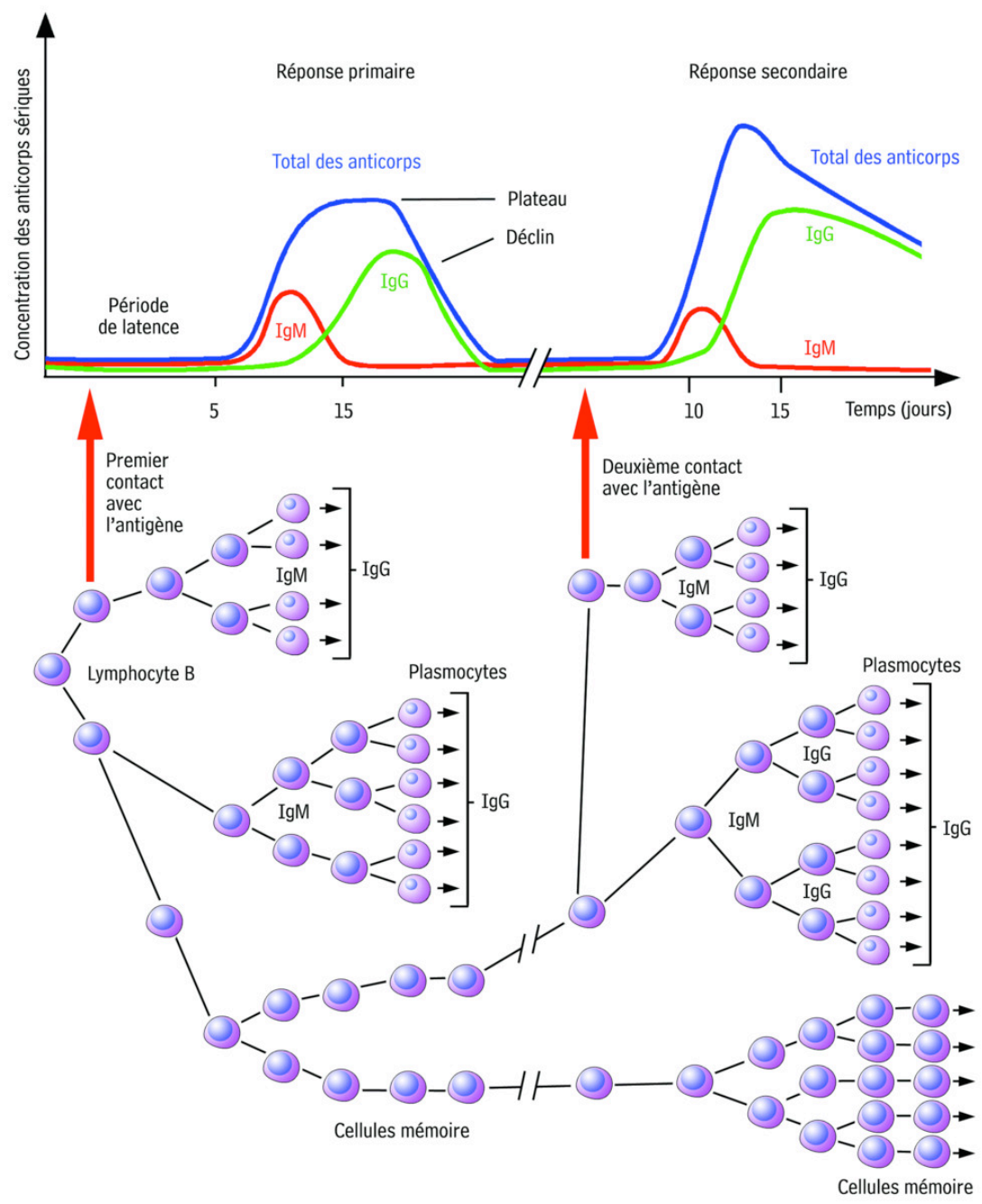

Figure 9: Mise en place de la réponse immunitaire. Le premier contact avec l'antigène, ou réponse primaire, donne lieu à la production d'lgM, puis la réponse secondaire, à la production d'lgG (6). 


\section{ii. Les anticorps « naturels»}

Par anticorps «naturels », on entend les anticorps présents en dehors de toute stimulation antigénique apparente, c'est à dire en absence de grossesses ou transfusions incompatibles antérieures. Lorsqu'un anticorps " naturel » est systématiquement présent chez un sujet dépourvu de l'antigène correspondant, il est dit « naturel régulier ». C'est le cas des anticorps anti-A, anti-B et anti-AB du système ABO. II semble que la production de ces anticorps soit surtout stimulée par le contact avec des substances étrangères, comme des bactéries, répandues dans la nature. De composition chimique apparentée à celle des antigènes du système $A B O$ (avec notamment une structure glucidique similaire), ces substances étrangères entrainent la production d'anticorps chez le nourrisson, dès les premiers mois de vie (27). Ce sont donc des hétéro-anticorps. Ils peuvent causer une hémolyse intravasculaire, par activation du complément, et sont à prendre en compte en transfusion sanguine (15). Les anticorps "naturels " sont le plus souvent de nature IgM, dont l'optimum thermique est bas $\left(+4^{\circ} \mathrm{C}\right)$.

Lorsqu'un anticorps «naturel » n'est observé que de manière inconstante chez le sujet dépourvu de l'antigène correspondant, il est dit « naturel irrégulier». Les principaux sont les anti-M, anti-N, anti-P1, anti-Lea, anti-H, anti-Cw,... Ces anticorps peuvent apparaître suite à une stimulation environnementale. Ils ne sont généralement pas dangereux en transfusion sanguine et sont le plus souvent de nature IgM (même si une fraction IgG peut être parfois retrouvée) (11).

\section{iii. Les anticorps « immuns »}

Par opposition au terme « naturel », on parle d'anticorps « immuns » lorsque ceux-ci surviennent à la suite d'une stimulation antigénique transfusionnelle ou obstétricale. Ce sont des allo-anticorps. Ces anticorps sont «irréguliers », par leur présence inconstante. Ils apparaissent à l'occasion du premier contact entre le sujet et l'antigène (réponse immunitaire primaire) et sont de classe lgM puis lgG. Le danger apparait lors du contact suivant, la réponse immunitaire secondaire est alors beaucoup plus rapide et intense, les anticorps sécrétés sont de nature lgG et entrainent l'élimination ou la lyse des globules rouges portant l'antigène. L'alloimmunisation anti-érythrocytaire correspond donc à la réponse immunitaire d'un individu vis-à-vis d'antigènes érythrocytaires étrangers, c'est-à-dire absents à la surface de ses hématies (28). L'allo-immunisation fœto-maternelle aboutit à la 
production d'allo-anticorps par la mère contre un antigène présent chez le fœtus et transmis par son père biologique (29). Ces anticorps sont extrêmement dangereux en contexte transfusionnel ou obstétrical, leur recherche est une obligation dans ces situations (15).

Les systèmes de groupes sanguins les plus immunogènes, capables d'induire la formation d'anticorps immuns chez la femme enceinte ou le patient polytransfusé sont les systèmes Rhésus, Kell, Duffy, Kidd et MNS (30).

\section{2) Le système $A B O$}

II s'agit du système le plus important en transfusion sanguine et greffes (CSH ou organes solides). Ce système est caractérisé par :

- la présence de quatre antigènes de surface du globule rouge : $A, B, A B$ et $A 1$

- la présence constante, dans le plasma d'un individu, d'anticorps anti-A, anti-B, anti$A B$ naturels, correspondants aux antigènes absents des globules rouges.

On définit ainsi quatre phénotypes principaux de groupe sanguin ABO (Tableau 1).

\begin{tabular}{|l|l|l|l|c|} 
Phénotypes & Génotypes & $\begin{array}{c}\text { Antigène(s) } \\
\text { présent(s) sur } \\
\text { I'hématie }\end{array}$ & \multicolumn{1}{|c|}{$\begin{array}{c}\text { Anticorps présent(s) } \\
\text { dans le plasma }\end{array}$} & $\begin{array}{c}\text { Fréquence } \\
\text { en France }\end{array}$ \\
\hline A & A/A ou A/O & A & anti-B & $45 \%$ \\
\hline B & B/B ou B/O & B & anti-A & $9 \%$ \\
\hline O & O & ni A, ni B & anti-A, anti-B et anti-AB & $43 \%$ \\
\hline AB & A/B & A et B & ni anti-A, ni anti-B, ni anti-AB & $3 \%$ \\
\hline
\end{tabular}

Tableau 1 : Les quatre phénotypes érythrocytaires ABO principaux (26).

\section{a. Biosynthèse des antigènes}

La présence des antigènes du système $A B O$ à la surface des hématies est sous la dépendance de trois allèles : les allèles $A$ et $B$ sont codominants tandis que l'allèle $O$ est récessif. Le gène $A B O$ est localisé sur le chromosome 9.

Les antigènes du système $\mathrm{ABO}$ sont de nature glucidique: ce sont des chaines oligosaccharidiques construites par addition successive de monosaccharides spécifiques sur le disaccharide terminal des chaines latérales de 
glycoprotéines et glycolipides membranaires. Ils sont formés grâce à l'action des enzymes glycosyltransférases $A$ et $B$. Cette synthèse se déroule dans le réticulum endoplasmique et dans l'appareil de Golgi selon trois étapes : l'initiation, l'élongation et la terminaison (26).

L'étape d'initiation correspond à la fixation du premier monosaccharide sur la glycoprotéine ou le glycolipide membranaire.

L'étape d'élongation correspond à l'adjonction successive et répétée du motif Gal $\beta 1 \rightarrow 4$ GlcNac $\beta 1 \rightarrow 3$ à la suite du premier monosaccharide, formant ainsi le précurseur des antigènes, appelé substance $H$ (ou antigène $H$ ).

L'étape de terminaison est caractérisée par l'ajout des sucres terminaux spécifiques de chaque antigène sur la partie périphérique des chaines précurseurs. En fonction du génotype $A B O$ de chaque individu, la biosynthèse se termine de cette manière :

- chez le sujet possédant au moins un allèle $A$, l'enzyme fonctionnelle $N$ acétylgalactosaminyl-transférase (glycosyltransférase $A$ ) catalyse la fixation d'un $\mathrm{N}$ acétylgalactosamine sur le déterminant $H$ pour former l'antigène $A$.

- chez le sujet possédant au moins un allèle $B$, l'enzyme fonctionnelle $\alpha$ galactosyltransférase (glycosyltransférase $B$ ) fixe un galactose sur la substance $\mathrm{H}$, aboutissant ainsi à la formation de l'antigène $B$.

- chez un sujet de groupe $O$ (possédant les deux allèles $O$ ), la biosynthèse s'achève à la substance $\mathrm{H}$ en raison de l'absence d'enzyme fonctionnelle pour fixer un dernier sucre.

- enfin, chez un sujet de groupe $A B$, possédant donc les allèles $A$ et $B$, il y aura à la fois fixation de $\mathrm{N}$-acétylgalactosamine et de galactose sur le déterminant $\mathrm{H}$. 

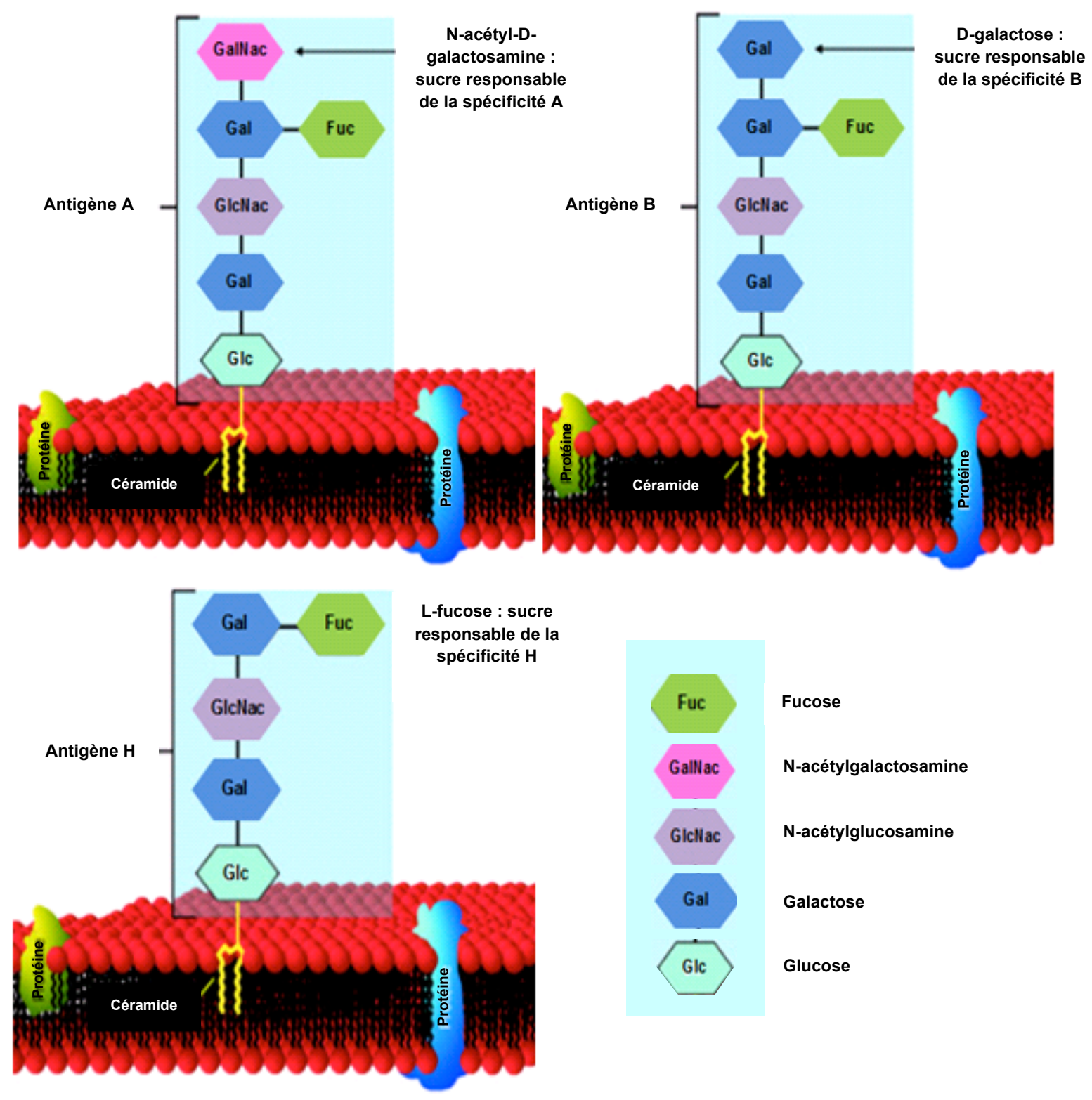

Figure 10 : Biosynthèse des antigènes $A, B$ et $H$. (Figure adaptée de R. L'Italien, 2008 (6)).

\section{b. Phénotypes ABO particuliers}

Il existe plusieurs phénotypes $A$ définis par le nombre de sites antigéniques $A$ présents à la surface de l'hématie. Les deux principaux sont $A 1$ et $A 2$ (pour $A 1$, la substance $\mathrm{H}$ est presque totalement transformée alors que pour $\mathrm{A} 2$ la transformation est incomplète). Ceci peut-être relié à des différences d'efficacité des glycosyltransférases. Environ $80 \%$ des personnes de groupes $A$ et $A B$ sont en fait $A 1$ et A1B, contre $20 \%$ de $A 2$ et A2B. II existe des variants phénotypiques faibles, plus rares présentant un nombre décroissant de sites antigéniques à la surface des hématies. Les phénotypes $A$ faibles sont classés en sous-groupes: $A_{3}, A_{x}, A_{m}, A_{y}$, 
$A_{\text {end, }} A_{\text {el }}$ (Figure 11). Ils sont notamment caractérisés par des réactions d'agglutinations affaiblies voire négatives avec les anticorps anti-A (31).

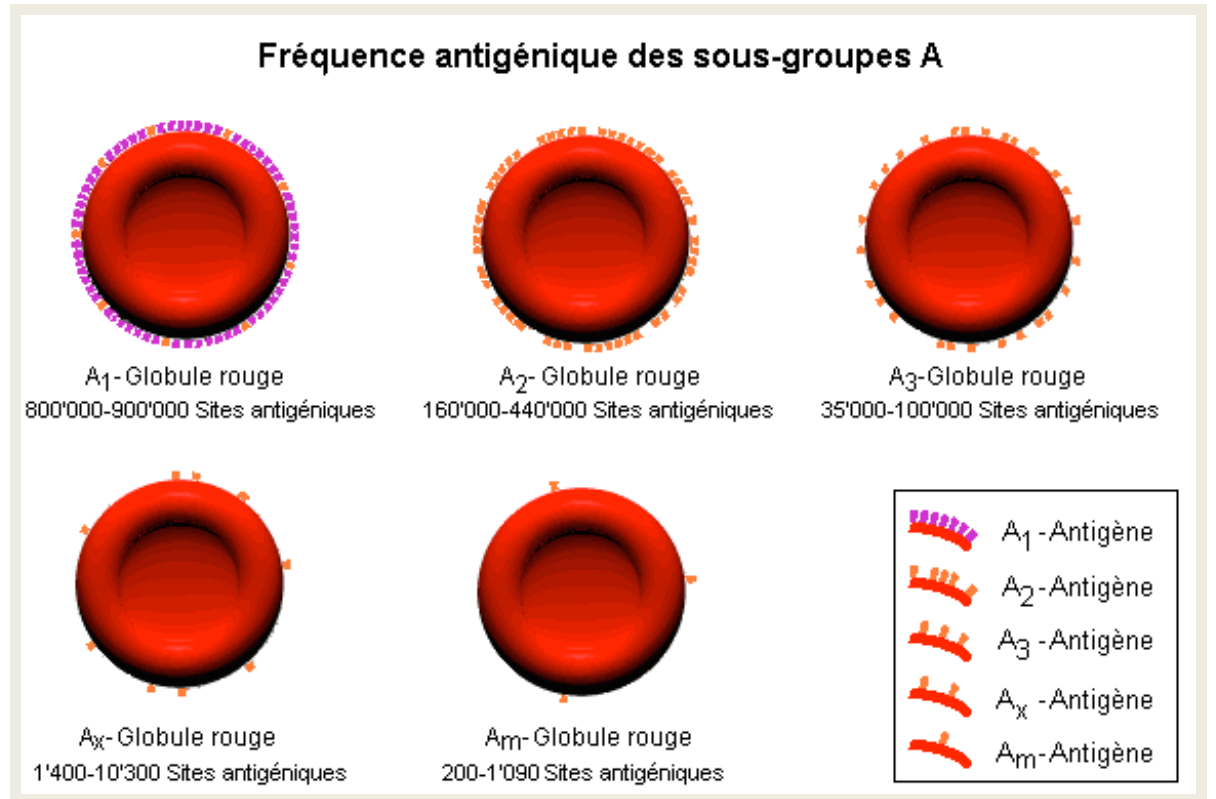

Figure 11 : Nombre de sites antigéniques par hématies, de quelques-uns des sous-groupes A (Image Diamed()

II en est de même pour les phénotypes B faibles, ils sont encore plus rares que les phénotypes $A$ faibles et très hétérogènes (32). Par analogie on les classe également en $B_{3}, B_{x}, B_{m}$ et $B_{e l}$.

\section{3) Le système Rhésus}

C'est le système de groupe sanguin le plus complexe. II contient 54 antigènes (21) dont les cinq plus importants sont les antigènes RH1 (D), RH2 (C), RH3 (E), RH4 (c) et RH5 (e) (Tableau 2). Les antigènes du système RH sont localisés sur deux protéines codées par deux gènes homologues étroitement liés, localisés sur le chromosome 1. Le gène $R H D$, s'il est présent, code pour la protéine RHD qui porte l'antigène $\mathrm{RH} 1$ et définit le phénotype $\mathrm{RH}: 1$ (appelés couramment Rhésus positif). $\mathrm{A}$ l'inverse, les sujets RH:-1 (appelés Rhésus négatif) sont dépourvus du gène $D$, l'antigène $\mathrm{RH} 1$ est donc absent de la surface de leurs hématies. Le gène RHCE code pour la protéine RHCE qui porte les antigènes $\mathrm{RH} 2(\mathrm{C})$ ou $\mathrm{RH} 4$ (c) et RH3 (E) ou RH5 (e). Les antigènes RH2 et RH4 (de même que les antigènes RH3 et RH5) sont dits antithétiques, lorsque l'un est absent, l'autre est automatiquement présent (Tableau 3). 


\begin{tabular}{|c|c|}
\hline Antigène & Fréquence \\
\hline D (RH1) & $85 \%$ \\
\hline C (RH2) & $68 \%$ \\
\hline E (RH3) & $29 \%$ \\
\hline c (RH4) & $81 \%$ \\
\hline e (RH5) & $98 \%$ \\
\hline
\end{tabular}

Tableau 2: Fréquence des cinq principaux antigènes du système Rhésus dans la population caucasienne (26).

Les cinq phénotypes Rhésus les plus fréquents en Europe sont les suivants:

\section{Phénotypes}

\begin{tabular}{|c|c|c|}
\hline$D+C+E-C+e+$ & $\mathrm{RH}: 1,2,-3,4,5$ & $35 \%$ \\
\hline$D+C+E-c-e+$ & $\mathrm{RH}: 1,2,-3,-4,5$ & $20 \%$ \\
\hline D-C-E- C+e+ & $\mathrm{RH}:-1,-2,-3,4,5$ & $15 \%$ \\
\hline$D+C+E+c+e+$ & $\mathrm{RH}: 1,2,3,4,5$ & $14 \%$ \\
\hline$D+C-E+c+e+$ & $\mathrm{RH}: 1,-2,3,4,5$ & $12 \%$ \\
\hline
\end{tabular}

Tableau 3: Fréquence des cinq phénotypes Rhésus les plus rependus dans la population caucasienne. Les treize autres phénotypes sont rares ou exceptionnels (11).

De la même façon que pour les groupes $A B O$, il existe des phénotypes variants, caractérisés par des modifications quantitatives ou qualitatives de la protéine RHD (33). Les phénotypes $\mathrm{RH} 1$ faibles présentent une expression membranaire affaiblie de l'antigène $\mathrm{RH} 1$, ils sont rares, les réactifs anti-RH1 utilisés pour le groupage sanguin doivent permettre leur détection. D'autre part, les phénotypes $\mathrm{RH} 1$ partiels sont caractérisés par le manque de certains épitopes de l'antigène RH1 «normal». Plusieurs phénotypes RH1 partiels ont été décrits, certains peuvent conduire à une immunisation en cas de transfusion par des concentrés de globules rouges $\mathrm{RH}: 1$ (CGR).

Les antigènes du système Rhésus sont fortement immunogènes et peuvent induire la production d'anticorps immuns. La transfusion d'un sujet $\mathrm{RH}:-1$ avec des CGR RH : 1 aboutit à la synthèse d'un anticorps anti-RH1 dans $80 \%$ des cas (34). Les allo-anticorps sont de nature $\mathrm{lgG}$, leur importance est majeure en pathologie humaine en raison de leur implication dans des maladies hémolytiques fœtales et néonatales (MHNN) sévères et du risque de réaction hémolytique immédiate et intense en cas de non-respect de leur compatibilité en contexte transfusionnel. L'antigène RH1 est le plus immunogène des antigènes érythrocytaires (28). Les autres antigènes de système Rhésus (antigènes RH2, RH3, RH4 et RH5) le sont également, mais dans une moindre mesure. 


\section{4) Le système Kell}

Ce système comporte 35 antigènes (21) exprimés sur la glycoprotéine Kell codée par le gène Kel localisé sur le chromosome 7. Les antigènes les plus importants de ce système sont les antigènes antithétiques KEL1 ( $K$ ou Kell) et KEL2 ( $k$ ou Cellano). La fréquence de l'antigène KEL1 est de $9 \%$ dans la population européenne, alors que l'antigène KEL2 est un antigène de haute fréquence dans toutes les populations (antigène public) (Tableau 4).

\begin{tabular}{|l|c|}
\hline \multicolumn{1}{|c|}{ Phénotypes } & Incidence en Europe (\%) \\
\hline K-k+ (KEL : - 1, 2) & 91 \\
\hline K+k+ (KEL : 1, 2) & 8,8 \\
\hline K+k- (KEL : 1, -2) & 0,2 \\
\hline
\end{tabular}

Tableau 4 : Fréquence des trois phénotypes Kell dans la population caucasienne (6).

Les antigènes du système Kell peuvent, comme ceux du système Rhésus, être immunogènes et engendrer la production d'anticorps immuns. L'antigène KEL1 est l'antigène le plus immunogène après l'antigène RH1 (28). L'allo-anticorps antiKEL1 peut être responsable de réactions transfusionnelles graves ou d'anémies fœetales sévères dans le cadre d'une MHNN.

\section{5) Prévention de l'incompatibilité ABO et de l'allo-immunisation RHK}

L'incidence des examens immuno-hématologiques est extrêmement importante puisque leurs résultats peuvent conditionner l'acte transfusionnel. II est donc indispensable d'avoir des méthodes fiables et de connaître les limites de chacune d'entre elles. C'est pour cette raison que le laboratoire IHE possède plusieurs méthodes de groupage sanguin ABORHK et de RAI. Les performances et les limites de chaque méthode sont clairement établies et connues. Ainsi, le laboratoire met en œuvre la méthode la plus performante et la plus adaptée en fonction du contexte (urgence vitale, transfusion programmée, suivi de grossesse, expertise biologique), du patient (femme enceinte, nouveau-né, patient transfusé, antécédents d'allo- ou d'auto-anticorps),... II est également essentiel de pouvoir contrôler un résultat avec une autre méthode dont les performances diffèrent 
(réactifs avec clones antigéniques différents, seuil de détection des doubles population plus bas, meilleure détection des variants,....).

\section{a. Groupage ABORHK}

Cette analyse est réalisée dans un contexte pré-transfusionnel avéré ou potentiel, ou dans un contexte prénuptial, pré- ou périnatal. Le groupage sanguin associe systématiquement la détermination du groupe $\mathrm{ABO}-\mathrm{RH} 1$ et du phénotype RH-KEL1 conformément à la réglementation (19), (20).

Une réalisation du groupage $\mathrm{ABO}$ repose sur deux épreuves obligatoires et complémentaires qui doivent être concordantes entre elles :

- une épreuve globulaire (Beth-Vincent) pour la recherche des antigènes $A$ et $B$ à la surface des hématies avec des réactifs monoclonaux anti-A, anti-B et anti-AB ;

- une épreuve plasmatique (Simonin) pour la recherche des anticorps naturels réguliers anti-A et anti-B avec des hématies-tests $A 1$ et $B$.

Ces deux épreuves doivent impérativement être concordantes.

Une réalisation du groupage $\mathrm{RH} 1$ consiste à rechercher les antigènes $\mathrm{RH} 1$ (D) à la surface des hématies avec obligatoirement un réactif monoclonal anti-RH1 (antiD) et un réactif témoin dépourvu de toute activité anticorps.

Une réalisation du phénotypage $\mathrm{RH}-\mathrm{KEL} 1$ comporte la recherche les antigènes $\mathrm{RH} 2(\mathrm{C}), \mathrm{RH} 3(\mathrm{E}), \mathrm{RH} 4(\mathrm{c}), \mathrm{RH} 5(\mathrm{e})$ et $\mathrm{KEL} 1(\mathrm{~K})$ à la surface des hématies avec des réactifs spécifiques et du réactif témoin dépourvu de toute activité anticorps. II est recommandé d'utiliser des réactifs d'origine monoclonale.

Selon les conditions techniques, une détermination de groupe ABORHK comporte soit :

- une seule réalisation avec transfert dans des conditions d'automation et d'informatisation valides

- deux réalisations manuelles par deux techniciens, suivies d'une double saisie en aveugle.

Une carte de groupes sanguins est valide après deux déterminations sur deux prélèvements différents (avec des résultats concordants entre les deux réalisations et avec les antériorités). 


\section{b. RAI}

La recherche d'anticorps irréguliers (RAI) consiste à détecter, sur le sérum ou plasma du patient, des anticorps dirigés contre des antigènes érythrocytaires autres que $A$ et $B$. Elle est basée sur la mise en présence du plasma du patient et des hématies-tests sélectionnées en utilisant une technique d'agglutination: le test indirect à l'antiglobuline humaine (TIA). Elle comporte deux étapes: un dépistage dans un premier temps (avec un panel de trois hématies-tests), puis, si cette première étape est positive, une identification du ou des anticorps dépistés (avec un panel d'au moins dix hématies-tests) (35).

La recherche d'anticorps irréguliers (RAI) doit être réalisée dans le cadre de la prévention des accidents immuno-hémolytiques transfusionnels, chez tout patient susceptible d'être transfusé à court terme ou récemment transfusé (15), et dans le cadre du suivi immuno-hématologique de la femme enceinte $(16,17)$. Les bonnes pratiques transfusionnelles fixent le délai de validité de la RAI à 3 jours à compter du prélèvement (une dérogation du prescripteur peut porter ce délai de validité à 21 jours si le patient ne possède pas d'antécédents transfusionnels ou obstétricaux dans les 6 mois) (36).

La RAl négative ne garantit pas l'absence de risque immunologique mais seulement l'absence d'anticorps circulants. Elle ne renseigne aucunement sur la présence d'éventuels lymphocytes-mémoires qui aboutiraient à une synthèse massive et rapide d'anticorps. II est donc indispensable que la carte de groupe sanguin porte mention des allo-anticorps connus chez un individu (même si ceux-ci ne sont plus détectables : « un anticorps un jour = un anticorps toujours »)

\section{6) Principe et indications du TDA}

Les anticorps irréguliers sont le plus souvent de nature IgG mais n'aboutissent pas systématiquement à une agglutination, ils sont parfois qualifiés d'« incomplets » . Les hématies recouvertes d'anticorps ou de complément et non agglutinées sont dites « sensibilisées ». Le test de Coombs direct appelé Test Direct à l'Antiglobuline (TDA) permet de révéler cette sensibilisation in vivo des hématies, par un anticorps et/ou le stigmate de son passage c'est-à-dire la fraction C3d du complément (37). Ce test repose sur l'utilisation d'antiglobulines humaines $(A G H)$ dont la portion Fab 
reconnaît les marqueurs isotypiques d'immunoglobulines ou des composants du complément spécifiquement fixés sur les hématies sensibilisés, entrainant ainsi leur agglutination.

Cette méthode est utilisée en routine pour le diagnostic de syndrome hémolytique, qu'il soit clinique ou biologique. Le TDA permet de mettre en évidence le caractère immunologique ou non immunologique de l'hémolyse. On peut observer une hémolyse avec un mécanisme immunologique dans les cas suivants :

- Présence d'auto-anticorps anti-érythrocytaires fixés, responsables d'anémies hémolytiques auto-immunes (38),

- Présence d'allo-anticorps anti-érythrocytaires maternels sur les hématies du nouveau-né dans le cadre de la Maladie Hémolytique du Nouveau-Né (MHNN) (le TDA chez le nouveau-né met en évidence la sensibilisation de ses hématies par les allo-anticorps de nature lgG d'origine maternelle) (9),

- Présence d'allo-anticorps anti-érythrocytaires fixés sur les hématies incompatibles transfusées, au décours d'un conflit immuno-hématologique transfusionnel (39),

- Présence d'anticorps anti-médicaments, mis en évidence lors d'une anémie hémolytique d'origine médicamenteuse, avec fixation des anticorps sur les hématies sensibilisées par le médicament (pénicillines et céphalosporines, rifampicine, quinine, diclofénac,...) (40).

Les causes non immunologiques de l'hémolyse sont diverses: certaines anomalies des globules rouges (hémoglobine, enzymes ou membrane), contextes infectieux (Plasmodium, Clostridium perfringens...), mécaniques (valves cardiaques) ou toxiques (intoxication, venins...).

\section{7) Principe et indications du test de Kleihauer}

Décrit en 1957 par les allemands Enno Kleihauer et Klaus Betke (41), cet examen met en évidence la présence d'hématies fœtales dans le sang maternel. Son but est de détecter une hémorragie fœto-maternelle suite à une situation à risque hémorragique, en pré- ou post-natal (42). En contexte post-natal, il permet d'adapter la posologie d'injection d'immunoglobulines anti-D (Rhophylac®), chez la patiente $\mathrm{RH}-1$, dans le cadre de la prévention de l'allo-immunisation fœto-maternelle anti-RH1 (43). 


\section{VALIDATION DE METHODE}

\section{1) L'accréditation selon la norme NF EN ISO 15189}

L'ordonnance du 13 janvier 2010 impose l'accréditation de tous les laboratoires de biologie médicale en France d'ici 2020. L'accréditation est la reconnaissance de la compétence d'un LBM à réaliser des examens de biologie médicale fiables et de qualité, dans le seul intérêt du patient. Le LBM demandant l'accréditation doit satisfaire aux dispositions législatives et réglementaires, aux exigences normatives (norme NF EN ISO 15189 (1)), et aux documents d'application du COFRAC. Le COFRAC est le seul organisme indépendant en France agréé pour reconnaitre la compétence des LBM. Ce processus d'accréditation repose sur un système de management de la qualité visant à maitriser tous les paramètres inhérents à la bonne réalisation d'un examen de biologie médicale. Ces paramètres sont les suivants: le système documentaire, les locaux, le matériel et les équipements, les réactifs, le système informatique, le personnel, la réalisation de la phase pré-analytique, celle de la phase analytique et enfin celle de la phase postanalytique. Tout ce processus tend à optimiser la maîtrise des méthodes et à améliorer la prestation de conseils.

L'objet de ce travail de mémoire de DES porte sur un point d'amélioration mis en évidence par les évaluateurs COFRAC: les conditions de transport des échantillons primaires à l'EFS RA site de Grenoble. II convient donc de s'intéresser tout particulièrement à l'étape pré-analytique des examens d'immuno-hématologie érythrocytaire, puis aux méthodes utilisées pour réaliser ces examens.

\section{2) L'étape pré-analytique au laboratoire d'IHE}

La norme NF EN ISO 15189 précise la nécessité pour les LBM de rédiger une convention avec ses clients, précisant notamment les éléments de réalisation de la phase pré-analytique et les conditions d'acheminement des échantillons. II doit également mettre à disposition de toute personne réalisant les prélèvements d'échantillons biologiques un manuel de prélèvement. Celui-ci consigne, entre 
autres, les exigences du LBM relatives aux prélèvements et au transport des échantillons primaires.

\section{a. Manuel de prélèvement de l'EFS RA}

Le laboratoire d'IHE de l'EFS RA a défini dans son manuel de prélèvement les exigences suivantes concernant l'acheminement des échantillons biologiques :

- Délai d'acheminement des échantillons primaires : inférieur à 72 heures.

- Si transmission non immédiate : Conserver les prélèvements entre $+2^{\circ} \mathrm{C}$ et $+8^{\circ} \mathrm{C}$ avant l'envoi, à l'exception des agglutinines froides à température ambiante.

- Le transport est réalisé à température ambiante.

Ces exigences ont été établies en fonction des données de la littérature et des dossiers de validation de méthodes du laboratoire.

\section{b. Transport et conservation des échantillons dans les autres disciplines de la biologie médicale}

Il est important de regarder ce qui a déjà été fait au sujet des conditions de conservation et de transport des échantillons sanguins dans les autres domaines de la biologie médicale, et particulièrement en hématologie-cytologie pour la stabilité des globules rouges, ainsi qu'en immunologie pour la stabilité des anticorps.

C'est en premier lieu du côté de la biochimie que les études les plus pertinentes ont été réalisées, avec des travaux portant sur l'intérêt de stocker soit du sérum, soit du plasma, soit du sang total (44), sur la durée de conservation avant analyse et sur l'impact de la température de conservation (45),(46) ou de transport (47) en fonction de chaque paramètre à analyser. Ainsi, la plupart des examens de biochimie ont désormais leurs consignes concernant le pré-traitement à appliquer à l'échantillon, la température de conservation et d'acheminement et la durée de stabilité du paramètre avant son analyse.

En immunologie, les anticorps sont généralement stockés à $+4^{\circ} \mathrm{C}$ à court terme (quelques jours à quelques semaines), sans perte significative de leur activité. Le stockage à température ambiante entraine la dégradation des anticorps et/ou leur perte d'activité, généralement à la suite de contaminations (48). Les travaux sur la 
conservation à long terme des anticorps (48)(49) démontrent une meilleure conservation prolongée à $-20^{\circ} \mathrm{C}$ ou $-80^{\circ} \mathrm{C}$. II apparaît donc que les anticorps ont une meilleure stabilité à $+4^{\circ} \mathrm{C}$ plutôt qu'à des températures plus élevées.

En hématocytologie, il est recommandé de transmettre les numérations formules sanguines (NFS) au LBM à température ambiante et de les réaliser dans un délai de 6 heures après le prélèvement. En cas d'impossibilité ou bien de contrôle, il est accepté de réaliser cet examen jusqu'à 24 heures après le prélèvement si celui-ci est conservé à $+4^{\circ} \mathrm{C}$, voire à température ambiante. II est également rappelé que le transport doit être effectué de manière à éviter tout choc thermique ou mécanique pouvant entraîner une hémolyse (50). Au delà de 24 heures, des altérations de la morphologie érythrocytaire (échinocytes) ou une augmentation du volume globulaire moyen (VGM) peuvent être observés. L'intégrité des cellules sanguines, sur le plan qualitatif et quantitatif doit être préservée (51). Imeri et al. (52) ont engagé d'autres travaux en vue d'allonger ce délai de conservation jusqu'à 72 heures, voire 6 jours notamment pour les globules rouges, en fonction des méthodes utilisées. Les différentes données bibliographiques tendent à privilégier la température ambiante comme température optimale pour préserver les cellules sanguines. En hématocytologie, le délai optimal de réalisation des examens est court (6 heures) en vue de quantifier et d'étudier la morphologie des hématies. En IHE, seuls les antigènes de surface sont étudiés, expliquant l'allongement du délai de conservation des échantillons biologiques à 72 heures.

\section{3) La validation de méthode au laboratoire d'IHE}

\section{a. Le dossier de validation de méthode}

Pour mettre en place une méthode d'analyse, le LBM peut soit adopter une méthode reconnue, soit adapter une méthode validée sur la base de publications scientifiques et l'ajuster à ses besoins. Le LBM doit alors réaliser, dans le premier cas, une vérification de la méthode sur site, ou bien dans le deuxième cas, la validation de la méthode (53). La validation d'une méthode est la caractérisation par des preuves tangibles (dossier de validation, d'adaptation de méthode ou de développement de la méthode) que les exigences pour une utilisation spécifique ou 
une application prévue ont été satisfaites et qu'elles répondent aux besoins du laboratoire et de ses clients (54).

La validation de méthode comporte trois étapes essentielles: l'étude de documents bibliographiques, la détermination des critères de performance pertinents à établir avec des limites d'acceptabilité correspondantes, et enfin la réalisation des vérifications expérimentales selon la procédure établie par le LBM. Le dossier de validation de méthode rassemble tous ces éléments et doit vérifier les paramètres suivants :

- Spécificité analytique

- Sensibilité diagnostique

- Contamination entre échantillons

- Stabilité des réactifs

- Robustesse

- Comparaison avec une méthode de référence ou avec une méthode déjà utilisée au LBM

- Limites de la méthode

Et également, lorsqu'il s'agit d'une méthode quantitative :

- Fidélité (répétabilité et fidélité intermédiaire)

- Justesse

- Intervalle de mesure (limite de quantification et limites de linéarité)

- Incertitudes et facteurs de variabilité

- Intervalle de référence

La plupart des examens d'IHE sont qualitatifs et pour ces méthodes qualitatives, seuls les premiers éléments ont été vérifiés. La validation de méthode permet d'établir les limites des différentes méthodes utilisées.

\section{b. La robustesse d'une méthode}

Par « robustesse » d'une méthode d'analyse, on entend une mesure de sa capacité à ne pas être affectée par des variations faibles mais délibérées des paramètres de la méthode, et qui fournit une indication sur sa fiabilité dans les conditions normales d'utilisation. 
Plusieurs travaux ont été effectués ces dernières années, dans le cadre de l'accréditation COFRAC, pour déterminer les tolérances métrologiques des différentes techniques utilisées en routine en immuno-hématologie.

Deux équipes ont travaillé sur la robustesse des analyses d'IHE. Un premier groupe de travail a étudié et défini les écarts maximums tolérables (EMT) pour la RAI en test indirect à l'antiglobuline en microfiltration et l'épreuve plasmatique de groupage sanguin $\mathrm{ABO}$ en microfiltration et en microplaque (55). Le second a étudié la méthode de groupage $\mathrm{ABO}-\mathrm{RH} 1$ en microplaque (épreuve globulaire et épreuve plasmatique) (56). Ces deux études portent sur les paramètres suivants: température d'incubation, durée d'incubation et volumes des réactants. Ces travaux démontrent la grande robustesse de ces méthodes en définissant des EMT importants pour le paramètre physique susceptible d'influencer les résultats.

Actuellement, aucune publication n'aborde le sujet des températures et des conditions de transport des échantillons biologiques destinés aux examens d'immunohématologie. II apparaît donc essentiel d'étudier l'influence de la température de transport des échantillons biologiques sur les résultats des principaux examens d'IHE.

\section{c. Les paramètres évalués au laboratoire}

\section{i. Robustesse}

La plupart des méthodes utilisées au laboratoire d'IHE de I'EFS RA site de Grenoble ont déjà fait l'objet d'une validation de méthode. Certains paramètres de robustesse et de stabilité ont été vérifiés.

La centrifugation de l'échantillon primaire a été étudiée au laboratoire IHE, dans le but de standardiser la vitesse et la durée de centrifugation. Le groupage sanguin ABORHK, la RAl et le TDA nécessitent une étape de centrifugation avant la réalisation de l'examen. Les méthodes ont toutes été validées pour des échantillons prélevés sur anticoagulant, centrifugés à $2500 \mathrm{~g}$ pendant 5 minutes, de manière à n'avoir qu'une seule consigne de centrifugation pour tous ces examens.

Des essais ont été réalisés concernant la température des réactifs et des échantillons (à température ambiante du laboratoire et à $+4^{\circ} \mathrm{C}$ ) à $\mathrm{J} 0$, juste avant 
analyse. Les validations de méthodes n'ont montré aucune variation de résultats en faisant varier la température des réactifs et des échantillons.

Enfin, la stabilité des méthodes a été vérifiée, sur 7 jours pour le groupage ABORHK, sur 3 jours pour la RAl et le test de Kleihauer, et sur 2 jours pour le TDA.

Aucun essai n'a donc été réalisé concernant la conservation des échantillons à différentes températures sur 3 jours consécutifs, pour toutes les méthodes citées précédemment.

\section{ii. Sensibilité}

Pour les méthodes de groupage sanguin ABORHK, le laboratoire a défini plusieurs limites de méthodes. L'une d'entre elles concerne la capacité de détection des doubles populations. Ces doubles populations correspondent à la présence conjointe, dans un échantillon sanguin, d'hématies porteuses d'un antigène et d'hématies dépourvues de ce même antigène. Une double population peut être observée dans un certain nombre de situations cliniques ou biologiques : après une transfusion sanguine (< 4 mois), après une greffe de cellules souches hématopoïétiques, dans le cadre d'hémopathies malignes, en cas de gémellité dizygote, en cas de prélèvement de sang de cordon, ou même chez le sujet âgé. II est important que les méthodes de groupage sanguin soient capables de détecter ces doubles populations de manière à ne pas rendre un résultat de groupage sanguin erroné. Un seuil de détection des doubles populations est donc établi pour chaque méthode de groupage sanguin $A B O R H K$ et pour chaque antigène. 


\section{Partie II : ETUDE DE LA ROBUSTESSE DES ANALYSES d'IMMUNO-HEMATOLOGIE ERYTHROCYTAIRE}

\section{A. Objectifs}

L'objectif principal de ce travail est d'étudier si la température et les conditions d'acheminement des échantillons biologiques au laboratoire d'IHE de l'EFS RA site de Grenoble affectent les méthodes d'analyse utilisées.

Le transport des échantillons biologiques à température ambiante peut être soumis à de nombreuses variations et nous souhaitons étudier les conséquences de ces variations sur les résultats d'examens d'IHE. Pour ce travail nous avons choisi de tester le groupage sanguin ABORHK, la RAI, le TDA et le test de Kleihauer. Ce sont les examens les plus fréquemment transmis par les établissements de soin ou les laboratoires extérieurs. Pour ces quatre examens nous avons simulé différentes températures de transport. Les échantillons biologiques sont conservés aux températures de $+4^{\circ} \mathrm{C},+22^{\circ} \mathrm{C}$ et $+38^{\circ} \mathrm{C}$ pour couvrir l'essentiel de l'amplitude thermique annuelle de Grenoble.

Dans un deuxième temps, nous avons également voulu déterminer l'impact d'une centrifugation avant transmission au laboratoire d'IHE.

Les tests sont réalisés sur des échantillons prélevés le jour même. Les examens sont réalisés sur trois jours consécutifs, correspondant au délai maximum d'acheminement des échantillons biologiques, exigé par le manuel de prélèvement de I'EFS RA. 


\section{B. Matériels et méthodes}

\section{1) Echantillons}

Nous avons travaillé sur des échantillons de sang total, prélevés sur anticoagulant EDTA (tubes BD Vacutainer ${ }^{\circledR}$ ). Ces échantillons proviennent de donneurs sains de l'EFS RA et de patients du CHU de Grenoble (Tableau 5). Quatre tubes EDTA de $6 \mathrm{~mL}$ ont été prélevés chez les donneurs sains. Pour les patients du CHU nous n'avons utilisé que des prélèvements surnuméraires envoyés au laboratoire d'IHE (volume de sang total d'environ $4 \mathrm{~mL}$ ).

\begin{tabular}{|l|c|c|}
\hline \multicolumn{1}{|c|}{ Examens } & Donneurs sains & Patients \\
\hline Groupages sanguins & $\mathbf{3 0}$ & $\mathbf{0}$ \\
\hline Doubles populations groupages sanguins & $\mathbf{4}$ (fabriqués) & $\mathbf{0}$ \\
\hline RAI négatives & 30 & 0 \\
\hline RAl positives & 30 & 0 \\
\hline TDA négatifs & 30 & $\mathbf{3}$ \\
\hline TDA positifs & $\mathbf{0}$ & $\mathbf{3 0}$ \\
\hline Kleihauer négatifs & $\mathbf{0}$ & $\mathbf{2 0}$ \\
\hline Kleihauer positifs & $\mathbf{1 2}$ (fabriqués) & $\mathbf{2}$ \\
\hline
\end{tabular}

Tableau 5 : Récapitulatif des effectifs de l'étude. Plusieurs échantillons issus de donneurs ont permis la réalisation de différents examens (groupage, RAl et TDA).

- Groupage sanguin ABORHK

Nous avons réalisé 30 groupages et phénotypages sanguins. L'effectif est constitué de donneurs sains de groupes $A, B, O$ et $A B$, avec des phénotypes Rhésus et Kell différents (Tableau 6).

\begin{tabular}{|c|c|}
\hline $\begin{array}{c}\text { Groupe } \\
\text { ABO }\end{array}$ & Effectif \\
\hline A & 13 \\
\hline O & 11 \\
\hline B & 4 \\
\hline AB & 2 \\
\hline
\end{tabular}

Tableau 6.a.

\begin{tabular}{|lc|c|}
\hline \multicolumn{2}{|c|}{ Groupe Rhésus } & Effectif \\
\hline D+ C+ E- c+ e+ & $(\mathrm{RH}: 1,2,-3,4,5)$ & 12 \\
\hline D+ C+ E- c- e+ & $(\mathrm{RH}: 1,2,-3,-4,5)$ & 8 \\
\hline D+ C- E+ c+ e+ & $(\mathrm{RH}: 1,-2,3,4,5)$ & 4 \\
\hline D- C- E- c+ e+ & $(\mathrm{RH}:-1,-2,-3,4,5)$ & 4 \\
\hline D+ C- E+ c+ e- & $(\mathrm{RH}: 1,-2,3,4,-5)$ & 2 \\
\hline
\end{tabular}

Tableau 6.b.

\begin{tabular}{|l|c|}
\hline Groupe Kell & Effectif \\
\hline K+ (KEL : 1$)$ & 3 \\
\hline K- (KEL : -1) & 27 \\
\hline
\end{tabular}

Tableau 6.c

Tableau 6: Effectif des 30 groupages sanguins "normaux »: a. Répartition des sujets selon leur groupe $A B O$; b. Répartition des sujets selon leur phénotype Rhésus ; $c$. Répartition des sujets selon leur phénotype Kell. 
Pour étudier l'influence des conditions de transport sur un groupage sanguin post-transfusionnel, nous avons artificiellement créé des doubles populations (Tableau 7). Pour chaque échantillon nous avons procédé au mélange de deux prélèvements de sang total isogroupe $A B O$ mais de phénotype RHK différent. Le mélange est réalisé en proportion 50/50.

\begin{tabular}{|c|c|c|c|c|c|c|}
\hline \multirow{2}{*}{ Groupe ABO } & \multicolumn{7}{|c|}{ Phénotype RHKEL } \\
\cline { 2 - 7 } & D & C & E & C & e & K \\
\hline A & $\mathrm{dp}$ & $\mathrm{dp}$ & - & + & + & - \\
\hline A & + & $\mathrm{dp}$ & $\mathrm{dp}$ & + & $\mathrm{dp}$ & $\mathrm{dp}$ \\
\hline $\mathbf{O}$ & + & + & - & $\mathrm{dp}$ & + & $\mathrm{dp}$ \\
\hline $\mathbf{O}$ & + & $\mathrm{dp}$ & $\mathrm{dp}$ & + & + & $\mathrm{dp}$ \\
\hline
\end{tabular}

Tableau 7 : Profil des quatre échantillons créés artificiellement pour l'étude des doubles populations ( $d p=$ double population).

\section{- RAI}

La recherche d'agglutinines irrégulières a été réalisée chez 60 sujets : 30 RAI négatives et 30 RAI positives. Parmi ces RAI positives, 12 anticorps différents ont été identifiés (Tableau 8).

\begin{tabular}{|c|c|c|c|}
\hline Résultat RAI & Effectif & Résultat RAI & Effectif \\
\hline Négative & 30 & anti-Jka & 3 \\
\hline anti-D & 4 & anti-M & 3 \\
\hline anti-E & 7 & anti-S & 1 \\
\hline anti-c & 1 & anti-s & 1 \\
\hline anti-Cw & 2 & anti-Lub & 1 \\
\hline anti-K & 4 & anti-Leb & 1 \\
\hline anti-Fya & 1 & Non spécifique & 1 \\
\hline
\end{tabular}

Tableau 8: Effectif des 30 RAl négatives et des 30 RAl positives. Douze anticorps irréguliers différents ont été étudiés, un anticorps n’a pas été identifié (non spécifique).

\section{- TDA}

Le test direct à l'antiglobuline a été réalisé chez 60 sujets : 30 TDA négatifs et 30 TDA positifs. Les TDA positifs sont de type IgG, de type C3d ou de type mixte IgG et C3d (Tableau 9).

\begin{tabular}{|c|c|}
\hline Résultat TDA & Effectif \\
\hline Négatif & 30 \\
\hline Positif de type IgG & 19 \\
\hline Positif de type C3d & 3 \\
\hline Positif mixte IgG/C3d & 8 \\
\hline
\end{tabular}

Tableau 9 : Effectif des 30 TDA négatifs et des 30 TDA positifs. Trois types de profils sont possibles pour les TDA positifs. 
- Test de Kleihauer

Nous avons étudié 34 tests de Kleihauer : 20 tests négatifs et 14 tests positifs. Deux tests positifs sont de "vrais » échantillons, issus de deux patientes enceintes du CHU de Grenoble. La concentration d'hématies fœtales de ces deux échantillons est inférieure au seuil pathologique (< $8 \mathrm{HF}$ pour $10000 \mathrm{HA}$ ).

Les patientes enceintes avec un test de Kleihauer positif étant rares nous avons créé 12 échantillons positifs. Ces échantillons ont été élaborés selon le même procédé de fabrication que les témoins positifs utilisés en routine pour ce test. Un volume de sang total de nouveau-né (prélevé le jour même) a été dilué dans un volume de sang total d'une donneuse saine (prélevé le jour même également). Plusieurs dilutions on été réalisées afin d'obtenir différentes concentrations d'hématies fœtales, allant de $8 \mathrm{HF}$ pour $10000 \mathrm{HA}$ à environ $200 \mathrm{HF}$ pour $10000 \mathrm{HA}$ (Tableau 10).

\begin{tabular}{|c|c|}
\hline $\begin{array}{c}\text { Dilution } \\
\text { (ST fotal } / \mathbf{S T} \text { adulte) }\end{array}$ & $\begin{array}{c}\text { Concentration approximative } \\
\text { (nb d'HF / } \mathbf{1 0} \mathbf{0 0 0} \text { HA) }\end{array}$ \\
\hline $1 / 50^{\text {ème }}$ & 200 \\
\hline $1 / 100^{\text {ème }}$ & 100 \\
\hline $1 / 200^{\text {ème }}$ & 50 \\
\hline $1 / 400^{\text {ème }}$ & 25 \\
\hline $1 / 800^{\text {ème }}$ & 12 \\
\hline $1 / 1200^{\text {ème }}$ & 8 \\
\hline
\end{tabular}

Tableau 10: Gamme de concentration des tests de Kleihauer positifs créés artificiellement. Concentrations approximatives obtenues après dilution de sang total fœtal dans du sang total adulte.

\section{2) Matériels}

Nous présentons ici tous les équipements et réactifs nécessaires à la réalisation de notre protocole d'étude ainsi qu'à la réalisation du groupage sanguin ABORHK, de la RAI, du TDA et du test de Kleihauer.

\section{Protocole général de l'étude}

Centrifugeuse Heraeus Multifuge X3 ( $n^{\circ} 24203057$ qualifiée le 04.11.13)

Centrifugeuse Heraeus Multifuge X3R ( $n^{\circ} 24207628$ qualifiée le 04.7.14)

Réfrigérateur ( $n^{\circ} 111976$ qualifié le 05.12.13)

THERMO FISHER SCIENTIFIC

THERMO FISHER SCIENTIFIC

Enceinte thermostatée PC $1200 \mathrm{i}\left(\mathrm{n}^{\circ} 114046\right.$ qualifiée le 18.4.13)

Incubateur ScanGel system ( $n^{\circ} 111040$ qualifié le 04.12.13))

HELMER

Tableau 11 : Liste des matériels nécessaires pour la réalisation de notre protocole d'étude. 
Groupage sanguin ABORHK manuel sur plaque

Plaque de réaction Hema 6

DIAMED

Panel d'hématies Hematest A1, B, O

DIAGAST

anti-A (clone 9113 D10)

DIAGAST

anti-B (clone 9621A8)

DIAGAST

anti-AB (clone 152D12 + 9113 D10)

DIAGAST

anti-RH1 IgM1 (P3x61)

DIAGAST

anti-RH2 (clone P3X25513 G8 + MS24)

DIAGAST

anti-RH3 (clone 906)

anti-RH4 (clone 951)

DIAGAST

anti-RH5 (clone P3GD512 + MS63)

DIAGAST

anti-KEL1 (clone MS56)

DIAGAST

Contrôle négatif

DIAGAST

Tableau 12: Liste des matériels nécessaires pour la réalisation du groupage sanguin ABORHK en technique manuelle sur plaque.

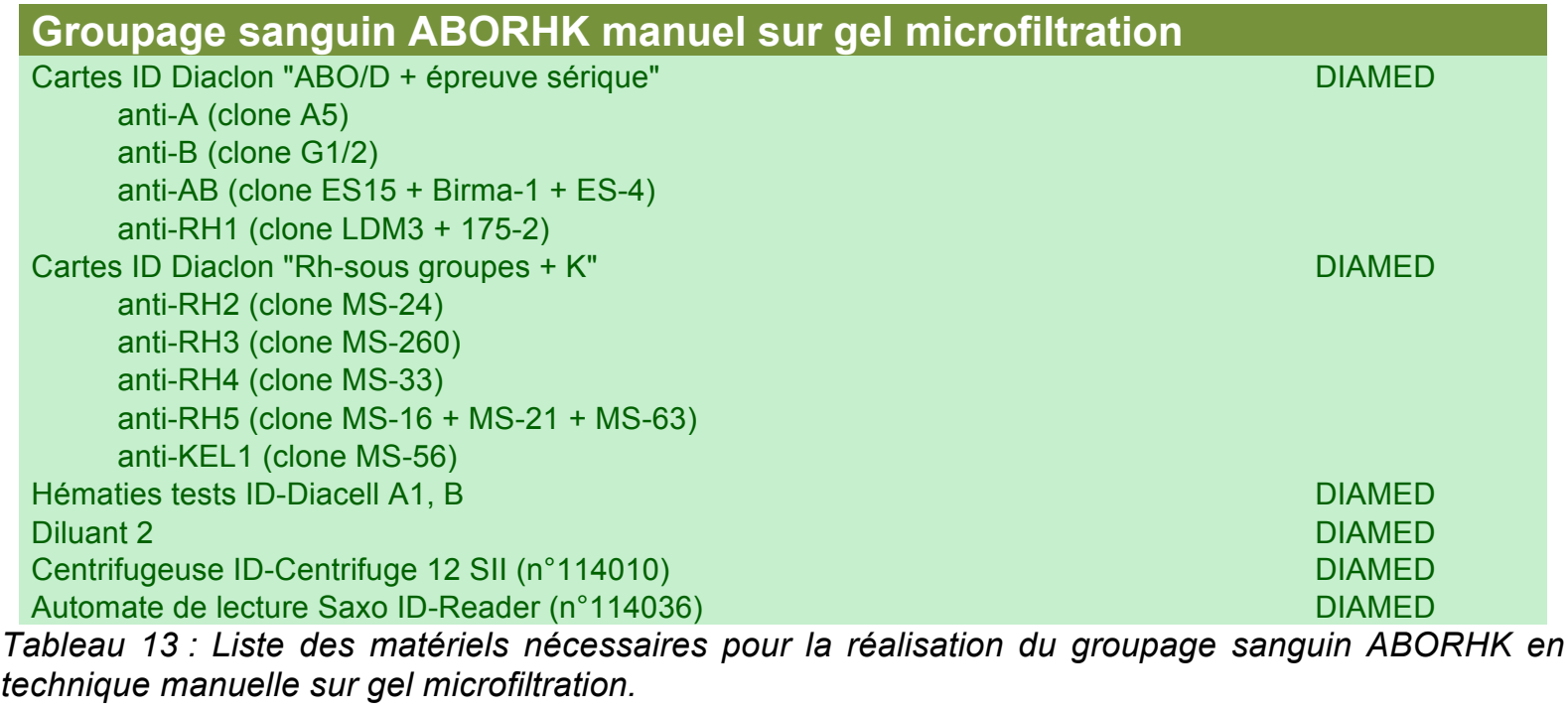

\section{Groupage sanguin ABORHK manuel sur automate Galileo@}

$\begin{array}{lr}\text { Automate Galileo } & \text { IMMUCOR } \\ \text { Perasafe } & \text { IMMUCOR } \\ \text { Galileo system liquide } & \text { IMMUCOR } \\ \text { Eau distillée non stérile 10 L } & \text { AGUETTANT } \\ \text { Galileo diluent } & \text { IMMUCOR } \\ \text { Propanol 2 (Isopropanol) } & \text { SODIPRO } \\ \text { Galileo Microplates (Barcoded) } & \text { IMMUCOR } \\ \text { Referencells A1, B } & \text { IMMUCOR } \\ \text { RH Contrôle Galileo } & \text { IMMUCOR } \\ \text { anti-A Galileo (clone F98 7C6) } & \text { IMMUCOR } \\ \text { anti-B Galileo (clone F84 3D6 + F97 2D6) } & \text { IMMUCOR } \\ \text { anti-AB Galieo (clone Birma-1+ ES4 + ES15) } & \text { IMMUCOR } \\ \text { anti-RH1 IgM + IgG (clone D175 + D415) } & \text { IMMUCOR } \\ \text { anti-RH2 Galileo (clone MS273) } & \text { IMMUCOR } \\ \text { anti-RH3 Galileo (clone MS12 + MS260) } & \text { IMMUCOR } \\ \text { anti-RH4 Galileo (clone MS35) } & \text { IMMUCOR } \\ \text { anti-RH5 Galileo (clone MS62 + MS69) } & \text { IMMUCOR } \\ \text { anti-KEL1 Galileo (clone K1.1.21.HM.EF) } & \text { IMMUCOR }\end{array}$

Tableau 14: Liste des matériels nécessaires pour la réalisation du groupage sanguin ABORHK en technique automatique sur Galileo®. 


\section{RAl manuelle sur gel microfiltration}

Carte ID Liss COOMBS (IgG polyclonal lapin + C3d monoclonal C 139-9)

DIAMED

Carte ID NaCl Enzyme

DIAMED

ID Diacell I, II, III

DIAMED

ID Diapanel Coombs

DIAMED

ID Diapanel papaïne

DIAMED

ID papaïne

DIAMED

Diluant 2

Incubateur ScanGel system ( $\left.n^{\circ} 111040\right)$

Centrifugeuse ID-Centrifuge 12 SII ( $\left.n^{\circ} 114010\right)$

DIAMED

Automate de lecture Saxo ID-Reader ( $\left.n^{\circ} 114036\right)$

BIORAD

Tableau 15 : Liste des matériels nécessaires pour la réalisation de la RAl (dépistage et identification) en technique manuelle sur gel microfiltration.

\section{RAl manuelle sur automate Qwalys $®$}

\begin{tabular}{lr} 
Automate Qwalys & \\
$\quad$ Cleanlys $1 X$ & DIAGAST \\
Alcool modifié & DIAGAST \\
ScreenLys & GIFRER \\
Nanolys & DIAGAST \\
Screen Diluent & DIAGAST \\
HemaScreen $1,2,3$ & DIAGAST \\
Blue Control & DIAGAST \\
\hline
\end{tabular}

Tableau 16: Liste des matériels nécessaires pour la réalisation de la RAI (dépistage) en technique automatique sur Qwalys ${ }^{\circledR}$.

\section{TDA manuel sur gel microfiltration}

Carte ID NaCl Enzyme

DIAMED

Diluant 2

DIAMED

Centrifugeuse ID-Centrifuge 12 SII ( $\left.n^{\circ} 114010\right)$

DIAMED

Automate de lecture Saxo ID-Reader ( $\left.n^{\circ} 114036\right)$

DIAMED

Tableau 17 : Liste des matériels nécessaires pour la réalisation du TDA en technique manuelle sur gel microfiltration.

\section{Test de Kleihauer}

\section{Ethanol absolu}

Kit Hemoglobine fœtale

Lames porte-objet $76 \times 26 \times 1 \mathrm{~mm}$

Huile à immersion

Microscope Axiostar plus ( $\left.n^{\circ} 112929\right)$

\section{VWR \\ LABO MODERNE}

VWR

CARGILLE

ZEISS

Tableau 18: Liste des matériels nécessaires pour la réalisation du test de Kleihauer par la technique Shepard modifiée.

\section{3) Méthodes}

\section{a. Protocole de l'étude pour le groupage ABORHK, la RAl et le TDA}

Le protocole mis en place pour cette étude impose de travailler exclusivement sur des échantillons de sang total prélevés le jour même. Chaque échantillon est réparti de la façon suivante : 
- Un tube de sang total de $6 \mathrm{~mL}$ : prélèvement centrifugé et utilisé pour réaliser l'examen à $\mathrm{J} 0$, il sera ensuite conservé à $+22^{\circ} \mathrm{C}$ puis de nouveau analysé à $\mathrm{J} 1, \mathrm{~J} 2$ et $\mathrm{J} 3$,

- Un tube de sang total de $6 \mathrm{~mL}$ : prélèvement conservé à la température de $+4^{\circ} \mathrm{C}$, il sera analysé à $\mathrm{J} 1, \mathrm{~J} 2$ et $\mathrm{J} 3$,

- Un tube de sang total de $6 \mathrm{~mL}$ : prélèvement conservé à la température de $+22^{\circ} \mathrm{C}$, il sera analysé à $\mathrm{J} 1, \mathrm{~J} 2$ et $\mathrm{J} 3$.

- Un tube de sang total de $6 \mathrm{~mL}$ : prélèvement conservé à la température de $+38^{\circ} \mathrm{C}$, il sera analysé à $\mathrm{J} 1, \mathrm{~J} 2$ et $\mathrm{J} 3$.

Conservation à $+4^{\circ} \mathrm{C}$ : Nous avons utilisé une enceinte réfrigérée, qualifiée et maintenue à la température de $+4^{\circ} \mathrm{C}\left(+/-1^{\circ} \mathrm{C}\right)$ pendant toute la durée de l'étude.

Conservation à $+22^{\circ} \mathrm{C}$ : Les échantillons sont placés dans une enceinte thermostatée et qualifiée, permettant de conserver les concentrés plaquettaires. Cette enceinte assure une température de $+22^{\circ} \mathrm{C}\left(+/-1^{\circ} \mathrm{C}\right)$.

Les enceintes à $+4^{\circ} \mathrm{C}$ et $+22^{\circ} \mathrm{C}$ sont placées sous contrôle centralisé par des sondes GTC (Gestion Technique Centralisée) de marque C2AI. (Tableau 11).

Conservation à $+38^{\circ} \mathrm{C}$ : Nous avons placé les échantillons dans un incubateur Scan Gel qualifié. Habituellement utilisé pour incuber les cartes gel pour la RAI, il est constamment à $+38^{\circ} \mathrm{C}$ (pour que les micro-colonnes des cartes gels soient, au centre, à $+37^{\circ} \mathrm{C}$ pendant $15 \mathrm{~min}$ ) (Tableau 11 ).

Le prélèvement testé à $\mathrm{J} 0$ est centrifugé pendant 5 min à $2500 \mathrm{~g}$, puis analysé selon les méthodes retenues. Le résultat obtenu à J0 est considéré comme le résultat de référence. Ce prélèvement centrifugé est ensuite conservé à $+22^{\circ} \mathrm{C}$ pour la suite de l'étude.

Le lendemain (J1) les trois prélèvements de sang total conservés respectivement à $+4^{\circ} \mathrm{C},+22^{\circ} \mathrm{C}$ et $+38^{\circ} \mathrm{C}$ sont homogénéisés et $2 \mathrm{~mL}$ de sang total sont prélevés pour réaliser les analyses du jour. Le volume de sang total restant est remis rapidement dans son enceinte de conservation. Le prélèvement centrifugé utilisé à J0 est également repris. Les 4 prélèvements obtenus, J1 (J0 centrifugé $\left.+22^{\circ} \mathrm{C}\right), \mathrm{J} 1\left(+4^{\circ} \mathrm{C}\right), \mathrm{J} 1\left(+22^{\circ} \mathrm{C}\right)$, et $\mathrm{J} 1\left(+38^{\circ} \mathrm{C}\right)$ sont centrifugés 5 min à $2500 \mathrm{~g}$ et analysés selon les méthodes retenues. Ce mode opératoire est répété à $\mathrm{J} 2$ puis à $\mathrm{J} 3$ (Figure12). 


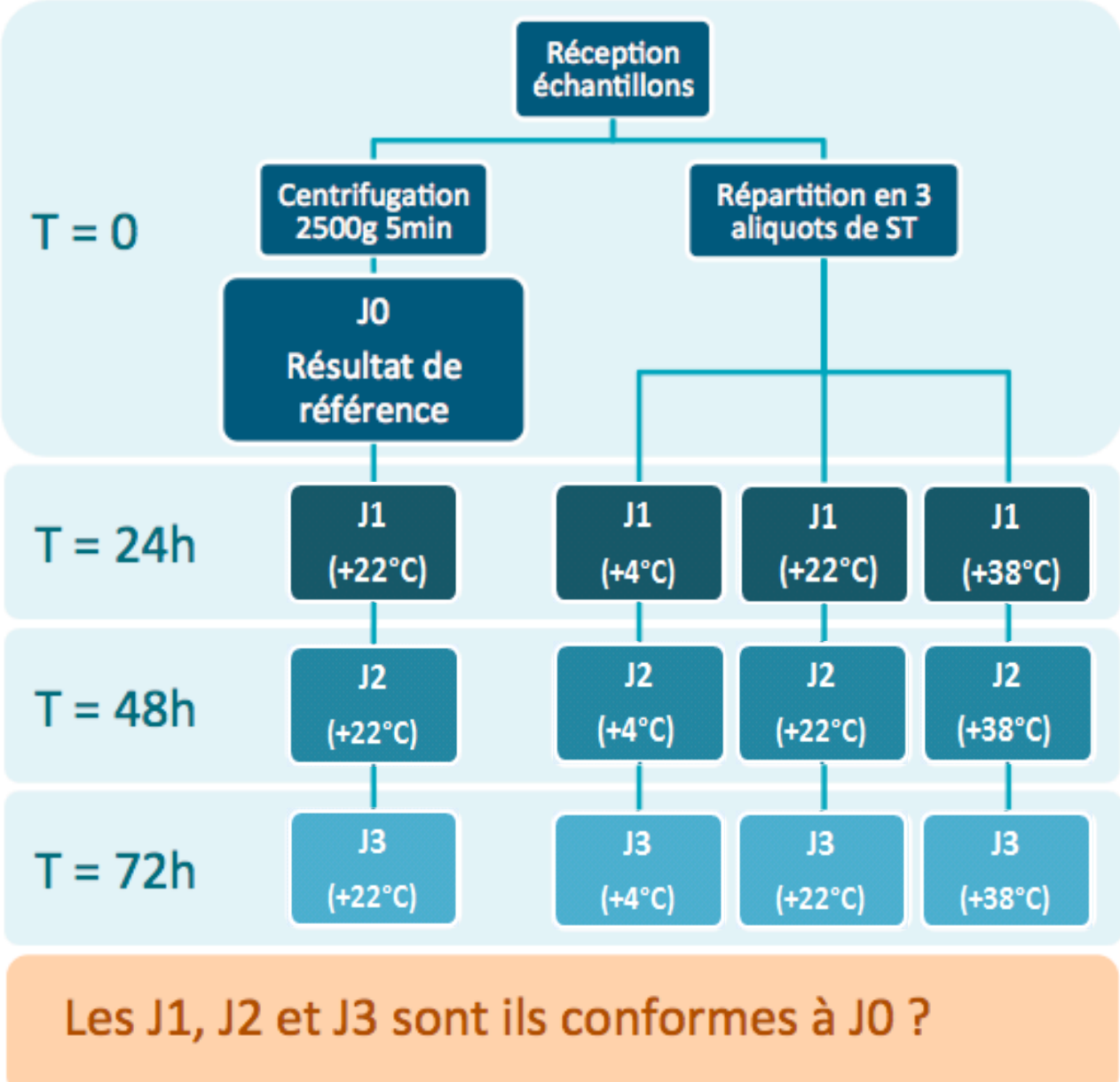

Figure 12 : Représentation schématique du protocole de l'étude pour le groupage sanguin, la RAl et le TDA.

\section{b. Protocole test de Kleihauer}

Pour cet examen, le protocole diffère légèrement. Le test du Kleihauer s'effectue sur sang total, les étapes de centrifugations sont donc inutiles (Figure 13). Chaque échantillon est réparti de la façon suivante :

- Un tube de sang total de $1 \mathrm{~mL}$ : prélèvement analysé à J0, puis conservé à $+22^{\circ} \mathrm{C}$ pour être de nouveau analysé à $\mathrm{J} 1, \mathrm{~J} 2$ et $\mathrm{J} 3$,

- Un tube de sang total de $1 \mathrm{~mL}$ : prélèvement conservé à la température de $+4^{\circ} \mathrm{C}$, il sera analysé à $\mathrm{J} 1, \mathrm{~J} 2$ et $\mathrm{J} 3$,

- Un tube de sang total de $1 \mathrm{~mL}$ : prélèvement conservé à la température de $+38^{\circ} \mathrm{C}$, il sera analysé à $\mathrm{J} 1, \mathrm{~J} 2$ et $\mathrm{J} 3$. 


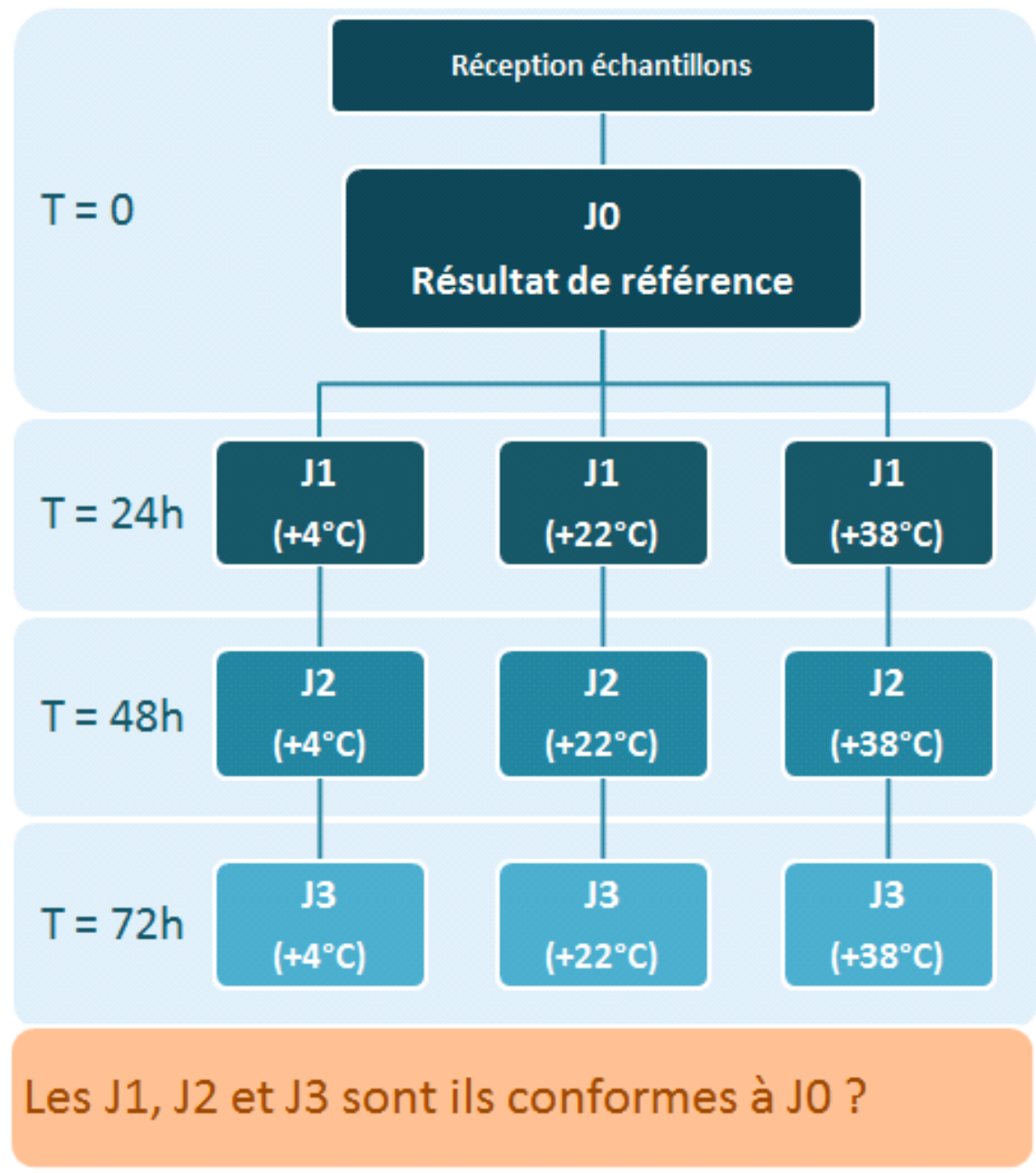

Figure 13 : Représentation schématique du protocole de l'étude pour le test de Kleihauer.

\section{c. Groupage sanguin ABORHK sur plaque}

La méthode manuelle sur plaque est une méthode d'hémagglutination directe. Elle consiste, pour l'épreuve globulaire et le phénotypage RHK, à mettre en contact une goutte de culot d'hématies du patient avec deux gouttes de réactifs anticorps monoclonaux sur une plaque à usage unique comportant plusieurs cupules réactionnelles. A l'inverse, pour l'épreuve plasmatique, une goutte de chaque hématie-test $A, B$ et $O$ est déposée sur la plaque réactionnelle, puis deux gouttes du plasma du patient (Figure 14). 


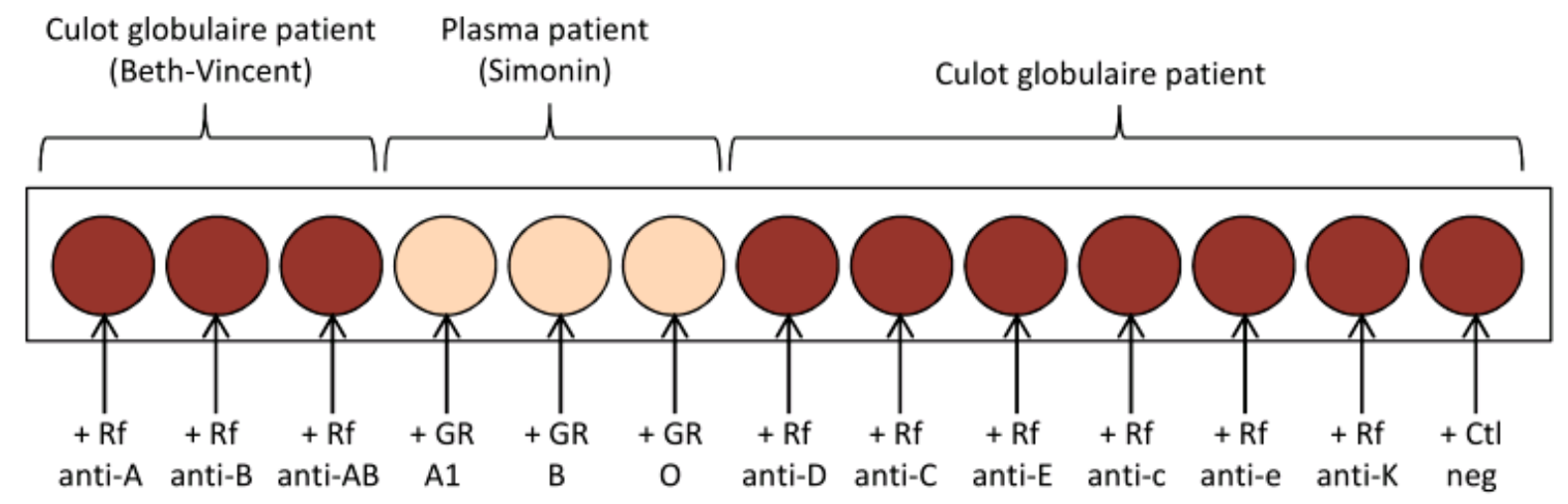

Figure 14 : Schéma d'une plaque réactionnelle pour la réalisation d'un groupage sanguin.

Après avoir chaloupé la plaque pendant 3 minutes pour homogénéiser les mélanges, les réactions d'hémagglutination sont lues par l'opérateur. La réaction est positive lorsqu'il y a une agglutination visible à l'œil nu dans la cupule, sinon celle-ci est considérée comme négative (Figure 15). Les épreuves globulaire et plasmatique doivent obligatoirement être concordantes, et la réaction avec le contrôle négatif doit être négative.

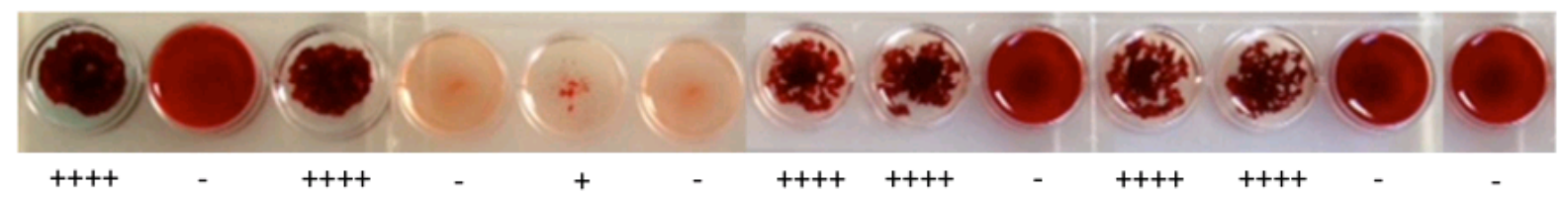

Figure 15: Photo d'une plaque réactionnelle du groupage $A B O R H K$ d'un patient de groupe $A$ et phénotype $D+C+E-c+e+K-$.

Pour l'épreuve globulaire et le phénotypage RHK, l'intensité de l'hémagglutination est cotée à l'aide d'une échelle de valeur allant de 1+ à 4+ pour les réactions positives (Figure 16). Pour l'épreuve plasmatique, la réaction d'hémagglutination est soit négative $(0)$, soit positive (1+).

\begin{tabular}{|c|c|c|c|c|c|c|}
\hline $\begin{array}{c}\text { Interprétation } \\
\text { Laboratoire IHE } \\
\text { EFS RA }\end{array}$ & Résultat & Positif & Positif & Positif & Positif & Négatif \\
\hline & Intensité & $\mathbf{+ + + +}$ & $\mathbf{+ + +}$ & $\mathbf{+ +}$ & $\mathbf{+}$ & - \\
\hline $\begin{array}{c}\text { Plaque * } \\
\text { (lecture } \\
\text { macroscopique) }\end{array}$ & & & & & & \\
\hline
\end{tabular}

Figure 16: Interprétation des réactions d'hémagglutination sur plaque en fonction de l'intensité observée (lecture macroscopique). 


\section{d. Groupage sanguin ABORHK sur gel microfiltration}

La méthode de groupage sanguin manuelle sur gel microfiltration est basée sur l'hémagglutination directe des hématies dans des micro-colonnes de filtration en gel. Pour l'épreuve globulaire et le phénotypage RHK, les réactifs anticorps sont déjà pré-inclus dans les micro-colonnes. Une suspension d'hématies du patient est réalisée en diluant $25 \mu \mathrm{L}$ de culot globulaire dans $500 \mu \mathrm{L}$ de LISS (le LISS est un milieu de basse force ionique qui facilite l'accessibilité aux antigènes et la rapidité de fixation des anticorps (57)). $10 \mu \mathrm{L}$ de cette suspension sont déposés dans la chambre réactionnelle de chaque colonne.

Pour l'épreuve plasmatique, $50 \mu \mathrm{L}$ d'hématies-tests $\mathrm{A} 1$ et $\mathrm{B}$ sont déposées dans un premier temps dans les micro-colonnes, puis $50 \mu \mathrm{L}$ de plasma du patient sont ajoutés (Figure 17).

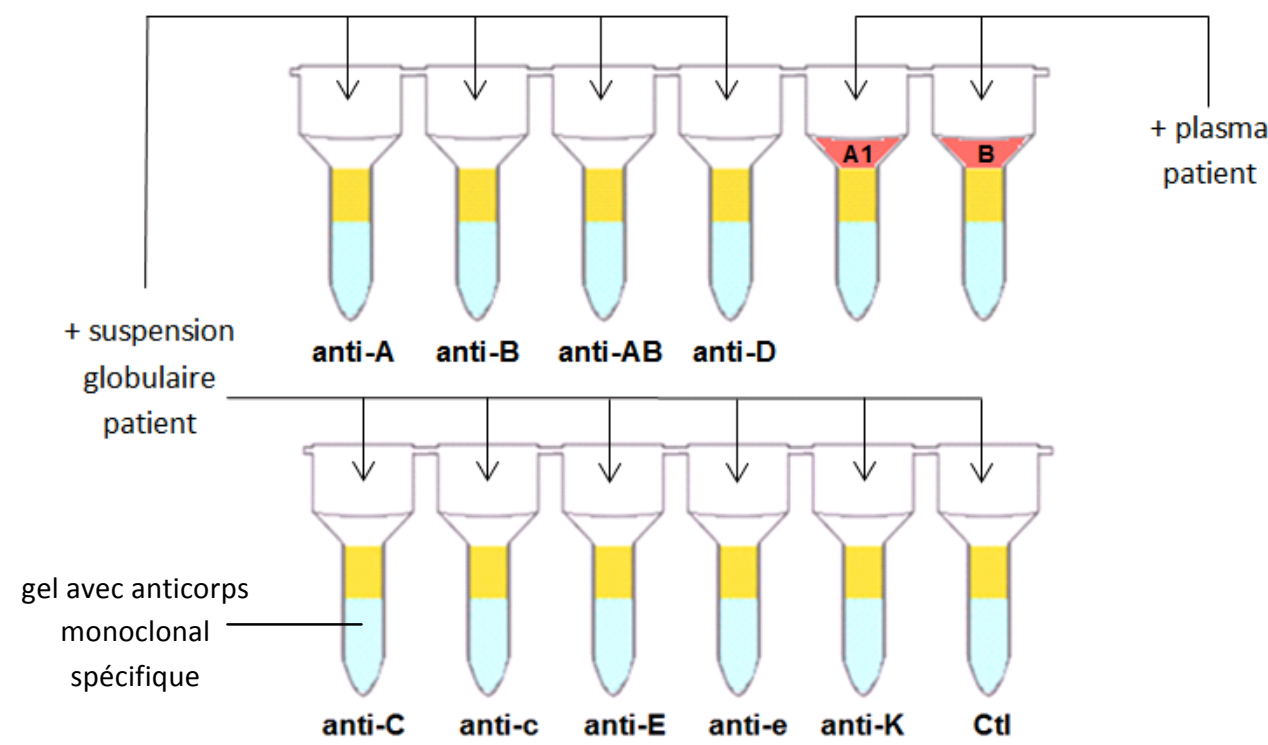

Figure 17 : Schéma d'une carte-gel réactionnelle (gel microfiltration) pour la réalisation d'un groupage sanguin.

Les supports de réactions sont centrifugés 10 minutes. Si les hématies du patient portent l'antigène correspondant à l'anticorps présent dans la micro-colonne, alors celles-ci vont être arrêtées par le gel. En revanche si les hématies sont dépourvues de cet antigène, elles traverseront le gel sans être arrêtées (58) (Figure 18). 


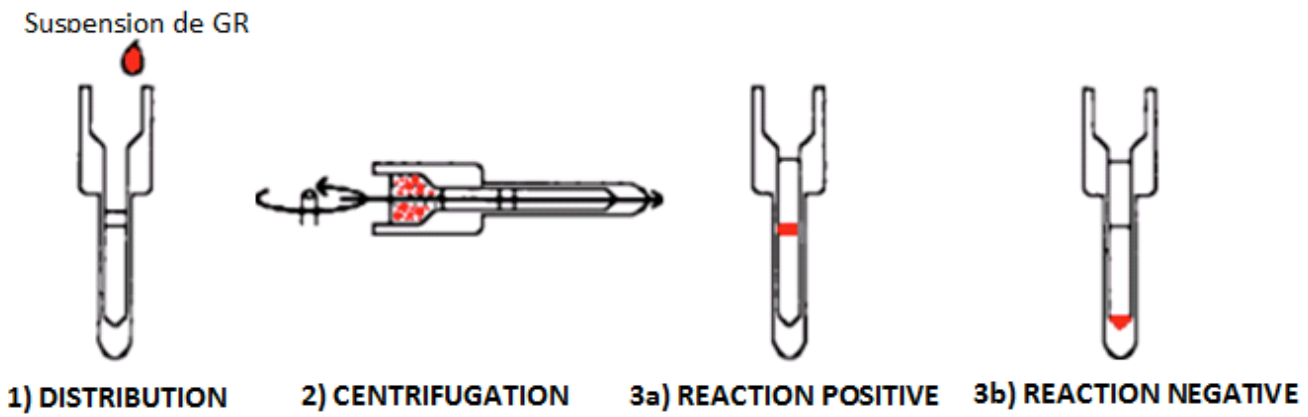

Figure 18 : Etapes d'un groupage sanguin en technique sur gel microfiltration (59).

L'intensité de l'hémagglutination des réactions positives est cotée à l'aide d'une échelle de valeur allant de 1+ à 4+ pour les épreuves globulaire et plasmatique (Figure 19). La lecture des résultats est réalisée par un lecteur automatique Saxo®, et vérifiée par un technicien habilité.

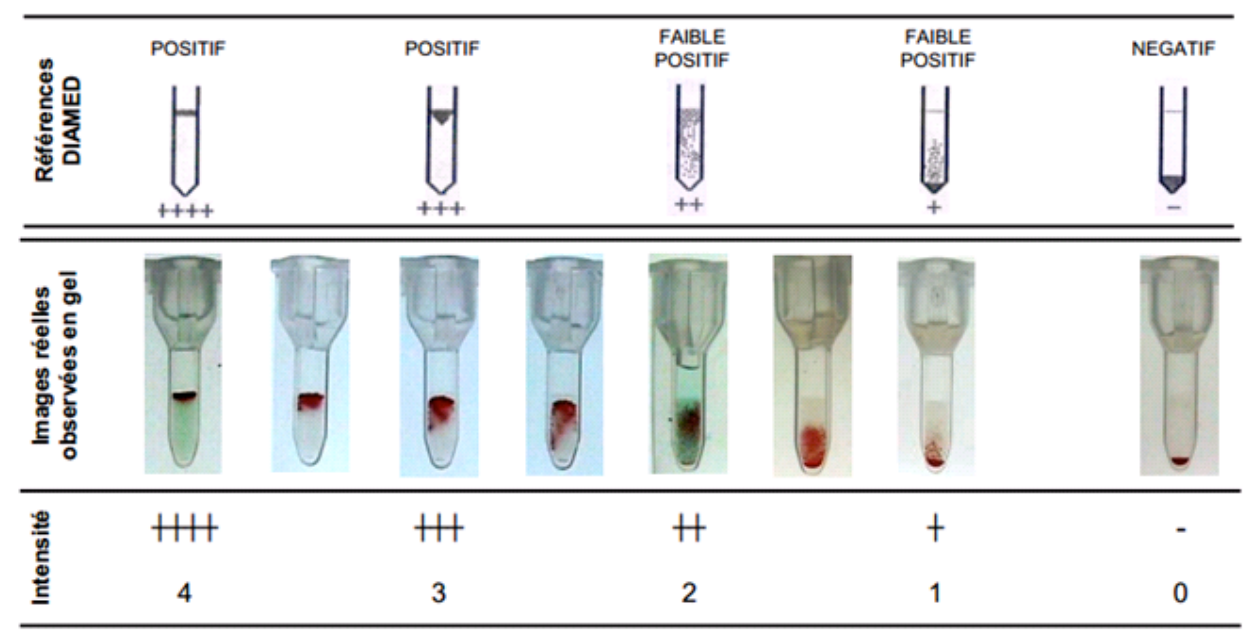

Figure 19 : Interprétation des réactions d'hémagglutination sur gel microfiltration, en fonction de l'intensité observée (lecture macroscopique).

\section{e. Groupage sanguin ABORHK sur automate Galileo® Immucor}

Le Galileo® est un automate complet de groupage sanguin, basé sur I'hémagglutination directe. II gère la distribution des réactifs et échantillons sur une microplaque réactionnelle, puis son incubation et sa centrifugation. Un culot globulaire se forme alors au fond de chaque puits et l'automate agite la microplaque pour remettre en suspension les culots globulaires. A l'issue de cette agitation, soit le culot se disperse ce qui signe l'absence d'hémagglutination dans le puits, soit le culot reste agglutiné au fond du puits ce qui signe la présence de l'antigène correspondant au réactif sur les hématies du patient (ou de l'anticorps correspondant à l'hématie- 
test dans le plasma du patient) (58). Les microplaques sont lues par le lecteur de l'automate (Figure 20), puis contrôlées par un technicien habilité.

\begin{tabular}{|c|c|c|c|c|c|c|c|}
\hline \multirow{2}{*}{$\begin{array}{c}\text { Interpritation } \\
\text { RA }\end{array}$} & Résultat & Positif & Positif & Positif & Positif & Douteux & Négatif \\
\cline { 2 - 7 } & score & 1 & 1 & 1 & 1 & NTD & - \\
\hline $\begin{array}{c}\text { Images } \\
\text { observées } \\
\text { (groupes) }\end{array}$ & & - & - & -1 & & & \\
\hline
\end{tabular}

Figure 20 : Interprétation des réactions d'hémagglutination en microplaque sur automate Galileo® (lecture automatique ou visuelle).

\section{f. Recherche d'anticorps irréguliers sur gel microfiltration}

- Dépistage (Test indirect à l'antiglobuline)

La RAI sur gel microfiltration repose sur le principe de centrifugation contrôlée au cours de laquelle les hématies passent à travers un gel d'acrylamide contenu dans la micro-colonne (58). D'abord $50 \mu \mathrm{L}$ hématies-tests du panel de dépistage puis $25 \mu \mathrm{L}$ de plasma du patient sont déposés dans la chambre de réaction (Figure 21). Trois micro-colonnes sont nécessaires pour tester les trois hématies-tests du panel de dépistage. Les supports de réactions sont incubés à $+37^{\circ} \mathrm{C}$ pendant 15 minutes dans un incubateur. Les réactions sont effectuées en milieu de basse force ionique (LISS) qui facilité l'accessibilité des antigènes et accroît la fixation des anticorps. Les anticorps immuns recherchés sont de nature lgG et ne permettent pas d'agglutiner directement les hématies, ils se fixent à la paroi des hématies-tests.

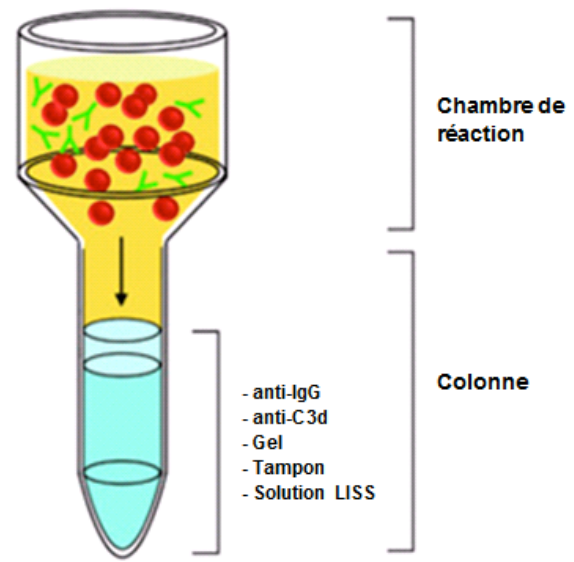

Figure 21 : Schéma d'une micro-colonne réactionnelle (gel microfiltration) (6). 
Les supports de réactions sont centrifugés 10 minutes et lors de cette phase, l'antiIgG polyvalente et l'anti-C3d incluses dans la colonne reconnaissent le fragment Fc des anticorps immuns lgG du patient et la fraction C3d du complément, à la surface des hématies sensibilisées. Les complexes ainsi formés, de taille supérieure à celle des mailles du gel sont freinés lors de leur migration vers le fond de la colonne. Ce procédé de filtration peut également révéler l'agglutination des hématies-tests par un anticorps de type IgM directement agglutinant. A l'issue de la centrifugation, en absence d'anticorps irréguliers, les hématies-tests sédimentent au fond de la colonne (11). En revanche, en présence d'anticorps irréguliers, la migration des complexes est visible dans la colonne et l'intensité des réactions positives est cotée de 1+ à 4+. La lecture des résultats est réalisée par un lecteur automatique Saxo® et vérifiée visuellement par un technicien habilité (Figure 22).

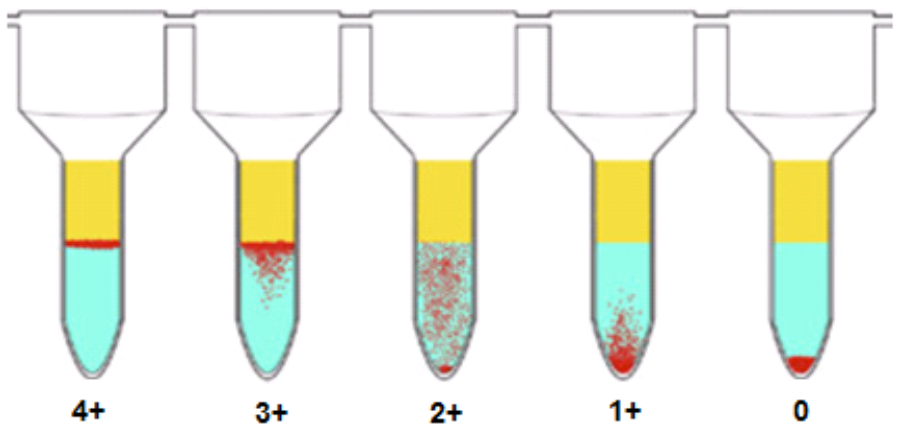

Figure 22 : Cotation du résultat de la RAI en fonction de l'intensité réactionnelle (6).

Si les trois hématies-tests provoquent une réaction négative, alors la RAl est rendue négative. Si au moins une des trois hématies-tests provoque une réaction positive, même faible, on procèdera à l'étape d'identification.

- Identification (Test indirect à l'antiglobuline)

Le principe de l'identification est le même que celui du dépistage. II repose sur l'utilisation, selon le même protocole, d'au moins 10 hématies-tests et la réalisation d'un témoin autologue.

- Identification (Technique enzymatique)

Si l'identification n'est pas concluante, il est possible d'avoir recours à d'autres techniques complémentaires, dites enzymatiques (utilisation de cartes gel neutres et d'un panel d'hématies-tests papaïnées). Le traitement par les enzymes protéolytiques réduit la distance entre les hématies (en diminuant leurs charges électriques à leur surface), favorisant leur agglutination par des lgG. L'enzyme la 
plus couramment utilisée est la papaïne, elle améliore l'accessibilité des antigènes de certains systèmes (Rhésus, Lewis), mais elle peut aussi en détruire certains (Duffy, MNS) (11).

\section{g. Recherche d'anticorps irréguliers sur automate Qwalys ${ }^{\circledR}$ Diagast}

Le Qwalys ${ }^{\circledR}$ est un automate complet dont le principe EM Technology ${ }^{\circledR}$ repose sur la magnétisation des hématies (60) (61). II utilise un test indirect à l'antiglobuline (TIA), en phase solide, combiné à un champ magnétique. Cette méthode permet uniquement la détection des anticorps de nature lgG : le fond des puits de la microplaque réactionnelle est tapissé par une antiglobuline anti-lgG.

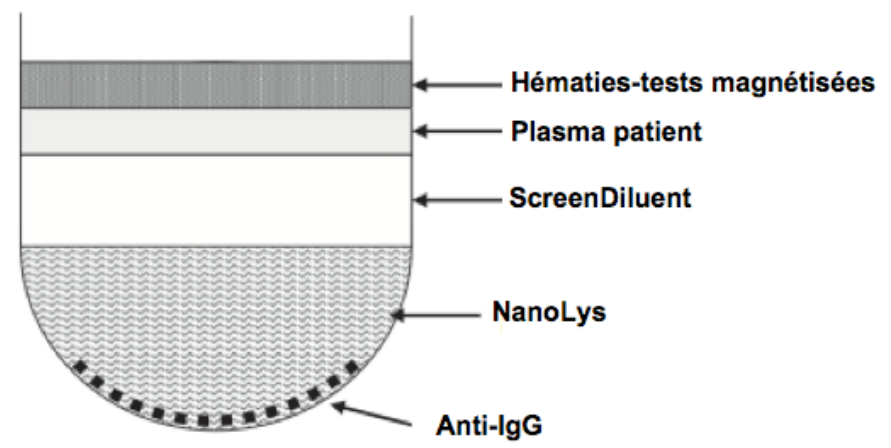

Figure 23 : Schéma d'un puits réactionnel de RAI en EM Technology ${ }^{8}(61)$.

Pendant une incubation de 20 minutes à $+37^{\circ} \mathrm{C}$ les éventuels anticorps lgG du plasma du patient fixent les antigènes correspondants à la surface des hématiestests et viennent se déposer à la surface du NanoLys (solution de haute densité). La microplaque réactionnelle est ensuite soumise à un champ magnétique permettant aux hématies magnétisées de migrer au travers du NanoLys et d'aller au contact de l'antiglobuline du fond du puits. En présence d'un allo-anticorps du patient reconnaissant une cible antigénique des hématies-tests, les complexes ainsi formés vont être fixés par les antiglobulines ant-lgG du fond du puits. L'image obtenue est celle d'un tapis globulaire recouvrant plus ou moins le fond du puits selon l'intensité de la réaction. A l'inverse, une réaction négative se traduit par la sédimentation des hématies-tests au fond du puits, en un point compact clairement défini (Figure 24). 


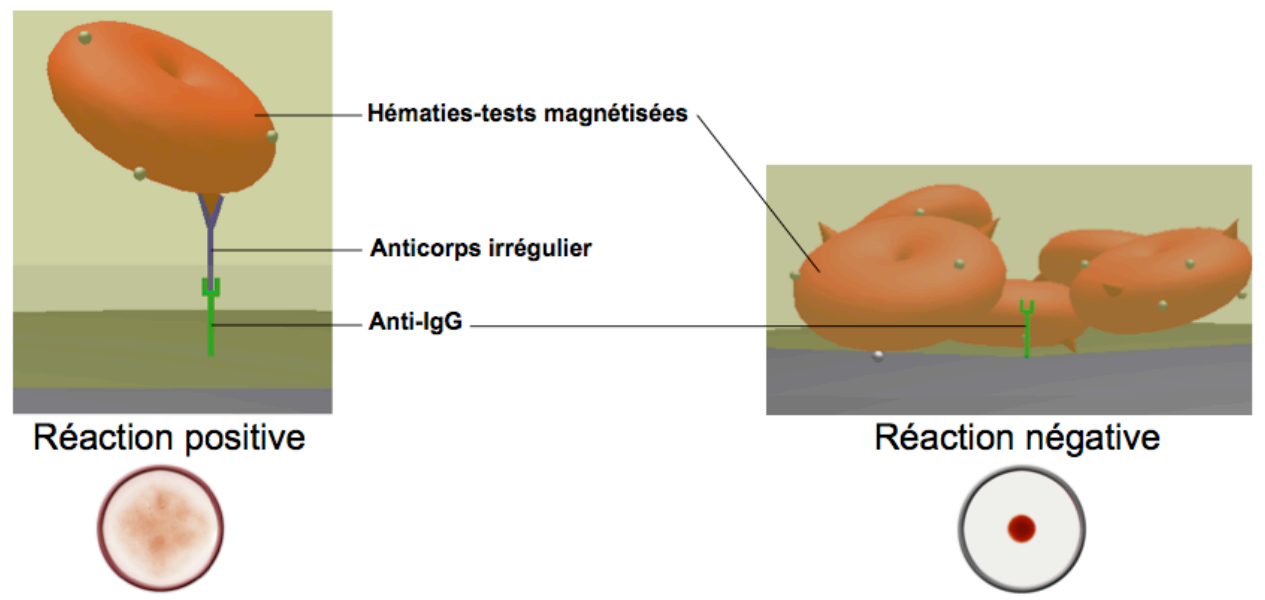

Figure 24 : Principe de l'EM Technology ${ }^{\circledR}$, représentation des réactions positive et négative (images Diagast).

Les microplaques sont lues par le lecteur de l'automate. Le résultat est rendu sous forme d'une valeur chiffrée qui est ensuite convertie en intensité d'agglutination (Figure 25). Les plaques réactionnelles sont contrôlées visuellement par un technicien habilité. Celui-ci doit particulièrement être attentif aux formes douteuses, pas toujours détectées par l'automate (celui-ci peut rendre une valeur de 0).

\begin{tabular}{|c|c|c|c|c|c|c|}
\hline Positif & Positif & Positif & Positif & Positif & Douteux & Négatif \\
\hline $\mathbf{+ + + +}$ & $\mathbf{+ + +}$ & $\mathbf{+ +}$ & + & $\mathbf{+}$ & $\boldsymbol{?}$ & - \\
$89-99$ & $75-88$ & $59-74$ & $45-58$ & $23-44$ & $10-22$ & $0-9$ \\
\hline & & & & & \\
\hline
\end{tabular}

Figure 25 : Interprétation des réactions d'hémagglutination en microplaque sur automate Qwalys ${ }^{\circledR}$ (lecture automatique ou visuelle). Les résultats en valeurs chiffrées sont traduits en résultats cotés entre 0 et $4+$.

\section{h. Test direct à l'antiglobuline sur gel microfiltration}

Les supports de réaction sont composés de trois micro-colonnes de gel dans lesquelles sont incluses les antiglobulines. Une première micro-colonne contient de l'anti-IgG, la seconde de l'anti-C3d et la troisième sert de témoin négatif. Une dilution des hématies du patient est réalisée $(10 \mu \mathrm{L}$ de culot globulaire dans $1000 \mu \mathrm{L}$ de 
LISS). $50 \mu \mathrm{L}$ de cette dilution sont déposés dans la chambre réactionnelle de chaque micro-colonne (Figure 26).

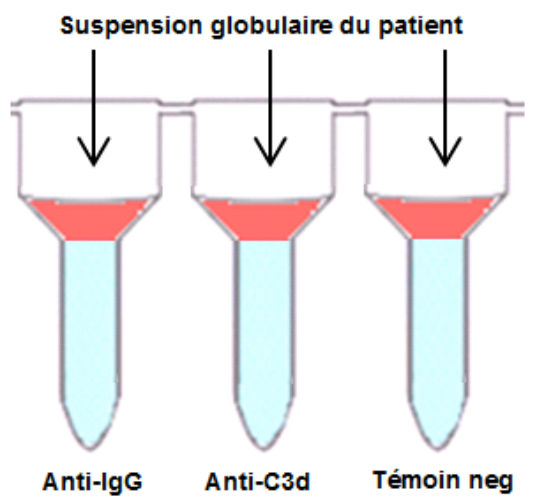

Figure 26: Schéma d'un support réactionnel (gel microfiltration) pour le TDA.

Les supports de réactions sont ensuite centrifugés 10 minutes et les hématies vont migrer dans les micro-colonnes et entrer en contact avec l'antiglobuline. Celle-ci va fixer les hématies sensibilisées et les complexes ainsi formés vont être plus ou moins retenus dans le gel. En revanche si les hématies ne sont pas sensibilisées, elles traverseront le gel sans être arrêtées. L'intensité de la réaction est cotée à l'aide d'une échelle de valeur allant de 1+ à 4+ (Figure 27). La lecture des résultats est réalisée par l'automate de lecture $S a x o ®$, et vérifiée visuellement par un technicien habilité.
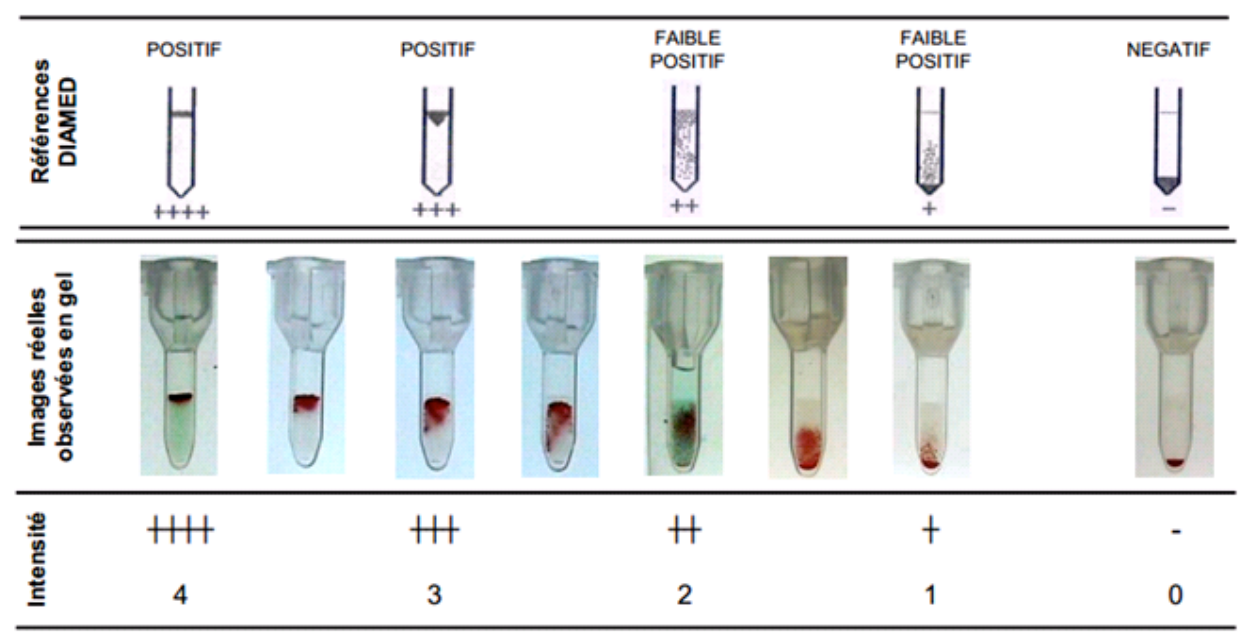

Figure 27 : Interprétation des réactions d'hémagglutination sur gel en fonction de l'intensité observée (lecture macroscopique).

\section{i. Test de Kleihauer par la technique modifiée Shepard}

Le test de Kleihauer est basé sur la résistance de l'hémoglobine fœtale au traitement à l'acide. Le sang total de la patiente enceinte est dilué au 1/3 dans une solution de $\mathrm{NaCl} 0,9 \%$ puis l'opérateur réalise des frottis sur lame de cette dilution. 
Ces frottis sont ensuite fixés pendant 5 minutes dans une solution d'éthanol à $80 \%$ (réactif 1) puis trempés dans une solution acide (réactif 2) pendant 20 secondes afin d'éluer l'hémoglobine $A$. L'hémoglobine $F$ résiste à ce traitement. Enfin les frottis sont colorés pendant 3 minutes avec par une solution d'éosine à 1\% (réactif 3) (figure 28).

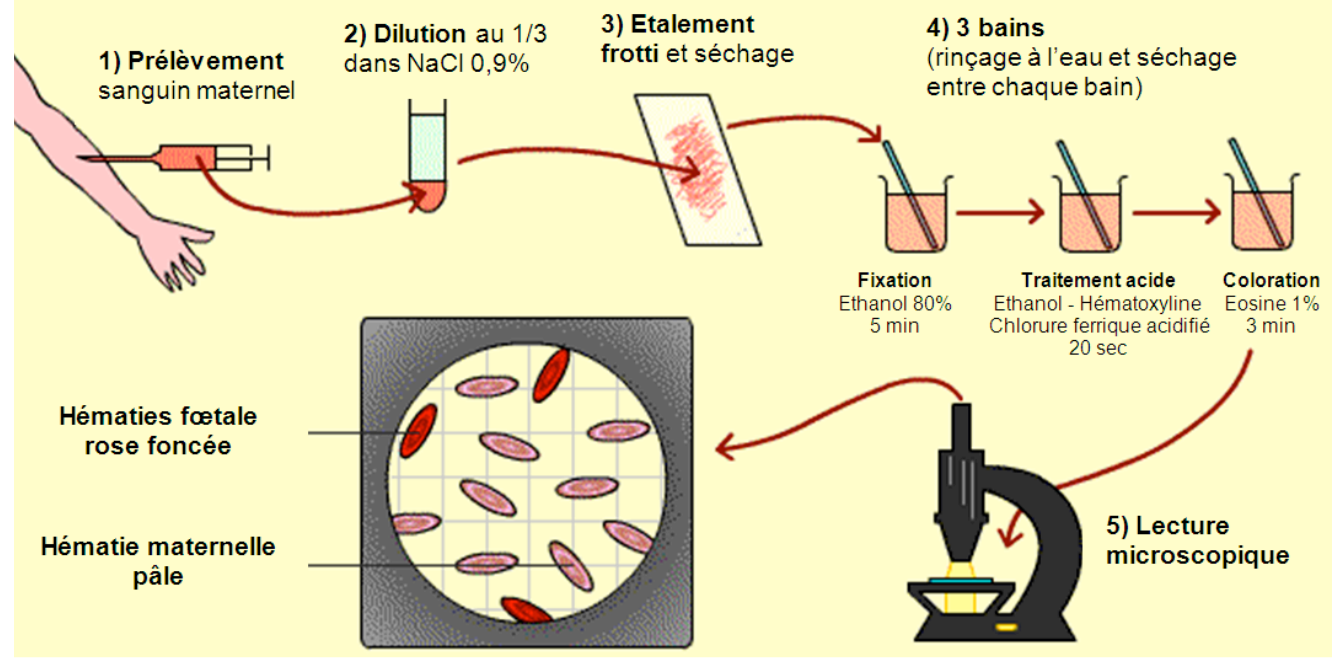

Figure 28: Principe du test de Kleihauer. Image adaptée de http://www.snv.jussieu.fr/vie/dossiers/gpes-sanguins/03merefoetus.htm.

La détection des hématies fœtales se fait par lecture microscopique : celles-ci sont colorées en rose tandis que les hématies maternelles restent pâles (non colorées). En absence d'hématies fœtales le test est rendu négatif. En revanche, en présence d'hématies fœtales sur le frottis, le technicien procède à un compte précis des hématies fœetales pour 10000 hématies adultes. Ce résultat est converti en volume de sang fœto-placentaire estimé.

\section{4) Analyses statistiques}

Les calculs statistiques ont été réalisés à l'aide du logiciel GraphPad Prism. Nous avons utilisé le test de Friedman (alternative non-paramétrique au test d'ANOVA) pour comparer nos résultats de groupages sanguin sur l'automate Galileo $\AA$, et nos résultats de tests de Kleihauer. Nous avons regardé si les résultats, rendus après différentes conditions de conservation, étaient significativement différents ( $p$-valeur $<0,01)$ ou non ( $p$-valeur $>0,05)$ du résultat de référence obtenu à J0 (sans conservation). 


\section{Résultats}

\section{1) Groupages sanguins $A B O$ aux différentes conditions de conservation :}

\section{a. Techniques manuelles}

Nous présentons les résultats de 30 groupages sanguins $A B O$ (Tableau 19), analysés en technique manuelle sur plaque et en technique manuelle sur gel microfiltration, aux différentes conditions de conservation (délai : 1, 2 ou 3 jours, températures : $+4^{\circ} \mathrm{C},+22^{\circ} \mathrm{C}$ et $+38^{\circ} \mathrm{C}$, conservation échantillon centrifugé ou sang total).

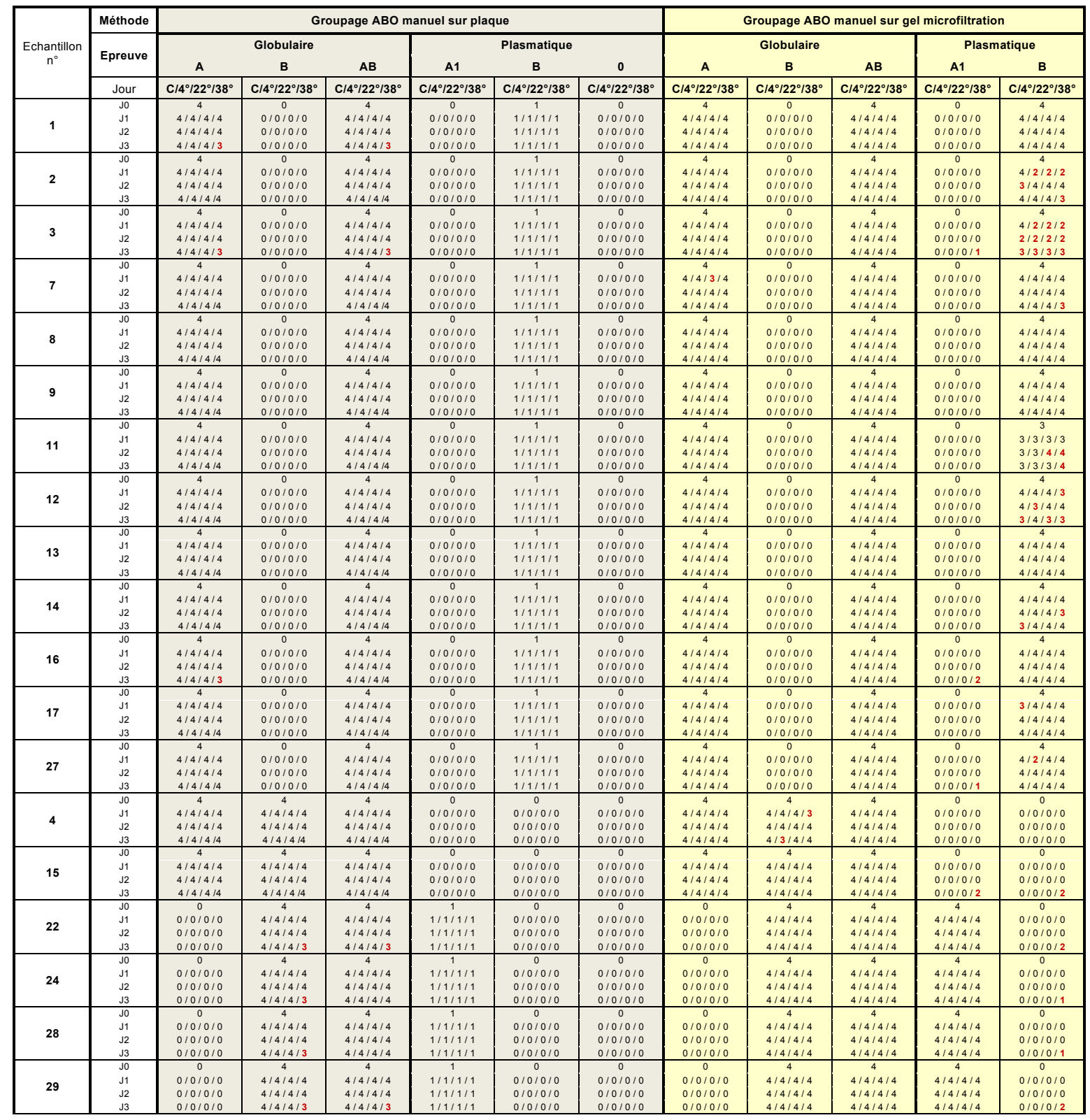




\begin{tabular}{|c|c|c|c|c|c|c|c|c|c|c|c|c|}
\hline \multirow{3}{*}{5} & so & 0 & 0 & 0 & 1 & 1 & 0 & 0 & 0 & 0 & 4 & 4 \\
\hline & $\mathrm{J1}$ & $0 / 0 / 0 / 0$ & $0 / 0 / 0 / 0$ & $0 / 0 / 0 / 0$ & $1 / 1 / 1 / 1$ & $1 / 1 / 1 / 1$ & $0 / 0 / 010$ & $0 / 0 / 0 / 0$ & $0 / 0 / 0 / 0$ & $0 / 0 / 0 / 0$ & $4 / 4 / 4 / 4$ & $4 / 4 / 4 / 4$ \\
\hline & $\mathrm{J}_{3}$ & $\begin{array}{l}0101010 \\
0 / 01010\end{array}$ & $\begin{array}{l}0101010 \\
0 / 10 / 0\end{array}$ & $0 / 0 / 010$ & $\begin{array}{l}1 / 1 / 1 / 1 / 1 \\
1\end{array}$ & $\begin{array}{l}1 / 11 / 1 / 1 \\
1 / 1 / 1 / 1\end{array}$ & $\begin{array}{l}0 / 1 / 0 / 0 \\
0 / 0 / 0 / 0\end{array}$ & $\begin{array}{l}0 / 010 / 0 \\
0 / 10 / 0 / 0\end{array}$ & $\begin{array}{l}0 / 010 / 0 \\
0 / 10 / 0 / 0\end{array}$ & $\begin{array}{l}0 / 1 / 0 / 0 \\
0 / 0 / 0 / 0\end{array}$ & $\begin{array}{l}4 / / / 4 / 4 \\
4 / 4 / 4 / 4\end{array}$ & $\begin{array}{l}4 / 4 / 4 / 4 \\
4 / 4 / 4 / 3\end{array}$ \\
\hline \multirow{4}{*}{6} & Jo & & & & & & & & & & & \\
\hline & $\mathrm{J} 1$ & $0 / 0 / 0 / 0$ & $0 / 0 / 0 / 0$ & $0 / 0 / 0 / 0$ & $1 / 1 / 1 / 1$ & $1 / 1 / 1 / 1$ & $0 / 0 / 0 / 0$ & $0 / 0 / 0 / 0$ & $0 / 0 / 0 / 0$ & $0 / 0 / 0 / 0$ & $4 / 4 / 4 / 4$ & $4 / 4 / 4 / 4$ \\
\hline & J2 & $0 / 0 / 0 / 0$ & $0 / 0 / 0 / 0$ & $0 / 0 / 0 / 0$ & $1 / 1 / 1 / 1$ & $1 / 1 / 1 / 1$ & $0 / 0 / 0 / 0$ & $0 / 0 / 0 / 0$ & $0 / 0 / 0 / 0$ & $0 / 0 / 0 / 0$ & $4 / 4 / 4 / 4$ & $4 / 4 / 4 / 4$ \\
\hline & $\mathrm{J} 3$ & $0 / 0 / 0 / 0$ & $0 / 0 / 0 / 0$ & $0 / 0 / 0 / 0$ & $1 / 1 / 1 / 1$ & $1 / 1 / 1 / 1$ & $0 / 0 / 0 / 0$ & $0 / 0 / 0 / 0$ & $0 / 0 / 0 / 0$ & $0 / 0 / 0 / 0$ & $4 / 4 / 4 / 3$ & $4 / 4 / 4 / 3$ \\
\hline \multirow{4}{*}{10} & Jo & 0 & 0 & 0 & 1 & 1 & 0 & 0 & 0 & 0 & 4 & 4 \\
\hline & $\mathrm{J} 1$ & $0 / 0 / 0 / 0$ & $0 / 0 / 0 / 0$ & $0 / 0 / 0 / 0$ & $1 / 1 / 1 / 1$ & $1 / 1 / 1 / 1$ & $0 / 0 / 0 / 0$ & $0 / 0 / 0 / 0$ & $0 / 0 / 0 / 0$ & $0 / 0 / 0 / 0$ & $4 / 4 / 4 / 4$ & $4 / 4 / 4 / 4$ \\
\hline & $\mathrm{J} 2$ & $0 / 0 / 0 / 0$ & $0 / 0 / 0 / 0$ & $0 / 0 / 0 / 0$ & $1 / 1 / 1 / 1$ & $1 / 1 / 1 / 1$ & $0 / 0 / 0 / 0$ & $0 / 0 / 0 / 0$ & $0 / 0 / 0 / 0$ & $0 / 0 / 0 / 0$ & $4 / 4 / 4 / 4$ & $4 / 4 / 4 / 4$ \\
\hline & J3 & $0 / 0 / 0 / 0$ & $0 / 0 / 0 / 0$ & $0 / 0 / 0 / 0$ & $1 / 1 / 1 / 1$ & $1 / 1 / 1 / 1$ & $0 / 0 / 0 / 0$ & $0 / 0 / 0 / 0$ & $0 / 0 / 0 / 0$ & $0 / 0 / 0 / 0$ & $4 / 4 / 4 / 4$ & $4 / 4 / 4 / 4$ \\
\hline \multirow{4}{*}{18} & Jo & 0 & 0 & 0 & 1 & 1 & 0 & 0 & 0 & 0 & 3 & 4 \\
\hline & $\mathrm{J} 1$ & $0 / 0 / 0 / 0$ & $0 / 0 / 0 / 0$ & $0 / 0 / 0 / 0$ & $1 / 1 / 1 / 1$ & $1 / 1 / 1 / 1$ & $0 / 0 / 0 / 0$ & $0 / 0 / 0 / 0$ & $0 / 0 / 0 / 0$ & $0 / 0 / 0 / 0$ & $3 / 4 / 4 / 4$ & $4 / 4 / 4 / 4$ \\
\hline & $\mathrm{J} 2$ & $0 / 0 / 0 / 0$ & $0 / 0 / 0 / 0$ & $0 / 0 / 0 / 0$ & $1 / 1 / 1 / 1$ & $1 / 1 / 1 / 1$ & $0 / 0 / 0 / 0$ & $0 / 0 / 0 / 0$ & $0 / 0 / 0 / 0$ & $0 / 0 / 0 / 0$ & $3 / 3 / 3 / 3$ & $3 / 4 / 4 / 4$ \\
\hline & J3 & $0 / 0 / 0 / 0$ & $0 / 0 / 0 / 0$ & $0 / 0 / 0 / 0$ & $1 / 1 / 1 / 1$ & $1 / 1 / 1 / 1$ & $0 / 0 / 0 / 0$ & $0 / 0 / 0 / 0$ & $0 / 0 / 0 / 0$ & $0 / 0 / 0 / 0$ & $4 / 4 / 3 / 3$ & $4 / 4 / 3 / 4$ \\
\hline \multirow{4}{*}{19} & Jo & 0 & 0 & 0 & 1 & 1 & 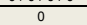 & 0 & 0 & 0 & 2 & 4 \\
\hline & $\mathrm{J} 1$ & $0 / 0 / 0 / 0$ & $0 / 0 / 0 / 0$ & $0 / 0 / 0 / 0$ & $1 / 1 / 1 / 1$ & $1 / 1 / 1 / 1$ & $0 / 0 / 0 / 0$ & $0 / 0 / 0 / 0$ & $0 / 0 / 0 / 0$ & $0 / 0 / 0 / 0$ & $2 / 2 / 2 / 2$ & $4 / 4 / 4 / 4$ \\
\hline & J2 & $0 / 0 / 0 / 0$ & $0 / 0 / 0 / 0$ & $0 / 0 / 0 / 0$ & $1 / 1 / 1 / 1$ & $1 / 1 / 1 / 1$ & $0 / 0 / 0 / 0$ & $0 / 0 / 0 / 0$ & $0 / 0 / 0 / 0$ & $0 / 0 / 0 / 0$ & $2 / 2 / 2 / 2$ & $4 / 4 / 4 / 4$ \\
\hline & J3 & $0 / 0 / 0 / 0$ & $0 / 0 / 0 / 0$ & $0 / 0 / 0 / 0$ & $1 / 1 / 1 / 1$ & $1 / 1 / 1 / 1$ & $0 / 0 / 0 / 0$ & $0 / 0 / 0 / 0$ & $0 / 0 / 0 / 0$ & $0 / 0 / 0 / 0$ & $2 / 2 / 2 / 2$ & $4 / 4 / 4 / 4$ \\
\hline \multirow{4}{*}{20} & $\begin{array}{l}\text { Jo } \\
\end{array}$ & 0 & 0 & 0 & 1 & 1 & 0 & 0 & 0 & 0 & 4 & $\frac{4 \sqrt{4 / 7 / 4}}{4}$ \\
\hline & $\mathrm{J} 1$ & $0 / 0 / 0 / 0$ & $0 / 0 / 0 / 0$ & $0 / 0 / 0 / 0$ & $1 / 1 / 1 / 1$ & $1 / 1 / 1 / 1$ & $0 / 0 / 0 / 0$ & $0 / 0 / 0 / 0$ & $0 / 0 / 0 / 0$ & $0 / 0 / 0 / 0$ & $4 / 4 / 4 / 4$ & $4 / 4 / 4 / 4$ \\
\hline & $\mathrm{J} 2$ & $0 / 0 / 0 / 0$ & $0 / 0 / 0 / 0$ & $0 / 0 / 0 / 0$ & $1 / 1 / 1 / 1$ & $1 / 1 / 1 / 1$ & $0 / 0 / 0 / 0$ & $0 / 0 / 0 / 0$ & $0 / 0 / 0 / 0$ & $0 / 0 / 0 / 0$ & $4 / 4 / 4 / 4$ & $4 / 4 / 4 / 4$ \\
\hline & $\mathrm{J} 3$ & $0 / 0 / 0 / 0$ & $0 / 0 / 0 / 0$ & $0 / 0 / 0 / 0$ & $1 / 1 / 1 / 1$ & $1 / 1 / 1 / 1$ & $0 / 0 / 0 / 0$ & $0 / 0 / 0 / 0$ & $0 / 0 / 0 / 0$ & $0 / 0 / 0 / 0$ & $4 / 4 / 4 / 4$ & $4 / 4 / 4 / 4$ \\
\hline \multirow{4}{*}{21} & Jo & 0 & 0 & 0 & 1 & 1 & 0 & 0 & 0 & 0 & 4 & 4 \\
\hline & $\mathrm{J} 1$ & $0 / 0 / 0 / 0$ & $0 / 0 / 0 / 0$ & $0 / 0 / 0 / 0$ & $1 / 1 / 1 / 1$ & $1 / 1 / 1 / 1$ & $0 / 0 / 0 / 0$ & $0 / 0 / 0 / 0$ & $0 / 0 / 0 / 0$ & $0 / 0 / 0 / 0$ & $4 / 4 / 4 / 4$ & $4 / 4 / 4 / 4$ \\
\hline & $\mathrm{J} 2$ & $0 / 0 / 0 / 0$ & $0 / 0 / 0 / 0$ & $0 / 0 / 0 / 0$ & $1 / 1 / 1 / 1$ & $1 / 1 / 1 / 1$ & $0 / 0 / 0 / 0$ & $0 / 0 / 0 / 0$ & $0 / 0 / 0 / 0$ & $0 / 0 / 0 / 0$ & $4 / 4 / 4 / 4$ & $4 / 4 / 4 / 4$ \\
\hline & J3 & $0 / 0 / 0 / 0$ & $0 / 0 / 0 / 0$ & $0 / 0 / 0 / 0$ & $1 / 1 / 1 / 1$ & $1 / 1 / 1 / 1$ & $0 / 0 / 0 / 0$ & $0 / 0 / 0 / 0$ & $0 / 0 / 0 / 0$ & $0 / 0 / 0 / 0$ & $4 / 4 / 4 / 4$ & $4 / 4 / 4 / 4$ \\
\hline \multirow{4}{*}{23} & Jo & 0 & 0 & & 1 & 1 & 0 & 0 & 0 & 0 & 4 & 4 \\
\hline & $\mathrm{J} 1$ & $0 / 0 / 0 / 0$ & $0 / 0 / 0 / 0$ & $0 / 0 / 0 / 0$ & $1 / 1 / 1 / 1$ & $1 / 1 / 1 / 1$ & $0 / 0 / 0 / 0$ & $0 / 0 / 0 / 0$ & $0 / 0 / 0 / 0$ & $0 / 0 / 0 / 0$ & $4 / 4 / 4 / 4$ & $4 / 4 / 4 / 4$ \\
\hline & $\mathrm{J} 2$ & $0 / 0 / 0 / 0$ & $0 / 0 / 0 / 0$ & $0 / 0 / 0 / 0$ & $1 / 1 / 1 / 1$ & $1 / 1 / 1 / 1$ & $0 / 0 / 0 / 0$ & $0 / 0 / 0 / 0$ & $0 / 0 / 0 / 0$ & $0 / 0 / 0 / 0$ & $4 / 4 / 4 / 4$ & $4 / 4 / 4 / 4$ \\
\hline & J3 & $0 / 0 / 0 / 0$ & $0 / 0 / 0 / 0$ & $0 / 0 / 0 / 0$ & $1 / 1 / 1 / 1$ & $1 / 1 / 1 / 1$ & $0 / 0 / 0 / 0$ & $0 / 0 / 0 / 0$ & $0 / 0 / 0 / 0$ & $0 / 0 / 0 / 0$ & $4 / 4 / 4 / 4$ & $4 / 4 / 4 / 4$ \\
\hline \multirow{4}{*}{25} & Jo & 0 & 0 & 0 & 1 & 1 & 0 & 0 & 0 & 0 & 4 & 4 \\
\hline & $\mathrm{J} 1$ & $0 / 0 / 0 / 0$ & $0 / 0 / 0 / 0$ & $0 / 0 / 0 / 0$ & $1 / 1 / 1 / 1$ & $1 / 1 / 1 / 1$ & $0 / 0 / 0 / 0$ & $0 / 0 / 0 / 0$ & $0 / 0 / 010$ & $0 / 0 / 0 / 0$ & $4 / 4 / 4 / 4$ & $4 / 4 / 4 / 4$ \\
\hline & $\mathrm{J} 2$ & $0 / 0 / 0 / 0$ & $0 / 0 / 0 / 0$ & $0 / 0 / 0 / 0$ & $1 / 1 / 1 / 1$ & $1 / 1 / 1 / 1$ & $0 / 0 / 0 / 0$ & $0 / 0 / 0 / 0$ & $0 / 0 / 0 / 0$ & $0 / 0 / 0 / 0$ & $4 / 4 / 4 / 4$ & $4 / 4 / 4 / 4$ \\
\hline & J3 & $0 / 0 / 0 / 0$ & $0 / 0 / 0 / 0$ & $0 / 0 / 0 / 0$ & $1 / 1 / 1 / 1$ & $1 / 1 / 1 / 1$ & $0 / 0 / 0 / 0$ & $0 / 0 / 0 / 0$ & $0 / 0 / 0 / 0$ & $0 / 0 / 0 / 0$ & $4 / 4 / 4 / 4$ & $4 / 4 / 4 / 4$ \\
\hline \multirow{4}{*}{26} & Jo & 0 & 0 & 0 & 1 & 1 & 0 & 0 & 0 & 0 & $\begin{aligned} 4 / 4 / 4 / 4 \\
4\end{aligned}$ & $\frac{4 / 4 / 4 / 7}{4}$ \\
\hline & $\mathrm{J} 1$ & $0 / 0 / 0 / 0$ & $0 / 0 / 0 / 0$ & $0 / 0 / 0 / 0$ & $1 / 1 / 1 / 1$ & $1 / 1 / 1 / 1$ & $0 / 0 / 0 / 0$ & $0 / 0 / 0 / 0$ & $0 / 0 / 0 / 0$ & $0 / 0 / 0 / 0$ & $4 / 4 / 4 / 4$ & $4 / 4 / 4 / 4$ \\
\hline & $\mathrm{J} 2$ & $0 / 0 / 0 / 0$ & $0 / 0 / 0 / 0$ & $0 / 0 / 0 / 0$ & $1 / 1 / 1 / 1$ & $1 / 1 / 1 / 1$ & $0 / 0 / 0 / 0$ & $0 / 0 / 0 / 0$ & $0 / 0 / 0 / 0$ & $0 / 0 / 0 / 0$ & $\begin{array}{l}4 / 4 / 4 / 4 \\
4\end{array}$ & $4 / 4 / 4 / 4$ \\
\hline & $\mathrm{J}_{3}$ & $0 / 0 / 0 / 0$ & $0 / 0 / 0 / 0$ & $\begin{array}{r}0 / 0 / 0 \\
\end{array}$ & $1 / 1 / 1 / 1$ & $1 / 1 / 1 / 1$ & $0 / 0 / 0 / 0$ & $\begin{array}{l}0 / 0 / 0 / 0 \\
\end{array}$ & $0 / 0 / 0 / 0$ & $\begin{array}{r}0 / 0 / 0 / 0 \\
\end{array}$ & $\begin{array}{l}4 / 4 / 4 / 4 \\
\end{array}$ & $4 / 4 / 4 / 4$ \\
\hline \multirow{4}{*}{30} & Jo & 0 & 0 & 0 & 1 & 1 & 0 & 0 & 0 & 0 & 3 & 3 \\
\hline & $\mathrm{J} 1$ & $0 / 0 / 0 / 0$ & $0 / 0 / 0 / 0$ & $0 / 0 / 0 / 0$ & $1 / 1 / 1 / 1$ & $1 / 1 / 1 / 1$ & $0 / 0 / 0 / 0$ & $0 / 0 / 0 / 0$ & $0 / 0 / 0 / 0$ & $0 / 0 / 0 / 0$ & $3 / 3 / 3 / 3$ & $4 / 4 / 4 / 4$ \\
\hline & J2 & $0 / 0 / 0 / 0$ & $0 / 0 / 0 / 0$ & $0 / 0 / 0 / 0$ & $1 / 1 / 1 / 1$ & $1 / 1 / 1 / 1$ & $0 / 0 / 0 / 0$ & $0 / 0 / 0 / 0$ & $0 / 0 / 0 / 0$ & $0 / 0 / 0 / 0$ & $3 / 3 / 3 / 3$ & $4 / 4 / 4 / 4$ \\
\hline & J3 & $0 / 0 / 0 / 0$ & $0 / 0 / 0 / 0$ & $0 / 0 / 0 / 0$ & $1 / 1 / 1 / 1 / 1$ & $1 / 1 / 1 / 1 / 1$ & $0 / 0 / 0 / 0$ & $0 / 0 / 0 / 0$ & $0 / 0 / 0 / 0$ & $0 / 0 / 0 / 0$ & $3 / 3 / 3 / 3$ & $4 / 4 / 4 / 4$ \\
\hline
\end{tabular}

Tableau 19: Résultats des intensités réactionnelles des 30 groupages sanguins $A B O$ réalisés en technique manuelle, sur plaque et sur gel microfiltration. Les jours de test sont indiqués " J0 », "J1 », " $J 2$ » et « $J 3$ ». Les températures sont indiquées " $C$ » pour le tube de départ centrifugé et repris chaque jour, puis " $4^{\circ}$ », " $22^{\circ}$ » et « $38^{\circ}$ ». Les résultats sont cotés de 0 (négatif) à 4 pour l'épreuve globulaire sur plaque et sur gel microfiltration. Les résultats sont rendus 0 (négatif) ou 1 (positif) pour l'épreuve plasmatique sur plaque, et de 0 (négatif) à 4 sur gel microfiltration.

\section{i. Technique sur plaque}

- Epreuve globulaire:

Epreuve globulaire attendue négative :

Les sujets de groupe $A$ présentent une réaction négative pour l'antigène $B$, de même que les sujets de groupe $B$ pour l'antigène $A$ et les sujets de groupe $O$ pour les antigènes $A$ et $B$. Cette réaction reste négative quelles que soient les conditions de conservation appliquées aux échantillons (Tableau 19).

Epreuve globulaire attendue positive :

L'observation des réactions positives montre que les intensités réactionnelles pour les antigènes $A, B$ et $A B$ sont toutes cotées 4+ à J0.

Parmi les 13 sujets de groupe $A$, nous observons une baisse de l'intensité réactionnelle à $3+$ après trois jours de conservation à $+38^{\circ} \mathrm{C}$ sur l'antigène $A$ seulement chez un sujet $\left(n^{\circ} 16\right)$, et sur les antigènes $A$ et $A B$ chez deux sujets $\left(n^{\circ} 1\right.$ et 3).

Parmi les 4 sujets de groupe $B$, nous observons une baisse de l'intensité réactionnelle à $3+$ après trois jours de conservation à $+38^{\circ} \mathrm{C}$ sur l'antigène $\mathrm{B}$ chez 
deux sujets ( $n^{\circ} 24$ et 28 ), et sur les antigènes $B$ et $A B$ chez deux sujets ( $n^{\circ} 22$ et 29$)$ (Tableau 19) (Figure 29).

Les 2 sujets de groupe $A B$ ne présentent pas de baisse d'intensité réactionnelle pour les antigènes $A, B$ et $A B$, dans toutes les conditions de conservation.
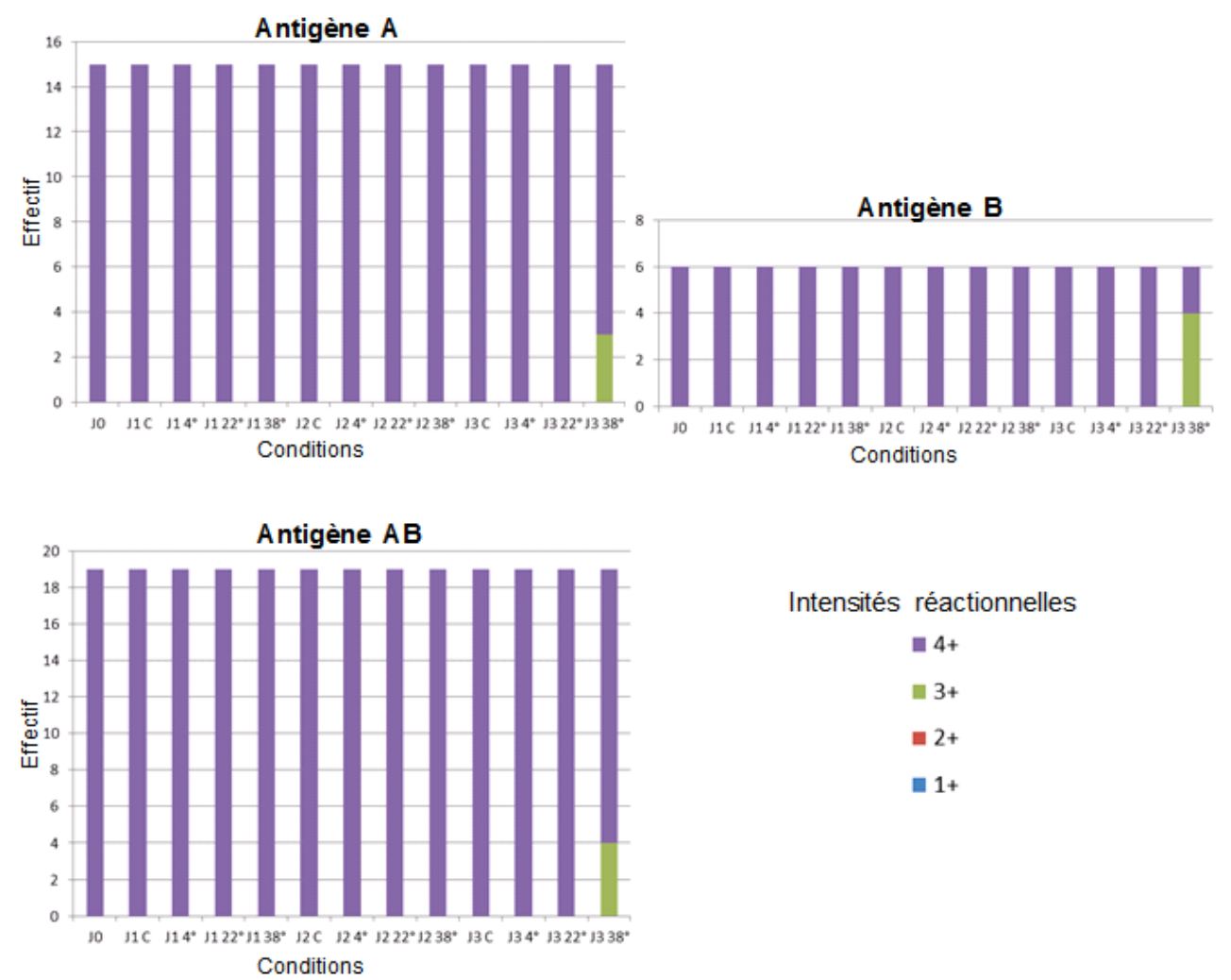

Intensités réactionnelles

घ4+

$\because 3+$

$=2+$

$\because 1+$

Figure 29 : Représentation des résultats d'intensités réactionnelles positifs pour les antigènes $A, B$ et $A B$, en technique manuelle sur plaque.

- Epreuve plasmatique:

Epreuve plasmatique attendue négative :

Les résultats ne sont pas exprimés en intensité réactionnelle mais en réaction positive (cotée 1 ) ou réaction négative (cotée 0 ). Toutes les réactions négatives à J0 (sujets dépourvus de l'anticorps correspondant à l'hématie-test A1 et/ou B) restent négatives quelles que soient les conditions de conservation appliquées à l'échantillon.

Epreuve plasmatique attendue positive :

Chez tous les sujets de groupe A, la réaction entre leur anti-B plasmatique et les hématies-tests $\mathrm{B}$ est positive à $\mathrm{J} 0$ et le reste dans toutes les conditions de conservation. II en est de même pour les sujets de groupe B (anti-A plasmatique avec les hématies-tests $A 1)$. 


\section{- En résumé :}

Malgré un très léger affaiblissement des réactions d'agglutination à l'épreuve globulaire après 3 jours de conservation à $+38^{\circ} \mathrm{C}$, les 30 sujets testés pour le groupage sanguin $A B O$, en technique manuelle sur plaque, présentent un résultat de groupe $A B O$ sans discordance par rapport au résultat de référence obtenu à $\mathrm{J} 0$, quelles que soient les conditions de conservation.

\section{ii. Technique sur gel microfiltration}

\section{- Epreuve globulaire:}

Epreuve globulaire attendue négative :

Les sujets de groupe $A$ présentent une réaction négative pour l'antigène $B$, de même que les sujets de groupe $B$ pour l'antigène $A$ et les sujets de groupe $O$ pour les antigènes $A$ et $B$. Cette réaction reste négative quelles que soient les conditions de conservation appliquées aux échantillons (Tableau 19).

Epreuve globulaire attendue positive :

Les intensités réactionnelles pour les antigènes $A, B$ et $A B$ sont toutes cotées $4+$ à J0. Parmi les sujets de groupe $A$, l'intensité réactionnelle sur l'antigène $A$ baisse à $3+$ chez 1 sujet $\left(n^{\circ} 7\right)$, après 1 jour de conservation à $+22^{\circ} \mathrm{C}$. Chez 1 sujet de groupe $A B\left(n^{\circ} 4\right)$, nous observons une baisse d'intensité réactionnelle $\left(3^{+}\right)$à $\mathrm{J} 1$ $+38^{\circ} \mathrm{C}$ et à $\mathrm{J} 3+4^{\circ} \mathrm{C}$, sur l'antigène $\mathrm{B}$ (Tableau 19) (Figure 30 ). 

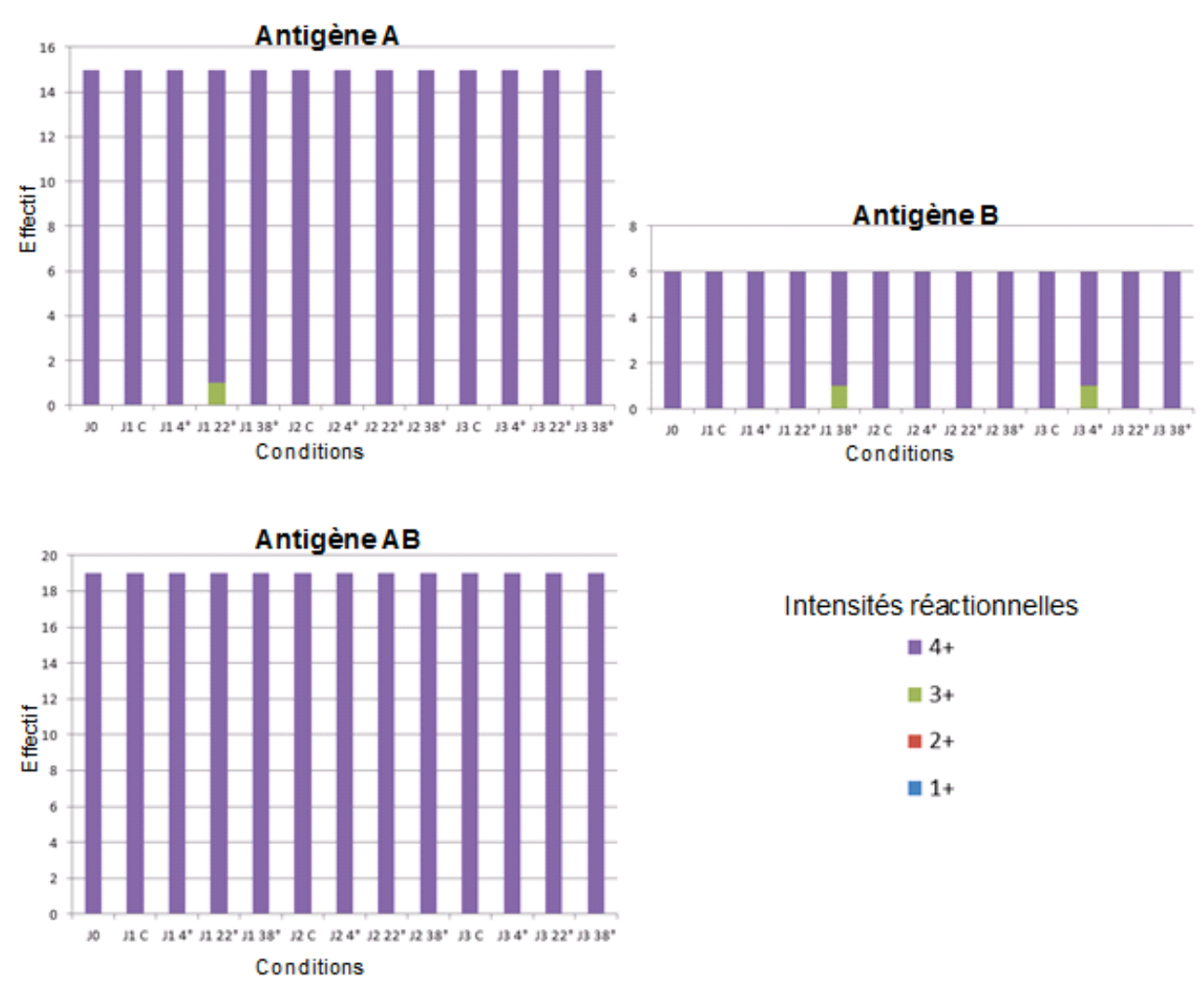

Intensités réactionnelles

a $4+$

a $3+$

= $2+$

$\because 1+$

Figure 30 : Représentation des résultats d'intensités réactionnelles positifs, pour les antigènes $A, B$ et $A B$, en technique manuelle sur gel microfiltration.

- Epreuve plasmatique:

Epreuve plasmatique attendue négative :

Tous les sujets de groupes $A$ et $A B$ ont une réaction négative avec les hématies-tests $\mathrm{A} 1$ à $\mathrm{J} 0$ (comme attendue). Cette réaction reste négative dans toutes les conditions de conservation sauf après 3 jours de conservation à $+38^{\circ} \mathrm{C}$ pour 4 sujets. Tous les sujets de groupes $B$ et $A B$ donnent une réaction négative avec les hématies-tests $\mathrm{B}$ à $\mathrm{J0}$ (comme attendue). Cette réaction reste négative dans toutes les conditions de conservation sauf après 3 jours de conservation à $+38^{\circ} \mathrm{C}$ pour 4 sujets. On observe chez ces 8 sujets un plasma hémolysé (Figure 31), du fait de la conservation à $+38^{\circ} \mathrm{C}$, induisant une réaction faussement positive à l'épreuve plasmatique (trace rouge dans le gel lue positive) (Figure 32). 


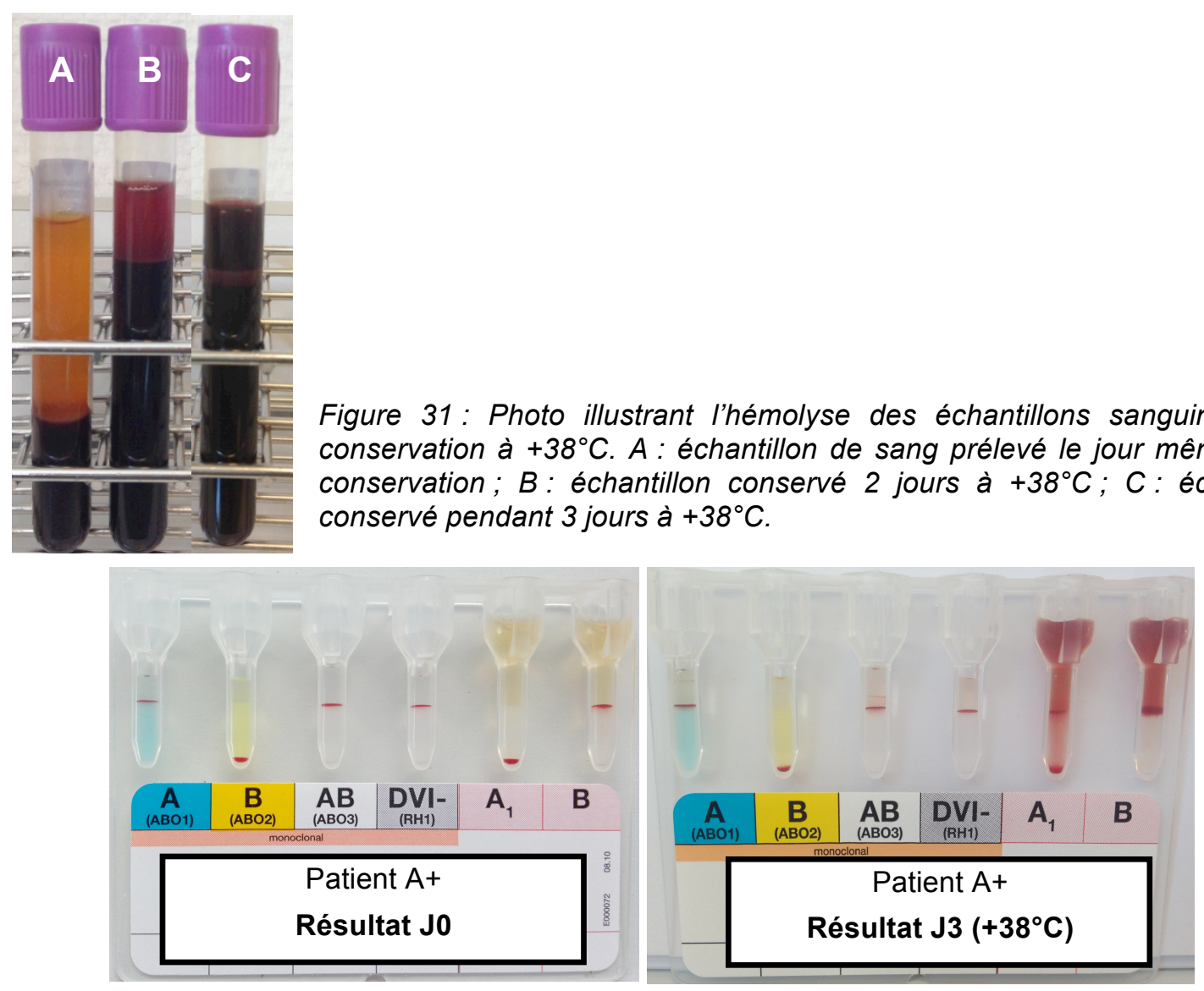

Figure 32 : Photo des supports de gel microfiltration pour groupage ABO. A gauche le résultat d'un sujet de groupe $A$ à $J 0$ (sans conservation) ; A droite le résultat du même patient mais sur l'échantillon conservé pendant 3 jours à $+38^{\circ} \mathrm{C}$ : l'hémolyse de l'échantillon perturbe la lecture du résultat de l'épreuve plasmatique (micro-colonnes de droite $A 1$ et $B$ ), le plasma rouge laisse une trace dans la micro-colonne et des débris globulaires restent en surface du gel.

\section{Epreuve plasmatique attendue positive :}

Vingt-quatre sujets de l'étude possèdent un anticorps anti-B dans leur plasma (sujets de groupe $\mathrm{A}$ et $\mathrm{O}$ ). Pour 11 d'entre eux, l'intensité réactionnelle pour l'anti-B est cotée 4+ à $\mathrm{J} 0$ et le reste dans toutes les autres conditions de conservation. En revanche, pour les 13 autres sujets, les intensités réactionnelles varient entre 2+ et $4^{+}$, sans révéler de tendance concernant les conditions de conservation (variations à $+4^{\circ} \mathrm{C},+22^{\circ} \mathrm{C}$ et/ou $+38^{\circ} \mathrm{C}$, à $\mathrm{J} 1, \mathrm{~J} 2$ et/ou J3). Nous pouvons faire la même observation chez les 15 sujets possédant un anticorps anti-A (sujets de groupe $B$ et O) : 13 sujets présentent une intensité réactionnelle positive pour l'anti-A à J0 qui reste constante dans toutes les autres conditions de conservation (11 sujets cotés $4+, 1$ sujet coté $3+$ et 1 sujet coté $2+), 1$ sujet présente une baisse d'intensité réactionnelle le $3^{\text {ème }}$ jour à $+38^{\circ} \mathrm{C}$, et 1 sujet présente des intensités réactionnelles entre $2+$ et $4+$ sans révéler de tendances concernant les conditions de conservation (Tableau 19). 
- En résumé :

Malgré une très légère baisse d'intensité réactionnelle à l'épreuve globulaire, les 30 échantillons présentent un résultat de groupe $A B O$ sans discordance par rapport au résultat de référence obtenu à J0 jusqu'à 3 jours de conservation à $+4^{\circ} \mathrm{C}$ et $+22^{\circ} \mathrm{C}$, et jusqu'à 2 jours à $+38^{\circ} \mathrm{C}$. L'hémolyse de l'échantillon, provoquée par une conservation prolongée ( 3 jours) à la température élevée de $+38^{\circ} \mathrm{C}$, perturbe la lecture des supports de réaction pour 8 échantillons sur 30 , induisant un résultat faussement positif à l'épreuve plasmatique.

\section{b. Technique automatique}

- Epreuve globulaire:

Epreuve globulaire attendue négative :

Les sujets de groupe $A$ présentent une réaction négative pour l'antigène $B$, de même que les sujets de groupe $B$ pour l'antigène $A$ et les sujets de groupe $O$ pour les antigènes $A$ et $B$. Cette réaction est rendue négative par l'automate quelles que soient les conditions de conservation appliquées aux échantillons.

Epreuve globulaire attendue positive :

Nous observons une légère baisse des valeurs rendues par l'automate, pour les résultats d'antigènes $A, B$ et $A B$, à la température de $+38^{\circ} \mathrm{C}$ par rapport aux autres températures de conservation. Ces résultats sont représentés sur la figure 33 . Cependant, l'analyse statistique des résultats ne montre aucune différence significative ( $p$-valeur $>0,05$ ) entre les résultats rendus à J0 par l'automate et les résultats rendus dans toutes les autres conditions de conservation, pour les antigènes $A, B$ et $A B$ à l'épreuve globulaire. 


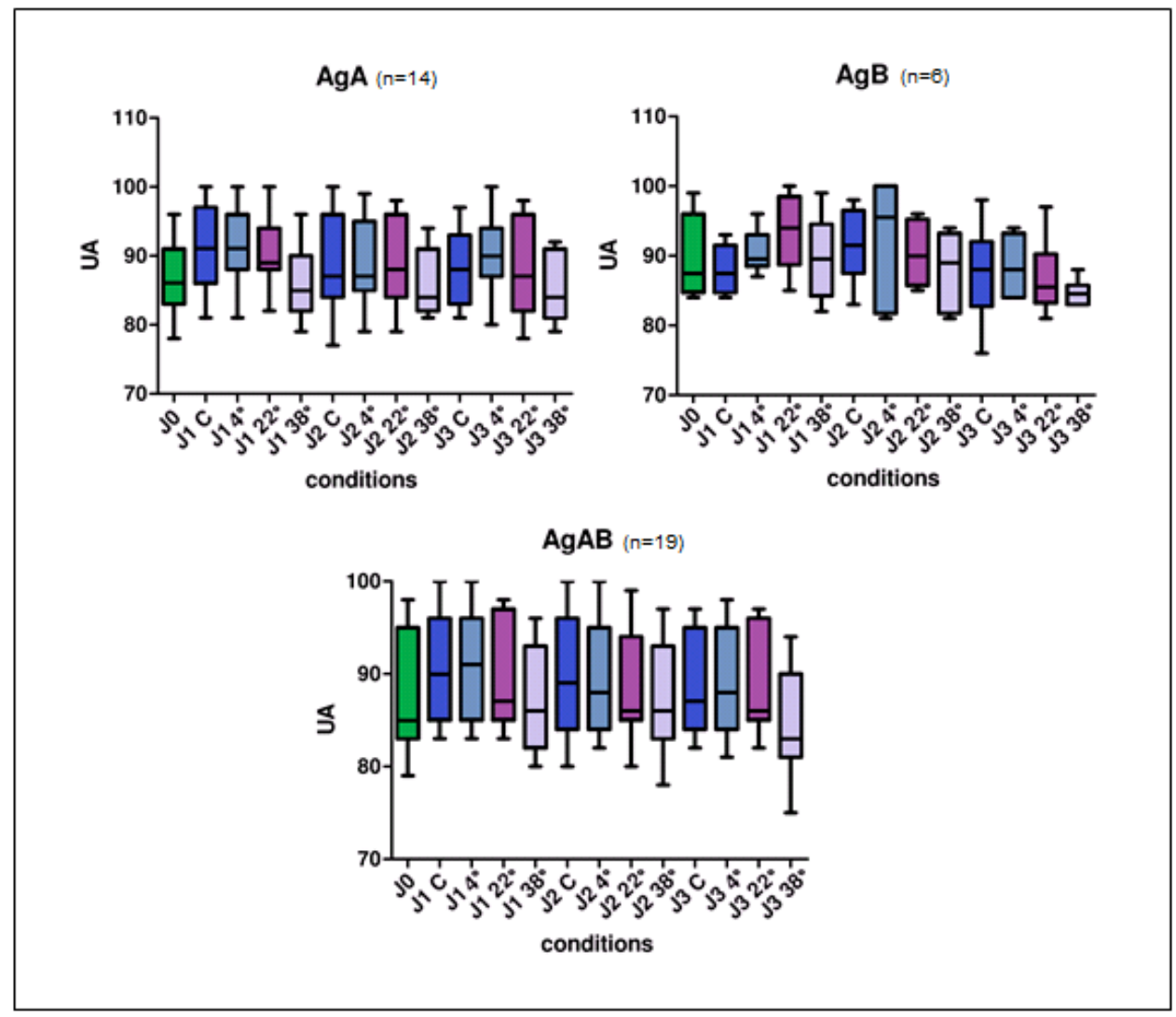

Figure 33: Représentation graphique des résultats rendus par l'automate Galileo® pour les antigènes $A, B$ et $A B$. Absence de différence significative ( $p$-valeur $>0,05)$ entre les valeurs de références (JO) et celles obtenues dans toutes les conditions de conservation.

- Epreuve plasmatique:

Epreuve plasmatique attendue négative :

Toutes les réactions rendues négatives à $\mathrm{J} 0$ par l'automate (sujets dépourvus de l'anticorps correspondant à l'hématie-test A1 et/ou B) sont également rendues négatives quelles que soient les conditions de conservation appliquées à l'échantillon.

Epreuve plasmatique attendue positive :

Nous observons une baisse plus franche des valeurs rendues par l'automate, pour les résultats d'anti- $\mathrm{A}$ et d'anti-B, à la température de $+38^{\circ} \mathrm{C}$, particulièrement au bout de 2 jours puis 3 jours de conservation (Figure 34). Ce phénomène est expliqué par l'hémolyse des échantillons dès 2 jours de conservation à $+38^{\circ} \mathrm{C}$, celle-ci interfère sur la lecture du résultat par l'automate Galileo®. Un échantillon avec un plasma très lactescent donne même des résultats d'anti-A très bas à $+38^{\circ} \mathrm{C}$ dès le premier jour. L'analyse statistique des résultats montre une diminution significative $(p$-valeur $<0,01)$ des résultats d'anti-A et d'anti-B rendus par l'automate Galileo® après 2 et 3 jours de conservation à $+38^{\circ} \mathrm{C}$. 


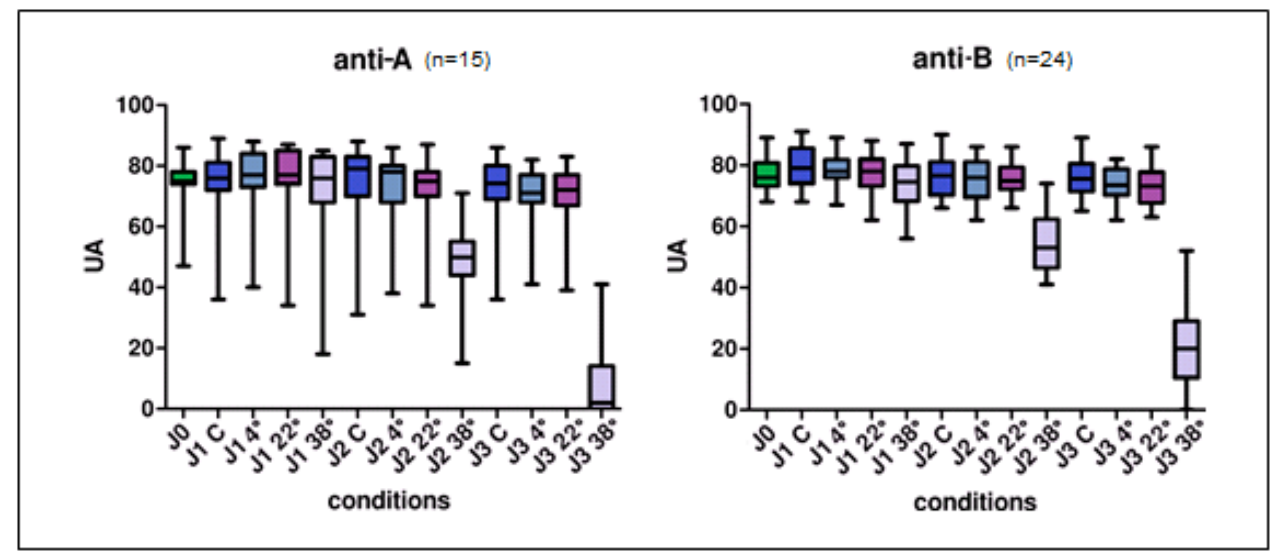

Figure 34 : Représentation graphique des résultats rendus par l'automate Galileo® pour l'anti- $A$ et l'anti-B. Diminution significative des valeurs obtenues aux $2^{\text {eme }}$ et $3^{\text {ème }}$ jours à $+38^{\circ} \mathrm{C}$ pour les deux anticorps ( $p$-valeur<0,01) par rapport aux valeurs de références $\mathrm{J} 0$.

\section{- En résumé :}

Malgré une diminution des réactions d'agglutination à l'épreuve globulaire, les 30 échantillons présentent un résultat de groupe $A B O$ sans discordance par rapport au résultat de référence obtenu à $\mathrm{J} 0$, jusqu'à 3 jours de conservation à $+4^{\circ} \mathrm{C}$ et $+22^{\circ} \mathrm{C}$. Il en est de même pour 29 échantillons conservés jusqu'à 2 jours à $+38^{\circ} \mathrm{C}$. En raison de l'hémolyse, 22 échantillons obtiennent un résultat à l'épreuve plasmatique trop faible après 3 jours de conservation à $+38^{\circ} \mathrm{C}$. Ces résultats sont non interprétés par l'automate car discordants avec l'épreuve globulaire.

2) Phénotypages sanguins RHK aux différentes conditions de conservation :

\section{a. Techniques manuelles}

Nous présentons les résultats de 30 phénotypages sanguins RHK (Tableau 20), analysés en technique manuelle sur plaque et sur gel microfiltration, aux différentes conditions de conservation (délai : 1,2 ou 3 jours, températures : $+4^{\circ} \mathrm{C}$, $+22^{\circ} \mathrm{C}$ et $+38^{\circ} \mathrm{C}$, conservation échantillon centrifugé ou sang total).

\begin{tabular}{|c|c|c|c|c|c|c|c|c|c|c|c|c|c|}
\hline \multirow{3}{*}{$\begin{array}{c}\text { Echantillon } \\
n^{\circ}\end{array}$} & Méthode & \multicolumn{6}{|c|}{ Phénotypage RHK manuel en Plaque } & \multicolumn{6}{|c|}{ Phénotypage RHK manuel en Colonne Filtration } \\
\hline & \multirow{2}{*}{ Jour } & RH1 & RH2 & RH3 & RH4 & RH5 & KEL1 & RH1 & RH2 & RH3 & RH4 & RH5 & KEL1 \\
\hline & & $\mathrm{C} / 4^{\circ} / 22^{\circ} / 38^{\circ}$ & $\mathrm{C} / 4^{\circ} / 22^{\circ} / 38^{\circ}$ & $\mathrm{C} / 4^{\circ} / 22^{\circ} / 38^{\circ}$ & $\mathrm{C} / 4^{\circ} / 22^{\circ} / 38^{\circ}$ & $\mathrm{C} / 4^{\circ} / 22^{\circ} / 38^{\circ}$ & $\mathrm{C} / 4^{\circ} / 22^{\circ} / 38^{\circ}$ & $\mathrm{C} / 4^{\circ} / 22^{\circ} / 38^{\circ}$ & $\mathrm{C} / 4^{\circ} / 22^{\circ} / 38^{\circ}$ & $\mathrm{C} / 4^{\circ} / 22^{\circ} / 38^{\circ}$ & $\mathrm{C} / 4^{\circ} / 22^{\circ} / 38^{\circ}$ & $\mathrm{C} / 4^{\circ} / 22^{\circ} / 38^{\circ}$ & $\mathrm{C} / 4^{\circ} / 22^{\circ} / 38^{\circ}$ \\
\hline \multirow{3}{*}{1} & $\begin{array}{l}\mathrm{J} 0 \\
\mathrm{~J} 1\end{array}$ & 3 & 3 & 0 & 3 & $\begin{array}{l}4 \\
4 / 4 / 4\end{array}$ & $\begin{array}{l}0 \\
0 / 0\end{array}$ & $\begin{array}{c}4 \\
4 / 4\end{array}$ & $\begin{array}{l}4 \\
4 / 4 / 4\end{array}$ & $\begin{array}{l}0 \\
0 / 0 / 0\end{array}$ & $\begin{array}{l}4 \\
4 / 4 / 4\end{array}$ & $\begin{array}{l}4 \\
4 / 4 / 4\end{array}$ & $\begin{array}{l}0 \\
0 / 0 / 0\end{array}$ \\
\hline & J5 & $3 / 3 / 3 / 3$ & $12 / 2$ & 10/0 & $12 / 2$ & $3 / 3 / 3 / 3$ & $0 / 0 / 0 / 0$ & $4 / 4 / 4 / 4$ & $\begin{array}{l}4 / 4 / 4 / 4 \\
4 / 4 / 4\end{array}$ & $10 / 0$ & $\begin{array}{l}4 / 4 / 4 / 4 \\
4 / 4 / 4\end{array}$ & $\begin{array}{l}4 / 4 / 4 / 4 \\
4 / 4 / 4\end{array}$ & $0 / 0 / 0 / 0$ \\
\hline & $\mathrm{J} 3$ & $3 / 3 / 3$ & $3 / 3 / 3 / 2$ & $0 / 0 / 0 / 0$ & $2 / 2 / 2 / 1$ & $3 / 3 / 3 / 3$ & $0 / 0 / 0 / 0$ & $4 / 4 / 4 / 4$ & $4 / 4 / 4 / 4$ & $0 / 0 / 0$ & $4 / 4 / 4 / 4$ & $4 / 4 / 4 / 4$ & $0 / 0 / 0 / 0$ \\
\hline \multirow{3}{*}{2} & $\begin{array}{lll}\mathrm{J} 0 \\
\mathrm{~J} 1\end{array}$ & $\begin{array}{l}3 \\
3 / 3 / 2\end{array}$ & $\begin{array}{l}3 \\
3 / 3 / 2\end{array}$ & 0 & 0 & 4 & $\begin{array}{l}0 \\
0 / 0\end{array}$ & $4 / 4 / 4$ & 4 & 0 & $0 / 010$ & 4 & 0 \\
\hline & $\mathrm{J} 2$ & $2 / 2 / 2 / 2$ & $2 / 2 / 2 / 2$ & $\begin{array}{l}0 / 0 / 0 / 0 \\
0\end{array}$ & $0 / 0 / 0 / 0$ & $3 / 3 / 3 / 2$ & $0 / 0 / 0 / 0$ & $4 / 4 / 4 / 4$ & $4 / 4 / 4 / 4$ & $0 / 0 / 0 / 0$ & $0 / 0 / 0 / 0$ & $4 / 4 / 4 / 4$ & $0 / 0 / 0 / 0$ \\
\hline & $\mathrm{J} 3$ & & & $0 / 0 / 0 / 0$ & $0 / 0 / 0 / 0$ & $1 / 3 / 3 / 2$ & $10 / 0 / 0$ & $14 / 4 / 4$ & $4 / 4 / 4 / 4$ & $0 / 0 / 0 / 0$ & $0 / 0 / 0 / 0$ & $4 / 4 / 4 / 4$ & $0 / 010 / 0$ \\
\hline
\end{tabular}




\begin{tabular}{|c|c|c|c|c|c|c|c|c|c|c|c|c|c|}
\hline 3 & $\begin{array}{l}\text { Jo } \\
\mathrm{J1} \\
\mathrm{J} 2 \\
\mathrm{J3} \\
\end{array}$ & $\begin{array}{r}4 \\
4 / 4 / 4 / 4 \\
3 / 3 / 3 / 3 \\
3 / 3 / 3 / 2 \\
\end{array}$ & $\begin{array}{r}4 \\
4 / 4 / 4 / 4 \\
4 / 4 / 3 / 3 \\
3 / 3 / 3 / 2 \\
\end{array}$ & $\begin{array}{r}0 \\
010 / 0 / 0 \\
0 / 10 / 0 / 0 \\
0 / 10 / 0 / 0 \\
\end{array}$ & $\begin{array}{r}0 \\
0101010 \\
0 / 101010 \\
0 / 01010 \\
\end{array}$ & $\begin{array}{r}4 \\
4 / 4 / 4 / 4 \\
4 / 4 / 4 / 3 \\
3 / 3 / 3 / 2 \\
\end{array}$ & $\begin{array}{l}0 \\
0 / 0 / 10 \\
0 / 010 / 0 \\
0 / 010 / 10 \\
0.0\end{array}$ & $\begin{array}{r}4 \\
4 / 4 / 4 / 4 \\
4 / / 4 / 4 / 4 \\
4 / 4 / 4 / 4 \\
\end{array}$ & $\begin{array}{r}4 / 4 / 4 \\
4 / 4 / 4 / 4 \\
4 / 4 / 4 / 4 \\
4 / 4 / 4 / 4 \\
\end{array}$ & $\begin{array}{r}0 \\
0101010 \\
0 / 101010 \\
0 / 01010 \\
\end{array}$ & $\begin{array}{r}0 \\
01010 / 0 \\
0 / 10 / 0 / 0 \\
0 / 1010 / 0 \\
\end{array}$ & $\begin{array}{r}4 / 4 / 4 \\
4 / 4 / 4 / 4 \\
4 / 4 / 4 / 4 / 4 \\
\end{array}$ & $\begin{array}{l}0 \\
0 / 0 / 0 \\
0 / 0 / 10 / 0 \\
0 / 0 / 0 / 0 \\
\end{array}$ \\
\hline 4 & $\begin{array}{l}\mathrm{J0} \\
\mathrm{J1} \\
\mathrm{J} 2 \\
\mathrm{J3}\end{array}$ & $\begin{array}{c}4 \\
4 / 4 / 4 / 4 \\
4 / 3 / 3 / 3 \\
3 / 3 / 3 / 2\end{array}$ & $\begin{array}{c}4 \\
4 / 4 / 4 / 3 \\
3 / 3 / 3 / 3 \\
2 / 2 / 2 / 2 \\
\end{array}$ & $\begin{array}{r}0 \\
0 / 0 / 0 \\
0 / 10 / 010 \\
0 / 0 / 0 / 0 \\
\end{array}$ & $\begin{array}{r}4 \\
4 / 4 / 4 / 3 \\
2 / 2 / 2 / 2 \\
2 / 2 / 2 / 1 \\
\end{array}$ & $\begin{array}{c}4 \\
4 / 4 / 4 / 4 \\
3 / 3 / 3 / 3 \\
3 / 3 / 3 / 3 \\
\end{array}$ & $\begin{array}{c}0 \\
010 / 0 / 0 \\
0 / 010 / 0 \\
0 / 0 / 0 / 0\end{array}$ & $\begin{array}{c}4 \\
4 / 4 / 4 / 4 \\
4 / 4 / 4 / 4 \\
4 / 4 / 4 / 4 \\
\end{array}$ & $\begin{array}{c}4 \\
4 / 4 / 4 / 4 \\
4 / 4 / 4 / 4 \\
4 / 4 / 4 / 4\end{array}$ & $\begin{array}{r}0 \\
010 / 010 \\
0 / 1010 / 0 \\
0 / 0 / 0 / 0 \\
0\end{array}$ & $\begin{array}{c}4 \\
4 / 4 / 4 / 4 \\
4 / 4 / 4 / 4 \\
4 / 4 / 4 / 4\end{array}$ & $\begin{array}{c}4 \\
4 / 4 / 4 / 4 \\
4 / 4 / 4 / 4 \\
4 / 4 / 4 / 4\end{array}$ & $\begin{array}{r}0 \\
0 / 0 / 10 \\
0 / 0 / 10 / 0 \\
0 / 0 / 0 / 0\end{array}$ \\
\hline 5 & $\begin{array}{l}J_{0} \\
J_{1} \\
J_{2} \\
\end{array}$ & $\begin{array}{r}4 \\
4 / 4 / 4 / 4 \\
4 / 4 / 4 / 4 \\
4 / 4 / 4 / 4 \\
\end{array}$ & $\begin{array}{r}0 \\
0 / 010 / 0 \\
0 / 10 / 0 / 0 \\
0 / 1 / 0 / 0 / 0\end{array}$ & $\begin{array}{l}44 / 4 / 4 / 4 \\
3 / 3 / 3 / 2 \\
3 / 3 / 3 / 2 \\
\end{array}$ & $\begin{array}{r}4 \\
4 / 4 / 4 / 3 \\
3 / 2 / 2 / 2 / 2 \\
2 / 2 / 2 / 2 \\
\end{array}$ & $\begin{array}{r}3 \\
3 / 3 / 3 / 3 \\
2 / 2 / 2 / 2 \\
2 / 2 / 2 / 2 \\
\end{array}$ & $\begin{array}{l}0 \\
0 / 0 / 10 / 0 \\
0 / 010 / 0 \\
0 / 0 / 0 / 10 \\
0.0\end{array}$ & $\begin{array}{l}4 / 4 / 3 / 4 \\
4 / 4 / 4 / 4 \\
4 / 4 / 4 / 4 \\
\end{array}$ & $\begin{array}{r}0 \\
010 / 0 / 0 \\
0 / 010 / 0 \\
0 / 10 / 0 / 0 \\
\end{array}$ & $\begin{array}{r}4 \\
4 / 4 / 4 / 4 \\
4 / / 4 / 4 / 4 \\
4 / 4 / 4 / 4 \\
\end{array}$ & $\begin{array}{l}4 / 4 / 4 / 4 \\
4 / 4 / 4 / 4 \\
4 / / 4 / 4 / 4 \\
\end{array}$ & $\begin{array}{l}4 / 4 / 4 / 4 \\
4 / 4 / 4 / 4 \\
4 / 4 / 4 / 4 \\
\end{array}$ & 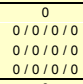 \\
\hline 6 & $\begin{array}{l}\mathrm{j} 0 \\
\mathrm{J1} \\
\mathrm{J} 2 \\
\mathrm{J3} \\
\end{array}$ & $\begin{array}{c}4 / 4 \\
4 / 4 / 4 / 4 \\
4 / 1 / 4 / 4 \\
4 / 4 / 4 / 2\end{array}$ & $\begin{array}{l}4 / 4 / 4 / 4 \\
4 / 4 / 4 / 4 \\
4 / 4 / 4 / 3 \\
\end{array}$ & $\begin{array}{l}0 \\
010 / 0 / 0 \\
0 / 010 / 0 \\
0 / 0 / 0 / 0\end{array}$ & $\begin{array}{c}0 \\
010 / 010 \\
0 / 1 / 0100 \\
0 / 0 / 10 / 0 \\
\end{array}$ & $\begin{array}{c}4 / 4 / 4 / 4 \\
4 / 4 / 4 / 4 \\
4 / 4 / 4 / 3 \\
\end{array}$ & $\begin{array}{c}0 \\
0 / 0 / 10 / 0 \\
0 / 010 / 0 \\
0 / 0 / 0 / 0\end{array}$ & $\begin{array}{l}4 / 4 / 4 / 4 \\
4 / 4 / 4 / 4 \\
4 / / 4 / 4 / 4\end{array}$ & $\begin{array}{l}4 / 4 / 4 / 4 \\
4 / 4 / 4 / 4 / 4 \\
4 / 4 / 4 / 4\end{array}$ & $\begin{array}{c}0 \\
0101010 \\
0 / 101010 \\
0 / 010 / 0 \\
\end{array}$ & $\begin{array}{c}0 \\
010 / 0 / 0 \\
0 / 10 / 0 / 0 \\
0 / 10 / 0 / 0\end{array}$ & $\begin{array}{c}4 / 4 / 4 / 4 \\
4 / 4 / 4 / 4 \\
4 / 4 / 4 / 4\end{array}$ & $\begin{array}{c}0 \\
0 / 0 / 10 \\
0 / 0 / 10 \\
0 / 0 / 0 / 0 \\
0.0\end{array}$ \\
\hline 7 & $\begin{array}{l}\mathrm{J} 0 \\
\mathrm{~J} 1 \\
\mathrm{~J} 2 \\
\mathrm{~J} 3\end{array}$ & $\begin{array}{c}4 \\
4 / 4 / 4 / 4 \\
4 / 4 / 4 / 4 \\
4 / 4 / 4 / 3\end{array}$ & $\begin{array}{c}0 \\
0 / 010 / 0 \\
0 / 10 / 0 / 0 \\
0 / 10 / 0 / 0\end{array}$ & $\begin{array}{c}4 \\
4 / 4 / 4 / 3 \\
4 / 4 / 4 / 2 \\
4 / 4 / 3 / 2\end{array}$ & $\begin{array}{l}4 \\
4 / 4 / 4 / 3 \\
4 / 1 / 4 / 3 \\
3 / 3 / 3 / 3\end{array}$ & $\begin{array}{c}3 \\
3 / 3 / 3 / 3 \\
3 / 3 / 3 / 3 \\
3 / 3 / 2 / 2 / 2\end{array}$ & $\begin{array}{l}0 \\
010 / 0 / 0 \\
0 / 010 / 0 \\
0 / 0 / 0 / 0\end{array}$ & $\begin{array}{c}4 \\
4 / 4 / 4 / 4 \\
4 / 4 / 4 / 4 \\
4 / / 4 / 4 / 4\end{array}$ & $\begin{array}{c}0 \\
0 / 0 / 0 / 0 \\
0 / 10 / 0 \\
0 / 0 / 0 / 0\end{array}$ & $\begin{array}{c}4 \\
4 / 4 / 4 / 4 \\
4 / 1 / 4 / 4 \\
4 / 4 / 4 / 4\end{array}$ & $\begin{array}{c}4 \\
4 / 4 / 4 / 4 \\
4 / / 4 / 4 \\
4 / / 4 / 4 / 4\end{array}$ & $\begin{array}{c}4 \\
4 / 4 / 4 / 4 \\
4 / 4 / 4 / 4 \\
4 / 3 / 4 / 4\end{array}$ & $\begin{array}{l}0 \\
0 / 0 / 0 / 0 \\
0 / 0 / 10 / 0 \\
0 / 0 / 0 / 0\end{array}$ \\
\hline 8 & $\begin{array}{l}\mathrm{J} 0 \\
\mathrm{J1} \\
\mathrm{J} 2 \\
\mathrm{J3} \\
\end{array}$ & $\begin{array}{r}0 \\
0 / 10 / 0 \\
0 / 1 / 100 \\
0 / 0 / 0 / 0 \\
0\end{array}$ & $\begin{array}{r}0 \\
0 / 0 / 0 / 0 \\
0 / 10 / 0 / 0 \\
0 / 1 / 0 / 0 / 0\end{array}$ & $\begin{array}{r}0 \\
010 / 0 / 0 \\
01010 / 0 \\
0 / 0 / 0 / 0 \\
\end{array}$ & $\begin{array}{r}4 / 4 / 4 / 3 \\
3 / 1 / 3 / 3 / 2 \\
3 / 3 / 3 / 2 \\
\end{array}$ & $\begin{array}{r}4 / 3 / 3 / 3 \\
3 / 3 / 3 / 3 \\
3 / 3 / 3 / 3 \\
\end{array}$ & $\begin{array}{l}0 \\
0 / 0 / 10 / 0 \\
0 / 010 / 0 \\
0 / 0 / 0 / 0\end{array}$ & $\begin{array}{r}0 \\
0 / 01010 \\
0101010 \\
0 / 10 / 010 \\
\end{array}$ & $\begin{array}{l}0 \\
010 / 0 / 0 \\
0100 / 0 / 0 \\
0 / 0 / 0 / 0 \\
\end{array}$ & $\begin{array}{r}0 \\
0101010 \\
0101010 \\
0 / 010 / 0 \\
\end{array}$ & $\begin{array}{l}4 / 4 / 4 / 4 \\
4 / 4 / 4 / 4 \\
4 / 4 / 4 / 4 \\
\end{array}$ & $\begin{array}{c}4 / 4 / 4 / 4 \\
4 / 4 / 4 / 4 \\
4 / 4 / 4 / 4 \\
4\end{array}$ & $\begin{array}{l}0 \\
0 / 0 / 10 \\
0 / 0 / 10 / 0 \\
0 / 0 / 0 / 0 \\
0.0\end{array}$ \\
\hline 9 & $\begin{array}{l}\mathrm{J0} \\
\mathrm{J1} \\
\mathrm{J} 2 \\
\mathrm{J3}\end{array}$ & $\begin{array}{c}4 \\
4 / 4 / 4 / 4 \\
4 / 4 / 4 / 3 \\
4 / 4 / 4 / 3\end{array}$ & $\begin{array}{c}4 \\
4 / 4 / 4 / 4 \\
4 / 4 / 4 / 3 \\
4 / 4 / 4 / 3\end{array}$ & $\begin{array}{c}0 \\
0 / 0 / 0 / 0 \\
0 / 10 / 0 / 0 \\
0 / 0 / 0 / 0\end{array}$ & $\begin{array}{c}4 \\
3 / 4 / 3 / 3 \\
3 / 3 / 3 / 2 \\
3 / 3 / 3 / 1\end{array}$ & $\begin{array}{c}4 \\
4 / 4 / 4 / 4 \\
4 / 4 / 4 / 4 \\
4 / 4 / 4 / 4\end{array}$ & $\begin{array}{c}0 \\
010 / 0 / 0 \\
0 / 010 / 0 \\
0 / 0 / 0 / 0\end{array}$ & $\begin{array}{c}4 \\
4 / 4 / 4 / 4 \\
4 / 4 / 4 / 4 \\
4 / 4 / 4 / 4\end{array}$ & $\begin{array}{c}4 \\
4 / 4 / 4 / 4 \\
4 / 4 / 4 / 4 \\
4 / 4 / 4 / 4\end{array}$ & $\begin{array}{c}0 \\
0101010 \\
0 / 1010 / 0 \\
0 / 0 / 0 / 0\end{array}$ & $\begin{array}{c}4 \\
4 / 4 / 4 / 4 \\
4 / 4 / 4 / 4 \\
4 / / 4 / 4 / 4\end{array}$ & $\begin{array}{c}4 \\
4 / 4 / 4 / 4 \\
4 / 4 / 4 / 4 \\
4 / 4 / 4 / 4\end{array}$ & $\begin{array}{r}0 \\
0 / 0 / 10 \\
0 / 0 / 10 \\
0 / 0 / 0 / 0\end{array}$ \\
\hline 10 & $\begin{array}{l}\mathrm{J} 0 \\
\mathrm{J1} \\
\mathrm{J} 2 \\
\mathrm{J3} \\
\end{array}$ & $\begin{array}{r}4 \\
4 / 4 / 4 / 4 \\
4 / 4 / 4 / 4 \\
4 / 4 / 4 / 3 \\
\end{array}$ & $\begin{array}{r}4 \\
4 / 4 / 4 / 4 \\
4 / 4 / 4 / 4 \\
4 / 4 / 4 / 3 \\
\end{array}$ & $\begin{array}{r}0 \\
010 / 0 / 0 \\
01010 / 0 \\
0 / 0 / 0 / 0 \\
\end{array}$ & $\begin{array}{r}0 \\
0101010 \\
0 / 1010100 \\
0 / 0 / 0 / 1 \\
\end{array}$ & $\begin{array}{r}4 \\
4 / 4 / 4 / 4 \\
4 / 4 / 4 / 3 \\
4 / 4 / 4 / 3 \\
\end{array}$ & $\begin{array}{c}0 \\
0 / 0 / 10 / 0 \\
0 / 010 / 0 \\
0 / 0 / 0 / 0\end{array}$ & $\begin{array}{r}4 \\
4 / 4 / 4 / 4 \\
4 / 4 / 4 / 4 \\
4 / 4 / 4 / 4 \\
\end{array}$ & $\begin{array}{r}4 \\
4 / 4 / 4 / 4 \\
4 / 4 / 4 / 4 \\
4 / 4 / 4 / 4 \\
\end{array}$ & $\begin{array}{r}0 \\
0101010 \\
0 / 1010 / 0 \\
0 / 010 / 0 \\
\end{array}$ & $\begin{array}{r}0 \\
0 / 0 / 0 / 0 \\
0 / 10 / 0 / 0 \\
0 / 10 / 0 / 0 \\
\end{array}$ & $\begin{array}{c}4 \\
4 / 4 / 4 / 4 \\
4 / 4 / 4 / 4 \\
4 / 4 / 4 / 4 \\
\end{array}$ & $\begin{array}{c}0 \\
0 / 0 / 10 / 0 \\
010 / 10 / 0 \\
0 / 0 / 0 / 0 \\
0.0\end{array}$ \\
\hline 11 & $\begin{array}{l}\mathrm{J0} \\
\mathrm{J1} \\
\mathrm{J} 2 \\
\mathrm{~J} 3 \\
\end{array}$ & $\begin{array}{r}4 \\
4 / 4 / 4 / 4 \\
4 / / 4 / 4 / 3 \\
4 / 4 / 4 / 3 \\
\end{array}$ & $\begin{array}{r}4 / 4 / 3 \\
4 / 4 / 4 / 3 \\
4 / 4 / 4 / 3 \\
4 / 4 / 4 / 3\end{array}$ & $\begin{array}{r}0 \\
010 / 0 / 0 \\
0 / 10 / 0 \\
0 / 010 / 0 \\
\end{array}$ & $\begin{array}{r}3 \\
3 / 3 / 3 / 2 \\
3 / 3 / 3 / 2 \\
3 / 3 / 3 / 1 \\
\end{array}$ & $\begin{array}{r}4 \\
4 / 4 / 4 / 4 \\
4 / 4 / 4 / 3 \\
4 / 4 / 4 / 3 \\
\end{array}$ & $\begin{array}{l}0 \\
0 / 0 / 10 / 0 \\
0 / 010 / 0 \\
0 / 0 / 0 / 0\end{array}$ & $\begin{array}{c}4 \\
4 / 4 / 4 / 4 \\
4 / 4 / 4 / 4 \\
4 / 4 / 4 / 4 \\
\end{array}$ & $\begin{array}{c}4 \\
4 / 4 / 4 / 4 \\
4 / 4 / 4 / 4 \\
4 / 4 / 4 / 4 \\
\end{array}$ & $\begin{array}{l}0 \\
0101010 \\
0 / 10 / 010 \\
0 / 0 / 0 / 0 \\
\end{array}$ & $\begin{array}{l}4 \\
4 / 4 / 4 / 4 \\
4 / 4 / 4 / 4 \\
4 / 4 / 4 / 4 \\
\end{array}$ & $\begin{array}{l}4 / 4 / 4 / 4 \\
4 / 4 / 4 / 4 \\
4 / 4 / 4 / 4 \\
\end{array}$ & $\begin{array}{l}0,0 / 0 \\
0 / 0 / 10 \\
0 / 0 / 10 / 0 \\
0 / 0 / 0 / 0\end{array}$ \\
\hline 12 & $\begin{array}{l}\mathrm{J} 0 \\
\mathrm{~J} 1 \\
\mathrm{~J} 2 \\
\mathrm{~J} 3 \\
\end{array}$ & $\begin{array}{c}0 \\
0 / 0 / 0 / 0 \\
0 / 0 / 0 / 0 \\
0 / 0 / 0 / 0 \\
\end{array}$ & $\begin{array}{c}0 \\
0 / 0 / 0 / 0 \\
0 / 10 / 0 \\
0 / 0 / 0 / 0 \\
\end{array}$ & $\begin{array}{c}0 \\
0 / 0 / 0 / 0 \\
0 / 0 / 0 / 0 \\
0 / 0 / 0 / 0 \\
\end{array}$ & $\begin{array}{c}4 \\
4 / 4 / 4 / 3 \\
3 / 3 / 3 / 2 \\
3 / 3 / 3 / 2 \\
\end{array}$ & $\begin{array}{c}4 \\
4 / 4 / 4 / 4 \\
4 / 4 / 4 / 3 \\
4 / 4 / 4 / 3 \\
\end{array}$ & $\begin{array}{l}0 \\
0 / 0 / 0 / 0 \\
0 / 010 / 0 \\
0 / 0 / 0 / 0 \\
\end{array}$ & $\begin{array}{c}0 \\
0 / 0 / 0 / 0 \\
0 / 0 / 0 / 0 \\
0 / 0 / 0 / 0 \\
\end{array}$ & $\begin{array}{c}0 \\
0 / 0 / 0 / 0 \\
0 / 0 / 0 / 0 \\
0 / 0 / 0 / 0 \\
\end{array}$ & $\begin{array}{c}0 \\
0 / 0 / 0 / 0 \\
0 / 0 / 0 / 0 \\
0 / 0 / 0 / 0 \\
\end{array}$ & $\begin{array}{c}4 / 4 / 4 \\
4 / 4 / 4 / 4 \\
4 / / 4 / 4 \\
4 / 4 / 4 / 4 \\
\end{array}$ & $\begin{array}{l}/ 4 / 4 / 4 / 4 \\
4 / 4 / 4 / 4 \\
4 / 4 / 4 / 4 \\
4 / 4 / 4 / 4 \\
\end{array}$ & $\begin{array}{l}0,0 / 0 \\
0 / 0 / 0 / 0 \\
0 / 0 / 10 / 0 \\
0 / 0 / 0 / 0 \\
\end{array}$ \\
\hline 13 & $\begin{array}{l}\mathrm{J0} \\
\mathrm{J1} \\
\mathrm{J} 2 \\
\mathrm{J3} \\
\end{array}$ & $\begin{array}{c}4 \\
4 / 4 / 4 / 4 \\
4 / / 4 / 4 / 4 \\
4 / 4 / 4 / 3 \\
\end{array}$ & $\begin{array}{r}0 \\
0 / 10 / 0 \\
0 / 10 / 0 / 0 \\
0 / 0 / 0 / 0 \\
\end{array}$ & $\begin{array}{c}3 \\
3 / 3 / 3 / 2 \\
3 / 3 / 3 / 2 \\
3 / 3 / 3 / 2\end{array}$ & $\begin{array}{r}3 \\
3 / 3 / 3 / 2 \\
3 / 3 / 3 / 2 \\
3 / 3 / 3 / 2 \\
\end{array}$ & $\begin{array}{c}4 \\
3 / 3 / 2 / 2 \\
3 / 3 / 3 / 2 \\
3 / 3 / 3 / 2 \\
\end{array}$ & $\begin{array}{c}0 \\
010 / 0 / 0 \\
0 / 010 / 0 \\
0 / 0 / 0 / 10\end{array}$ & $\begin{array}{c}4 \\
4 / 4 / 4 / 4 \\
4 / 4 / 4 / 4 \\
4 / 4 / 4 / 4 \\
\end{array}$ & $\begin{array}{r}0 \\
010 / 010 \\
0100 / 010 \\
01010 / 10\end{array}$ & $\begin{array}{c}4 \\
4 / 4 / 4 / 4 \\
4 / 4 / 4 / 4 \\
4 / 4 / 4 / 4 \\
\end{array}$ & $\begin{array}{c}4 \\
4 / 4 / 4 / 4 \\
4 / 4 / 4 / 4 \\
4 / 4 / 4 / 4 \\
\end{array}$ & $\begin{array}{c}4 \\
4 / 4 / 4 / 4 \\
4 / 4 / 4 / 4 \\
4 / 4 / 4 / 4\end{array}$ & $\begin{array}{rl}0 & 0 / 0 \\
0 / 0 / 1 / 0 \\
0 / 0 / 1 / 0 \\
0 / 0 / 0 / 0\end{array}$ \\
\hline 14 & $\begin{array}{l}\mathrm{J} 0 \\
\mathrm{J1} \\
\mathrm{J} 2 \\
\mathrm{J3} \\
\end{array}$ & $\begin{array}{c}0 \\
0 / 0 / 0 / 0 \\
010 / 0 / 0 \\
0 / 0 / 0 / 0 \\
\end{array}$ & $\begin{array}{r}0 \\
0 / 0 / 0 / 0 \\
0 / 0 / 0 \\
0 / 0 / 0 / 0 \\
\end{array}$ & $\begin{array}{c}0 \\
0 / 0 / 0 / 0 \\
0 / 0 / 0 / 0 \\
0 / 0 / 0 / 0 \\
\end{array}$ & $\begin{array}{c}4 \\
4 / 4 / 4 / 3 \\
4 / 4 / 4 / 3 \\
3 / 4 / 3 / 2 \\
\end{array}$ & $\begin{array}{c}4 \\
4 / 4 / 4 / 3 \\
4 / 4 / 4 / 3 \\
3 / 4 / 4 / 3 \\
\end{array}$ & $\begin{array}{l}2 \\
2 / 2 / 2 / 2 \\
2 / 2 / 2 / 1 \\
2 / 2 / 2 / 1 \\
\end{array}$ & $\begin{array}{r}0 \\
0 / 0 / 0 / 0 \\
0 / 0 / 0 / 0 \\
0 / 0 / 0 / 0\end{array}$ & $\begin{array}{c}0 \\
0 / 0 / 0 / 0 \\
0 / 0 / 0 / 0 \\
0 / 0 / 0 / 0\end{array}$ & $\begin{array}{l}0 \\
0 / 0 / 0 / 0 \\
0 / 10 / 0 \\
0 / 0 / 0 / 0 \\
\end{array}$ & $\begin{array}{c}4 \\
4 / 4 / 4 / 4 \\
4 / 4 / 4 / 4 \\
4 / 4 / 4 / 4 \\
\end{array}$ & $\begin{array}{l}4 / 4 / 4 / 4 / 4 \\
4 / 4 / 4 / 4 \\
4 / 4 / 4 / 4 \\
\end{array}$ & $\begin{array}{l}4 / 4 / 4 \\
4 / 4 / 4 / 4 \\
4 / 4 / 4 / 4 \\
4 / 4 / 4 / 4 \\
\end{array}$ \\
\hline 15 & $\begin{array}{l}\mathrm{J} 0 \\
\mathrm{J1} \\
\mathrm{J} 2 \\
\mathrm{~J} 3 \\
\end{array}$ & $\begin{array}{r}4 \\
4 / 4 / 4 / 3 \\
3 / 3 / 3 / 32 \\
3 / 3 / 3 / 2 \\
\end{array}$ & $\begin{array}{r}4 \\
4 / 4 / 4 / 4 \\
4 / 4 / 4 / 4 \\
4 / / / 4 / 3 \\
\end{array}$ & $\begin{array}{r}0 \\
010 / 0 / 0 \\
0 / 0,0 / 0 \\
0 / 0 / 0 / 0 \\
\end{array}$ & $\begin{array}{r}3 \\
3 / 3 / 3 / 2 \\
3 / 3 / 3 / 3 / 2 \\
3 / 3 / 3 / 2 \\
\end{array}$ & $\begin{array}{r}4 \\
4 / 4 / 4 / 4 \\
4 / 4 / 4 / 4 \\
4 / 4 / 4 / 3 \\
\end{array}$ & $\begin{array}{l}0 \\
0 / 0 / 0 / 0 \\
0 / 0 / 0 / 0 \\
0 / 0 / 0 / 0 \\
0.010\end{array}$ & $\begin{array}{c}4 \\
4 / 4 / 4 / 4 \\
4 / 4 / 4 / 4 \\
4 / 4 / 4 / 4 \\
\end{array}$ & $\begin{array}{c}4 / 4 / 4 / 4 \\
4 / 4 / 4 / 4 \\
4 / 4 / 4 / 4 \\
\end{array}$ & $\begin{array}{r}0 \\
0101010 \\
0 / 1 / 01010 \\
0 / 0 / 010 \\
\end{array}$ & $\begin{array}{r}4 / 4 / 4 / 4 \\
4 / / 4 / 4 / 4 \\
4 / 4 / 4 / 4 \\
\end{array}$ & $\begin{array}{l}4 / 4 / 4 / 4 \\
4 / 4 / 4 / 4 \\
4 / 4 / 4 / 4 \\
\end{array}$ & $\begin{array}{rl}0 & 0 / 0 \\
0 / 0 / 1 / 0 \\
0 / 0 / 1 / 0 \\
0 / 0 / 0 / 0\end{array}$ \\
\hline 16 & $\begin{array}{l}\mathrm{J0} \\
\mathrm{J1} \\
\mathrm{J} 2 \\
\mathrm{~J} 3 \\
\end{array}$ & $\begin{array}{c}4 \\
4 / 4 / 4 / 4 \\
4 / / 4 / 4 / 4 \\
4 / 4 / 4 / 3 \\
\end{array}$ & $\begin{array}{r}0 \\
01010 / 0 \\
0 / 1010 / 0 \\
0 / 1010 / 0\end{array}$ & $\begin{array}{c}44 / 4 / 3 \\
4 / 4 / 4 / 3 \\
4 / 4 / 2 / 2 \\
3 / 3 / 3 / 2\end{array}$ & $\begin{array}{r}4 \\
4 / 4 / 3 / 3 \\
4 / 4 / 4 / 3 \\
4 / 4 / 3 / 2 \\
\end{array}$ & $\begin{array}{c}3 \\
3 / 3 / 3 / 2 \\
4 / 4 / 4 / 3 \\
3 / 3 / 3 / 2 \\
\end{array}$ & $\begin{array}{l}0 \\
0 / 0 / 10 / 0 \\
0 / 010 / 0 \\
0 / 0 / 0 / 0\end{array}$ & $\begin{array}{c}4 \\
4 / 4 / 4 / 4 \\
4 / 4 / 4 / 4 \\
4 / 4 / 4 / 4\end{array}$ & $\begin{array}{c}0 \\
010 / 010 \\
01010 / 0 \\
01010 / 0\end{array}$ & $\begin{array}{c}4 \\
4 / 4 / 4 / 4 \\
4 / / 4 / 4 / 4 \\
4 / 4 / 4 / 4\end{array}$ & $\begin{array}{c}4 \\
4 / 4 / 4 / 4 \\
4 / 4 / 4 / 4 \\
4 / 4 / 4 / 4\end{array}$ & $\begin{array}{c}4 / 4 / 4 / 4 \\
4 / 4 / 4 / 4 \\
4 / 4 / 4 / 4 \\
\end{array}$ & $\begin{array}{l}0 \\
0,0 / 10 \\
0 / 0 / 10 / 0 \\
0 / 0 / 0 / 0 \\
\end{array}$ \\
\hline 17 & $\begin{array}{l}\mathrm{J0} \\
\mathrm{J1} \\
\mathrm{J} 2 \\
\mathrm{J3} \\
\end{array}$ & $\begin{array}{r}4 \\
4 / 4 / 4 / 4 \\
4 / / 4 / 4 / 4 \\
4 / 4 / 4 / 3 \\
\end{array}$ & $\begin{array}{r}4 \\
4 / 4 / 4 / 4 \\
4 / 4 / 4 / 4 \\
4 / 4 / 4 / 4\end{array}$ & $\begin{array}{l}0 \\
010 / 0 \\
0 / 0 / 0 / 0 \\
0 / 10 / 0 / 0\end{array}$ & $\begin{array}{r}0 \\
0101010 \\
01 / 101010 \\
0 / 01010 \\
\end{array}$ & $\begin{array}{r}4 \\
4 / 4 / 4 / 4 \\
4 / 4 / 4 / 4 \\
4 / 4 / 4 / 3 \\
\end{array}$ & $\begin{array}{r}0 \\
0 / 0 / 0 / 0 \\
0 / 010 / 0 \\
0 / 0 / 0 / 0\end{array}$ & $\begin{array}{r}4 \\
4 / 4 / 4 / 3 \\
4 / 4 / 4 / 4 \\
4 / 4 / 4 / 4\end{array}$ & $\begin{array}{c}4 / 4 / 4 \\
4 / 4 / 4 / 4 \\
4 / 4 / 4 / 4 \\
4 / 4 / 4 / 4\end{array}$ & $\begin{array}{r}0 \\
0 / 1010 \\
0,1 / 1010 \\
0 / 010 / 0 \\
\end{array}$ & $\begin{array}{r}0 \\
0 / 010 / 0 \\
0 / 10 / 0 / 0 \\
0 / 1 / 0 / 0 \\
\end{array}$ & $\begin{array}{r}4 / 4 / 4 \\
4 / 4 / 4 / 4 \\
4 / 4 / 4 / 4 / 4 \\
4 / 4 / 4 / 4\end{array}$ & $\begin{array}{l}0 \\
0 / 0 / 0 \\
0 / 0 / 10 / 0 \\
0 / 0 / 0 / 0 \\
\end{array}$ \\
\hline 18 & $\begin{array}{l}\text { J0 } \\
\mathrm{J1} \\
\mathrm{J} 2 \\
\mathrm{J3} \\
\end{array}$ & $\begin{array}{r}4 \\
4 / 4 / 4 / 4 \\
4 / / / 4 / 4 \\
4 / 4 / 4 / 2 \\
\end{array}$ & $\begin{array}{r}4 / 4 / 4 \\
4 / 4 / 4 / 4 \\
4 / 4 / 4 / 3 \\
4 / 4 / 4 / 2 \\
\end{array}$ & $\begin{array}{r}0 \\
010 / 010 \\
01010 / 0 \\
0 / 010 / 10 \\
\end{array}$ & $\begin{array}{r}4 \\
4 / 3 / 3 / 2 \\
3 / 3 / 3 / 2 / 2 \\
2 / 2 / 2 / 1 \\
\end{array}$ & $\begin{array}{r}4 \\
4 / 4 / 4 / 3 \\
4 / 4 / 4 / 3 \\
4 / 4 / 4 / 2 \\
\end{array}$ & $\begin{array}{c}0 \\
0 / 0 / 0 / 0 \\
0 / 010 / 0 \\
0 / 0 / 0 / 0 \\
0.010\end{array}$ & $\begin{array}{c}4 \\
4 / 4 / 4 / 4 \\
4 / 4 / 4 / 4 \\
4 / 4 / 4 / 4 \\
\end{array}$ & $\begin{array}{c}4 \\
4 / 4 / 4 / 4 \\
4 / 4 / 4 / 4 \\
4 / 4 / 4 / 4 \\
\end{array}$ & $\begin{array}{r}0 \\
0 / 10 / 010 \\
0 / 10 / 010 \\
0 / 0 / 010 \\
\end{array}$ & $\begin{array}{c}4 \\
4 / 4 / 4 / 4 \\
4 / 4 / 4 / 4 \\
4 / 4 / 4 / 4 \\
\end{array}$ & $\begin{array}{c}4 \\
4 / 4 / 4 / 4 \\
4 / 4 / 4 / 4 \\
4 / 4 / 4 / 4 \\
\end{array}$ & $\begin{array}{r}0 \\
0 / 0 / 10 \\
0 / 0 / 10 \\
0 / 0 / 0 / 0 \\
0\end{array}$ \\
\hline 19 & $\begin{array}{l}\mathrm{j} 0 \\
\mathrm{J1} \\
\mathrm{J} 2 \\
\mathrm{J3}\end{array}$ & $\begin{array}{l}4 / 4 / 4 / 4 \\
4 / 1 / 4 / 43 \\
4 / 3 / 3 / 2\end{array}$ & $\begin{array}{l}4 / 4 / 4 / 4 \\
4 / 4 / 4 / 4 \\
4 / 3 / 3 / 3 / 3\end{array}$ & $\begin{array}{l}0 \\
010 / 0 / 0 \\
01010 / 0 \\
010 / 0 / 0\end{array}$ & $\begin{array}{l}4 / 4 / 4 / 3 \\
3 / 1 / 3 / 3 / 2 \\
3 / 3 / 2 / 1\end{array}$ & $\begin{array}{c}4 / 4 / 4 \\
4 / 4 / 4 / 4 \\
4 / 4 / 4 / 4 \\
4 / / 4 / 4 / 3\end{array}$ & $\begin{array}{l}0 / 0 / 0 \\
010 / 10 \\
0 / 010 / 0 \\
0 / 0 / 0 / 0\end{array}$ & $\begin{array}{l}4 / 4 / 4 / 4 \\
4 / 4 / 4 / 4 \\
4 / 4 / 4 / 4 \\
4\end{array}$ & $\begin{array}{l}4 / 4 / 4 / 4 \\
4 / 4 / 4 / 4 \\
4 / 4 / 4 / 4\end{array}$ & $\begin{array}{r}0 \\
0101010 \\
0 / 101010 \\
0 / 10 / 1010\end{array}$ & $\begin{array}{l}4 / 4 / 4 / 4 \\
4 / 4 / 4 / 4 \\
4 / 4 / 4 / 4 \\
4 / 4 / 4 / 4\end{array}$ & $\begin{array}{l}4 / 4 / 4 / 4 \\
4 / 4 / 4 / 4 \\
4 / 4 / 4 / 4\end{array}$ & $\begin{array}{l}0 / 0 / 0 \\
0 / 0 / 10 \\
0 / 0 / 10 / 0 \\
0 / 0 / 0 / 0\end{array}$ \\
\hline 20 & $\begin{array}{l}\mathrm{J0} \\
\mathrm{J1} \\
\mathrm{J} 2 \\
\mathrm{~J} 3\end{array}$ & $\begin{array}{c}4 \\
3 / 3 / 3 / 3 \\
4 / 4 / 4 / 3 \\
4 / 3 / 3 / 3 / 2\end{array}$ & $\begin{array}{c}4 \\
4 / 4 / 4 / 4 \\
4 / 4 / 4 / 4 \\
4 / / 4 / 4 / 3\end{array}$ & $\begin{array}{c}0 \\
0 / 0 / 0 / 0 \\
0 / 010 / 0 \\
0 / 1 / 0 / 0\end{array}$ & $\begin{array}{c}4 \\
3 / 3 / 3 / 3 \\
3 / 3 / 3 / 2 \\
3 / 3 / 2 / 2 / 1\end{array}$ & $\begin{array}{c}4 \\
4 / 4 / 4 / 4 \\
4 / 4 / 4 / 3 \\
4 / / / 3 / 3\end{array}$ & $\begin{array}{c}3 \\
2 / 2 / 2 / 2 \\
2 / 2 / 2 / 1 \\
2 / 2 / 2 / 1\end{array}$ & $\begin{array}{c}4 \\
4 / 4 / 4 / 4 \\
4 / / 4 / 4 / 4 \\
4 / / 4 / 4 / 4\end{array}$ & $\begin{array}{c}4 \\
4 / 4 / 4 / 4 \\
4 / 4 / 4 / 4 \\
4 / / 4 / 4 / 4\end{array}$ & $\begin{array}{c}0 \\
0 / 0 / 0 / 0 \\
0 / 10 / 0 / 0 \\
0 / 0 / 0 / 0\end{array}$ & $\begin{array}{c}4 \\
4 / 4 / 4 / 4 \\
4 / / 4 / 4 \\
4 / / / 4 / 4\end{array}$ & $\begin{array}{c}4 / 4 / 4 / 4 \\
4 / 4 / 4 / 4 \\
4 / 4 / 4 / 4\end{array}$ & $\begin{array}{c}4 / 4 / 4 / 4 \\
3 / 4 / 4 / 4 \\
4 / 4 / 4 / 4\end{array}$ \\
\hline 21 & $\begin{array}{l}\mathrm{J0} \\
\mathrm{J} 1 \\
\mathrm{~J} 2 \\
\mathrm{J3} \\
\end{array}$ & $\begin{array}{c}4 \\
4 / 4 / 4 / 4 \\
4 / 4 / 4 / 4 \\
4 / 4 / 4 / 3 \\
\end{array}$ & $\begin{array}{c}4 \\
4 / 4 / 4 / 4 \\
4 / 4 / 4 / 4 \\
4 / 4 / 4 / 3 \\
\end{array}$ & $\begin{array}{c}0 \\
0 / 0 / 0 / 0 \\
0 / 0 / 0 / 0 \\
0 / 0 / 0 / 0 \\
\end{array}$ & $\begin{array}{c}0 \\
0 / 0 / 0 / 0 \\
0 / 10 / 0 \\
0 / 0 / 0 / 0 \\
\end{array}$ & $\begin{array}{c}4 \\
4 / 4 / 4 / 4 \\
4 / 4 / 4 / 3 \\
4 / 4 / 4 / 2 \\
\end{array}$ & $\begin{array}{l}0 \\
0 / 0 / 10 / 0 \\
0 / 010 / 0 \\
0 / 0 / 0 / 0 \\
\end{array}$ & $\begin{array}{c}4 \\
4 / 4 / 4 / 4 \\
4 / 4 / 4 / 4 \\
4 / 4 / 4 / 4 \\
\end{array}$ & $\begin{array}{c}4 \\
4 / 4 / 4 / 4 \\
4 / 4 / 4 / 4 \\
4 / 4 / 4 / 4 \\
\end{array}$ & $\begin{array}{c}0 \\
0 / 0 / 0 / 0 \\
0 / 0 / 0 / 0 \\
0 / 0 / 0 / 0 \\
\end{array}$ & $\begin{array}{l}4 / 4 / 4 / 4 \\
0 / 0 / 0 / 0 \\
0 / 0 / 0 / 0 \\
0 / 0 / 0 / 0 \\
\end{array}$ & $\begin{array}{l}4 / 4 / 4 / 4 \\
4 / 4 / 4 \\
4 / 4 / 4 / 4 \\
4 / 4 / 4 / 4 \\
4 / 4 / 4 / 4 \\
\end{array}$ & $\begin{array}{l}4 / 4 / 4 / 4 \\
0 / 0 / 10 \\
0 / 0 / 10 \\
0 / 0 / 0 / 0 \\
\end{array}$ \\
\hline 22 & $\begin{array}{l}\mathrm{J} 0 \\
\mathrm{~J} 1 \\
\mathrm{~J} 2 \\
\mathrm{J3}\end{array}$ & $\begin{array}{c}4 \\
4 / 4 / 4 / 3 \\
4 / 4 / 4 / 3 \\
4 / 4 / 4 / 3\end{array}$ & $\begin{array}{c}4 / 4 / 4 \\
4 / 4 / 4 / 4 \\
4 / 4 / 4 / 3 \\
4 / 4 / 4 / 2\end{array}$ & $\begin{array}{c}0 \\
0 / 0 / 0 / 0 \\
0 / 010 / 0 \\
0 / 0 / 0 / 0\end{array}$ & $\begin{array}{c}4 \\
4 / 3 / 3 / 2 \\
3 / 3 / 3 / 2 \\
2 / 3 / 2 / 1 / 1\end{array}$ & $\begin{array}{c}4 \\
4 / 4 / 4 / 4 \\
4 / 4 / 4 / 4 \\
4 / 4 / 4 / 3\end{array}$ & $\begin{array}{c}0 \\
0 / 0 / 10 / 0 \\
0 / 010 / 0 \\
0 / 0 / 0 / 0\end{array}$ & $\begin{array}{c}4 \\
4 / 4 / 4 / 4 \\
4 / 4 / 4 / 4 \\
4 / 4 / 4 / 4\end{array}$ & $\begin{array}{c}4 \\
4 / 4 / 4 / 4 \\
4 / 4 / 4 / 4 \\
4 / 4 / 4 / 4\end{array}$ & $\begin{array}{c}0 \\
0 / 01010 \\
0 / 10 / 010 \\
0 / 0 / 0 / 0\end{array}$ & $\begin{array}{c}4 \\
4 / 4 / 4 / 4 \\
4 / / 4 / 4 \\
4 / / 4 / 4 / 4\end{array}$ & $\begin{array}{c}4 \\
4 / 4 / 4 / 4 \\
4 / 4 / 4 / 4 \\
4 / 4 / 4 / 4\end{array}$ & $\begin{array}{l}0 \\
0 / 0 / 10 \\
0 / 0 / 10 \\
0 / 0 / 0 / 0\end{array}$ \\
\hline 23 & $\begin{array}{l}\mathrm{J0} \\
\mathrm{J1} \\
\mathrm{J} 2 \\
\mathrm{J3} \\
\end{array}$ & $\begin{array}{c}4 \\
4 / 4 / 4 / 4 \\
4 / 4 / 4 / 43 \\
4 / 4 / 4 / 3 \\
\end{array}$ & $\begin{array}{c}4 \\
3 / 3 / 3 / 3 \\
3 / 3 / 3 / 2 \\
3 / 3 / 3 / 2 \\
\end{array}$ & $\begin{array}{c}0 \\
0 / 0 / 0 / 0 \\
0 / 0 / 0 / 0 \\
0 / 0 / 0 / 0 \\
\end{array}$ & $\begin{array}{c}4 \\
4 / 4 / 4 / 3 \\
3 / 3 / 3 / 2 \\
3 / 3 / 3 / 2 \\
\end{array}$ & $\begin{array}{c}4 \\
4 / 4 / 4 / 4 \\
3 / 3 / 3 / 2 \\
3 / 3 / 3 / 2 \\
\end{array}$ & $\begin{array}{l}0 \\
0 / 0 / 10 \\
0 / 010 / 0 \\
0 / 0 / 0 / 0 \\
\end{array}$ & $\begin{array}{c}4 \\
4 / 4 / 4 / 4 \\
4 / 4 / 4 / 4 \\
4 / 4 / 4 / 4 \\
\end{array}$ & $\begin{array}{c}4 \\
4 / 4 / 4 / 4 \\
4 / 4 / 4 / 4 \\
4 / 4 / 4 / 4 \\
\end{array}$ & $\begin{array}{r}0 \\
0 / 0 / 0 / 0 \\
0 / 010 / 0 \\
0 / 0 / 0 / 0 \\
\end{array}$ & $\begin{array}{l}4 / 4 / 4 / 4 \\
4 / / / 4 / 4 \\
4 / / 4 / 4 / 4 \\
4 / 4 / 4 / 4 \\
\end{array}$ & $\begin{array}{l}4 / 4 / 4 / 4 \\
4 / 4 / 4 / 4 \\
4 / 4 / 4 / 4 \\
4 / 4 / 4 / 4 \\
\end{array}$ & $\begin{array}{l}0 / 0 / 0 \\
0 / 0 / 10 \\
0 / 0 / 10 \\
0 / 0 / 0 / 0 \\
\end{array}$ \\
\hline 24 & $\begin{array}{l}\mathrm{J0} \\
\mathrm{J1} \\
\mathrm{J} 2 \\
\mathrm{J3}\end{array}$ & $\begin{array}{c}0 \\
0101010 \\
0 / 101010 \\
0 / 010 / 0\end{array}$ & $\begin{array}{c}0 \\
0 / 0 / 0 / 0 \\
0 / 10 / 0 / 0 \\
0 / 0 / 0 / 0\end{array}$ & $\begin{array}{c}0 \\
0 / 0 / 0 / 0 \\
0 / 10 / 010 \\
0 / 0 / 0 / 0\end{array}$ & $\begin{array}{c}4 \\
4 / 4 / 4 / 4 \\
4 / 4 / 3 / 2 \\
4 / 4 / 4 / 3\end{array}$ & $\begin{array}{c}4 \\
4 / 4 / 4 / 4 \\
4 / 3 / 3 / 2 \\
4 / 4 / 4 / 3\end{array}$ & $\begin{array}{c}0 \\
010 / 10 \\
0 / 010 / 0 \\
0 / 0 / 0 / 0\end{array}$ & $\begin{array}{c}0 \\
01010 / 0 \\
01010 / 0 \\
0 / 10 / 0 / 0\end{array}$ & $\begin{array}{c}0 \\
0 / 0 / 0 / 0 \\
0 / 10 / 0 \\
0 / 10 / 0 / 0\end{array}$ & $\begin{array}{c}0 \\
0101010 \\
0 / 1010 / 0 \\
0 / 0 / 0 / 0\end{array}$ & $\begin{array}{c}4 \\
4 / 4 / 4 / 4 \\
4 / 4 / 4 / 4 \\
4 / / 4 / 4 / 4\end{array}$ & $\begin{array}{c}4 \\
4 / 4 / 4 / 4 \\
4 / 4 / 4 / 4 \\
4 / 4 / 4 / 4\end{array}$ & $\begin{array}{r}0 \\
0 / 0 / 10 \\
0 / 0 / 10 \\
0 / 0 / 0 / 0 \\
0 / 0,0\end{array}$ \\
\hline 25 & 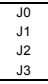 & $\begin{array}{r}4 \\
4 / 4 / 4 / 4 \\
4 / 4 / 4 / 4 \\
4 / 4 / 4 / 2 \\
\end{array}$ & $\begin{array}{r}4 \\
4 / 4 / 4 / 4 \\
4 / 4 / 4 / 4 \\
4 / 4 / 4 / 3 \\
\end{array}$ & $\begin{array}{r}0 \\
010 / 0 / 0 \\
0 / 010 / 0 \\
0 / 0 / 0 / 0 \\
\end{array}$ & $\begin{array}{r}0 \\
0101010 \\
0 / 101010 \\
0 / 01010 \\
\end{array}$ & $\begin{array}{r}4 \\
4 / 4 / 4 / 4 \\
4 / 4 / 4 / 3 \\
4 / 4 / 4 / 3 \\
\end{array}$ & $\begin{array}{c}3 \\
2 / 2 / 2 / 1 \\
2 / 2 / 2 / 1 \\
2 / 2 / 2 / 1 \\
2\end{array}$ & $\begin{array}{r}4 / 4 / 4 / 4 \\
4 / 4 / 4 / 4 \\
4 / 4 / 4 / 4 \\
\end{array}$ & $\begin{array}{r}4 \\
4 / 4 / 4 / 4 \\
4 / 4 / 4 / 4 \\
4 / 4 / 4 / 4 \\
\end{array}$ & $\begin{array}{r}0 \\
0101010 \\
0 / 101010 \\
0 / 010 / 0 \\
\end{array}$ & $\begin{array}{r}0 \\
0 / 0 / 0 / 0 \\
0 / 10 / 0 / 0 \\
0 / 10 / 0 / 0 \\
\end{array}$ & $\begin{array}{c}4 \\
4 / 4 / 4 / 4 \\
4 / 4 / 4 / 4 \\
4 / 4 / 4 / 4 \\
\end{array}$ & $\begin{array}{c}4 \\
4 / 4 / 4 / 4 \\
4 / 4 / 4 / 4 \\
4 / 4 / 4 / 4 \\
\end{array}$ \\
\hline 26 & $\begin{array}{l}J_{0} \\
J_{1} \\
J_{3} \\
\end{array}$ & $\begin{array}{l}4 \\
4 / 4 / 4 / 4 \\
4 / / 4 / 4 / 4 \\
4 / 4 / 4 / 3 \\
\end{array}$ & $\begin{array}{r}0 \\
0 / 010 / 0 \\
0 / 10 / 0 / 0 \\
0 / 1 / 0 / 0 / 0\end{array}$ & $\begin{array}{l}4 / 4 / 4 / 4 \\
4 / 4 / 4 / 3 \\
4 / 3 / 3 / 2 \\
\end{array}$ & $\begin{array}{r}4 \\
4 / 4 / 4 / 4 \\
3 / 3 / 4 / 3 \\
3 / 3 / 3 / 3 \\
\end{array}$ & $\begin{array}{r}0 \\
0101010 \\
0 / 1010 / 0 \\
0 / 10 / 010 \\
\end{array}$ & $\begin{array}{l}0 \\
0 / 0 / 10 / 0 \\
0 / 010 / 0 \\
0 / 0 / 0 / 10\end{array}$ & $\begin{array}{l}4 / 4 / 4 / 4 \\
4 / 4 / 4 / 4 \\
4 / 4 / 4 / 4 \\
\end{array}$ & $\begin{array}{l}0 \\
010 / 0 / 0 \\
01010 / 0 \\
0 / 10 / 0 / 0 \\
\end{array}$ & $\begin{array}{r}4 \\
4 / 4 / 3 / 4 \\
4 / 4 / 4 / 4 \\
4 / 4 / 4 / 4 \\
\end{array}$ & $\begin{array}{l}4 / 4 / 4 / 4 \\
4 / 4 / 4 / 4 \\
4 / / 4 / 4 / 4 \\
\end{array}$ & $\begin{array}{l}0 \\
010 / 0 / 0 \\
0 / 010 / 0 \\
0 / 0 / 0 / 1\end{array}$ & 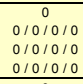 \\
\hline 27 & $\begin{array}{l}\mathrm{J} 0 \\
\mathrm{J1} \\
\mathrm{J} 2 \\
\mathrm{J3} \\
\end{array}$ & \begin{tabular}{|c|}
$4 / 4 / 4 / 4$ \\
$3 / 3 / 3 / 3$ \\
$3 / 3 / 3 / 3$ \\
\end{tabular} & $\begin{array}{c}4 / 4 / 4 / 4 \\
4 / 4 / 4 / 4 \\
4 / 4 / 4 / 3\end{array}$ & $\begin{array}{c}0 \\
010 / 0 / 0 \\
0 / 010 / 0 \\
0 / 0 / 0 / 0\end{array}$ & $\begin{array}{r}4 \\
3 / 3 / 3 / 3 \\
3 / 2 / 2 / 2 \\
3 / 3 / 3 / 2 \\
\end{array}$ & $\begin{array}{c}4 / 4 / 3 / 3 \\
4 / 4 / 3 / 2 \\
3 / 3 / 3 / 3 \\
\end{array}$ & $\begin{array}{c}0 \\
0 / 0 / 0 / 0 \\
0 / 010 / 0 \\
0 / 0 / 0 / 10\end{array}$ & $\begin{array}{c}4 / 4 / 4 / 4 \\
4 / 4 / 4 / 4 \\
4 / 4 / 4 / 4\end{array}$ & $\begin{array}{l}4 / 4 / 4 / 4 \\
4 / 4 / 4 / 4 \\
4 / 4 / 4 / 4\end{array}$ & $\begin{array}{c}0 \\
0101010 \\
01010100 \\
0 / 01010\end{array}$ & $\begin{array}{c}4 / 4 / 4 / 4 \\
4 / 4 / 4 / 4 \\
4 / 4 / 4 / 4\end{array}$ & $\begin{array}{c}4 / 4 / 4 / 4 \\
4 / 4 / 4 / 4 \\
4 / 4 / 4 / 4 \\
\end{array}$ & $\begin{array}{l}0 \\
0 / 0 / 10 \\
0 / 0 / 10 / 0 \\
0 / 0 / 0 / 0\end{array}$ \\
\hline 28 & $\begin{array}{l}\mathrm{J0} \\
\mathrm{J1} \\
\mathrm{J} 2 \\
\mathrm{~J} 3 \\
\end{array}$ & $\begin{array}{r}4 \\
4 / 4 / 4 / 4 \\
4 / / 4 / 4 / 4 \\
4 / 4 / 4 / 2 \\
\end{array}$ & $\begin{array}{r}4 \\
4 / 4 / 4 / 4 \\
4 / 4 / 4 / 4 \\
4 / 4 / 4 / 3 \\
\end{array}$ & $\begin{array}{r}0 \\
010 / 0 / 0 \\
0 / 010 / 0 \\
0 / 0 / 0 / 0 \\
\end{array}$ & $\begin{array}{r}0 \\
0 / 10 / 010 \\
0 / 101010 \\
0 / 01010 \\
\end{array}$ & $\begin{array}{r}4 \\
4 / 4 / 4 / 3 \\
4 / 4 / 4 / 3 \\
3 / 3 / 3 / 2 \\
\end{array}$ & $\begin{array}{r}0 \\
0 / 0 / 0 / 0 \\
0 / 010 / 0 \\
0 / 0 / 0 / 10\end{array}$ & $\begin{array}{r}4 \\
4 / 4 / 4 / 4 \\
4 / 4 / 4 / 4 \\
4 / 4 / 4 / 4 \\
\end{array}$ & $\begin{array}{r}4 / 4 / 4 / 4 \\
4 / 4 / 4 / 4 \\
4 / 4 / 4 / 4 \\
\end{array}$ & $\begin{array}{r}0 \\
0101010 \\
01 / 101010 \\
0 / 010 / 0 \\
\end{array}$ & $\begin{array}{r}0 \\
01010 / 0 \\
01010 / 0 \\
0 / 10 / 0 / 0 \\
\end{array}$ & $\begin{array}{c}4 / 4 / 4 / 4 \\
4 / 4 / 4 / 4 \\
4 / 4 / 4 / 4 \\
\end{array}$ & $\begin{array}{l}0 \\
0 / 0 / 10 \\
0 / 0 / 10 / 0 \\
0 / 0 / 0 / 0 \\
0.0\end{array}$ \\
\hline 29 & $\begin{array}{l}\mathrm{J0} \\
\mathrm{J1} \\
\mathrm{J} 2 \\
\mathrm{~J} 3 \\
\end{array}$ & $\begin{array}{r}4 \\
4 / 4 / 4 / 4 \\
4 / / / 4 / 4 \\
4 / 4 / 4 / 3 \\
\end{array}$ & $\begin{array}{r}0 \\
0101010 \\
0 / 1010 / 0 \\
0 / 10 / 0 / 0 \\
\end{array}$ & $\begin{array}{r}3 \\
3 / 3 / 3 / 3 \\
3 / 3 / 3 / 2 \\
3 / 3 / 3 / 2 \\
\end{array}$ & $\begin{array}{r}3 \\
3 / 3 / 3 / 3 \\
4 / 3 / 3 / 3 \\
3 / 3 / 3 / 2 \\
\end{array}$ & $\begin{array}{r}0 \\
0 / 010 / 0 \\
0 / 1010 / 0 \\
0 / 10 / 0 / 0 \\
\end{array}$ & $\begin{array}{l}0 \\
0 / 0 / 0 / 0 \\
0 / 010 / 0 \\
0 / 0 / 0 / 10\end{array}$ & $\begin{array}{r}4 \\
4 / 4 / 4 / 4 \\
4 / / 4 / 4 / 4 \\
4 / 4 / 4 / 4 \\
\end{array}$ & $\begin{array}{r}0 \\
01010 / 0 \\
0 / 10 / 0 / 0 \\
0 / 10 / 0 / 0 \\
\end{array}$ & $\begin{array}{r}4 \\
4 / 4 / 4 / 4 \\
4 / / / 4 / 4 \\
4 / 4 / 4 / 4 \\
\end{array}$ & $\begin{array}{r}4 \\
4 / 4 / 4 / 4 \\
4 / 4 / 4 / 4 \\
4 / / 4 / 4 / 4 \\
\end{array}$ & $\begin{array}{l}0 \\
0 / 0 / 0 / 0 \\
0 / 010 / 0 \\
0 / 0 / 0 / 11\end{array}$ & $\begin{array}{l}0 \\
0 / 0 / 10 \\
0 / 0 / 1 / 0 \\
0 / 0 / 0 / 0 \\
0\end{array}$ \\
\hline 30 & $\begin{array}{l}\mathrm{J} 0 \\
\mathrm{~J} 1 \\
\mathrm{~J} 2 \\
\mathrm{~J} 3 \\
\end{array}$ & $\begin{array}{c}4 \\
4 / 4 / 4 / 4 \\
4 / 4 / 4 / 3 \\
4 / 4 / 4 / 3 \\
\end{array}$ & $\begin{array}{c}4 \\
4 / 3 / 3 / 3 \\
4 / 3 / 3 / 3 \\
4 / 3 / 3 / 3 \\
\end{array}$ & $\begin{array}{c}0 \\
0 / 0 / 0 / 0 \\
0 / 0 / 0 / 0 \\
0 / 0 / 0 / 0 \\
\end{array}$ & $\begin{array}{c}3 \\
3 / 2 / 2 / 2 \\
3 / 2 / 2 / 2 / 2 \\
3 / 2 / 2 / 1 \\
\end{array}$ & $\begin{array}{c}3 \\
3 / 3 / 3 / 2 \\
3 / 3 / 3 / 2 \\
3 / 3 / 3 / 2 \\
\end{array}$ & $\begin{array}{c}0 \\
010 / 10 \\
0 / 0 / 0 / 0 \\
0 / 0 / 0 / 0 \\
0 / 0\end{array}$ & $\begin{array}{l}4 / 4 / 3 / 4 \\
4 / 4 / 4 / 4 \\
3 / 4 / 4 / 4 \\
\end{array}$ & $\begin{array}{c}4 \\
4 / 4 / 4 / 4 \\
4 / / 4 / 4 / 4 \\
4 / 4 / 4 / 4 \\
\end{array}$ & $\begin{array}{c}0 \\
0 / 10 / 0 / 0 \\
0 / 0 / 0 / 0 \\
0 / 0 / 0 / 0 \\
\end{array}$ & $\begin{array}{c} \\
4 / 4 / 4 / 4 \\
4 / / / 4 / 4 \\
4 / 4 / 4 / 4 \\
\end{array}$ & $\begin{array}{c}4 \\
4 / 4 / 4 / 4 \\
4 / 4 / 4 / 4 \\
4 / 4 / 4 / 4 \\
\end{array}$ & $\begin{array}{c}0 \\
0 / 0 / 10 \\
0 / 0 / 1 / 0 \\
0 / 0 / 0 / 0 \\
\end{array}$ \\
\hline
\end{tabular}

Tableau 20 : Résultats des intensités réactionnelles des 30 phénotypages sanguins $R H K$ réalisés en techniques manuelles sur plaque et sur gel microfiltration. Les jours de test sont indiqués "J0", " $J 1$ », " $J 2$ » et « $J 3$ ». Les températures sont indiquées " $C$ » pour le tube de départ centrifugé et repris chaque jour, puis " $4^{\circ}$ », " $22^{\circ}$ » et " $38^{\circ}$ ».Les résultats sont cotés de 0 (négatif) à 4. 


\section{i. Technique sur plaque}

- Réactions d'hémagglutinations attendues négatives:

Pour les 4 sujets $R H:-1$, les 10 sujets $R H:-2$, les 24 sujets $R H:-3$, les 8 sujets $\mathrm{RH}:-4$, les 2 sujets $\mathrm{RH}:-5$ et les 27 sujets KEL: -1 , les résultats d'agglutinations sont négatifs pour ces antigènes, à $\mathrm{J} 0$ et dans toutes les conditions de conservation.

- Réactions d'hémagglutinations attendues positives :

Pour les 26 sujets $\mathrm{RH}: 1$, les intensités réactionnelles de l'échantillon testé à J0 sont élevées. Un seul sujet conserve la même intensité réactionnelle dans toutes les conditions de conservation. En revanche, les 25 autres sujets perdent tous en intensité réactionnelle au fil des jours de test (4 sujets voient leur intensité réactionnelle diminuer dès $\mathrm{J} 1,8$ dès $\mathrm{J} 2$, et 13 à $\mathrm{J} 3$ ). De plus nous observons que cette baisse d'intensité réactionnelle touche essentiellement les échantillons conservés à $+38^{\circ} \mathrm{C}$ (Tableau 20). Concernant les températures de conservation de $+4^{\circ} \mathrm{C}$ et $+22^{\circ} \mathrm{C}$ aucune tendance n'est observée, il en est de même pour la condition " échantillon centrifugé » versus " échantillon non centrifugé». La même observation est faite pour les 20 sujets $\mathrm{RH}: 2$, les 6 sujets $\mathrm{RH}: 3$ et les 28 sujets $\mathrm{RH}: 5$ : les intensités réactionnelles, plutôt élevées à J0, baissent au fil des jours de conservation et plus particulièrement à la température de $+38^{\circ} \mathrm{C}$. Pour ces 4 antigènes du système $\mathrm{RH}$, les intensités réactionnelles restent toutefois toujours cotées au moins $2+$.

Concernant les sujets $\mathrm{RH}: 4$, la même tendance est observée. Cependant, parmi les 22 sujets porteurs de cet antigènes, 9 donnent une intensité réactionnelle cotée $1+$ après 3 jours de conservation à $+38^{\circ} \mathrm{C}$. La faiblesse de ce résultat impose un contrôle en technique manuelle sur gel microfiltration (Figure 35).

Trois sujets de notre étude sont KEL : 1. L'intensité réactionnelle de départ (J0) est de 3+ pour deux sujets et de 2+ pour un sujet. Cette intensité baisse au fil des jours et particulièrement après conservation à $+38^{\circ} \mathrm{C}$, celle-ci n'est plus cotée que $1+$ chez un sujet dès $\mathrm{J} 1$ et dès $\mathrm{J} 2$ chez les deux autres sujets. Le résultat devient même négatif chez deux sujets après 3 jours de conservation à $+38^{\circ} \mathrm{C}$ (Figure 35). 


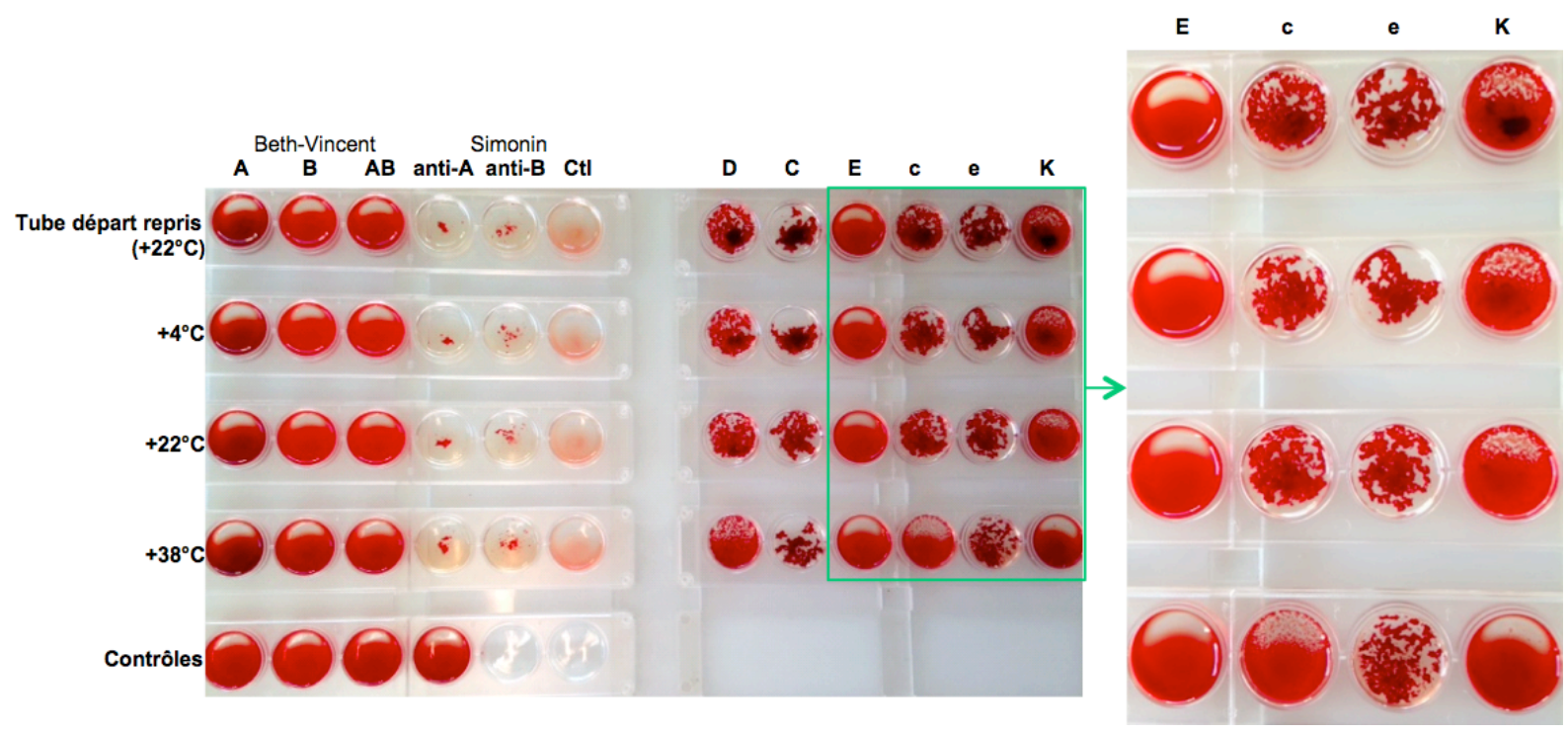

Figure 35: Photo du groupage sur plaque d'un individu $O D+C+E-c+e+K+$, le $3^{\text {ème }}$ jour de conservation. Négativation de la réaction d'agglutination de l'antigène $K E L 1(K)$ après 3 jours à $+38^{\circ} \mathrm{C}$ et baisse d'intensité franche pour l'antigène RH4 (c).

\section{- En résumé :}

Une diminution globale d'intensité réactionnelle survient au fil des jours de conservation et particulièrement en conservant l'échantillon à $+38^{\circ} \mathrm{C}$ pour tous les antigènes RH. Malgré cette diminution, les 30 échantillons testés en technique manuelle sur plaque présentent un résultat de phénotype $\mathrm{RH}$ identique au résultat de référence obtenu à $\mathrm{J} 0$, dans toutes les conditions de conservation.

Deux sujets KEL : 1 (à J0) sur trois, sont rendus à tort KEL : -1 après 3 jours de conservation à $+38^{\circ} \mathrm{C}$. Pour les 28 autres sujets, le résultat de phénotype $\mathrm{K}$ est identique au résultat de référence obtenu à $\mathrm{J} 0$, dans toutes les conditions de conservation.

ii. Technique sur gel microfiltration

- Réactions d'hémagglutinations attendues négatives :

Les 4 sujets $\mathrm{RH}:-1$, les 10 sujets $\mathrm{RH}:-2$, les 24 sujets $\mathrm{RH}:-3$, les 8 sujets $\mathrm{RH}:-4$ et les 27 sujets $\mathrm{KEL}:-1$, présentent des résultats d'agglutinations négatifs pour ces antigènes, à $\mathrm{J} 0$ et dans toutes les conditions de conservation. En revanche, les 2 sujets $\mathrm{RH}$ : -5 présentent également une réaction négative à $\mathrm{J} 0$ et dans toutes 
les conditions de conservation sauf le $3^{\text {ème }}$ jour à $+38^{\circ} \mathrm{C}$ : pour les 2 sujets nous obtenons une réaction positive cotée 1+ (Tableau 20).

- Réactions d'hémagglutinations attendues positives :

Les 20 sujets $\mathrm{RH}$ : 2 et les 22 sujets $\mathrm{RH}: 4$ présentent une intensité réactionnelle cotée 4+ le J0. Aucune perte d'intensité réactionnelle n'est observée pour toutes les conditions de conservation. Les 26 sujets $\mathrm{RH}: 1$, les 6 sujets $\mathrm{RH}: 3$, les 28 sujets $\mathrm{RH}$ : 5 et les 3 sujets KEL : 1, présentent une intensité réactionnelle cotée 4+ le J0. Une baisse d'intensité réactionnelle à 3+ est observée chez plusieurs sujets, sans révéler de tendance concernant le délai ou la température de conservation (Tableau 20).

\section{- En résumé :}

Malgré un très léger affaiblissement des intensités réactionnelles pour certains antigènes, 28 sujets sur 30 présentent un résultat de phénotype RHK identique au résultat de référence obtenu à $\mathrm{J} 0$, dans toutes les conditions de conservation. Cependant, après 3 jours de conservation à $+38^{\circ} \mathrm{C}$, les 2 sujets RH : -5 (à J0) sont rendus, à tort, RH : 5 .

\section{b. Technique automatique}

- Réactions d'hémagglutinations attendues négatives:

Pour les 4 sujets $\mathrm{RH}:-1$, les 10 sujets $\mathrm{RH}:-2$, les 24 sujets $\mathrm{RH}:-3$, les 8 sujets $\mathrm{RH}:-4$, les 2 sujets $\mathrm{RH}$ : -5 et les 27 sujets KEL : -1 , les résultats sont négatifs pour ces antigènes à $\mathrm{J} 0$ et dans toutes les conditions de conservation.

- Réactions d'hémagglutinations attendues positives :

Pour tous les antigènes, nous observons une baisse des valeurs pour les échantillons conservés à $+38^{\circ} \mathrm{C}$ par rapport aux autres températures de conservation. Cette baisse est particulièrement visible à partir de 2 jours de conservation (Figure 36). L'analyse statistique des résultats ne montre pas de différence significative ( $p$-valeur $>0,05$ ) entre les résultats rendus à J0 par l'automate et les résultats rendus dans toutes les autres conditions de conservation, pour les 
antigènes $\mathrm{RH} 2, \mathrm{RH} 3$ et $\mathrm{RH} 5$. Cependant, l'analyse statistique démontre une baisse significative ( $p$-valeur $<0,01)$ des résultats rendus après 3 jours de conservation à $+38^{\circ} \mathrm{C}$, pour l'antigène $\mathrm{RH} 1$, et après 2 et 3 jours de conservation à $+38^{\circ} \mathrm{C}$ pour l'antigène RH5, par rapport aux résultats de référence (J0). Nous n'avons pas procédé à l'analyse statistique des résultats de l'antigène KEL1 en raison de l'effectif trop faible.

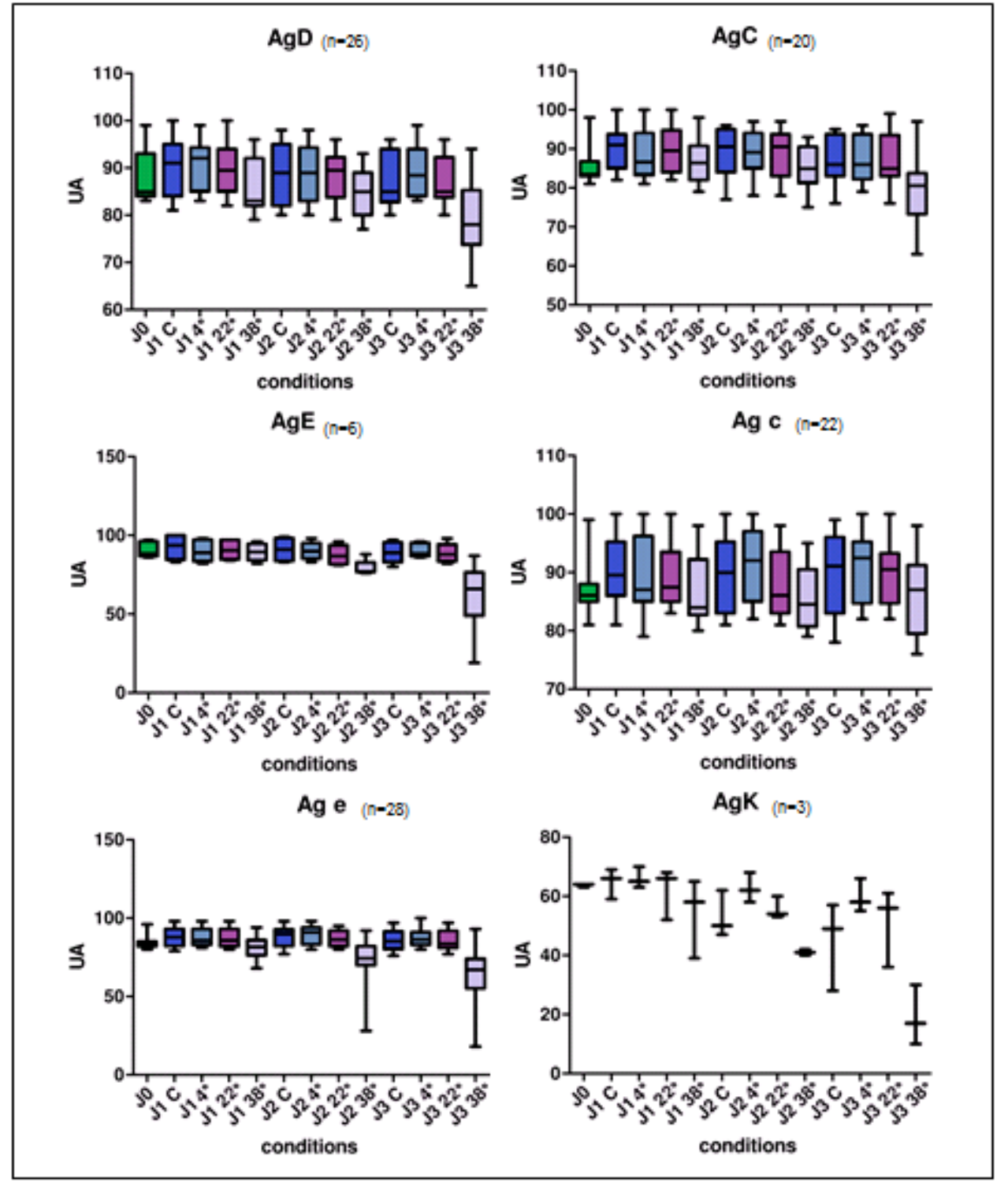

Figure 36: Représentation graphique des résultats rendus par l'automate Galileo® pour les antigènes des système Rhésus et Kell. Diminution significative des valeurs obtenues au $3^{\text {ème }}$ jour à $+38^{\circ} \mathrm{C}$ pour l'antigène RH1 $(D)$, et aux $2^{\text {ème }}$ et $3^{\text {ème }}$ jours pour l'antigène $R H 5(e)$, ( $p$-valeur $\left.<0,01\right)$, par rapport aux valeurs de références $(\mathrm{JO})$.

Concernant les antigènes du système Rhésus, l'automate Galileo® a rendu quatre discordances de phénotypage à $\mathrm{J} 3+38^{\circ} \mathrm{C}$ par rapport aux résultats obtenus à J0 : deux sujets $\mathrm{RH}$ : 1 rendus douteux, un sujet $\mathrm{RH}: 5$ rendu $\mathrm{RH}$ : -5 , et un sujet 
$\mathrm{RH}: 3$ rendu $\mathrm{RH}:-3$. Pour le système Kell nous observons également deux résultats discordants : deux sujets KEL : 1 sont rendus KEL : -1 .

\section{- En résumé :}

Des différences significatives de résultats sont observées à partir de 2 jours (antigène RH5) et 3 jours (antigène RH1) de conservation à $+38^{\circ} \mathrm{C}$. Même si 24 sujets ont obtenu un phénotype RHK identique à J0 dans toutes les conditions de conservation, 6 sujets ont en revanche présenté un résultat discordant après 3 jours de conservation à $+38^{\circ} \mathrm{C}$.

\section{c. Détection des doubles populations}

- Doubles populations sur les antigènes RH1, et RH2:

Nous avons testé 1 échantillon présentant une double population sur l'antigène $\mathrm{RH} 1$ et 3 échantillons présentant une double population sur l'antigène $\mathrm{RH} 2$ (Tableau 21). Les doubles populations sont détectées dans les trois techniques de phénotypage (sur plaque, sur gel microfiltration, sur automate Galileo®), dans toutes les conditions de conservation.

\begin{tabular}{|c|c|c|c|c|c|c|c|c|c|c|c|c|c|}
\hline & \multirow{2}{*}{\multicolumn{3}{|c|}{$\begin{array}{c}\text { DP AgD (RH1/RH-1) } \\
\text { Echantillon } 0001\end{array}$}} & \multicolumn{9}{|c|}{ DP AgC (RH2/RH-2) } \\
\hline & & & & & \multicolumn{3}{|c|}{ Echantillon 0001} & \multicolumn{3}{|c|}{ Echantillon 0003} & \multicolumn{3}{|c|}{ Echantillon 0004} \\
\hline & & Plaque & Gel & Galileo & Plaque & Gel & Galileo & Plaque & Gel & Galileo & Plaque & Gel & Galileo \\
\hline & Jo & $\mathrm{dp}$ & $\mathrm{dp}$ & $43(?)$ & $\mathrm{dp}$ & $\mathrm{dp}$ & $45(?)$ & $\mathrm{dp}$ & $\mathrm{dp}$ & $77(+) \rightarrow(?)$ & $\mathrm{dp}$ & $\mathrm{dp}$ & $63(?)$ \\
\hline \multirow{4}{*}{ J1 } & c & $\mathrm{dp}$ & $\mathrm{dp}$ & $38(?)$ & $\mathrm{dp}$ & $\mathrm{dp}$ & $49(?)$ & $\mathrm{dp}$ & $d p$ & $70(?)$ & $d p$ & $\mathrm{dp}$ & $61(?)$ \\
\hline & $+4^{\circ} \mathrm{C}$ & $d p$ & $\mathrm{dp}$ & $48(?)$ & $d p$ & $\mathrm{dp}$ & $45(?)$ & $d p$ & $\mathrm{dp}$ & 70 (?) & $d p$ & $\mathrm{dp}$ & $56(?)$ \\
\hline & $+22^{\circ} \mathrm{C}$ & $\mathrm{dp}$ & $\mathrm{dp}$ & 51 (?) & $\mathrm{dp}$ & $\mathrm{dp}$ & $51(?)$ & $d p$ & $\mathrm{dp}$ & $77(+) \rightarrow(?)$ & $\mathrm{dp}$ & $\mathrm{dp}$ & $63(?)$ \\
\hline & $+38^{\circ} \mathrm{C}$ & $\mathrm{dp}$ & $\mathrm{dp}$ & $53(?)$ & $\mathrm{dp}$ & $\mathrm{dp}$ & $51(?)$ & $\mathrm{dp}$ & $\mathrm{dp}$ & $76(+) \rightarrow(?)$ & $\mathrm{dp}$ & $\mathrm{dp}$ & $58(?)$ \\
\hline \multirow{4}{*}{ J2 } & C & $\mathrm{dp}$ & $\mathrm{dp}$ & 60 (?) & $\mathrm{dp}$ & $\mathrm{dp}$ & $59(?)$ & $\mathrm{dp}$ & $d p$ & 65 (?) & $\mathrm{dp}$ & $\mathrm{dp}$ & $64(?)$ \\
\hline & $+4^{\circ} \mathrm{C}$ & $d p$ & $\mathrm{dp}$ & $59(?)$ & $d p$ & $\mathrm{dp}$ & $51(?)$ & $d p$ & $d p$ & $66(?)$ & $d p$ & $\mathrm{dp}$ & $63(?)$ \\
\hline & $+22^{\circ} \mathrm{C}$ & $\mathrm{dp}$ & $\mathrm{dp}$ & 57 (?) & $\mathrm{dp}$ & $\mathrm{dp}$ & $54(?)$ & $\mathrm{dp}$ & $\mathrm{dp}$ & 67 (?) & $\mathrm{dp}$ & $\mathrm{dp}$ & 65 (?) \\
\hline & $+38^{\circ} \mathrm{C}$ & $\mathrm{dp}$ & $\mathrm{dp}$ & 67 (?) & $\mathrm{dp}$ & $\mathrm{dp}$ & $62(?)$ & $\mathrm{dp}$ & $d p$ & $63(?)$ & $\mathrm{dp}$ & $\mathrm{dp}$ & $58(?)$ \\
\hline \multirow{4}{*}{ J3 } & $\mathrm{C}$ & $d p$ & $\mathrm{dp}$ & $72(+) \rightarrow(?)$ & $d p$ & $\mathrm{dp}$ & $60(?)$ & $d p$ & $d p$ & 60 (?) & $d p$ & $\mathrm{dp}$ & 47 (?) \\
\hline & $+4^{\circ} \mathrm{C}$ & $\mathrm{dp}$ & $\mathrm{dp}$ & 53 (?) & $\mathrm{dp}$ & $\mathrm{dp}$ & $43(?)$ & $\mathrm{dp}$ & $\mathrm{dp}$ & 69 (?) & $\mathrm{dp}$ & $\mathrm{dp}$ & $52(?)$ \\
\hline & $+22^{\circ} \mathrm{C}$ & $d p$ & $\mathrm{dp}$ & 61 (?) & $d p$ & $\mathrm{dp}$ & 49 (?) & $\mathrm{dp}$ & $d p$ & $65(?)$ & $d p$ & $\mathrm{dp}$ & 59 (?) \\
\hline & $+38^{\circ} \mathrm{C}$ & $\mathrm{dp}$ & $\mathrm{dp}$ & $63(?)$ & $\mathrm{dp}$ & $\mathrm{dp}$ & $55(?)$ & $\mathrm{dp}$ & $d p$ & $68(?)$ & $d p$ & $\mathrm{dp}$ & 49 (?) \\
\hline
\end{tabular}

Tableau 21: Résultats de l'échantillon comportant une double population sur l'antigène RH1, et des échantillons comportant une double population sur l'antigène RH2. Pour les techniques manuelles (plaque et gel microfiltration), " $d p$ » indique que la double population est détectée. Dans la colonne "Galileo® ", sont transcrites les valeurs chiffrées rendues par l'automate, avec l'interprétation de l'automate : (-) pour négatif, (+) pour positif et (?) pour indéterminé (=double population). La mention « (?) » indique une correction par le technicien habilité lorsque la double population est visible sur la microplaque de réaction. Toutes les doubles populations ont été détectées, dans toutes les conditions de conservation. 
- Doubles populations sur l'antigène RH3 :

Nous avons testé 2 échantillons présentant une double population sur l'antigène RH3 (Tableau 22). Les doubles populations sont détectées avec les trois méthodes de groupage et dans toutes les conditions de conservation, sauf pour un échantillon après 3 jours à $+38^{\circ} \mathrm{C}$, sur l'automate Galileo ${ }$.

- Doubles populations sur l'antigène RH5:

Nous avons testé 1 échantillon présentant une double population sur l'antigène RH5 (Tableau 22). La double population est détectée avec les trois méthodes de groupage et dans toutes les conditions de conservation, sauf après 2 et 3 jours de conservation à $+38^{\circ} \mathrm{C}$, en technique sur gel microfiltration.

\begin{tabular}{|c|c|c|c|c|c|c|c|c|c|c|}
\hline & & \multicolumn{6}{|c|}{ DP Ag E (RH3/RH-3) } & \multirow{2}{*}{\multicolumn{3}{|c|}{$\begin{array}{c}\text { DP Ag e (RH5/RH-5) } \\
\text { Echantillon } 0004\end{array}$}} \\
\hline & & \multicolumn{3}{|c|}{ Echantillon 0003} & \multicolumn{3}{|c|}{ Echantillon 0004} & & & \\
\hline & & Plaque & Gel & Galileo & Plaque & Gel & Galileo & Plaque & Gel & Galileo \\
\hline & Jo & $\mathrm{dp}$ & $\mathrm{dp}$ & $23(-) \rightarrow(?)$ & $\mathrm{dp}$ & $\mathrm{dp}$ & $39(?)$ & $\mathrm{dp}$ & $\mathrm{dp}$ & 69 (?) \\
\hline \multirow{4}{*}{ J1 } & C & $d p$ & $\mathrm{dp}$ & $17(-) \rightarrow(?)$ & $d p$ & $\mathrm{dp}$ & $41(?)$ & $d p$ & $\mathrm{dp}$ & $62(?)$ \\
\hline & $+4^{\circ} \mathrm{C}$ & $\mathrm{dp}$ & $\mathrm{dp}$ & $29(?)$ & $\mathrm{dp}$ & $\mathrm{dp}$ & $46(?)$ & $\mathrm{dp}$ & $\mathrm{dp}$ & $62(?)$ \\
\hline & $+22^{\circ} \mathrm{C}$ & $\mathrm{dp}$ & $\mathrm{dp}$ & $26(?)$ & $d p$ & $\mathrm{dp}$ & $54(?)$ & $\mathrm{dp}$ & $\mathrm{dp}$ & $68(?)$ \\
\hline & $+38^{\circ} \mathrm{C}$ & $\mathrm{dp}$ & $\mathrm{dp}$ & $31(?)$ & $d p$ & $\mathrm{dp}$ & $64(?)$ & $d p$ & $\mathrm{dp}$ & $53(?)$ \\
\hline \multirow{4}{*}{$\mathbf{J} 2$} & C & $\mathrm{dp}$ & $\mathrm{dp}$ & $39(?)$ & $\mathrm{dp}$ & $\mathrm{dp}$ & $53(?)$ & $d p$ & $\mathrm{dp}$ & $69(?)$ \\
\hline & $+4^{\circ} \mathrm{C}$ & $d p$ & $\mathrm{dp}$ & $30(?)$ & $d p$ & $d p$ & $50(?)$ & $\mathrm{dp}$ & $\mathrm{dp}$ & $69(?)$ \\
\hline & $+22^{\circ} \mathrm{C}$ & $\mathrm{dp}$ & $\mathrm{dp}$ & $27(?)$ & $\mathrm{dp}$ & $d p$ & $50(?)$ & $d p$ & $\mathrm{dp}$ & 68 (?) \\
\hline & $+38^{\circ} \mathrm{C}$ & $\mathrm{dp}$ & $\mathrm{dp}$ & $27(?)$ & $\mathrm{dp}$ & $\mathrm{dp}$ & $52(?)$ & $\mathrm{dp}$ & RH5 & $47(?)$ \\
\hline \multirow{4}{*}{ J3 } & C & $\mathrm{dp}$ & $\mathrm{dp}$ & $37(?)$ & $\mathrm{dp}$ & $\mathrm{dp}$ & $52(?)$ & $\mathrm{dp}$ & $\mathrm{dp}$ & $50(?)$ \\
\hline & $+4^{\circ} \mathrm{C}$ & $\mathrm{dp}$ & $\mathrm{dp}$ & $24(?)$ & $\mathrm{dp}$ & $\mathrm{dp}$ & $47(?)$ & $d p$ & $\mathrm{dp}$ & 57 (?) \\
\hline & $+22^{\circ} \mathrm{C}$ & $\mathrm{dp}$ & $\mathrm{dp}$ & $28(?)$ & $d p$ & $\mathrm{dp}$ & $41(?)$ & $d p$ & $d p$ & 59 (?) \\
\hline & $+38^{\circ} \mathrm{C}$ & $d p$ & $\mathrm{dp}$ & $16(-)$ & $d p$ & $\mathrm{dp}$ & $26(?)$ & $d p$ & RH5 & 33 (?) \\
\hline
\end{tabular}

Tableau 22 : Résultats des échantillons comportant une double population sur l'antigène RH3, et de l'échantillon comportant une double population sur l'antigène RH5. Pour les techniques manuelles (plaque et gel microfiltration), "dp » indique que la double population est détectée. Dans la colonne "Galileo® ", sont transcrites les valeurs chiffrées rendues par l'automate, avec l'interprétation de l'automate: (-) pour négatif, (+) pour positif et (?) pour indéterminé (=double population). La mention « (?) » indique une correction par le technicien habilité lorsque la double population est visible sur la microplaque de réaction. La double population portant sur l'antigène RH3 n'est pas détectée pour l'échantillon conservé 3 jours à $+38^{\circ} \mathrm{C}$ en technique sur Galileo. La double population portant sur l'antigène RH5 n'est pas détectée pour un échantillon conservé 2 et 3 jours à $+38^{\circ} \mathrm{C}$ en technique sur gel microfiltration.

\section{- Doubles populations sur l'antigène RH4:}

Nous avons testé 1 échantillon présentant une double population sur l'antigène RH4 (Tableau 23). En techniques manuelles (sur plaque et sur gel microfiltration), la double population est détectée dans toutes les conditions de 
conservation. En revanche, sur l'automate $G a l i l e o ®$, la double population n'est pas détectée à J0, ni à J1. Elle n'est ensuite détectée qu'aléatoirement à J2 et J3.

- Doubles populations sur l'antigène KEL1:

Nous avons testé 3 échantillons présentant une double population sur l'antigène KEL1 (Tableau 23). Pour l'un d'entre eux, la double population n'est pas détectée sur l'automate Galileo® (sauf à $\mathrm{J} 1+38^{\circ} \mathrm{C}$ ). Pourtant en technique sur plaque et sur gel microfiltration, la double population est détectée dans toutes les conditions de conservation (sauf après 2 et 3 jours de conservation à $+38^{\circ} \mathrm{C}$ en technique sur plaque). Les deux autres échantillons avec une double population sur l'antigène KEL1 présentent un défaut de détection avec l'automate Galileoß après 2 et 3 jours de conservation à $+38^{\circ} \mathrm{C}$ : l'antigène $\mathrm{KEL} 1$ est rendu négatif à tort $(\mathrm{KEL}$ : 1).

\begin{tabular}{|c|c|c|c|c|c|c|c|c|c|c|c|c|c|}
\hline & \multirow{2}{*}{\multicolumn{3}{|c|}{$\begin{array}{c}\text { DP Agc (RH4/RH-4) } \\
\text { Echantillon } 0002\end{array}$}} & \\
\hline & & & & & \multicolumn{6}{|c|}{$\begin{array}{c}\text { DP AgK (KEL1/KEL-1) } \\
\text { Echantillon } 0003\end{array}$} & \multicolumn{3}{|c|}{ Echantillon 0004} \\
\hline & & Plaque & Gel & Galileo & Plaque & Gel & Galileo & Plaque & Gel & Galileo & Plaque & Gel & Galileo \\
\hline & Jo & $\mathrm{dp}$ & $\mathrm{dp}$ & $94(+)$ & $\mathrm{dp}$ & $\mathrm{dp}$ & $31(?)$ & $\mathrm{dp}$ & $\mathrm{dp}$ & $47(?)$ & $\mathrm{dp}$ & $\mathrm{dp}$ & $18(-)$ \\
\hline \multirow{4}{*}{ J1 } & C & $\mathrm{dp}$ & $\mathrm{dp}$ & $79(+)$ & $\mathrm{dp}$ & $\mathrm{dp}$ & $22(?)$ & $\mathrm{dp}$ & $\mathrm{dp}$ & $37(?)$ & $\mathrm{dp}$ & $\mathrm{dp}$ & $16(-)$ \\
\hline & $+4^{\circ} \mathrm{C}$ & $\mathrm{dp}$ & $\mathrm{dp}$ & $84(+)$ & $\mathrm{dp}$ & $\mathrm{dp}$ & $24(?)$ & $\mathrm{dp}$ & $\mathrm{dp}$ & $37(?)$ & $\mathrm{dp}$ & $\mathrm{dp}$ & $16(-)$ \\
\hline & $+22^{\circ} \mathrm{C}$ & $\mathrm{dp}$ & $\mathrm{dp}$ & $84(+)$ & $d p$ & $\mathrm{dp}$ & $23(?)$ & $\mathrm{dp}$ & $\mathrm{dp}$ & $34(?)$ & $\mathrm{dp}$ & $\mathrm{dp}$ & $21(-)$ \\
\hline & $+38^{\circ} \mathrm{C}$ & $\mathrm{dp}$ & $\mathrm{dp}$ & $86(+)$ & $\mathrm{dp}$ & $\mathrm{dp}$ & $26(?)$ & $\mathrm{dp}$ & $\mathrm{dp}$ & $36(?)$ & $\mathrm{dp}$ & $\mathrm{dp}$ & $23(?)$ \\
\hline \multirow{4}{*}{ J2 } & C & $\mathrm{dp}$ & $\mathrm{dp}$ & $70(?)$ & $\mathrm{dp}$ & $\mathrm{dp}$ & $24(?)$ & $\mathrm{dp}$ & $\mathrm{dp}$ & $28(?)$ & $\mathrm{dp}$ & $\mathrm{dp}$ & $20(-)$ \\
\hline & $+4^{\circ} \mathrm{C}$ & $d p$ & $\mathrm{dp}$ & $75(+) \rightarrow(?)$ & $d p$ & $d p$ & $25(?)$ & $d p$ & $d p$ & $38(?)$ & $d p$ & $\mathrm{dp}$ & $18(-)$ \\
\hline & $+22^{\circ} \mathrm{C}$ & $d p$ & $\mathrm{dp}$ & $75(+) \rightarrow(?)$ & $d p$ & $\mathrm{dp}$ & 30 (?) & $\mathrm{dp}$ & $\mathrm{dp}$ & $39(?)$ & $\mathrm{dp}$ & $\mathrm{dp}$ & $19(-)$ \\
\hline & $+38^{\circ} \mathrm{C}$ & $d p$ & $\mathrm{dp}$ & $65(?)$ & $\mathrm{dp}$ & $\mathrm{dp}$ & $27(?)$ & $\mathrm{dp}$ & $\mathrm{dp}$ & $18(-)$ & $\mathrm{dp}$ & $\mathrm{dp}$ & $13(-)$ \\
\hline \multirow{4}{*}{ J3 } & C & $d p$ & $\mathrm{dp}$ & 70 (?) & $d p$ & $d p$ & $21(-) \rightarrow(?)$ & $d p$ & $\mathrm{dp}$ & $27(?)$ & $d p$ & $\mathrm{dp}$ & $14(-)$ \\
\hline & $+4^{\circ} \mathrm{C}$ & $d p$ & $\mathrm{dp}$ & $85(+)$ & $d p$ & $\mathrm{dp}$ & 25 (?) & $d p$ & $\mathrm{dp}$ & $42(?)$ & $d p$ & $\mathrm{dp}$ & $16(-)$ \\
\hline & $+22^{\circ} \mathrm{C}$ & $\mathrm{dp}$ & $\mathrm{dp}$ & $76(+) \rightarrow(?)$ & $d p$ & $d p$ & 31 (?) & $\mathrm{dp}$ & $d p$ & $35(?)$ & $d p$ & $\mathrm{dp}$ & $16(-)$ \\
\hline & $+38^{\circ} \mathrm{C}$ & $d p$ & $\mathrm{dp}$ & $72(+) \rightarrow(?)$ & $d p$ & $\mathrm{dp}$ & $19(-)$ & $d p$ & $\mathrm{dp}$ & $23(?)$ & $\mathrm{dp}$ & $\mathrm{dp}$ & $12(-)$ \\
\hline
\end{tabular}

Tableau 23 : Résultats de l'échantillon comportant une double population sur l'antigène RH4, et des échantillons comportant une double population sur l'antigène KEL1. Pour les techniques manuelles (plaque et gel microfiltration), "dp » indique que la double population est détectée. Dans la colonne "Galileo® », sont transcrites les valeurs chiffrées rendues par l'automate, avec l'interprétation de l'automate : (-) pour négatif, (+) pour positif et (?) pour indéterminé (=double population). La mention « (?) » indique une correction par le technicien habilité lorsque la double population est visible sur la microplaque de réaction. La double population portant sur l'antigène RH4 n'est pas détectée par le Galileo dès le J0, elle est détectée aléatoirement à J2 et J3. Les doubles populations portant sur l'antigène KEL1 ne sont pas détectées par le Galileo à $\mathrm{J} 3+38^{\circ} \mathrm{C}$ pour le $1^{\text {er }}$ échantillon, à $\mathrm{J} 2+38^{\circ} \mathrm{C}$ pour $2^{\text {nd }}$ échantillon, et dès le JO pour le dernier échantillon.

\section{- En résumé :}

Pour les antigènes $\mathrm{RH} 1$ et $\mathrm{RH} 2$, les doubles populations sont détectées dans toutes les conditions de conservation par les trois méthodes. 
Pour les antigènes $\mathrm{RH} 3$ et KEL1, nous observons, pour certains échantillons, un défaut de détection lorsque celui-ci est conservé 2 ou 3 jours à $+38^{\circ} \mathrm{C}$ par l'automate Galileo ${ }^{\circledR}$. II en est de même pour l'antigène RH5 mais en technique sur gel microfiltration.

3) RAl aux différentes conditions de conservation :

\section{a. Dépistage et identification en technique manuelle}

- RAl négatives :

Nous avons analysé 30 RAl négatives, en technique manuelle sur gel microfiltration. Le résultat de 2 échantillons est ininterprétable après 3 jours de conservation à $+38^{\circ} \mathrm{C}$. En effet, l'hémolyse à $+38^{\circ} \mathrm{C}$ interfère sur la lecture de la réaction (par le lecteur Saxo® et en lecture visuelle) : des débris globulaires restent en surface du gel tandis que le plasma laisse une trace rouge dans le gel (Figure $37)$.

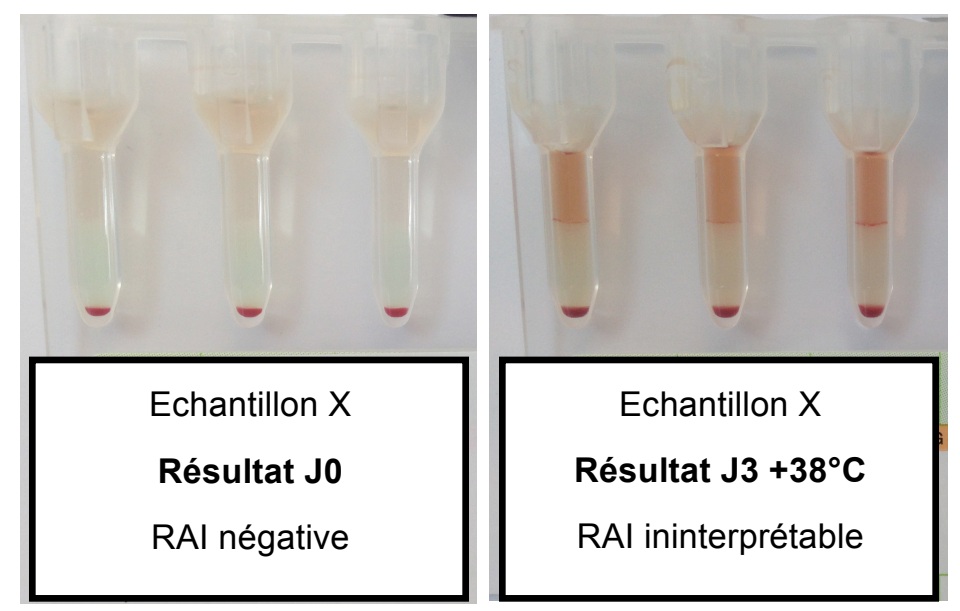

Figure 37: Photo des supports de gel microfiltration pour la RAI. A gauche le résultat négatif d'un échantillon à $\mathrm{JO}$ (sans conservation); $A$ droite le résultat du même échantillon mais après 3 jours de conservation à $+38^{\circ} \mathrm{C}$ : l'hémolyse de l'échantillon perturbe la lecture du résultat, le plasma rouge laisse une trace dans la micro-colonne et des débris globulaires restent en surface du gel.

- RAl positives :

Nous présentons les résultats de 30 RAl positives. De la même manière que pour les RAI négatives, l'hémolyse interfère sur le résultat de 7 échantillons au bout de 3 jours de conservation à $+38^{\circ} \mathrm{C}$ : tous les puits réactionnels des panels de dépistage et d'identification sont ininterprétables. 
Chez 20 sujets de notre étude, l'anticorps irrégulier attendu est dépisté et identifié avec une intensité réactionnelle forte : le nombre de réactions positives sur les panels de dépistage et d'identification reste le même dans toutes les conditions de conservation. L'intensité de ces réactions positives ne varie que très peu $(1+)$ en fonction des conditions de conservation. Cependant, nous observons plus fréquemment une légère baisse d'intensité réactionnelle sur les échantillons conservés à $+38^{\circ} \mathrm{C}$.

Pour 9 sujets de notre étude (Tableau 24), nous dépistons des anticorps irréguliers de faible intensité. Chez ces 9 sujets, nous observons une diminution du nombre d'hématies-tests informatives positives associée à une chute des intensités réactionnelles sur les panels de dépistage et d'identification. Cette diminution s'observe au fil des jours de conservation (pour 7 sujets la diminution s'observe dès le $1^{\mathrm{er}}$ jour de conservation, et pour 2 sujets dès le $2^{\text {ème }}$ jour). En comparant les différentes températures de conservation, il apparaît que les échantillons stockés à $+38^{\circ} \mathrm{C}$ présentent des intensités réactionnelles plus faibles que ceux stockés à $+4^{\circ} \mathrm{C}$ et $+22^{\circ} \mathrm{C}$. A l'inverse, les échantillons stockés à $+4^{\circ} \mathrm{C}$, maintiennent une intensité réactionnelle et un nombre d'hématies-tests positives plus stables.

Un sujet de notre étude présente un anticorps irrégulier que nous avons qualifié de non spécifique (Tableau 24). Cet anticorps est détecté uniquement par l'automate Qwalys ${ }^{\circledR}$ à $\mathrm{J} 0$ mais pas sur les panels de dépistage et d'identification sur gel microfiltration. Nous avons tenté d'identifier cet anticorps à l'aide d'une technique enzymatique complémentaire. Deux hématies-tests donnent une réaction positive faible $(1+)$ sans pouvoir déterminer une spécificité. Ces réactions positives faibles le restent dans toutes les conditions de conservation. Un autre échantillon (sujet avec un anticorps anti-Leb) a été analysé avec le panel d'identification en technique enzymatique, l'intensité des réactions positives reste également constante dans toutes les conditions de conservation. 


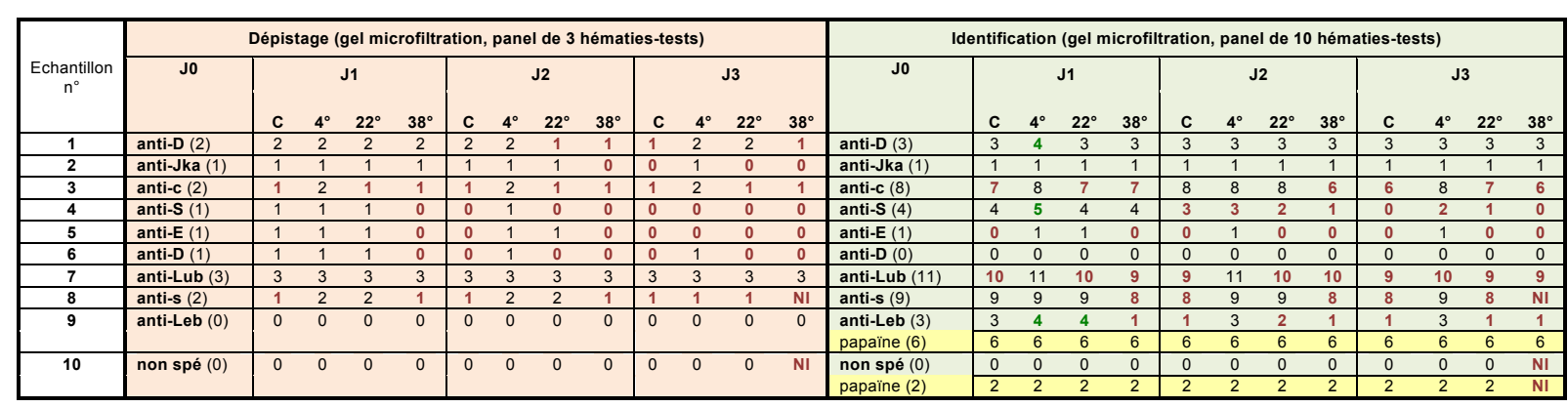

Tableau 24 : Résultats des 10 sujets présentant une RAI positive très faible dès J0. Les jours de test sont indiqués " $J 0$ », " $J 1$ », " J2 » et " J3 » et les températures sont indiquées " $C$ » pour le tube de départ centrifugé et repris chaque jour, puis " $4^{\circ}$ ", " $22^{\circ}$ " et " $38^{\circ}$ ". La nature de l'anticorps irrégulier est précisée dans la colonne "JO » ainsi que le nombre d'hématies-tests du panel positives (entre parenthèses). Sont ensuite notées, pour chaque condition, le nombre d'hématies-tests positives sur les panels de dépistage (à gauche) et d'identification (à droite). Le résultat du panel d'identification en technique enzymatique est indiqué " papaïne " sous les 2 échantillons concernés (9 et 10). Les résultats pour lesquels "NI » est mentionné correspondent aux résultats non interprétés en raison de l'hémolyse.

- En résumé :

L'hémolyse de l'échantillon, après 3 jours de conservation à $+38^{\circ} \mathrm{C}$, perturbe les résultats de RAl, comme lors de l'épreuve plasmatique du groupage sanguin $A B O$.

Malgré une baisse d'intensité réactionnelle lorsque les échantillons sont conservés à $+38^{\circ} \mathrm{C}$, les anticorps irréguliers d'intensité élevée à J0 sont dépistés et identifiés dans toutes les conditions de conservation.

En revanche, les anticorps irréguliers d'intensité faible à J0 perdent en intensité réactionnelle au fil des jours de conservation et à la température de $+38^{\circ} \mathrm{C}$, et risquent ainsi de ne pas être dépistés ou identifiés. On note que la conservation à $+4^{\circ} \mathrm{C}$ tend à limiter ce risque.

\section{b. Dépistage en technique automatique}

- RAl négatives :

Nous avons analysé 30 RAI négatives, sur l'automate $Q$ walys ${ }^{\circledR}$. De la même manière qu'en technique sur gel microfiltration, nous observons une interférence de l'hémolyse pour les échantillons conservés 3 jours à $+38^{\circ} \mathrm{C}: 11$ échantillons ont été rendus ininterprétables par l'automate à cause du plasma hémolysé. 
- RAl positives :

Les 30 échantillons de sujets porteurs d'un anticorps irrégulier ont également été analysés sur l'automate $Q$ walys $₫$. Le principe EM Technology $\AA$ de l'automate ne permet pas de dépister les anticorps irréguliers de type $\operatorname{lgM}$. Ainsi, pour 6 échantillons, l'anticorps irrégulier n'a pas été dépisté dès J0. De plus, comme pour les RAI négatives, l'hémolyse induit un résultat ininterprétable pour 6 échantillons conservés pendant 3 jours à $+38^{\circ} \mathrm{C}$.

Nous présentons les résultats des 24 RAl positives dépistées par l'automate. Le $Q$ walys $₫$ rend des résultats sous forme de valeurs chiffrées. Cependant il est très fréquent que le lecteur de l'automate rende un résultat à 0 (négatif) alors que l'aspect de la réaction soit à considérer comme douteux ou positif (correction visuelle du technicien). C'est pour cette raison que l'analyse statistique des données du Qwalys ${ }^{\circledR}$ n'a pu être réalisée, trop de réactions ont été rendues négatives par l'automate mais corrigées douteuses ou positives par la lecture visuelle d'un technicien.

Cependant, l'observation des résultats des 24 sujets présentant une réaction de RAI positive ou douteuse à $\mathrm{J} 0$ montre plusieurs tendances :

- 13 sujets présentent un anticorps irrégulier d'intensité plutôt élevée à J0 (résultat Qwalys ${ }^{\circledR}>50$ ). Pour ces anticorps forts, l'intensité des réactions reste constante au fil des jours de tests, mais une nette diminution est observée pour les échantillons conservés à $+38^{\circ} \mathrm{C}$.

- 11 sujets présentent un anticorps irrégulier d'intensité plus faible dès J0 (résultat Qwalys ${ }^{\circledR}<50$ ) (Tableau 25). On observe une baisse de l'intensité réactionnelle au fil des jours de conservation : chez ces 11 sujets nous observons des réactions douteuses ou négatives le $3^{\text {ème }}$ jour de conservation (dont 1 sujet dès le $2^{\text {ème }}$ jour et 8 sujets dès le $1^{\text {er }}$ jour de conservation) à toutes les températures.

II apparait également que les réactions négatives sont plus fréquemment observées pour les échantillons conservés à $+38^{\circ} \mathrm{C}$ et, qu'à l'inverse, les réactions douteuses restent plus fréquemment observées pour les échantillons conservés à $+4^{\circ} \mathrm{C}$. 


\begin{tabular}{|c|c|c|c|c|c|c|c|c|}
\hline \multirow{4}{*}{$\mathrm{n}^{\circ}$} & \multirow{4}{*}{ AcI } & \multirow{4}{*}{ Jour } & \multicolumn{3}{|c|}{ Dépistage Qwalys } & \multicolumn{3}{|c|}{ Correspondance (Correction technicien) } \\
\hline & & & \multicolumn{3}{|c|}{ Hématies-tests } & \multicolumn{3}{|c|}{ Hématies-tests } \\
\hline & & & 1 & 2 & 3 & 1 & 2 & 3 \\
\hline & & & $\mathrm{C} / 4^{\circ} / 22^{\circ} / 38^{\circ}$ & $\mathrm{C} / 4^{\circ} / 22^{\circ} / 38^{\circ}$ & $\mathrm{C} / 4^{\circ} / 22^{\circ} / 38^{\circ}$ & $\mathrm{C} / 4^{\circ} / 22^{\circ} / 38^{\circ}$ & $\mathrm{C} / 4^{\circ} / 22^{\circ} / 38^{\circ}$ & $\mathrm{C} / 4^{\circ} / 22^{\circ} / 38^{\circ}$ \\
\hline \multirow{4}{*}{1} & \multirow{4}{*}{ anti-D } & JO & 12 & 0 & 0 & $?$ & $?$ & \\
\hline & & $\mathrm{J} 1$ & $17 / 27 / 6 / 0$ & $0 / 0 / 0 / 0$ & $0 / 0 / 0 / 0$ & $? /(+) / ? / ?$ & ?/?/?/? & $-1-1-1-$ \\
\hline & & $\mathrm{J} 2$ & $0 / 0 / 0 / 0$ & $0 / 0 / 0 / 0$ & $0 / 0 / 0 / 0$ & $? / ? / ? / ?$ & $? / ? / ? / ?$ & $-1-1-1-$ \\
\hline & & $\mathrm{J} 3$ & $27 / 57 / 0 / 0$ & $13 / 50 / 17 / 0$ & $0 / 0 / 0 / 0$ & $(+) / 1+1-1-$ & $? / 1+/ ? / ?$ & $-1-1-1-$ \\
\hline \multirow{4}{*}{2} & \multirow{4}{*}{ anti-E } & Jo & 0 & 20 & 0 & & $(+)$ & \\
\hline & & $\mathrm{J} 1$ & $0 / 0 / 0 / 0$ & $24 / 31 / 27 / 15$ & $0 / 0 / 0 / 0$ & $-1-1-1-$ & $(+) /(+) /(+) /(+)$ & $-1-1-1-$ \\
\hline & & $\mathrm{J} 2$ & $0 / 0 / 0 / 0$ & $0 / 0 / 0 / 0$ & $0 / 0 / 0 / 0$ & $-1-1-1-$ & $? / ? / ? / ?$ & $-1-1-1-$ \\
\hline & & $\mathrm{J} 3$ & $0 / 0 / 0 / 0$ & $0 / 0 / 0 / 0$ & $0 / 0 / 0 / 0$ & $-1-1-1-$ & ?/?/?/- & $-1-1-1-$ \\
\hline \multirow{4}{*}{3} & \multirow{4}{*}{ anti-Jka } & Jo & 0 & 31 & 0 & & $(+)$ & \\
\hline & & $\mathrm{J} 1$ & $0 / 0 / 0 / 0$ & $33 / 20 / 0 / 110$ & $0 / 0 / 0 / 0$ & $-1-1-1-$ & $(+) /(+) /(+) /(+)$ & $-1-1-1-$ \\
\hline & & $\mathrm{J} 2$ & $0 / 0 / 0 / 0$ & $25 / 34 / 0 / 0$ & $0 / 0 / 0 / 0$ & $-1-1-1-$ & $(+) /(+) / ? / ?$ & $-1-1-1-$ \\
\hline & & $\mathrm{J} 3$ & $0 / 0 / 0 / 0$ & $0 / 0 / 0 / 0$ & $0 / 0 / 0 / 0$ & $-1-1-1-$ & $? / ? / ? / ?$ & $-1-1-1-$ \\
\hline \multirow{4}{*}{4} & \multirow{4}{*}{ anti-c } & Jo & 0 & 0 & 48 & & & $1+$ \\
\hline & & $\mathrm{J} 1$ & $0 / 0 / 0 / 0$ & $0 / 0 / 0 / 0$ & $0 / 22 / 0 / 0$ & $-1-1-1-$ & $-1-1-1-$ & ?/?/?/? \\
\hline & & $\mathrm{J} 2$ & $0 / 0 / 0 / 0$ & $0 / 0 / 0 / 0$ & $0 / 0 / 0 / 0$ & $-1-1-1-$ & $-1-1-1-$ & $? / ? / ? / ?$ \\
\hline & & $\mathrm{J} 3$ & $0 / 0 / 0 / 0$ & $0 / 0 / 0 / 0$ & $0 / 0 / 0 / 0$ & $-1-1-1-$ & $-1-1-1-$ & ? $/ ? / ? / ?$ \\
\hline \multirow{4}{*}{5} & \multirow{4}{*}{ anti-E } & Jo & 0 & 0 & 0 & & $?$ & \\
\hline & & $\mathrm{J} 1$ & $0 / 0 / 0 / 0$ & $0 / 0 / 0 / 0$ & $0 / 0 / 0 / 0$ & $-1-1-1-$ & $-1-1-1-$ & $-1-1-1-$ \\
\hline & & $\mathrm{J} 2$ & $0 / 0 / 0 / 0$ & $0 / 0 / 0 / 0$ & $0 / 0 / 0 / 0$ & $-1-1-1-$ & $-1-1-1-$ & $-1-1-1-$ \\
\hline & & $\mathrm{J} 3$ & $0 / 0 / 0 / 0$ & $0 / 0 / 0 / 0$ & $0 / 0 / 0 / 0$ & $-1-1-1-$ & $-1-1-1-$ & $-1-1-1-$ \\
\hline \multirow{4}{*}{6} & \multirow{4}{*}{ anti-D } & Jo & 0 & 0 & 0 & & $?$ & \\
\hline & & $\mathrm{J} 1$ & $0 / 0 / 0 / 0$ & $0 / 0 / 0 / 0$ & $0 / 0 / 0 / 0$ & $-1-1-1-$ & $-/ ? /-/-$ & $-1-1-1-$ \\
\hline & & $\mathrm{J} 2$ & $0 / 0 / 0 / 0$ & $0 / 0 / 0 / 0$ & $0 / 0 / 0 / 0$ & $-1-1-1-$ & ?/?/?/- & $-1-1-1-$ \\
\hline & & $\mathrm{J} 3$ & $0 / 0 / 0 / 0$ & $0 / 0 / 0 / 0$ & $0 / 0 / 0 / 0$ & $-1-1-1-$ & $-1 ? \mid-1-$ & $-1-1-1-$ \\
\hline \multirow{4}{*}{7} & \multirow{4}{*}{ anti-Lub } & JO & 0 & 11 & 0 & & $?$ & \\
\hline & & $\mathrm{J} 1$ & $0 / 0 / 0 / 0$ & $0 / 0 / 0 / 0$ & $0 / 0 / 0 / 0$ & $-1-1-1-$ & ?/?/?// - & $-1-1-1-$ \\
\hline & & $\mathrm{J} 2$ & $0 / 0 / 0 / 0$ & $0 / 0 / 0 / 0$ & $0 / 0 / 0 / 0$ & $-1-1-1-$ & ?/?/?/- & $-1-1-1-$ \\
\hline & & $\mathrm{J} 3$ & $0 / 0 / 0 / 0$ & $0 / 0 / 0 / 0$ & $0 / 0 / 0 / 0$ & $-1-1-1-$ & $-1 ? 1 ? 1-$ & $-1-1-1-$ \\
\hline & & Jo & 0 & 15 & 0 & - & $?$ & - \\
\hline & & $\mathrm{J} 1$ & $0 / 0 / 0 / 0$ & $0 / 0 / 0 / 0$ & $0 / 0 / 0 / 0$ & $-1-1-1-$ & $? / ? / ? / ?$ & $-1-1-1-$ \\
\hline 8 & anti-E & $\mathrm{J} 2$ & $0 / 0 / 0 / 0$ & $0 / 0 / 0 / 0$ & $0 / 0 / 0 / 0$ & $-1-1-1-$ & ?/?/?// & $-1-1-1-$ \\
\hline & & $\mathrm{J} 3$ & $0 / 0 / 0 / 0$ & $0 / 0 / 0 / 0$ & $0 / 0 / 0 / 0$ & $-1-1-1-$ & ? /?/?/- & $-1-1-1-$ \\
\hline & & JO & 0 & 0 & 0 & & $?$ & \\
\hline & & $\mathrm{J} 1$ & $0 / 0 / 0 / 0$ & $0 / 0 / 0 / 0$ & $0 / 0 / 0 / 0$ & $-1-1-1-$ & ? ? /?/? & $-1-1-1-$ \\
\hline 9 & anti-K & $\mathrm{J} 2$ & $0 / 0 / 0 / 0$ & $0 / 0 / 0 / 0$ & $0 / 0 / 0 / 0$ & $-1-1-1-$ & ?/?/?/? & $-1-1-1-$ \\
\hline & & $\mathrm{J} 3$ & $0 / 0 / 0 / 0$ & $0 / 0 / 0 / 0$ & $0 / 0 / 0 / 0$ & $-1-1-1-$ & ?/?/?/- & $-1-1-1-$ \\
\hline & & & & 0 & & & & \\
\hline & & $\mathrm{J} 1$ & $0 / 0 / 0 / 0$ & $0 / 20 / 0 / 0$ & $0 / 0 / 0 / 0$ & $-1-1-1-$ & ?/?/?/? & $-1-1-1-$ \\
\hline 10 & anti-s & $\mathrm{J} 2$ & $0 / 0 / 0 / 0$ & $0 / 0 / 0 / 0$ & $0 / 0 / 0 / 0$ & $-1-1-1-$ & $? 1 ? 1-1$ & $-1-1-1-$ \\
\hline & & $\mathrm{J} 3$ & $0 / 0 / 0 / 0$ & $0 / 0 / 0 / 0$ & $0 / 0 / 0 / 0$ & $-1-1-1-$ & $-1 ? 1-1-$ & $-1-1-1-$ \\
\hline & & Jo & 34 & 0 & 0 & $(+)$ & - & \\
\hline & & $\mathrm{J} 1$ & $12 / 0 / 0 / 0$ & $0 / 0 / 0 / 0$ & $0 / 0 / 0 / 0$ & ?/?/?/? & $-1-1-1-$ & $-1-1-1-$ \\
\hline 11 & non spé & $\mathrm{J} 2$ & $30 / 31 / 0 / 0$ & $0 / 0 / 0 / 0$ & $0 / 0 / 0 / 0$ & $(+) /(+) / ? / ?$ & $-1-1-1-$ & $-1-1-1-$ \\
\hline & & $\mathrm{J} 3$ & $0 / 0 / 0 / 103$ & $0 / 0 / 0 / 103$ & $0 / 0 / 0 / 103$ & ? $|?| ? \mid ?$ & $-1-1-1 ?$ & $-1-1-1 ?$ \\
\hline
\end{tabular}

Tableau 25 : Résultats des 11 sujets présentant une RAl positive sur l'automate Qwalys® très faible dès J0. Les jours de test sont indiqués " J0 », " J1", " J2 » et " J3 ». Les températures sont indiquées " $C$ " pour le tube de départ centrifugé et repris chaque jour, puis " $4^{\circ}$ ", " $22^{\circ}$ " et " $38^{\circ}$ ". La colonne "Dépistage Qwalys ${ }^{\circledR}$ » transcrit les résultats bruts obtenus sur l'automate. La colonne "correspondance (correction technicien)" indique l'intensité d'agglutination correspondant aux valeurs chiffrées rendues par l'automate. Dans cette même colonne nous notons en rouge l'intensité réactionnelle lue et corrigée par le technicien habilité qui contrôle les résultats. De nombreuses images douteuses ne sont pas détectées par l'automate mais par le technicien. Pour le dernier sujet (anticorps non spécifique), les résultats de l'échantillon $\mathrm{J} 3+38^{\circ} \mathrm{C}$ sont douteux pour toutes les hématies-tests, ceci est dû à l'hémolyse de l'échantillon.

\section{- En résumé :}

L'hémolyse de l'échantillon, après 3 jours de conservation à $+38^{\circ} \mathrm{C}$, perturbe les résultats de RAI sur l'automate Qwalys ${ }^{\circledR}$.

Malgré une baisse d'intensité réactionnelle lorsque les échantillons sont conservés à $+38^{\circ} \mathrm{C}$, les anticorps irréguliers d'intensité élevée à J0 sont dépistés par l'automate ou par le technicien habilité qui contrôle les résultats, dans toutes les conditions de conservation.

En revanche, les anticorps irréguliers d'intensité plus faible à J0 perdent en intensité réactionnelle au fil des jours de conservation et à la température de $+38^{\circ} \mathrm{C}$, et risquent ainsi de ne pas être dépistés. Cependant la conservation à $+4^{\circ} \mathrm{C}$ tend à limiter ce risque. 


\section{4) TDA aux différentes conditions de conservation :}

- TDA négatifs :

Nous avons testé 30 TDA négatifs à J0. Dix-huit restent négatifs dans toutes les conditions de conservation testées, 12 sont douteux après 3 jours de conservation à $+38^{\circ} \mathrm{C}$ (l'un d'entre eux est douteux dès le $2^{\text {ème }}$ jour à $+38^{\circ} \mathrm{C}$ ) (Figure 38). Les résultats douteux sont caractérisés par une légère " accroche " dans la micro-colonne de réaction lgG (pour 9 échantillons), ou par des débris globulaires qui restent en surface du gel au niveau des 3 micro-colonnes, à cause de l'hémolyse (pour 3 échantillons).

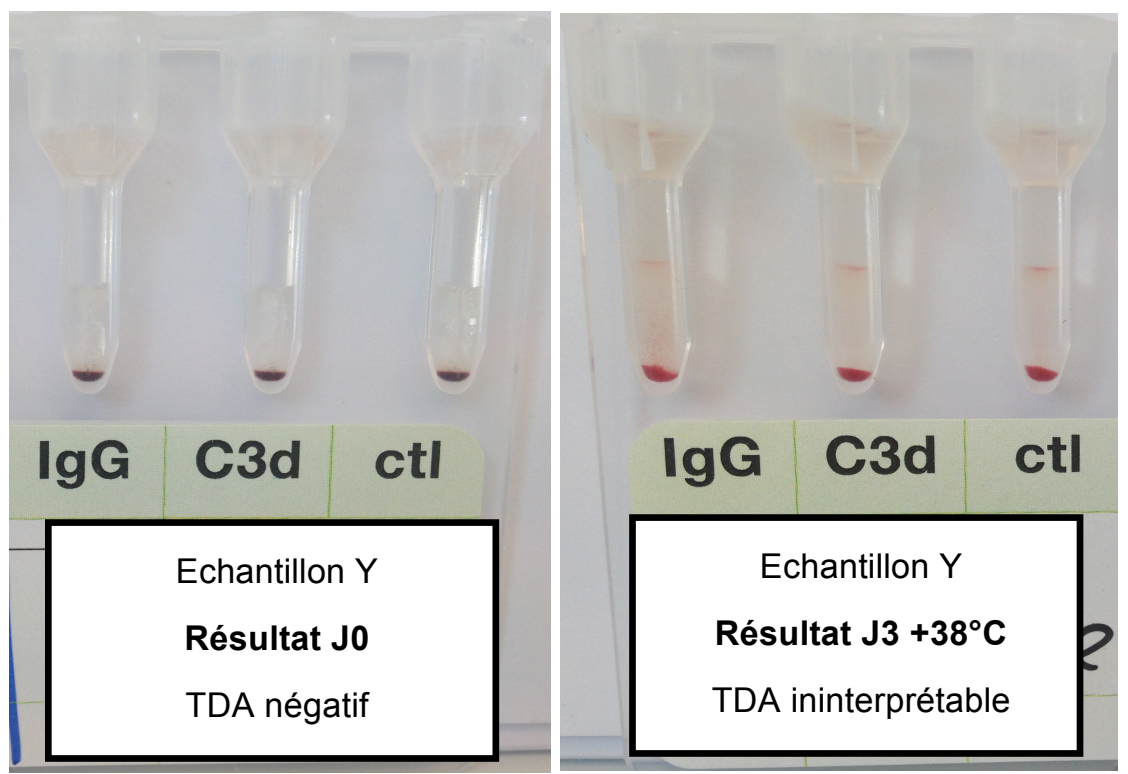

Figure 38: Photo des supports de gel microfiltration pour le TDA. A gauche le résultat négatif d'un échantillon à $J 0$ (sans conservation); A droite le résultat du même échantillon mais après 3 jours de conservation à $+38^{\circ} \mathrm{C}$ : l'hémolyse de l'échantillon perturbe la lecture du résultat, des débris globulaires restent en surface du gel, et la micro-colonne lgG présente une légère " accroche ".

- TDA positifs :

Nous présentons les résultats de 30 TDA positif à J0: 19 sont positifs uniquement en IgG, 3 sont positifs uniquement en C3d et 8 sont positifs mixtes (Tableau 26). 


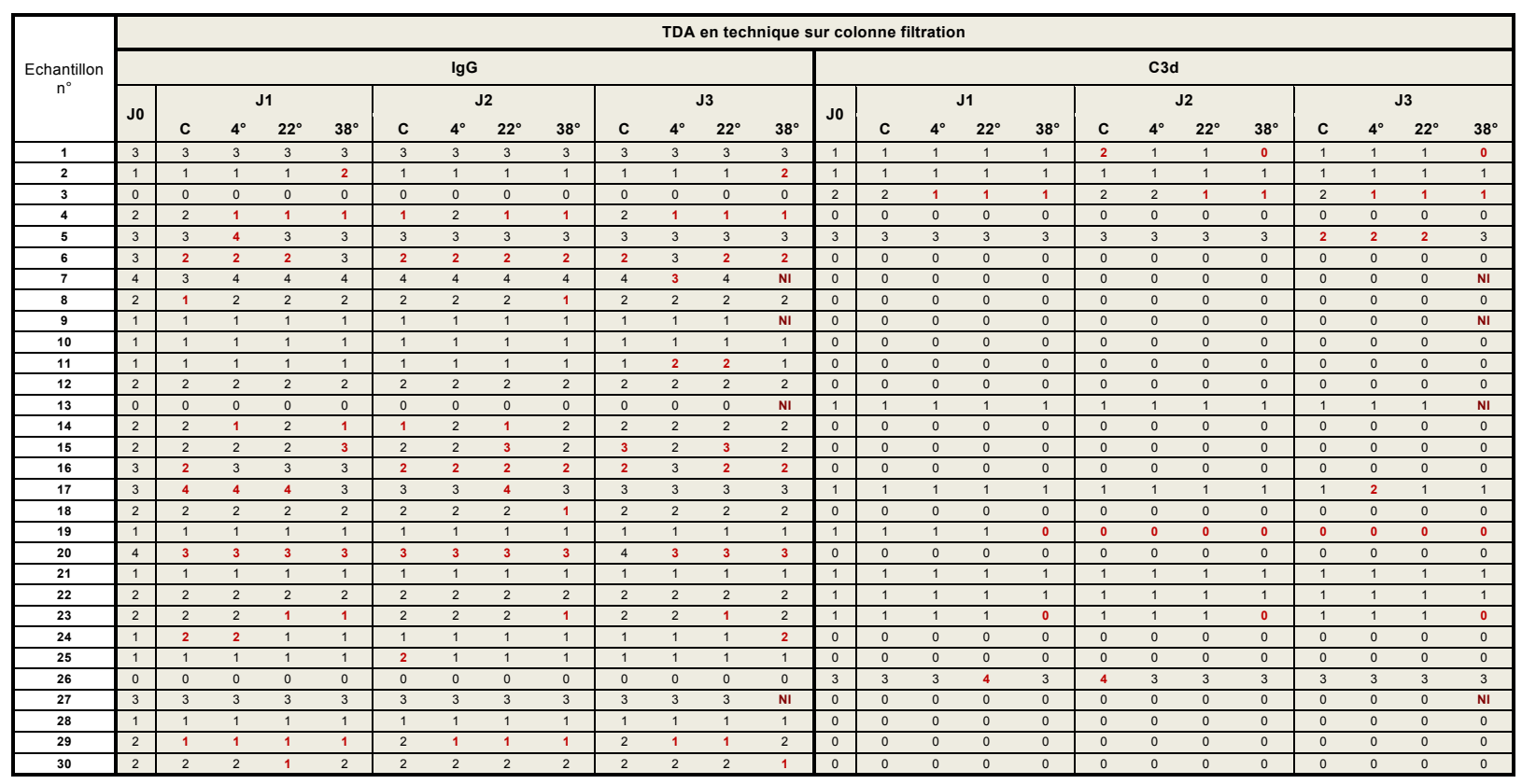

Tableau 26: Résultats des intensités réactionnelles des 30 TDA positifs, sur gel microfiltration. Les jours de test sont indiqués " J0 », " J1 », " J2 » et " J3 » et les températures sont indiquées " $C$ » pour le tube de départ centrifugé et repris chaque jour, puis " $4^{\circ}$ ", " $22^{\circ}$ " et " $38^{\circ}$ ". Les résultats pour lesquels «NI » est mentionné correspondent aux résultats non interprétés.

Nous observons, comme pour les TDA négatifs, des résultats douteux après 3 jours de conservation à $+38^{\circ} \mathrm{C}$ sur 4 échantillons.

Pour les 27 échantillons attendus positifs en lgG (19 lgG seuls et 8 mixtes), les intensités réactionnelles, obtenues dans les différentes conditions, varient seulement de 1+ (baisse ou hausse), sans démontrer de tendance concernant le délai de conservation ou bien la température de conservation.

Concernant les 11 échantillons attendus positifs en C3d (3 C3d seuls et 8 mixtes), nous observons une baisse des intensités réactionnelles pour 3 d'entre eux, dès le $1^{\text {er }}$ jour $\left(n^{\circ} 3\right)$, le $2^{\text {ème }}$ jour $\left(n^{\circ} 19\right)$ ou au $3^{\text {ème }}$ jour $\left(n^{\circ} 5\right)$. Pour 3 autres échantillons, nous observons une baisse d'intensité réactionnelle lorsque ceux-ci sont conservés à $+38^{\circ} \mathrm{C}\left(\mathrm{n}^{\circ} 1,19\right.$ et 23$)$ (Figure 39$)$. 


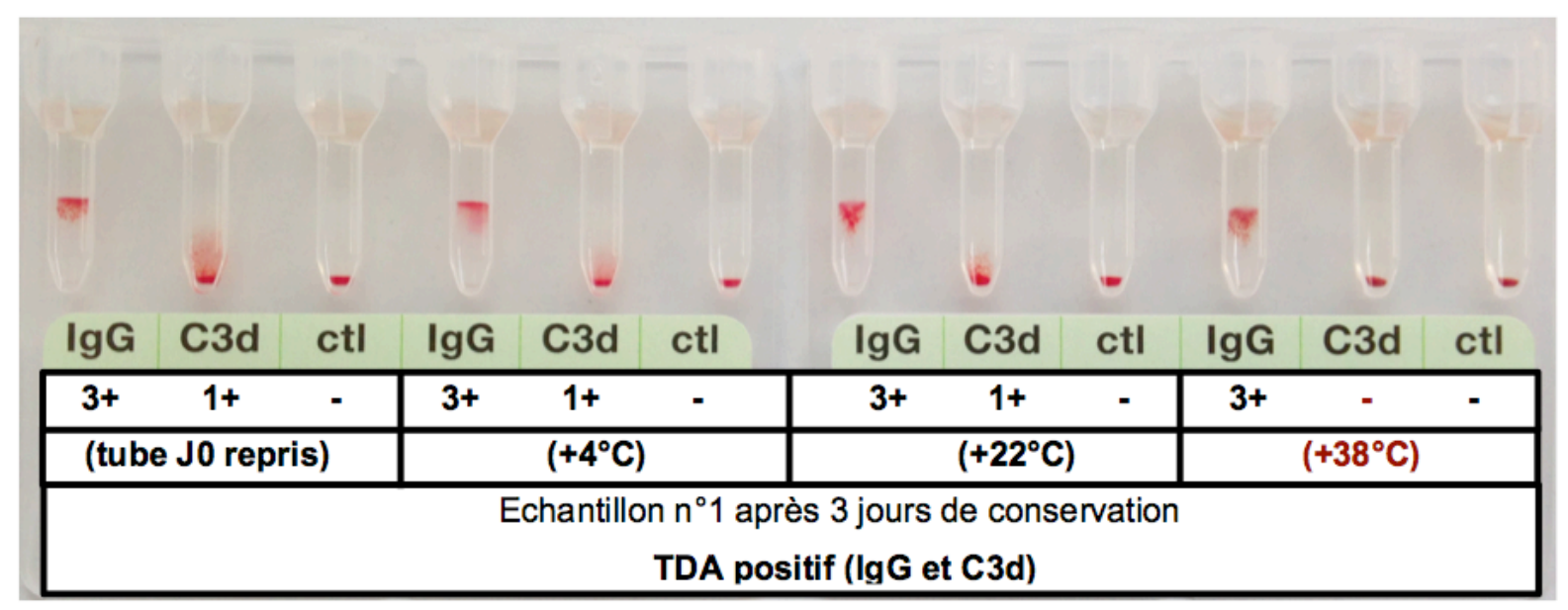

Figure 39 : Photo des supports de gel microfiltration pour le TDA de l'échantillon $n^{\circ} 1$ à J3. De gauche à droite les résultats de TDA réalisés : sur le tube de départ $J 0$ conservé à $+22^{\circ} \mathrm{C}$ et repris chaque jour de test, sur le sang total conservé à $+4^{\circ} \mathrm{C}$, sur le sang total conservé à $+22^{\circ} \mathrm{C}$ et sur le sang total conservé à $+38^{\circ} \mathrm{C}$. Tandis que l'intensité de la réaction de type lgG reste constante dans toutes les conditions de conservation, l'intensité de la réaction $\mathrm{C} 3 d$ devient nulle à la température de $+38^{\circ} \mathrm{C}$.

\section{- En résumé :}

Nous notons qu'après 3 jours de conservation à $+38^{\circ} \mathrm{C}$, des TDA initialement négatifs peuvent devenir douteux (IgG, C3d et puits contrôle).

Aucun échantillon positif de type IgG à J0 n'est devenu négatif au cours des 3 jours de tests, aux trois températures de conservation. En revanche, certains échantillons positifs de type $\mathrm{C} 3 \mathrm{~d}$ à $\mathrm{J} 0$ sont devenus négatifs lorsqu'ils sont conservés à $+38^{\circ} \mathrm{C}$ ( 2 échantillons) ou lorsqu'ils sont conservés plus de $24 \mathrm{~h}$ (pour 1 échantillon, quelle que soit la température).

\section{5) Test de Kleihauer aux différentes conditions de conservation :}

Nous avons analysé 34 échantillons. Plusieurs échantillons conservés à $+38^{\circ} \mathrm{C}$ ont présentés une altération partielle ou totale des globules rouges sur le frottis sanguin, rendant la lecture impossible. Cette hémolyse rend le test de Kleihauer ininterprétable. Ceci est observé le $3^{\text {ème }}$ jour pour 27 échantillons

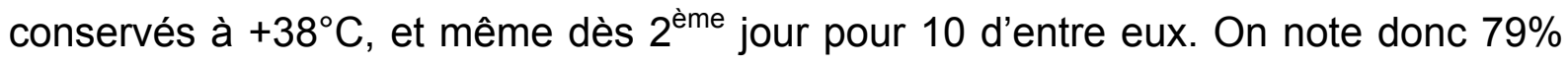
de frottis sanguins ininterprétables à J3 et $29 \%$ à J2, lorsque l'échantillon est maintenu à $+38^{\circ} \mathrm{C}$. Ainsi les résultats des échantillons conservés à $+38^{\circ} \mathrm{C}$ pendant 2 et 3 jours n'ont pas été analysés. 
Concernant les échantillons conservés à $+4^{\circ} \mathrm{C}$ et $+22^{\circ} \mathrm{C}$ pendant 3 jours, le frottis sanguin réalisé ne présente pas la même qualité que celui réalisé le J0. En effet, les hématies commencent à se déformer et on observe quelques échinocytes. Cependant, le résultat du test de Keihauer reste interprétable.

- Tests négatifs :

Les 20 prélèvements avec un test de Kleihauer négatif à J0 sont restés négatifs dans toutes les conditions de conservation.

- Tests positifs :

Les résultats des 14 prélèvements présentant un test de Kleihauer positif à J0 sont synthétisés dans le tableau 27. L'analyse statistique des résultats de comptes d'hématies fœtales pour les 14 échantillons positifs a été réalisée. Les résultats obtenus après 2 et 3 jours de conservation à $+38^{\circ} \mathrm{C}$ sont exclus de l'analyse en raison de l'hémolyse des échantillons rendant la majorité des résultats ininterprétable. Nous n'observons aucune différence significative ( $p$-valeur $>0,05$ ) entre les comptes d'hématies fœtales réalisés à $\mathrm{J} 0$ et ceux réalisés dans toutes les autres conditions de conservation (Figure 40).

\begin{tabular}{|c|c|c|c|c|c|c|c|c|c|c|}
\hline \multirow{3}{*}{$\begin{array}{c}\text { Echantillon } \\
n^{\circ}\end{array}$} & \multicolumn{10}{|c|}{ Test de Kleihauer (nb d'HF / 10000 HA) } \\
\hline & \multirow{2}{*}{ Jo } & \multicolumn{3}{|c|}{ J1 } & \multicolumn{3}{|c|}{ J2 } & \multicolumn{3}{|c|}{ J3 } \\
\hline & & $+4^{\circ} \mathrm{C}$ & $+22^{\circ} \mathrm{C}$ & $+38^{\circ} \mathrm{C}$ & $+4^{\circ} \mathrm{C}$ & $+22^{\circ} \mathrm{C}$ & $+38^{\circ} \mathrm{C}$ & $+4^{\circ} \mathrm{C}$ & $+22^{\circ} \mathrm{C}$ & $+38^{\circ} \mathrm{C}$ \\
\hline 1 & 2 & 2 & 1 & 2 & 2 & 1 & 2 & 1 & 1 & 1 \\
\hline 2 & 1 & 2 & 1 & 1 & 1 & 2 & 1 & 1 & 1 & 1 \\
\hline 3 & 136 & 146 & 146 & 141 & 150 & 156 & 140 & 157 & 148 & 1 \\
\hline 4 & 76 & 77 & 81 & 82 & 74 & 72 & 86 & 71 & 79 & 1 \\
\hline 5 & 43 & 42 & 45 & 43 & 45 & 39 & 1 & 42 & 45 & 1 \\
\hline 6 & 13 & 12 & 13 & 13 & 11 & 12 & 13 & 13 & 12 & 1 \\
\hline 7 & 31 & 33 & 37 & 29 & 36 & 38 & 1 & 31 & 39 & I \\
\hline 8 & 11 & 11 & 8 & 9 & 11 & 9 & I & 9 & 8 & I \\
\hline 9 & 168 & 161 & 173 & 149 & 171 & 172 & 162 & 156 & 171 & 1 \\
\hline 10 & 77 & 82 & 74 & 75 & 90 & 81 & $I$ & 89 & 79 & 1 \\
\hline 11 & 44 & 46 & 50 & 44 & 47 & 45 & 48 & 47 & 42 & 1 \\
\hline 12 & 10 & 10 & 9 & 11 & 10 & 13 & 10 & 10 & 12 & 1 \\
\hline 13 & 28 & 30 & 32 & 23 & 27 & 28 & 1 & 30 & 25 & 1 \\
\hline 14 & 8 & 10 & 9 & 8 & 10 & 8 & 8 & 10 & 10 & 1 \\
\hline
\end{tabular}

Tableau 27: Résultats des 14 tests de Kleihauer positifs, réalisés à J0, J1, J2 et J3, après conservation à $+4^{\circ} \mathrm{C},+22^{\circ} \mathrm{C}$ ou $+38^{\circ} \mathrm{C}$, avec la technique modifiée Shepard. Les 14 échantillons conservés 3 jours à $+38^{\circ} \mathrm{C}$ et 6 échantillons conservés 2 jours à $+38^{\circ} \mathrm{C}$ n'ont pu être analysés en raison de l'hémolyse de l'échantillon. 


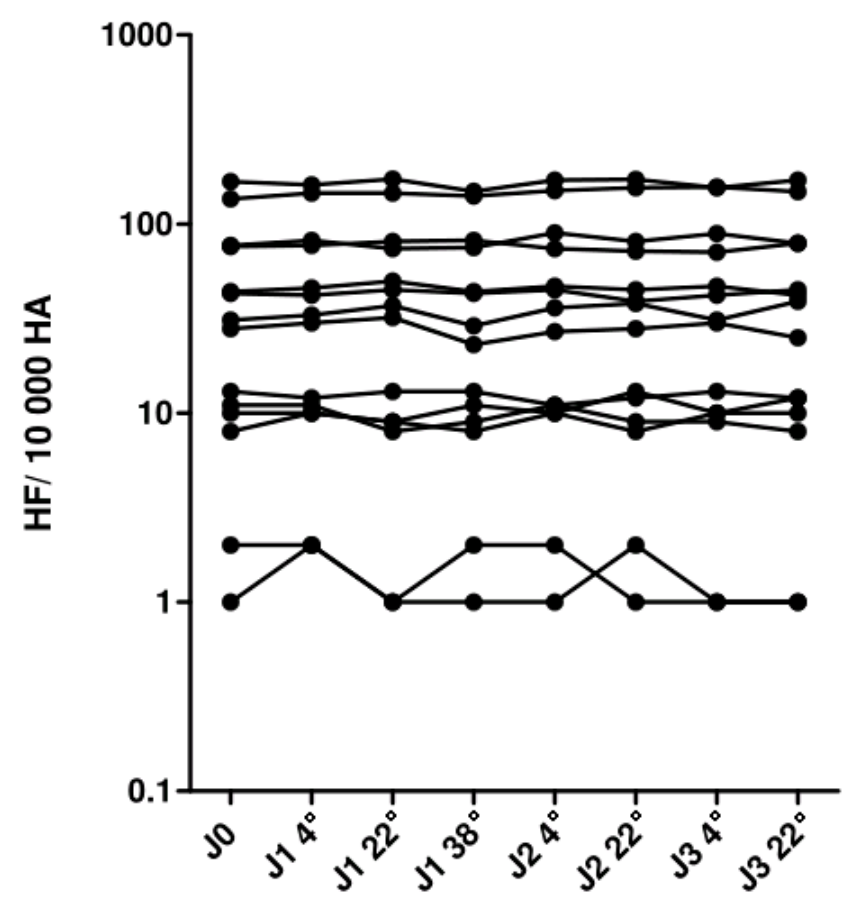

Figure 40: Représentation graphique (échelle logarithmique) des résultats de comptes d'hématies fœtales des 14 prélèvements positifs pour le test de Kleihauer.

- En résumé :

Aucune différence significative n'est observée au test de Kleihauer, pour tous les échantillons analysés (positifs et négatifs), entre le résultat de référence $(\mathrm{JO})$ et les résultats obtenus dans toutes les autres conditions de conservation. Cependant, la conservation des échantillons à $+38^{\circ} \mathrm{C}$ pendant plus d'un jour est à proscrire en raison de l'hémolyse qui altère la lecture du résultat. 


\section{DISCUSSION}

L'objectif de ce travail est d'étudier l'influence des conditions d'acheminement des échantillons biologiques sur les résultats des méthodes d'immuno-hématologie érythrocytaire. Ainsi, en soumettant les échantillons à différentes températures, sur un délai de un à trois jours, nous avons voulu simuler différentes conditions de transport des échantillons.

Pour respecter les exigences réglementaires, le laboratoire IHE de l'EFS accepte uniquement les échantillons primaires (non ré-étiquetés et non décantés). En revanche, nous n'avons pas les moyens de savoir si l'échantillon a été centrifugé au préalable puis ré-homogénéisé avant d'être adressé au laboratoire. C'est pourquoi nous avons également voulu étudier l'influence d'une centrifugation de l'échantillon, avant transmission, sur les résultats des examens. Pour les trois examens d'IHE nécessitant une étape de centrifugation (groupage ABORHK, RAI et TDA), nous avons testé, chaque jour, l'échantillon ayant servi à la réalisation de l'examen de référence à $\mathrm{J} 0$. Cet échantillon a été centrifugé à $\mathrm{J} 0$, puis de nouveau avant chaque examen à $\mathrm{J} 1, \mathrm{~J} 2$ et $\mathrm{J} 3$, il est conservé à $+22^{\circ} \mathrm{C}$ entre les examens. En parallèle nous avons analysé un échantillon de sang total, conservé également à $+22^{\circ} \mathrm{C}$, centrifugé une seule fois, juste avant la réalisation de l'examen. Aucune différence n'a été observée entre ces deux types d'échantillons.

Cette observation nous permet de nous assurer qu'une centrifugation préalable à l'envoi, vers le laboratoire de I'EFS, est sans conséquence sur la fiabilité des résultats rendus.

\section{- Groupage sanguin :}

Nous aborderons dans la discussion deux points d'interprétation :

- les résultats bruts de groupes sanguins (présence ou absence de l'antigène recherché),

- les intensités réactionnelles obtenues lors de la réalisation du groupage sanguin, utiles à la prestation de conseil. 


\section{Groupage sanguin $A B O$ :}

Les résultats de l'épreuve globulaire, obtenus jusqu'à trois jours de conservation aux températures de $+4^{\circ} \mathrm{C},+22^{\circ} \mathrm{C}$ et $+38^{\circ} \mathrm{C}$ sont conformes aux résultats de référence $(\mathrm{J} 0)$, pour les trois méthodes testées. Les intensités réactionnelles, pour les méthodes manuelles, sont élevées (supérieures à $3+$ ) et stables dans toutes les conditions de conservation. Les résultats de l'automate Galileo® ne sont pas significativement différents, dans toutes les conditions de conservation $(p>0,05)$.

Les résultats de l'épreuve plasmatique sont également conformes jusqu'à 3 jours de conservation aux températures de $+4^{\circ} \mathrm{C}$ et $+22^{\circ} \mathrm{C}$. Les essais de conservation à $+38^{\circ} \mathrm{C}$ mettent en évidence l'interférence de l'hémolyse de l'échantillon sanguin sur les résultats de l'épreuve plasmatique. En effet, la qualité de l'échantillon est altérée, induisant, pour certains échantillons, une discordance entre l'épreuve plasmatique et l'épreuve globulaire. Ceci est observé après 3 jours de conservation à $+38^{\circ} \mathrm{C}$ pour la méthode sur gel microfiltration et après 2 jours de conservation à $+38^{\circ} \mathrm{C}$ pour la méthode automatique sur automate Galileo®.

L'hémolyse peut donc être à l'origine d'un résultat inexact à l'épreuve plasmatique, mais la complémentarité entre les épreuves globulaire et plasmatique permet d'éliminer le risque de rendre un groupe sanguin $A B O$ erroné.

\section{Phénotypage sanguin RHK :}

Les résultats de phénotypage RHK obtenus jusqu'à 3 jours de conservation aux températures de $+4^{\circ} \mathrm{C}$ et $+22^{\circ} \mathrm{C}$ sont conformes aux résultats de références (JO), pour les trois méthodes testées. Il en est de même pour les échantillons conservés le premier jour à $+38^{\circ} \mathrm{C}$ (sur automate Galileo $®$ ) et les deux premiers jours à $+38^{\circ} \mathrm{C}$ (en techniques manuelles). Au delà, des perturbations de résultats peuvent être observées :

- Les résultats obtenus sur l'automate Galileo® montrent une différence significative $(p<0,01)$ sur l'antigène RH1 après 3 jours de conservation à $+38^{\circ} \mathrm{C}$, et pour l'antigène RH5 dès 2 jours de conservation à $+38^{\circ} \mathrm{C}$. L'analyse statistique n'a pas été réalisée pour l'antigène $K E L 1$, en raison du faible effectif, mais une baisse de réactivité est clairement observée dès 2 jours de conservation à $+38^{\circ} \mathrm{C}$. 
- Les intensités réactionnelles pour la méthode sur gel microfiltration sont élevées (supérieures à $3^{+}$) et restent très stables au fil des jours de conservation. Cependant, nous observons pour les deux sujets $\mathrm{RH}:-5$ de l'étude, une réaction positive après 3 jours de conservation à $+38^{\circ} \mathrm{C}$. L'hémolyse aurait pu conduire à un résultat erroné sur l'antigène $\mathrm{RH} 5$ et entrainer de graves conséquences en cas de transfusion chez ces sujets. En effet, une transfusion de concentrés de globules rouges (CGR) de phénotype $\mathrm{RH}$ : 5 chez un sujet $\mathrm{RH}$ : - 5 pourrait entraîner une éventuelle allo-immunisation.

- Concernant la méthode sur plaque, nous observons une baisse des intensités réactionnelles pour tous les antigènes $\mathrm{RH}$ et $\mathrm{KEL} 1$, au fil des jours de conservation, et particulièrement à $+38^{\circ} \mathrm{C}$. Dans notre étude, tous les échantillons conservés à $+4^{\circ} \mathrm{C}$ et $+22^{\circ} \mathrm{C}$ ont gardé une intensité réactionnelle d'au moins $2+$. En revanche après 3 jours de conservation à $+38^{\circ} \mathrm{C}$, l'intensité réactionnelle peut diminuer à 1+ pour l'antigène $\mathrm{RH} 4$. Tout antigène dont l'intensité réactionnelle est strictement inférieure à 2+, sur plaque, doit être contrôlé sur gel microfiltration afin de détecter un éventuel antigène faible ou variant. Pour des échantillons KEL : 1 , nous avons observé des réactions négatives après 3 jours de conservation à $+38^{\circ} \mathrm{C}$. Cet antigène KEL1 est connu pour être plus difficile à mettre en évidence que les autres antigènes, ceci peut, en partie, être expliqué par la faible présence de l'antigène KEL1 sur les hématies (entre 3500 et 17000 sites par hématie) (26). D'autre part, seuls deux clones de l'antigène KEL1 sont disponibles pour la fabrication des réactifs (anticorps monoclonal anti-KEL1) et le clone MS56, utilisé dans la méthode sur plaque (et dans toutes les autres méthodes sauf sur l'automate Galileoß), est connu pour son manque de performance. La conservation 3 jours à $+38^{\circ} \mathrm{C}$ pourrait donc conduire à rendre un résultat faussement négatif. II est probable qu'un variant avec un antigène faible ne soit pas détecté après conservation pendant 3 jours à $+38^{\circ} \mathrm{C}$. Cependant, en IHE, un antigène rendu faussement négatif n'a pas de conséquences en terme de sécurité transfusionnelle (absence de risque d'allo-immunisation).

II est donc indispensable pour le biologiste de connaître le délai entre le prélèvement et la réalisation du phénotypage, de manière à adapter son interprétation et ne pas engager d'examens complémentaires à la recherche d'un antigène faible ou variant, si la baisse d'intensité réactionnelle est expliquée par le délai ou la température de conservation de l'échantillon. De même, en cas 
d'antériorités connues pour le patient, la discordance de résultat observée entrainera des difficultés d'interprétation et des techniques complémentaires. Le retard au rendu du résultat pourrait être préjudiciable au patient.

\section{Détection des doubles populations RHK :}

Nous avons abordé dans cette étude la principale limite de méthode du groupage sanguin ABORHK : la capacité de détection des doubles populations. Les autres limites de méthode (variants, antigènes faibles) n'ont pas été étudiées dans notre effectif. De plus, les variants, à l'inverse des doubles populations, ne peuvent être créés artificiellement. Nous n'avons pas réalisé de doubles populations sur les antigènes du système $A B O$ pour des raisons techniques : notre étude porte sur la conservation des échantillons primaires, nous devions donc conserver uniquement du sang total. Or, il est impossible de mélanger deux échantillons de sang total non iso-groupes $A B O$, sans entrainer d'agglutination. En effet, la présence systématique, dans le plasma, des anticorps IgM correspondants aux antigènes absents de la surface des hématies entrainerait immédiatement l'hémagglutination de notre mélange non iso-groupe. Nous avons donc décidé d'étudier les doubles populations portant sur les antigènes RH et KEL1, afin de démontrer la robustesse des méthodes dans leurs limites de détection.

Cependant, notre mode opératoire de fabrication artificielle de doubles populations a introduit un biais dans les résultats. Nous avons réalisé des mélanges de deux échantillons de sang total, en proportion 50/50 d'antigènes négatifs et positifs, de manière à obtenir un taux de doubles populations détectable par les trois méthodes de groupage sanguin : en effet, les validations de méthodes réalisées au laboratoire IHE sur les techniques de routine ont permis de montrer la fiabilité de la détection des doubles populations dans cette proportion 50/50. L'étude de la capacité de détection des doubles populations, au cours des validations de méthodes, a été réalisée en mélangeant des culots globulaires, d'échantillons centrifugés, positifs et négatifs pour les antigènes testés. Dans ces conditions, le mélange est standardisé et s'affranchit de l'hématocrite des individus. Cependant, le protocole de notre étude, nous imposant l'utilisation d'échantillons de sang total, ne nous permet pas de maîtriser le taux d'hématocrite des sujets choisis et par conséquent la proportion d'hématies de chaque population dans l'échantillon final.

Cette hypothèse explique la non détection des doubles populations pour 2 
échantillons (un mélange RH4/RH-4 et un mélange KEL1/KEL-1). Pour ces deux échantillons, les doubles populations ne sont pas détectées par l'automate Galileo®, dès le groupage de référence à $\mathrm{J} 0$, ce qui indique que nos mélanges se trouvent en proportion inférieure au seuil de détection de la méthode. Ces doubles populations sont, en revanche, détectées par les deux méthodes manuelles, dont les seuils de détection sont différents.

Les résultats observés sont semblables à ceux mis en évidence lors de l'étude du phénotypage RHK : les doubles populations, pour tous les antigènes testés, sont détectées par les trois méthodes, sur les échantillons conservés à $+4^{\circ} \mathrm{C}$ et $+22^{\circ} \mathrm{C}$ jusqu'à 3 jours. La conservation à $+38^{\circ} \mathrm{C}$ entraine un défaut de détection des doubles populations pour certains antigènes: l'antigène RH3 (sur automate Galileo®, à 3 jours de conservation), l'antigène RH5 (sur gel microfiltration, à 3 jours de conservation) et sur l'antigène KEL1 (sur automate Galileo®, à 2 et 3 jours de conservation).

Ainsi, les résultats des groupages sanguins ABORHK démontrent la robustesse des trois méthodes testées, déjà évoquée dans les études précédentes $(55,56)$. II convient toutefois de préciser nos exigences à nos clients. L'acheminement des échantillons primaires doit être réalisé dans les $72 \mathrm{~h}$ suivant le prélèvement. Ces échantillons doivent être conservés entre $+2^{\circ} \mathrm{C}$ et $+8^{\circ} \mathrm{C}$ en cas de transmission différée, puis acheminés à température non dirigée, en évitant les températures négatives, et les températures supérieures à $+38^{\circ} \mathrm{C}$ pendant plus de $24 \mathrm{~h}$. Le laboratoire IHE doit en revanche être très attentif à l'aspect de l'échantillon et refuser tout échantillon présentant un aspect très hémolysé. Dans ce cas, un nouvel échantillon sera demandé, mais ce refus peut entrainer un retard à la transfusion, préjudiciable au patient.

\section{- Recherche d'anticorps irréguliers :}

L'hémolyse de l'échantillon, si celui-ci est conservé 3 jours à $+38^{\circ} \mathrm{C}$, peut perturber les résultats de RAI sur gel microfiltration (dépistage et identification) et sur automate Qwalys ${ }^{\circledR}$. L'hémolyse affecte autant les RAl négatives que les RAI positives. En cas de RAI négative rendue faussement positive, une identification complémentaire va être réalisée (délai de réalisation d'une heure minimum), voire 
d'autres techniques complémentaires (techniques enzymatiques, TDA,...). Ceci peut engendrer un retard à la transfusion. En cas de RAl positive, l'interférence de l'hémolyse peut générer des difficultés d'interprétation du résultat, engendrer la réalisation de techniques complémentaires ou nuire à la détection d'un anticorps hémolysant. En effet, certains anticorps, comme de rares anticorps anti-Lewis, habituellement sans conséquence transfusionnelle, peuvent devenir dangereux s'ils sont hémolysants à $+37^{\circ} \mathrm{C}(62)$.

Les anticorps irréguliers d'intensité élevée à J0 sont tous dépistés et identifiés dans toutes les conditions de conservation. Cependant, l'intensité réactionnelle sur gel microfiltration et les résultats de l'automate Qwalys ${ }^{\circledR}$ diminuent au fil des jours de conservation, et plus particulièrement lorsque l'échantillon est conservé à $+38^{\circ} \mathrm{C}$.

La même observation est faite pour les anticorps irréguliers d'intensité plus faible à $\mathrm{J} 0$ mais cette diminution de réactivité peut conduire à un résultat erroné de la RAI puisque certains anticorps ne sont plus dépistés ou identifiés (dès $24 \mathrm{~h}$ de conservation à $+38^{\circ} \mathrm{C}$, dès $48 \mathrm{~h}$ à $+22^{\circ} \mathrm{C}$ ). Un anticorps non détecté peut conduire à une inefficacité transfusionnelle, voire à un accident post-transfusionnel, en cas de transfusion de CGR incompatibles. Certains anticorps irréguliers, même de faible intensité sont considérés comme dangereux en transfusion, pouvant entrainer des hémolyses sévères $(63,64)$.

Deux points sont à discuter à ce sujet :

- Certains anticorps peuvent, s'ils sont trop faibles, ne pas être dépistés. La limite des méthodes de dépistage est alors atteinte, c'est un risque connu de la RAI.

- La plupart des laboratoires de biologie médicale réalisent uniquement le dépistage et adressent le prélèvement, en cas de dépistage positif, pour identification de l'anticorps au laboratoire IHE de l'EFS. Le délai d'acheminement peut varier de quelques heures à $48 \mathrm{~h}$. II est donc essentiel, dans ce cadre, que le laboratoire associe au prélèvement transmis les images et les intensités réactionnelles du dépistage. Devant une discordance de résultat observée à l'EFS, le biologiste devra tout mettre en œuvre pour s'assurer de la fiabilité du résultat rendu. Si les techniques complémentaires ne permettent pas de conclure de façon formelle, il est indispensable de demander un nouvel échantillon fraichement prélevé. La fiabilité du résultat peut être mise en doute par la conservation de l'échantillon, il est donc nécessaire de préciser nos exigences dans le manuel de prélèvement. 
La conservation à $+4^{\circ} \mathrm{C}$ a montré, à l'inverse, de meilleurs résultats qu'à $+22^{\circ} \mathrm{C}$. En effet, même si la réactivité de certains échantillons diminue au fil des jours, nous avons montré qu'elle reste plus élevée à cette température. Ces résultats sont cohérents avec les travaux menés en immunologie, indiquant une meilleure conservation des anticorps à $+4^{\circ} \mathrm{C}(48)$.

Nous avons confirmé la robustesse des méthodes de RAl, déjà évoquée dans les études précédentes $(55,56)$, pour les anticorps irréguliers d'intensité élevée. Toutefois, au regard des résultats de notre étude concernant les anticorps irréguliers de faible intensité, il semble nécessaire de prévoir une conservation et un acheminement des échantillons biologiques à $+4^{\circ} \mathrm{C}$ dans les $48 \mathrm{~h}$ ou bien à $+22^{\circ} \mathrm{C}$ dans les $24 \mathrm{~h}$. Si ces conditions ne peuvent être respectées, il est recommandé aux laboratoires de biologie médicale de confier directement le dépistage et l'identification au laboratoire IHE de l'EFS dès le prélèvement. Un acheminement à température non dirigée dans un délai de $72 \mathrm{~h}$ pourrait être toléré si le laboratoire associe, à l'échantillon transmis, les images et intensités réactionnelles obtenues lors du dépistage. En cas de discordance entre les résultats transmis par le laboratoire et ceux observés à l'EFS, un nouveau prélèvement fraichement prélevé sera demandé afin de ne pas risquer l'absence de détection d'un anticorps irrégulier d'intensité faible. Les clients doivent être informés que tout contrôle est susceptible de générer un retard à la transfusion.

\section{- Test direct à l'antiglobuline :}

L'hémolyse de l'échantillon, si celui-ci est conservé 3 jours à $+38^{\circ} \mathrm{C}$, peut perturber les résultats du TDA sur gel microfiltration. Cette perturbation touche autant les TDA négatifs que les TDA positifs. II y a donc un risque de rendre un résultat faussement positif ou faussement négatif, pouvant conduire à de mauvaises hypothèses diagnostiques. Un TDA faussement positif pourrait indiquer, à tort, une hémolyse d'origine immunologique et perturber l'exploration étiologique. A l'inverse, un TDA faussement négatif retarderait le diagnostic d'une hémolyse immunologique.

La méthode en gel filtration pour le test à l'antiglobuline (TDA) est une méthode sensible aux conditions de conservation de l'échantillon biologique. En 
effet, la réactivité du TDA peut diminuer au fil des jours de conservation (ceci est observé dès $24 \mathrm{~h}$ pour certains échantillons), particulièrement si l'échantillon est conservé à la température de $+38^{\circ} \mathrm{C}$, mais également à $+4^{\circ} \mathrm{C}$ et $+22^{\circ} \mathrm{C}$. Les variations observées au décours de la conservation des échantillons peuvent nuire à la fiabilité du résultat. En effet, cette baisse de réactivité du TDA, observée au delà de $24 \mathrm{~h}$ de conservation peut conduire, dans certains cas de notre étude, à sa négativation. Trois échantillons de notre étude ont présenté un résultat, de type $\mathrm{C} 3 \mathrm{~d}$, faussement négatif (seulement à $+38^{\circ} \mathrm{C}$ pour 2 échantillons, mais à toutes les températures pour 1 échantillon).

Le TDA est réalisé à la demande du clinicien dans plusieurs cas :

- pour un nouveau-né, en cas de suspicion d'incompatibilité fœto-maternelle,

- pour un patient présentant une anémie hémolytique,

- devant une inefficacité transfusionnelle.

L'interprétation du résultat se fait au regard d'éventuelles antériorités du patient, une variation de l'intensité réactionnelle du TDA doit être surveillée. En effet, dans certaines anémies auto-immunes, l'intensité réactionnelle du TDA est utile pour suivre l'efficacité d'un traitement immuno-modulateur.

Le TDA est plus largement ajouté à l'initiative du biologiste de l'EFS, devant un résultat d'identification évoquant un auto-anticorps ou un allo-anticorps fixé sur les hématies (65), ou bien devant un groupe sanguin ininterprétable. C'est dans ces cas où le TDA est ajouté en seconde intention qu'il convient d'être attentif au délai entre le prélèvement et la réalisation de l'examen. II est donc indispensable que le biologiste interprète le résultat en prenant en considération les conditions de conservation et d'acheminement de l'échantillon sanguin.

Au regard de nos résultats et en accord avec les données de la littérature (11), il est proposé qu'une demande de TDA par un client soit transmise dans un délai de $48 \mathrm{~h}$. Le transport peut être réalisé à température non dirigée, en évitant les températures négatives, et les températures supérieures à $+38^{\circ} \mathrm{C}$ pendant plus de $24 \mathrm{~h}$. Un contrôle visuel de l'échantillon sanguin par un technicien habilité devra être effectué. Les échantillons présentant un aspect hémolysé seront refusés et un nouvel échantillon sera demandé. 
Tout ajout d'un TDA par l'EFS sur une demande d'examen doit s'accompagner de la vérification du délai entre le prélèvement et la réalisation de l'examen.

\section{- Test de Kleihauer :}

L'hémolyse de l'échantillon, après 2 et 3 jours de conservation à la température de $+38^{\circ} \mathrm{C}$, altère considérablement la qualité du frottis sanguin pour le test de Kleihauer, rendant le résultat ininterprétable. Les résultats des tests de conservation de 2 et 3 jours à $+38^{\circ} \mathrm{C}$ n'ont donc pas été analysés statistiquement. En revanche, si l'échantillon est conservé jusqu'à 3 jours à la température de $+4^{\circ} \mathrm{C}$ ou de $+22^{\circ} \mathrm{C}$, la qualité du frottis sanguin est altérée mais le résultat reste interprétable : les hématies peuvent prendre la forme d'échinocytes mais les hématies fœtales sont toujours mises en évidence par leur couleur rose pâle. Ce point sur la conservation prolongée du test de Kleihauer est important puisque cet examen n'est pas urgent, hors contexte d'hémorragie fœto-maternelle avérée. Sa réalisation peut donc être différée. Cependant, notre protocole induit un biais puisque nous étudions des résultats connus positifs à $\mathrm{J} 0$, il est alors beaucoup plus aisé de lire le frotti malgré quelques échinocytes.

Nous avons testé des échantillons positifs avec différents taux d'hématies fœtales, notamment des taux proches du seuil décisionnel (8 HF pour 10000 HA). Les résultats n'ont pas montré de différence significative $(p$-valeur $>0,05)$ entre le résultat de référence $(\mathrm{J} 0)$ et les résultats obtenus après 1,2 ou 3 jours de conservation à $+4^{\circ} \mathrm{C}$ et $+22^{\circ} \mathrm{C}$, ni après 1 jour de conservation à $+38^{\circ} \mathrm{C}$. La prise en charge de la patiente ne sera donc pas impactée par la conservation de l'échantillon biologique.

Nos résultats montrent la robustesse du test de Kleihauer pour des échantillons conservés jusqu'à 3 jours à $+4^{\circ} \mathrm{C}$ et $+22^{\circ} \mathrm{C}$. La méthode tolère également une conservation à la température de $+38^{\circ} \mathrm{C}$ mais dans un délai inférieur à $24 \mathrm{~h}$. Au regard des données de la littérature en hématocytologie (50-52) et de notre expérience à l'EFS, il apparaît préférable de conserver les échantillons entre $+2^{\circ} \mathrm{C}$ et $+8^{\circ} \mathrm{C}$, en cas de réalisation différée de l'examen. 
L'acheminement des échantillons primaires doit être réalisé dans les $72 \mathrm{~h}$ suivant le prélèvement, à température non dirigée, en évitant les températures négatives, et les températures supérieures à $+38^{\circ} \mathrm{C}$ pendant plus de $24 \mathrm{~h}$. En revanche tout échantillon hémolysé sera refusé, le frottis sanguin étant illisible à cause de la destruction des hématies, et un nouvel échantillon fraichement prélevé sera demandé.

\section{- Perspectives:}

Notre étude a confirmé la robustesse des méthodes de groupage sanguin testées. Cependant, les résultats de ce travail nous incitent à explorer ces méthodes dans leurs limites. Parmi, ces limites, seule la capacité de détection des doubles populations a été étudiée, sur un faible effectif d'échantillons créés artificiellement. II serait donc important de poursuivre ce travail sur un effectif plus conséquent, de patients récemment transfusés et porteurs de doubles populations, notamment sur le système $A B O$. De même, pour parfaire l'exploration des limites des méthodes de groupage sanguin, il serait souhaitable de tester la conservation d'échantillons biologiques de sujets porteurs d'antigènes faibles ou variants, de manière à analyser l'influence du délai de conservation et de la température de conservation sur la capacité de détection de ces antigènes.

Compte tenu de nos résultats concernant la RAI, il semble indispensable de poursuivre l'étude sur une cohorte plus importante d'anticorps de faible intensité, de manière à optimiser leur conservation en vue de leur détection. En revanche, nous avons mis en évidence une meilleure conservation des anticorps irréguliers à $+4^{\circ} \mathrm{C}$. Afin de vérifier que les échantillons sont conservés avant transmission selon nos recommandations, il apparaît nécessaire que nous puissions nous assurer du respect de celles-ci au sein des laboratoires clients.

Nous avons également mis en évidence la perte de réactivité du TDA au fil des jours de conservation. Les résultats obtenus tendent à montrer qu'il est préférable de réaliser le TDA dans les 24 heures qui suivent le prélèvement. Toutefois, ce délai très court est contraignant pour les laboratoires de biologie 
médicale et nos tests n'ont porté que sur 30 échantillons de TDA positifs. Poursuivre ce travail sur un effectif plus important semble indispensable pour discuter du délai entre le prélèvement et la réalisation du TDA.

Enfin, le test de Kleihauer est un examen de lecture et d'interprétation délicates, en particulier lorsque la patiente présente une pathologie de l'hémoglobine. L'expérience des techniciens est donc fondamentale. Notre travail porte uniquement sur 2 tests de Kleihauer positifs (issus de patientes) et sur 12 tests de Kleihauer positifs créés artificiellement. II serait donc intéressant de tester la conservation des échantillons sur un effectif plus grand, et notamment de tester les limites de la méthode en réalisant des tests de Kleihauer chez des patientes présentant une hémoglobinopathie. 


\section{CONCLUSION}

Mémoire soutenu par $M^{\text {alk }}$ Elise BOITEUX

\section{TITRE : EVALUATION DE LA ROBUSTESSE DES EXAMENS D'IMMUNO-HEMATOLOGIE ERYTHROCYTAIRE EN FONCTION DU DELAI ET DE LA TEMPERATURE D'ACHEMINEMENT DES ECHANTILLONS BIOLOGIQUES}

Les examens d'immuno-hématologie érythrocytaires sont essentiels pour garantir la sécurite transfusionnelle, diagnostiquer les syndromes hemolytiques at assurer le suivi de la femme enceinte. Le laboratoire d'immuno-hématologie érythrocytaire de l'Etablissement Français de Sang, site de Grenoble, réalise ces examens pour le CHU de Grenoble, d'autres établissements de soins et laboratoires de biologie médicale.

Dans le cadre de l'accréditation des laboratoires de biologie médicale, il est indispensable de vérifier la robustesse des mèthodes dianalyses en fonction des conditions dacheminement des échantillons biologiques. Nous avons testé la robustesse du groupage sanguin ABORHK (ítechniques sur plaque, sur gel microfiltration, et sur automate Galileo), de la RAI (techniques sur gel microfiltration et sur automate Qwalys), du TDA (technique sur gel microfiltration) et du test de Kleihauer (technique Shepard modifiée). Différentes conditions d'acheminement ont été étudiées : dèlais de 1,2 ou 3 jours, températures de conservation de $+4^{\circ} \mathrm{C},+22^{\circ} \mathrm{C}$ et $+38^{\circ} \mathrm{C}$, échantillons centrifugès ou non avant transport.

Nos résultats démontrent la robustesse des mèthodes de groupage sanguin ABORHK, de RAI et du test de Kleihauer, sur des échantillons conservés jusqu'à trois jours $a ̀+4^{\circ} \mathrm{C}$ et $+22^{\circ} \mathrm{C}$. Ces méthodes sont également robustes pour des échantillons conservés à $+38^{\circ} \mathrm{C}$ pendant $24 \mathrm{~h}$, au delà la qualité de l'échantillon se dégrade et les résultats ne sont plus fiables. Nous montrons que les résultats du TDA sont sensibles aux délais d'acheminement et aux températures de conservation. Pour l'ensemble des examens évalués, nous montrons que la centrifugation avant transmission ne génère pas d'interférences sur les résultats.

Ce travail constituera la base d'une révision des exigences, des 10 laboratoires d'IHE de l'EFS RA, définies dans le manuel de prèlèvement, en précisant les conditions de conservation de l'échantillon biologique avant et pendant le transport vers I'EFS.

\section{VU ET PERMIS D'IMPRIMER}

Grenoble, le 15 septembre 2014
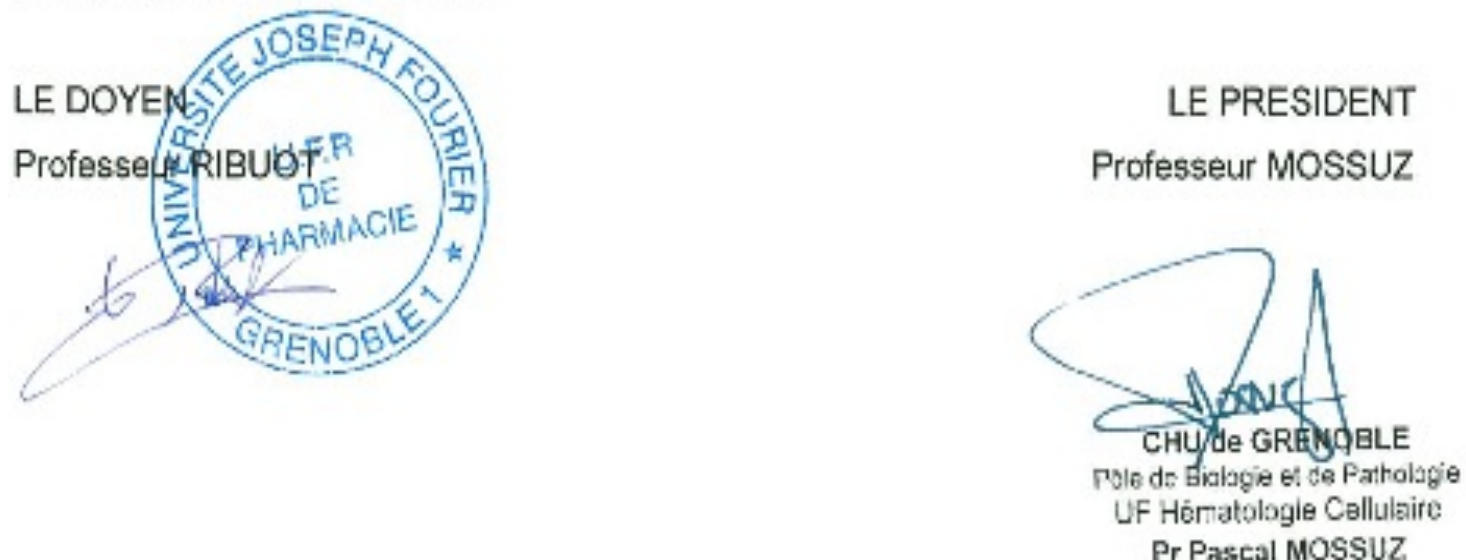


\section{BIBLIOGRAPHIE}

1. Laboratoires d'analyses de biologie médicale - Exigences concernant la qualité et la compétence. Norme NF EN ISO 15189. décembre 2012 ; www.afnor.org.

2. Article L6211-1 du Code de la Santé Publique. www.legifrance.gouv.

3. Ordonnance $n^{\circ} 2010-49$ du 13 janvier 2010 relative à la biologie médicale, modifiée par la Loi 2003-442 ; Mai 2013. www.legifrance.gouv.

4. GUI2008 Guide de la qualité environnementale dans l'architecture et l'urbanisme à Grenoble. 2008 ; http://fr.scribd.com/doc/8822307/GUI2008-qualite-Environnementale-ArchitectureUrbanisme-a-Grenoble-FR.

5. Janeway C, Travers P. Immunobiologie. 3ème édition. De Boeck Université; 2009.

6. L'Italien R. Immunohématologie. CCMD; 2008.

7. Goudemand M, Salmon C. Immunohématologie et Immunogénétique. Flammarion MédecineSciences; 1980.

8. Roitt $\mathrm{Y}$, Brostoff J, Male D. Immunology. 3ème édition, Traduction de la 6ème édition anglaise. De Boeck Université; 2002.

9. Miquel E, Cavelier B, Bonneau JC, Rouger P. Incompatibilités fœtomaternelles érythrocytaires (IFME): de la surveillance immunohématologique des femmes enceintes à la maladie hémolytique du nouveau-né (MHNN). Transfus Clin Biol. 2005;12(1):45-55.

10. Fernandes HP, Cesar CL, Barjas-Castro M de L. Electrical properties of the red blood cell membrane and immunohematological investigation. Rev Bras Hematol $E$ Hemoter. 2011;33(4):297-301.

11. Chiaroni J, Roubinet F, Bailly $P$, Mannessier L. Les analyses immunohématologiques et leurs applications cliniques. John Libbey Eurotext; 2012.

12. Van Oss CJ, Absolom DR. Zeta potentials, van der Waals forces and hemagglutination. Vox Sang. 1983;44(3):183-90.

13. Pollack W, Reckel RP. A reappraisal of the forces involved in hemagglutination. Int Arch Allergy Appl Immunol. 1977;54(1):29-42.

14. Van Oss CJ, Mohn JF, Cunningham RK. Influence of various physicochemical factors on hemagglutination. Vox Sang. 1978;34(6):351-61.

15. Circulaire DGS/DHOS/AFSSAPS n $03-582$ du 15 décembre 2003 relative à l'acte transfusionnel. www.hemovigilance-cncrh.fr.

16. Décret $n^{\circ} 92-143$ du 14 février 1992 relatif aux examens obligatoires prénuptial, pré- et post-natal, version consolidée du 26 mai 2003. www.legifrance.gouv.

17. Mannessier L. Suivi immunohématologique des femmes enceintes: nouvelles recommandations. Transfus Clin Biol. 2009;16(2):195-200.

18. Cartron J, Rouger P. Bases moléculaires des antigènes des groupes sanguins: de l'immunogénétique à la biologie cellulaire. Masson; 1998.

19. Arrêté du 26 avril 2002 modifiant l'arrêté du 26 novembre 1999 relatif à la bonne exécution des analyses de biologie médicale. www.legifrance.gouv.

20. Chiaroni J. Les bonnes pratiques d'immunohématologie clinique. Transfus Clin Biol. 2003;10(3):244-51. 
21. International Society of Blood Transfusion. Table of blood group antigens v3.3 [Internet]. Available from:

http://www.isbtweb.org/fileadmin/user_upload/WP_on_Red_Cell_Immunogenetics_and/Updates/T able_of_blood_group_antigens_within_systems_v3.3_131028.pdf

22. Peyrard T. La Transfusion des patients présentant un groupe sanguin rare : défis et perspectives [Internet]. SwissTransfusion 2013; 5 septembre 2013, Available from: http://www.swisstransfusion.ch/_pdf/Thierry\%20Peyrard_La\%20transfusion\%20des\%20patients\% 20pr\%C3\%A9sentant\%20un\%20groupe\%20sanguine\%20rare.pdf

23. Aymard J-P. Karl Landsteiner (1868-1943) et la découverte des groupes sanguins. Transfus Clin Biol. 2012;19(4-5):244-8.

24. Schwarz HP, Dorner F. Karl Landsteiner and his major contributions to haematology. $\mathrm{Br} J$ Haematol. 2003;121(4):556-65.

25. Daniels G. Structure and function of red cell surface antigens. ISTB Science Series. 2006;1:3-8.

26. Chiaroni J, Ferrera V, Dettori I, Roubinet F. Groupes sanguins érythrocytaires. EMC Hématologie. 2005;2(2):53-112.

27. Homberg J-C. Immunologie fondamentale: $2 e$ cycle des études de médecine, de pharmacie et d'odontologie. De Boeck Secundair; 1999.

28. Pham B-N, Le Pennec P-Y, Rouger P. Allo-immunisation anti-érythrocytaire. Transfus Clin Biol. 2012;19(6):321-32.

29. Rigal D, Meyer F, Mayrand E, Dupraz F. Les allo-immunisations fœto-maternelles antiérythrocytaires : état de l'art en 2008. Rev Francoph Lab. 2008;(402):51-62.

30. Daniels G, Poole J, de Silva M, Callaghan T, MacLennan S, Smith N. The clinical significance of blood group antibodies. Transfus Med. 2002;12(5):287-95.

31. Heier HE, Namork E, Calkovská Z, Sandin R, Kornstad L. Expression of A antigens on erythrocytes of weak blood group A subgroups. Vox Sang. 1994;66(3):231-6.

32. Lopez M, Le Meud J, Gerbal A, Salmon C. Measurement of weak B phenotypes by quantitative agglutination. Nouv Rev Fr Hématologie. 1973;13(1):107-17.

33. Flegel WA, Wagner FF. Molecular biology of partial $D$ and weak $D$ : implications for blood bank practice. Clin Lab. 2002;48(1-2):53-9.

34. Duboeuf S, Flourié F, Courbil R, Benamara A, Rigal E, Cognasse F, et al. Identification d'alloanticorps et leurs associations : bilan d'une année à l'Etablissement Français de Sang AuvergneLoire. Transfusion Clin Biol. 2012;19:358-65.

35. Roubinet $F$, Mannessier L, Chiaroni $J$, Lauroua $P$. Aide à la décision en immunohématologie: recherche des anticorps anti-érythrocytaires (RAI). Transfus Clin Biol. 2000;7(5):513-8.

36. Décision du 6 novembre 2006 définissant les principes de bonnes pratiques prévus à l'article L. 1223-3 du code de la santé publique. www.legifrance.gouv.

37. Meyer F, Raba M. Le test de Coombs direct. Rev Fr Lab. 1996;(282):195-8.

38. Gehrs BC, Friedberg RC. Autoimmune hemolytic anemia. Am J Hematol. 2002;69(4):258-71.

39. Chiaroni J. Risque immuno-hémolytique des transfusions sanguines et analyses d'immunohématologieérythrocytaire. Rev Fr Lab. 2003;(355):45-51.

40. Bollotte $A$, Vial $T$, Bricca $P$, Bernard $C$, Broussolle $C$, Sève $P$. Les anémies hémolytiques immunologiques médicamenteuses: étude rétrospective de 10 observations. Rev Médecine Interne [Internet]. 2014; Available from: http://dx.doi.org/10.1016/j.revmed.2014.05.009 
41. Kleihauer $\mathrm{E}$, Braun $\mathrm{H}$, Betke K. [Demonstration of fetal hemoglobin in erythrocytes of a blood smear]. Klin Wochenschr. 1957;35(12):637-8.

42. Kim YA, Makar RS. Detection of fetomaternal hemorrhage. Am J Hematol. 2012;87(4):417-23.

43. Cortey A, Brossard Y. Prévention de l'allo-immunisation Rhésus-D fœto-maternelle - Aspects pratiques. J Gynecol Obstet Biol Reprod. 2006;35(suppl. au n¹):123-30.

44. Boyanton BL, Blick KE. Stability studies of twenty-four analytes in human plasma and serum. Clin Chem. 2002;48(12):2242-7.

45. Stahl M, Brandslund I. Controlled storage conditions prolong stability of biochemical components in whole blood. Clin Chem Lab Med. 2005;43(2):210-5.

46. Heins M, Heil W, Withold W. Storage of serum or whole blood samples? Effects of time and temperature on 22 serum analytes. Eur J Clin Chem Clin Biochem. 1995;33(4):231-8.

47. Hankinson SE, London SJ, Chute CG, Barbieri RL, Jones L, Kaplan LA, et al. Effect of transport conditions on the stability of biochemical markers in blood. Clin Chem. 1989;35(12):2313-6.

48. Johnson M. Durée de vie des anticorps ou comment stocker les anticorps. 2013; Available from: http://www.labome.fr/method/Antibody-Shelf-Life-How-to-Store-Antibodies.html

49. Vaisman A, Paris-Hamelin A. Conservation des anticorps sériques dans la syphilis. Bull World Health Organ. 1966;34(3):461-6.

50. ANAES. Lecture critique de l'hémogramme: valeurs seuils à reconnaître comme probablement pathologiques et principales variations non pathologiques. 1997;

51. Trimoreau F, Gachard N, Leymarie V, Frébet E, Perroud P, Feuillard J. Etapes préanalytiques pour la numération et cytologie sanguine. EMC - Biol Médicale. 2011;1-10.

52. Imeri F, Herklotz R, Risch L, Arbetsleitner C, Zerlauth M, Risch GM, et al. Stability of hematological analytes depends on the hematology analyser used: a stability study with Bayer Advia 120, Beckman Coulter LH 750 and Sysmex XE 2100. Clin Chim Acta. 2008;397(1-2):68-71.

53. Expression et évaluation des portées d'accréditation - SH REF 08 - Révision 01, mars 2012 ; www.cofrac.fr.

54. Guide technique d'accréditation de vérification (portée A) / validation (portée B) des méthodes en biologie médicale - SH GTA 04 - Révision 00, avril 2011; www.cofrac.fr.

55. Mannessier L, Delamaire M, Bouix O, Krause C, Roubinet F. Maîtrise des tolérances métrologiques : application à la recherche des anticorps anti-érythrocytaires (RAI) en test indirect à l'antiglobuline (TIA) et au groupage sanguin $A B O$ par les procédés de filtration et en microplaque. Transfus Clin Biol. 2006;13(4):271-7.

56. Bouix O, Sanchez P, Reifenberg J-M. Définition des erreurs maximales tolérées pour les grandeurs physiques ayant un effet significatif sur le résultat du groupage $\mathrm{ABO}-\mathrm{RH} 1$ en technique microplaque. Transfus Clin Biol. 2007;14(3):348-51.

57. Grey D, Connolly M, Erber WN. Comparison of low ionic diluents for use with the Diamed antiglobulin gel test. Transfus Med. 2002;12(1):63-9.

58. Malomgré W, Neumeister B. Recent and future trends in blood group typing. Anal Bioanal Chem. 2009;393(5):1443-51.

59. Lapierre Y, Rigal D, Adam J, Josef D, Meyer F, Greber S, et al. The gel test: a new way to detect red cell antigen-antibody reactions. Transfusion. 1990;30(2):109-13. 
60. Schoenfeld H, Bulling K, von Heymann C, Neuner B, Kalus U, Kiesewetter H, et al. Evaluation of immunohematologic routine methods using the new erythrocyte-magnetized technology on the QWALYS 2 system. Transfusion. 2009;49(7):1347-52.

61. Bouix O, Ferrera V, Delamaire M, Redersdorff JC, Roubinet F. Erythrocyte-magnetized technology: an original and innovative method for blood group serology. Transfusion. 2008;48(9):1878-85.

62. Hoglund $P$, Rosengren-Lindquist $R$, Wikman AT. A severe haemolytic transfusion reaction caused by anti-Lea active at 37 ?C. Blood Transfus. 2013;11(3):456-9.

63. Liu C, Grossman BJ. Antibody of undetermined specificity : frequency, laboratory features, and natural history. Transfusion. $2013 ; 53: 931-938$.

64. Wright T, Brown P, Marais I, Hong FS. Acute haemolytic reaction due to anti-Wb : a case report. Vox Sanguinis. $2013 ; 105: 355-358$.

65. Aygun B, Padmanabhan S, Paley C, Chandrasekaran V. Clinical significance of RBC alloantibodies and autoantibodies in sickle cell patients who received transfusions. Transfusion. 2002;42(1):37-43. 


\section{ANNEXES}

Amplitude thermique année 2004

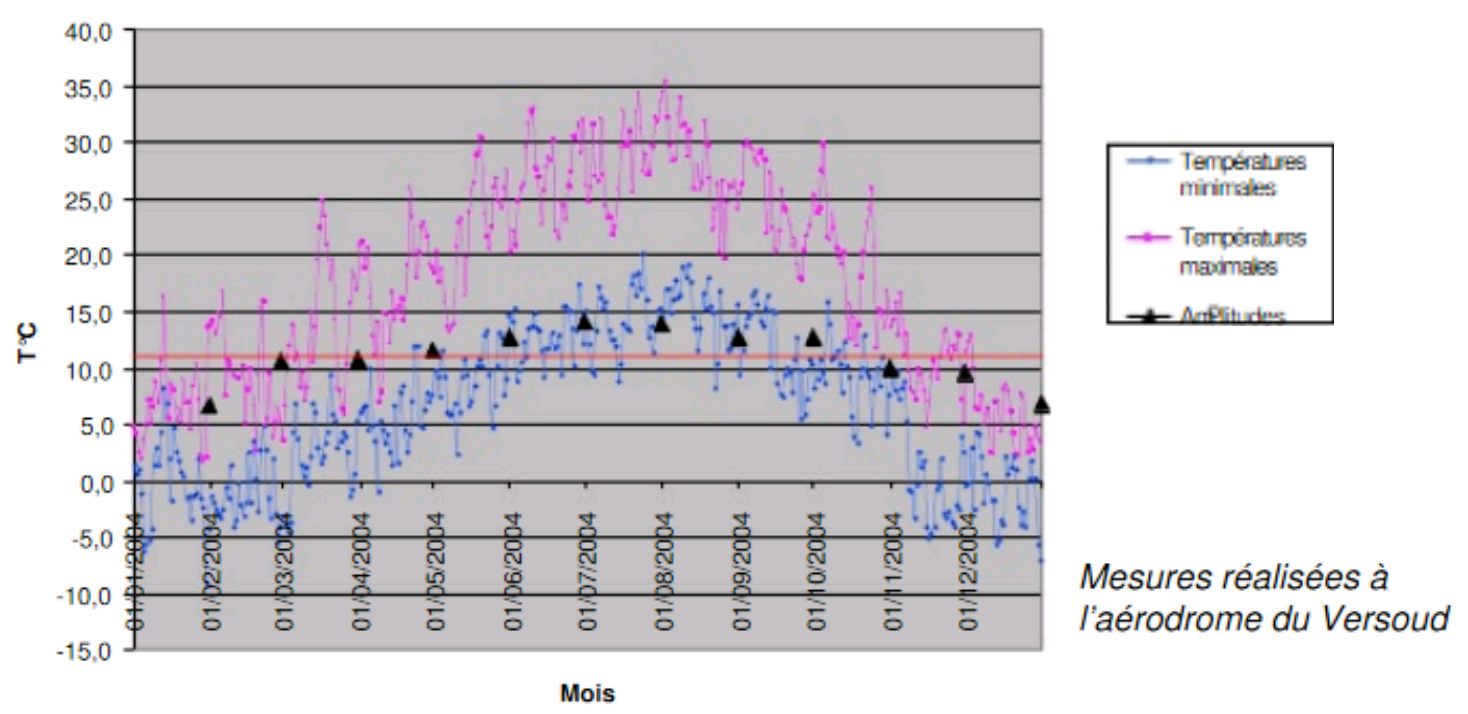

Annexe 1 : Amplitudes thermiques mensuelles estivales et hivernales de l'année 2004, sur la ville de Grenoble. GUI2008 Guide de la qualité environnementale dans l'architecture et l'urbanisme à Grenoble. 2008;

http://fr.scribd.com/doc/8822307/GUI2008-qualite-Environnementale-ArchitectureUrbanisme-a-Grenoble-FR. 
Table of blood group systems

\begin{tabular}{|c|c|c|c|c|c|}
\hline No. & System name & $\begin{array}{l}\text { System } \\
\text { symbol }\end{array}$ & Gene name(s)* & $\begin{array}{l}\text { Chromosomal } \\
\text { location }\end{array}$ & $\begin{array}{l}C D \\
\text { numbers }\end{array}$ \\
\hline 001 & $\mathrm{ABO}$ & $\mathrm{ABO}$ & $A B O$ & $9 q 34.2$ & \\
\hline 002 & MNS & MNS & GYPA, GYPB, GYPE & $4 q 31.21$ & CD235 \\
\hline 003 & P1PK & P1PK & $A 4 G A L T$ & $22 q 13.2$ & \\
\hline 004 & $\mathrm{Rh}$ & $\mathrm{RH}$ & $R H D, R H C E$ & $1 \mathrm{p} 36.11$ & CD240 \\
\hline 005 & Lutheran & LU & $\angle U$ & $19 q 13.32$ & CD239 \\
\hline 006 & Kell & KEL & KEL & $7 q 34$ & CD238 \\
\hline 007 & Lewis & LE & FUT3 & $19 \mathrm{p} 13.3$ & \\
\hline 008 & Duffy & FY & $D A R C$ & $1 q 23.2$ & CD234 \\
\hline 009 & Kidd & $\mathrm{JK}$ & $S L C 14 A 1$ & $18 q 12.3$ & \\
\hline 010 & Diego & DI & $S L C 4 A 1$ & $17 q 21.31$ & CD233 \\
\hline 011 & Yt & YT & ACHE & $7 q 22.1$ & \\
\hline 012 & $\mathrm{Xg}$ & $X G$ & $X G, M I C 2$ & Xp22.33 & CD99t \\
\hline 013 & Scianna & SC & ERMAP & $1 \mathrm{p} 34.2$ & \\
\hline 014 & Dombrock & DO & ART4 & $12 \mathrm{p} 12.3$ & CD297 \\
\hline 015 & Colton & $\mathrm{CO}$ & $A Q P 1$ & $7 p 14.3$ & \\
\hline 016 & $\begin{array}{l}\text { Landsteiner- } \\
\text { Wiener }\end{array}$ & LW & ICAM4 & $19 \mathrm{p} 13.2$ & CD242 \\
\hline 017 & Chido/Rodgers & $\mathrm{CH} / \mathrm{RG}$ & $C 4 A, C 4 B$ & $6 p 21.3$ & \\
\hline 018 & $H$ & $H$ & FUT1 & $19 q 13.33$ & CD173 \\
\hline 019 & $K x$ & XK & $X K$ & Xp21.1 & \\
\hline 020 & Gerbich & GE & GYPC & $2 q 14.3$ & CD236 \\
\hline
\end{tabular}

Annexe 2 : Table des groupes sanguins érythrocytaires $\mathrm{V} 3.0$.

Site de l'ISBT (International Society of Blood Transfusion). Deux groupes sanguins supplémentaires à ce jour (22).

http://www.isbtweb.org/fileadmin/user_upload/WP_on_Red_Cell_Immunogenetics_and/Ta ble_of_blood_group_antigens_v3.0_121028.pdf 
Table of blood group systems v3.0 121028

\begin{tabular}{|l|l|l|l|l|l|}
\hline No. & System name & $\begin{array}{l}\text { System } \\
\text { symbol }\end{array}$ & Gene name(s)* & $\begin{array}{l}\text { Chromosomal } \\
\text { location }\end{array}$ & $\begin{array}{l}\text { CD } \\
\text { numbers }\end{array}$ \\
\hline 021 & Cromer & CROM & CD55 & $1 \mathrm{q} 32.2$ & CD55 \\
\hline 022 & Knops & KN & CR1 & $1 \mathrm{q} 32.2$ & CD35 \\
\hline 023 & Indian & IN & CD44 & $11 \mathrm{p} 13$ & CD44 \\
\hline 024 & Ok & OK & BSG & $19 \mathrm{p} 13.3$ & CD147 \\
\hline 025 & Raph & RAPH & CD151 & $11 \mathrm{p} 15.5$ & CD151 \\
\hline 026 & John Milton & JMH & SEMA7A & $15 \mathrm{q} 24.1$ & CD108 \\
\hline 027 & I & I & GCNT2 & $6 \mathrm{p} 24.2$ & \\
\hline 028 & Globoside & GLOB & B3GALT3 & $3 \mathrm{q} 26.1$ & \\
\hline 029 & Gill & GIL & AQP3 & $9 \mathrm{p} 13.3$ & \\
\hline 030 & $\begin{array}{l}\text { Rh-associated } \\
\text { glycoprotein }\end{array}$ & RHAG & RHAG & $6 \mathrm{p} 21-\mathrm{qter}$ & CD241 \\
\hline 031 & FORS & FORS & GBGT1 & $9 \mathrm{q} 34.13$ & \\
\hline 032 & JR & JR & ABCG2 & $4 \mathrm{q} 22$ & $2 \mathrm{q} 36$ \\
\hline 033 & LAN & LAN & ABCB6 & & \\
\hline
\end{tabular}

*As recognised by the HUGO Gene Nomenclature Committee http://www.genenames.org/

†MIC2 product

Updated October 2012

Annexe 2 (suite) : Table des groupes sanguins érythrocytaires V3.0.

Site de I'ISBT (International Society of Blood Transfusion). Deux groupes sanguins supplémentaires à ce jour (22).

http://www.isbtweb.org/fileadmin/user_upload/WP_on_Red_Cell_Immunogenetics_a nd/Table_of_blood_group_antigens_v3.0_121028.pdf 


\section{LISTE DES ABREVIATIONS}

COFFRAC : Comité Français d'Accréditation

CGR : $\quad$ Concentré de Globules Rouges

$\mathrm{CSH}$ : $\quad$ Cellules Souches Hématopoïétiques

EFS : $\quad$ Etablissement Français du Sang

EFS RA : Etablissement Français du Sang Rhône-Alpes

EM : $\quad$ Erythrocytes Magnetized

EMT : $\quad$ Ecarts Maximums Tolérables

Fuc: $\quad$ Fucose

Gal : $\quad$ Galactose

GalNac: N-acétyl-Galactosamine

Glc: $\quad$ Glucose

GlcNac: N-acétyl-Glucosamine

GTC : Gestion Technique Centralisée

HA : Hématies Adultes

HF : $\quad$ Hématies Fœtales

HLA : Immuno-Histocompatibilité (pour Human Leukocyte Antigen)

IC : Immuno-Cellulaire

$\lg$ A : Immunoglobuline A

$\lg D$ : $\quad$ Immunoglobuline D

$\lg$ : $\quad$ Immunoglobuline $\mathrm{E}$

IgG : $\quad$ Immunoglobuline $G$

IgM : Immunoglobuline M

IHE : Immuno-Hématologie Erythrocytaire

IP : Immuno-Plaquettaire

ISBT : International Society of Blood Transfusion

LBM : $\quad$ Laboratoire de Biologie Médicale

MHNN : $\quad$ Maladie Hémolytique du Nouveau-Né

NFS : $\quad$ Numération Formule Sanguine

RAI : $\quad$ Recherche d'Agglutinines Irrégulières (ou Recherche d'Anticorps Irréguliers)

ST : $\quad$ Sang Total

TDA : $\quad$ Test Direct à l'Antiglobuline

TIA : $\quad$ Test Indirect à l'Antiglobuline

VGM : Volume Globulaire Moyen 


\section{LISTE DES ILLUSTRATIONS}

Figures:

Figure 1 : Représentation d'un antigène et de ses anticorps correspondants. p. 13

Figure 2 : Structure de base d'une molécule d'immunoglobuline (6).

p. 14

Figure 3 : a. Structure de base d'une $\lg$; $\boldsymbol{b}$. Structure de base d'une $\lg M$ (9).

Figure 4 : Forces impliquées dans la liaison antigène-anticorps (10).

p. 15

Figure 5 : Représentation de la distance minimum entre deux hématies (10).

p. 16

Figure 6 : Représentation schématique du potentiel Zeta (10).

p. 17

p. 17

Figure 7 : Représentation schématique de la capacité d'agglutination des hématies par les IgG et les IgM. (Image Diamed®)

p. 19

Figure 8 : Représentation schématique des systèmes de groupe sanguin sur la membrane érythrocytaire (11).

p. 22

Figure 9 : Mise en place de la réponse immunitaire (5).

p. 23

Figure 10 : Biosynthèse des antigènes $A, B$ et $H$. (adaptée de R. L'Italien, $2008(6))$

Figure 11 : Nombre de sites antigéniques par hématies de quelques-uns des sous-groupes A (Image Diamed $($ )

p. 28

Figure 12: Représentation schématique du protocole de l'étude pour le groupage sanguin, la RAI et le TDA.

p. 47

Figure 13 : Représentation schématique du protocole de l'étude pour le test de Kleihauer.

Figure 14: Schéma d'une plaque réactionnelle pour la réalisation d'un groupage sanguin.

Figure 15: Photo d'une plaque réactionnelle du groupage $A B O R H K$ d'un patient de groupe $A$ et phénotype $D+C+E-C+e+K-$.

Figure 16: Interprétation des réactions d'hémagglutination sur plaque en fonction de l'intensité observée (lecture macroscopique).

Figure 17 : Schéma d'une carte-gel réactionnelle (gel microfiltration) pour la réalisation d'un groupage sanguin. 
Figure 18 : Etapes d'un groupage sanguin en technique sur gel microfiltration (59).

Figure 19: Interprétation des réactions d'hémagglutination sur gel microfiltration, en fonction de l'intensité observée (lecture macroscopique).

Figure 20 : Interprétation des réactions d'hémagglutination en microplaque sur automate Galileo (lecture automatique ou visuelle).

Figure 21 : Schéma d'une micro-colonne réactionnelle (gel microfiltration) (6).

Figure 22: Cotation du résultat de la RAl en fonction de l'intensité réactionnelle (6).

Figure 23 : Schéma d'un puits réactionnel de RAI en EM Technology (61).

Figure 24: Principe de l'EM Technology, représentation des réactions positive et négative (images Diagast).

Figure 25 : Interprétation des réactions d'hémagglutination en microplaque sur automate Qwalys (lecture automatique ou visuelle).

Figure 26 : Schéma d'un support réactionnel (gel microfiltration) pour le TDA.

Figure 27: Interprétation des réactions d'hémagglutination sur gel en fonction de l'intensité observée (lecture macroscopique).

Figure 28: Principe du test de Kleihauer. Image adaptée de: http://www.snv.jussieu.fr/vie/dossiers/gpes-sanguins/03merefoetus.htm.

Figure 29 : Représentation des résultats d'intensités réactionnelles positifs pour les antigènes $A, B$ et $A B$ en technique manuelle sur plaque.

Figure 30 : Représentation des résultats d'intensités réactionnelles positifs, pour les antigènes $A, B$ et $A B$ en technique manuelle sur gel microfiltration.

Figure 31: Photo illustrant l'hémolyse des échantillons sanguins après conservation à $+38^{\circ} \mathrm{C}$.

Figure 32 : Photo des supports de gel microfiltration pour groupage ABO.

Figure 33: Représentation graphique des résultats rendus par l'automate Galileo pour les antigènes $A, B$ et $A B$.

Figure 34 : Représentation graphique des résultats rendus par l'automate Galileo pour l'anti-A et l'anti-B.

Figure 35: Photo du groupage en plaque d'un individu $\mathrm{O} D+C+E-C+e+K+$, le $3^{\text {ème }}$ jour de conservation.

Figure 36: Représentation graphique des résultats rendus par l'automate Galileo pour les antigènes des système Rhésus et Kell. 
Figure 37 : Photo des supports de gel microfiltration pour la RAI.

Figure 38 : Photo des supports de gel microfiltration pour le TDA.

Figure 39: Photo des supports de gel microfiltration pour le TDA de l'échantillon $\mathrm{n}^{\circ} 1$ à $\mathrm{J} 3$.

Figure 40 : Représentation graphique (échelle logarithmique) des résultats de comptes d'hématies fœtales des 14 prélèvements positifs pour le test de Kleihauer.

\section{Tableaux :}

Tableau 1 : Les quatre phénotypes érythrocytaires ABO principaux (26).

Tableau 2 : Fréquence des cinq principaux antigènes du système Rhésus dans la population caucasienne (26).

Tableau 3 : Fréquence des cinq phénotypes Rhésus les plus rependus dans la population caucasienne (5).

Tableau 4: Fréquence des trois phénotypes Kell dans la population caucasienne (6).

Tableau 5 : Récapitulatif des effectifs de l'étude.

Tableau 6 : Effectif des 30 groupages sanguins "normaux » : a. Répartition des sujets selon leur groupe $\mathrm{ABO}$; b. Répartition des sujets selon leur phénotype Rhésus ; c. Répartition des sujets selon leur phénotype Kell.

Tableau 7 : Profil des quatre échantillons créés artificiellement pour l'étude des doubles populations.

Tableau 8 : Effectif des 30 RAl négatives et des 30 RAl positives.

Tableau 9 : Effectif des 30 TDA négatifs et des 30 TDA positifs.

Tableau 10 : Gamme de concentration des tests de Kleihauer positifs créés artificiellement.

Tableau 11: Liste des matériels nécessaires pour la réalisation de notre protocole d'étude.

Tableau 12 : Liste des matériels nécessaires pour la réalisation du groupage sanguin $\mathrm{ABORHK}$ en technique manuelle sur plaque.

Tableau 13 : Liste des matériels nécessaires pour la réalisation du groupage sanguin $A B O R H K$ en technique manuelle sur gel microfiltration.

Tableau 14 : Liste des matériels nécessaires pour la réalisation du groupage sanguin ABORHK en technique automatique sur Galileo. 
Tableau 15 : Liste des matériels nécessaires pour la réalisation de la RAI (dépistage et identification) en technique manuelle sur gel microfiltration.

Tableau 16 : Liste des matériels nécessaires pour la réalisation de la RAI (dépistage) en technique automatique sur Qwalys.

Tableau 17 : Liste des matériels nécessaires pour la réalisation du TDA en technique manuelle sur gel microfiltration.

Tableau 18 : Liste des matériels nécessaires pour la réalisation du test de Kleihauer par la technique Shepard modifiée.

Tableau 19: Résultats des intensités réactionnelles des 30 groupages sanguins $A B O$ réalisés en techniques manuelles sur plaque et sur gel microfiltration.

Tableau 20 : Résultats des intensités réactionnelles des 30 phénotypages sanguins RHK réalisés en techniques manuelles sur plaque et sur gel microfiltration.

Tableau 21: Résultats de l'échantillon comportant une double population sur l'antigène $\mathrm{RH} 1$, et des échantillons comportant une double population sur l'antigène $\mathrm{RH} 2$.

Tableau 22 : Résultats des échantillons comportant une double population sur l'antigène $\mathrm{RH} 3$, et de l'échantillon comportant une double population sur l'antigène RH5.

Tableau 23 : Résultats de l'échantillon comportant une double population sur l'antigène $\mathrm{RH} 4$, et des échantillons comportant une double population sur l'antigène KEL1.

Tableau 24 : Résultats des 10 sujets présentant une RAI positive très faible dès J0.

Tableau 25: Résultats des 11 sujets présentant une RAI positive sur l'automate Qwalys très faible dès J0.

Tableau 26 : Résultats des intensités réactionnelles des 30 TDA positifs réalisés à $\mathrm{J} 0, \mathrm{~J} 1, \mathrm{~J} 2$ et $\mathrm{J} 3$, après conservation à $+4^{\circ} \mathrm{C},+22^{\circ} \mathrm{C}$ ou $+38^{\circ} \mathrm{C}$, avec la technique sur gel microfiltration.

Tableau 27 : Résultats des 14 tests de Kleihauer positifs, réalisés à J0, J1, $\mathrm{J} 2$ et $\mathrm{J} 3$, après conservation à $+4^{\circ} \mathrm{C},+22^{\circ} \mathrm{C}$ ou $+38^{\circ} \mathrm{C}$, avec la technique modifiée Shepard. 
Annexes:

Annexe 1: Amplitudes thermiques mensuelles estivales et hivernales de l'année 2004, sur la ville de Grenoble.

p. 101

Annexe 2: Table des antigènes de groupes sanguins érythrocytaires V3.0. Site de I'ISBT (International Society of Blood Transfusion).

p. 102 


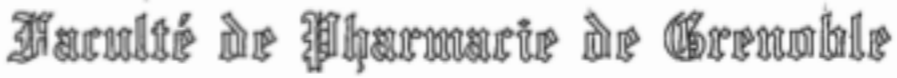

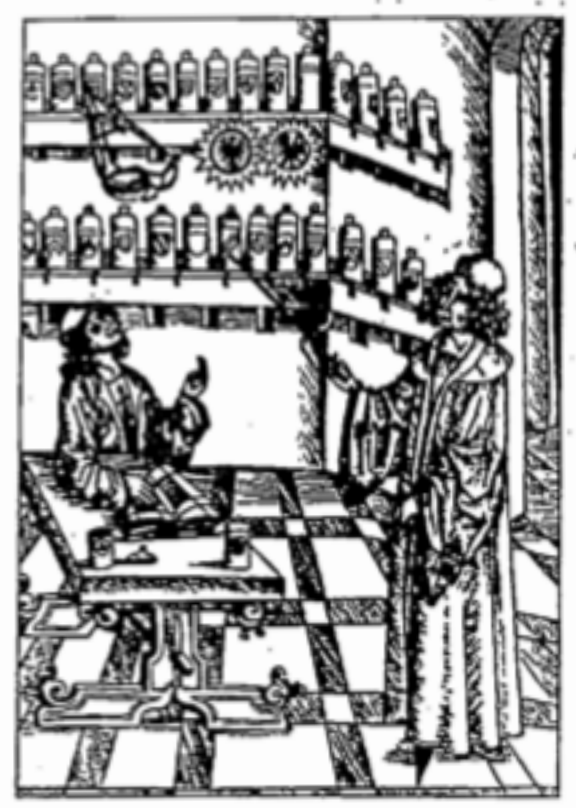

Sirntent

Iิx

\section{Aptothitrattex}

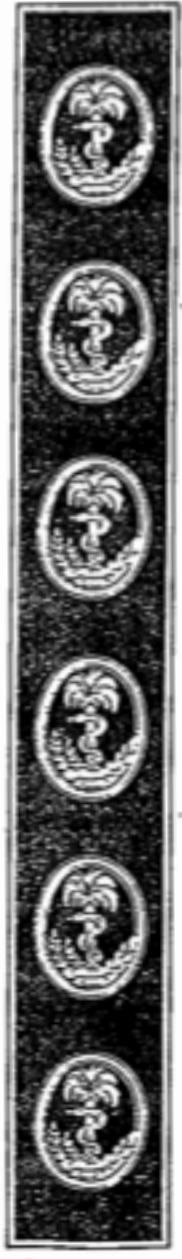

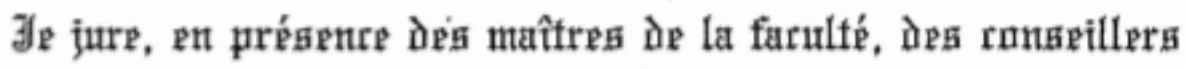

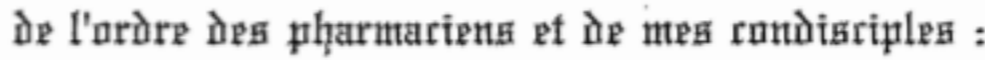

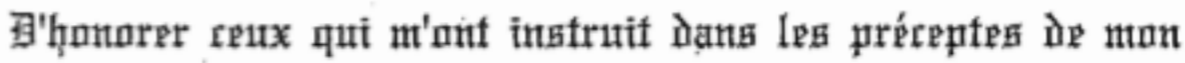

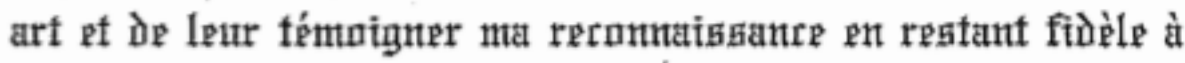
Lrur prefigntentent.

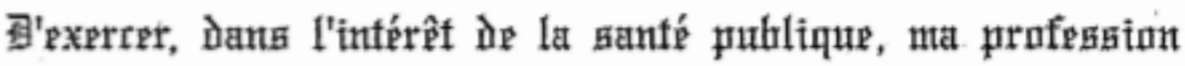
aupe rnteriznte ef ì regaterter non spulpment la législatinn

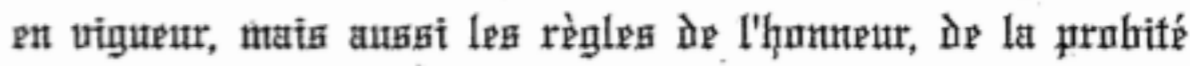

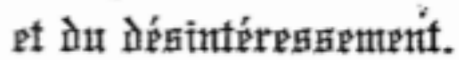

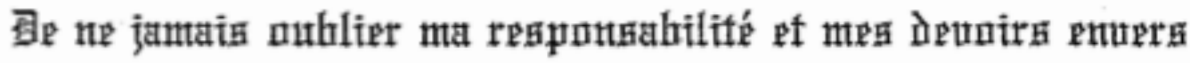

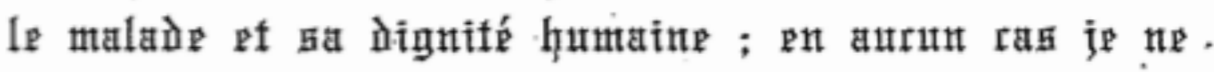

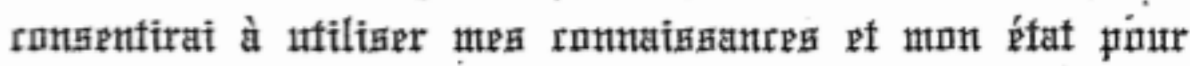

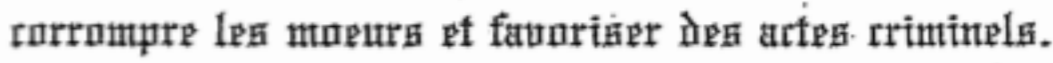

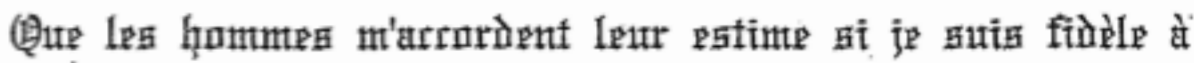

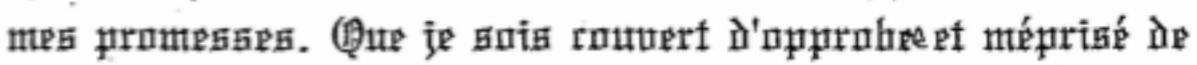

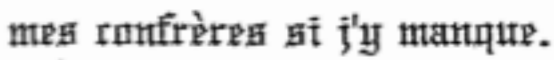

